\title{
WANDER OF LIFE
}

\section{AN AGORA TO FACILITATE ELDERLY'S AUTONOMOUS AND CONNECTED LIFE IN JOHNSONVILLE}

BY

YUQI KONG

A 120-point thesis

submitted to the Victoria University of Wellington in partial fulfilment of the requirements for the degree of Master of Architecture (Professional)

Victoria University of Wellington

School of Architecture

2016 


$P B \bar{F}$

ACT 
New Zealand is experiencing a demographic transitional period when there is increasing percentage of the elder population out of the total. Researches and scholars overseas have investigated in architecture's role of improving environments for the elderly, primarily from the perspective of disability. However, these considerations which solely come from the physicality point of view and can be easily treated just as after thoughts, sometimes still leaving the elderly in dilemmas.

As an attempt to response to such an issue, this thesis asks if accessible architecture can enable the elderly to be included in public space as community members rather than an isolated group. It aims to explore possibilities of creating accessible public space for elderly, which is also thoughtful towards other community members' interactions. These explorations are set on the intersection of environmental gerontology* and phenomenology, focus on making space accessibly to the elderly physically, sensorially and psychologically. 
To re-introduce the elderly as community members who are as significant as others, the diversity and complexity of their conditions and needs should be considered, which requires the design explorations to be site-specific to avoid over-generalization. To contextualise the question, Johnsonville is chosen as the site for study, thus, the character of local elderly can be considered for appropriate design iterations. To extend current design discourse about the role of architecture in the context of environmental gerontology, the theory of phenomenology and relevant case studies will be investigated. To highlight implications and limitations for elderly-accessible public space design, reflection will be made regarding the design explorations against the broader discursive arguments. 
One of the primary implications of this design-led thesis is for the discourse on elderly-friendly environments. The other implication is an advocacy for designing public space for a wider public interaction. It means taking everyone in the community into equal consideration and creating public space that is equal for every user.

* "Gerontology is broadly defined as the study of ageing from biological, psychological and social perspectives."

(Phillips, Ajrouch and Hillcoat-Nalletamby 118) 
Pre
fAce 
Jack came into the mall as usual. We had a brief chat when I was making him coffee. He walked away reluctantly with his own biscuits and coffee cause I had to get start preparing for the day. And I knew exactly what would happen. He would choose the table on the far end to sit down and look like he is staring blankly at the shops that are not even open yet. That moment, I wish there is a better place for an elderly to start the day... 


$$
\begin{aligned}
& \text { Arctono } \\
& \text { (B) Bó } \\
& \text { DJENT }
\end{aligned}
$$


This thesis will not be completed without all these people gave me constant supports. Firstly, I need to thank my parents for their love and faith in me. It is their support in countless ways which keeps me going throughout my degree even at the hardest time. I would also like to thank my late grandma for your devoting love and care to everyone, and being the inspiration of my thesis.

Secondly, I have to say a big "Thank you!" to all my friends for so many good things that I learned from you amazing people. And of course, thank you for all the emotional, intellectual, nutritional supports in the last five years. Those sleepless architecture nights we spent together will be the best memory of architecture school.

Thirdly, I need to thank the friendly librarians in Johnsonville library, staffs from the community centre and Keith Spry pool for their help and patience when I was doing my field research.

Last but not least, this would not happen without my supervisor Shenuka and her critical mind to stop me from lifting from the ground. 

"An individual human existence should be like a river - small as first, narrowly contained within its banks, and rushing passionately past boulders and over waterfalls. Gradually, the river grows wider, the banks recede, the water flow more quietly, and in the end, without any visible break, they become merged in the sea and painlessly loss their individual being"

(Baars and Phillipson 18) 


$$
\operatorname{CoN}_{T \in N / S}
$$




\begin{tabular}{|c|c|}
\hline Abstract & iv - vii \\
\hline 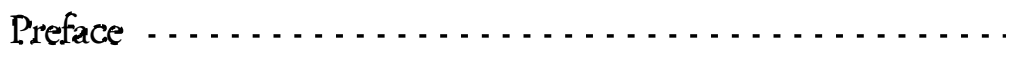 & viii - ix \\
\hline 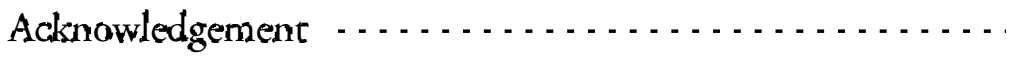 & $\mathrm{x}-\mathrm{xi}$ \\
\hline Epigraphs $\ldots \ldots$ & xii - xiii \\
\hline 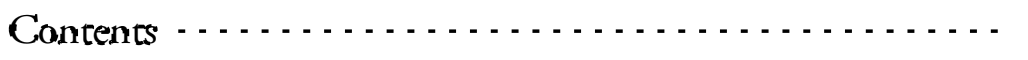 & $\mathrm{xiv}-\mathrm{xv}$ \\
\hline Intraduction - . . . . & $1-8$ \\
\hline Chapter 1: Ageing & $9-48$ \\
\hline Chapter 2: Jahnsonville & $49-94$ \\
\hline Chapter 3: Agora & $95-132$ \\
\hline 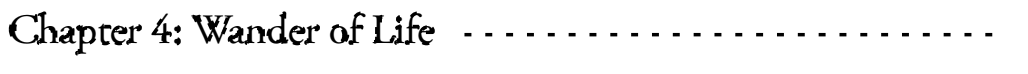 & $133-164$ \\
\hline Condusion & $167-171$ \\
\hline Bibliography . . . . . . . . . . . . . . . . . . . . . . & $172-179$ \\
\hline 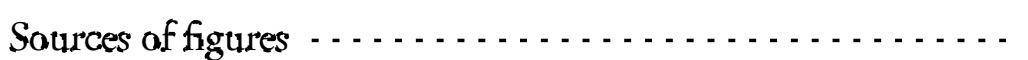 & $180-185$ \\
\hline
\end{tabular}




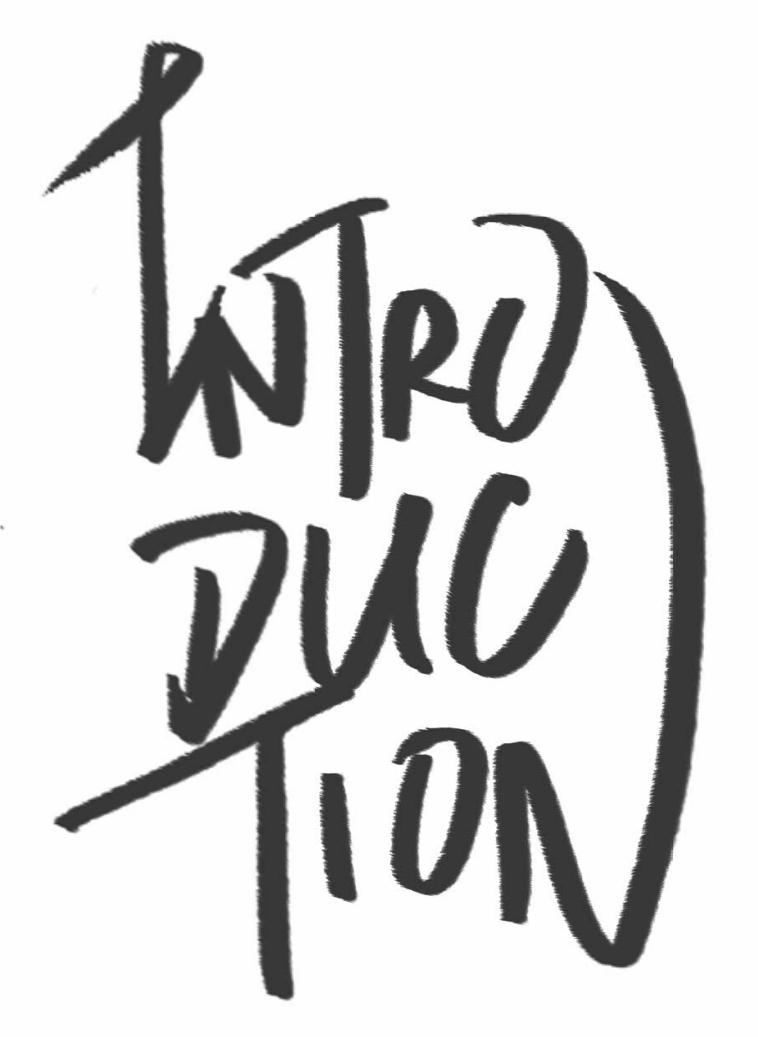




\section{Problm Statement}

As increasing ageing populations become a worldwide phenomenon, there is increasing attention being paid to the wellbeing of the elderly in an extensive array of fields (Rowles and Bernard; Johnson and Mutchler; Machielse and Hortulanus; Oerlemans, Bakker and Veenhoven). The question "How can we optimise people's later life?" has become much more frequently asked in the field of architecture. Out of consideration of one's shrinking activity space due to physical constrains, there have been discussions on improving domestic environments for the elderly in recent years (Wiles et al.; Davey et al.; HillcoatNalletamby; Hillcoat-Nalletamby and Ogg; Oswald and Wahl). With the potential of technological development, it is believed that elderly don't have to be homebound even if their physical strength decays. Technologies, such as mobility scooters, shared vehicles and other developing transportation modes, bring the topic of elderly accessibility to the realm of public space. 
Most studies of environments for the elderly focus their approaches in the perspective of physical accessibility. The psychological impacts brought by the inaccessible and accessible design rarely come into discussions (Boys). Inaccessible design can cause segregation between the elderly and others, however, sometimes even the provision of accessible design, although with the good intention, is not necessarily beneficial for senior's psychological wellbeing if the design is not enjoyable for all members of the community. 


\section{Research Question, Aims and Objectives}

This thesis asks if accessible architecture can enable the elderly to be included in public space as community members rather than an isolated group. It aims to explore possibilities of creating accessible public space for elderly, which is also thoughtful towards other community members' interactions. Three main objectives are formulated:

Apply the theory of phenomenology to extend current design discourse about the role of architecture in the context of environmental gerontology.

To investigate architecture's critical and instrumental role in elderly accessibility through site-specific design explorations.

To highlight implications and limitations for elderly-accessible public space design by evaluating the design explorations against the broader discursive arguments. 


\section{Design Methods and Process}

This thesis is primarily process-based and adopts a design-led methodology. Through drawing, physical and digital modelling, the research investigates elderly architecture in the realm of environmental gerontology, adopting the perspective of phenomenology. Louisiana Museum of Modern Art and Kiasma Museum of Contemporary Art are studied as precedents of phenomenological design to focus on user experience, rather than architectural form. In the design processes of producing drawings and models, there are regular self-reflections on the adequacy of consideration for seniors' psychological wellbeing. This process highlights potential weak points in the research approach for designing elderly architecture to improve and strengthen the design.

In response to the analysis of site and local demographic, agora is introduced as an instrument to practice the theory of phenomenology on elderly architecture. Through constructing a community meeting place, seniors are offered opportunities to maintain their connections after retirement in an accessible public environment. 


\section{Scope of the Design Research}

The thesis explores the potential of phenomenological architecture to help remaining the autonomy and connectedness of the elderly living in the suburb. It focuses on the elderly who are physically competent with or without assistant but constrained by environmental barriers. The scope of the design investigation is limited to the particular context of Johnsonville, Wellington and tests the research question through the development of iterational design explorations.

As the thesis situates itself against a great underlying social condition, the scope is narrowed to the specific Johnsonville context. However, there is limited amount of depth and detail it can go into due to the time constraint of Master thesis structure. Thus, certain assumptions/generalisations are made about the nature of the urban condition and the way architecture might engage with it. There is an emphasis on vision and image of architecture for the elderly where feasibility of cost and structure can be further researched. 
Thesis Structure

\section{Ageing}

2.1 Validity of Problem

Mindset

Elderly in Public Spaces

Dilemmas

Case studies:

Shopping Mall

Senior Centre
2.2 Autonomy \& Connectedness

Environmentle Gerontology

Universal Design

Case studies

$\downarrow$

Phenomenology

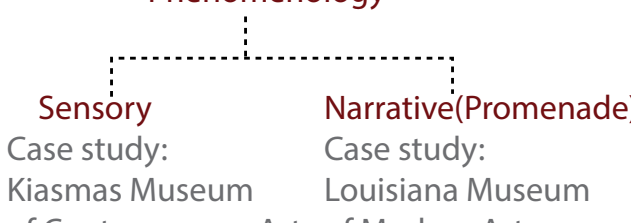

of Contemporary Art of Modern Art

\section{Johnsonville}

3.1 The Suburbia

Situating ageing in context

Agora

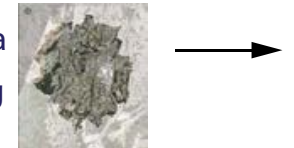

3.2 The Triangle

Project Site Selection

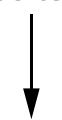

4.1 Agora

Case study:

Typology Proposal The Agora of Dronten

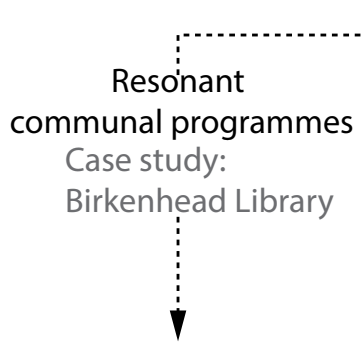

4.2 Community Dynamic

Programmes Proposal
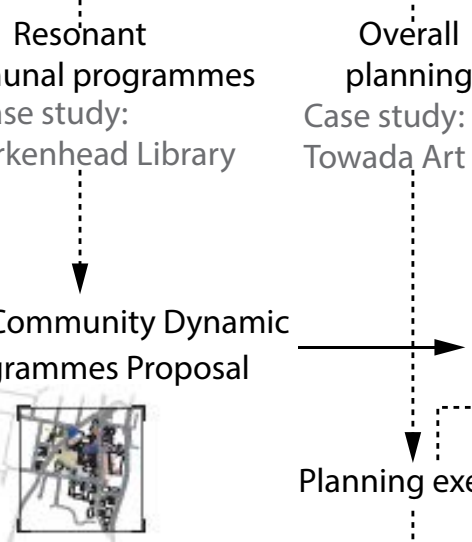

planning

Stage of life

Case study:

Case study: Onishi Town Hall

Towada Art Gallery

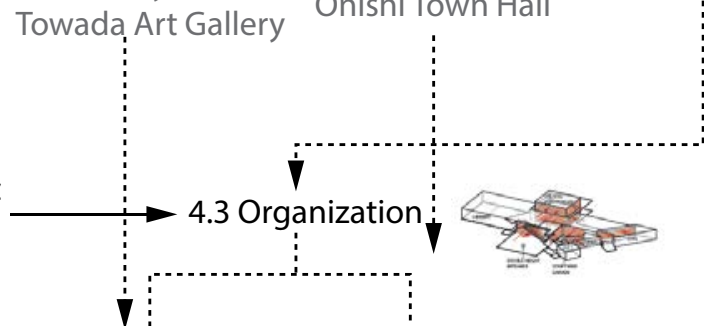

Planning exercise Visual connection

Wander of Life

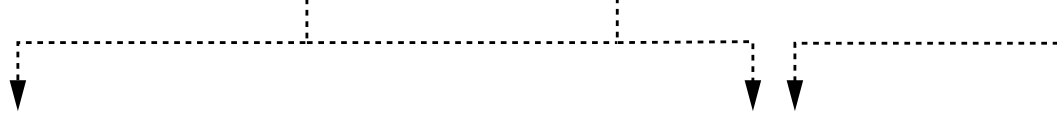

5.1 Formal development

5.2 Phenomenology Turn

from circulation to promenade

spatial experience to inform design
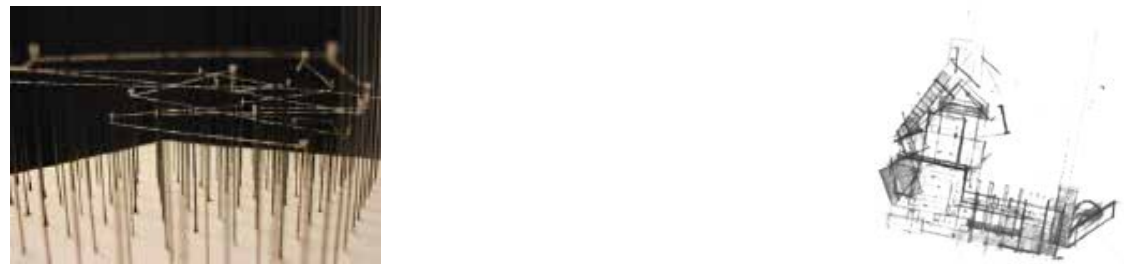
Ageing 2.1 Validity of Problem

Mindset

Elderly in Public Spaces

Dilemmas

Case studies:

Shopping Mall

Senior Centre
2.2 Autonomy \& Connectedness

Environmentle Gerontology

Universal Design

Case studies

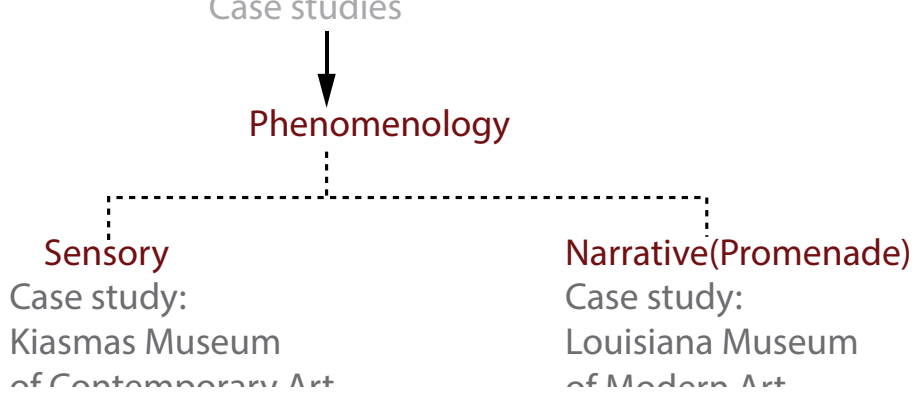


$f_{G E} / \mathrm{NG}$ 


\section{How well is our environment actually taking care of the elderly?}

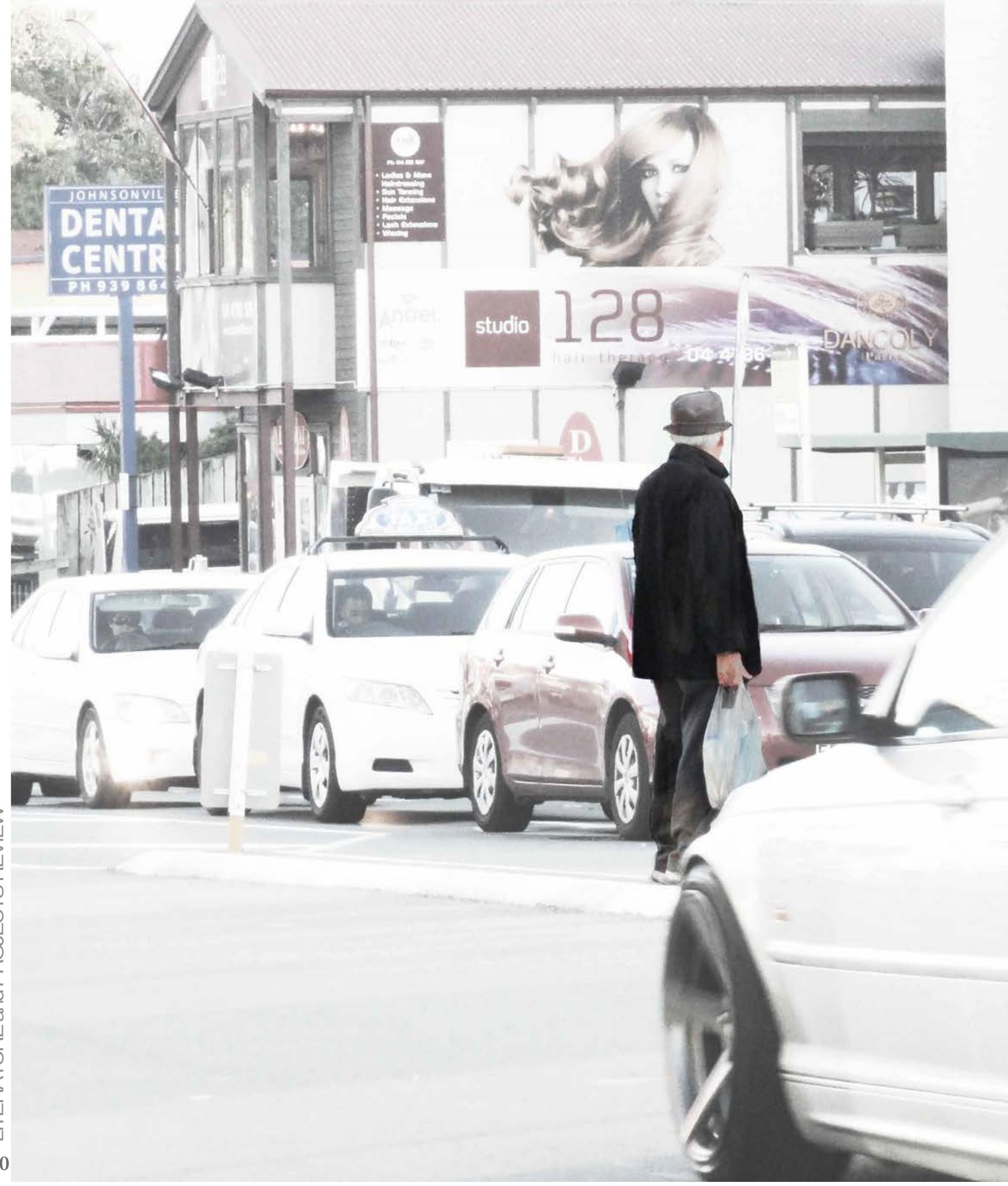



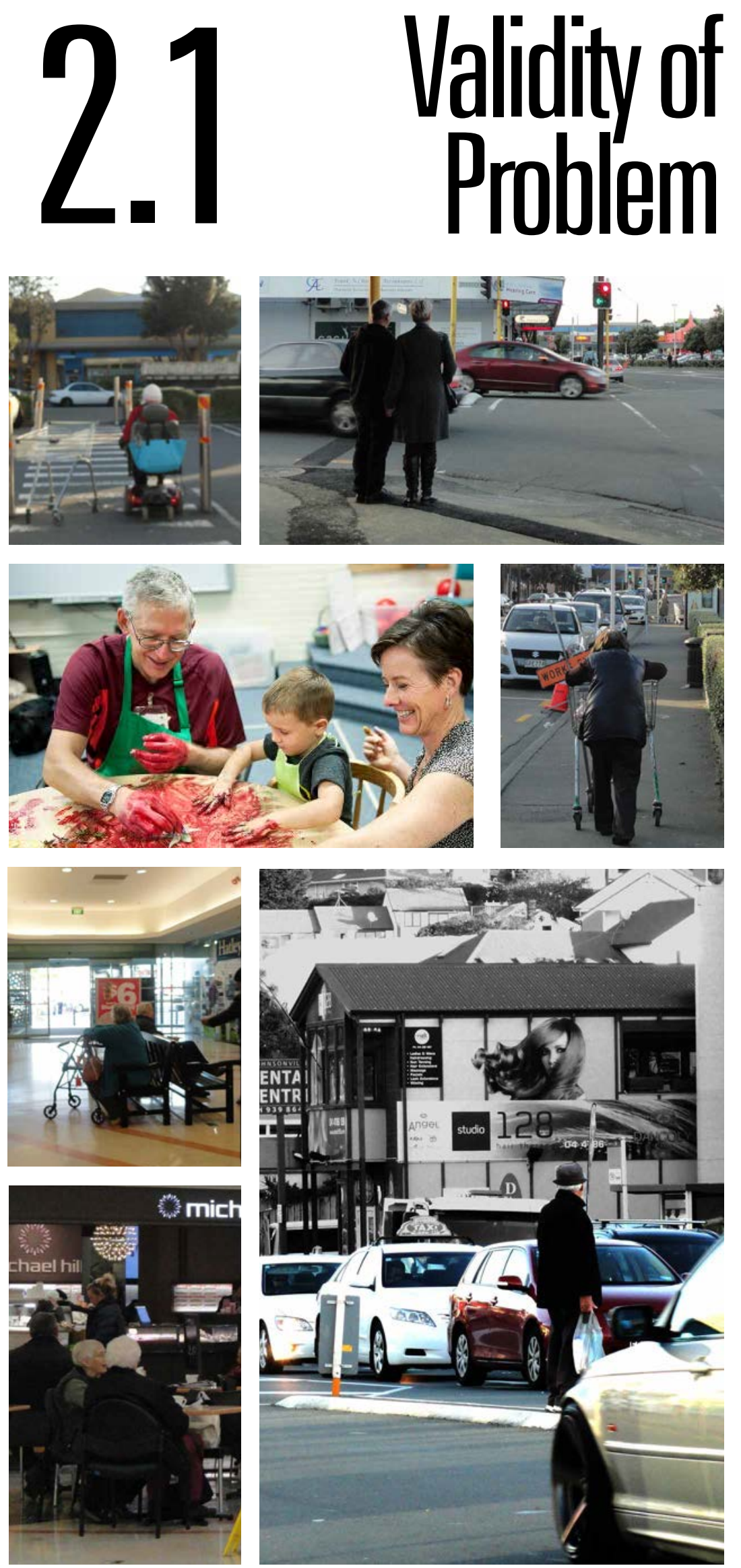


\subsection{1 [MINDSE] Inadequacy consideration on aged-friendly public space/community}

The idea of designing to incorporate the elderly has been researched in the field of architecture (Altman, Lawton and Wohlwill; Föbker and Grotz; Wiles et al.). However, constructing an aged-friendly space is often thought to be easily solvable by provision of additional lifts, ramps and railings, appearing as if they are just there to meet regulations. The diversity of seniors' ageing condition, and the complexity of the needs for older people's psychological wellbeing, are rarely paid enough attention to or crassly labelled as one generic demographic group. Usually dealt with in a manner where their individual differences are rubbed off ruthlessly (Lupien and Wan 1413; Machielse and Hortulanus 12,25). It is this notion in society, even among the designers of space, which helps shape current dilemmas of ageing (fig 2.1.). As Jos Boys, a teaching fellow from Faculty of Arts, Design and social Sciences at University of Northumbria, wrote in her book Doing Disability Differently,

"We live in a world where individual mobility, autonomy and personal competence are both highly valued and seen as normal. People who are less than fully mobile, are interdependent with others, or seem 'slow' then become the problem." (Boys 21)

The acknowledgement and social value which constitutes these issues

Fig 2.2. [Opposite page] Collage of seniors' interaction with spaces. can be seen from Boys writing. Similar realization can also be found in the writing of Dr. Peace, Professor of Society Gerontology in the Faculty of Health 


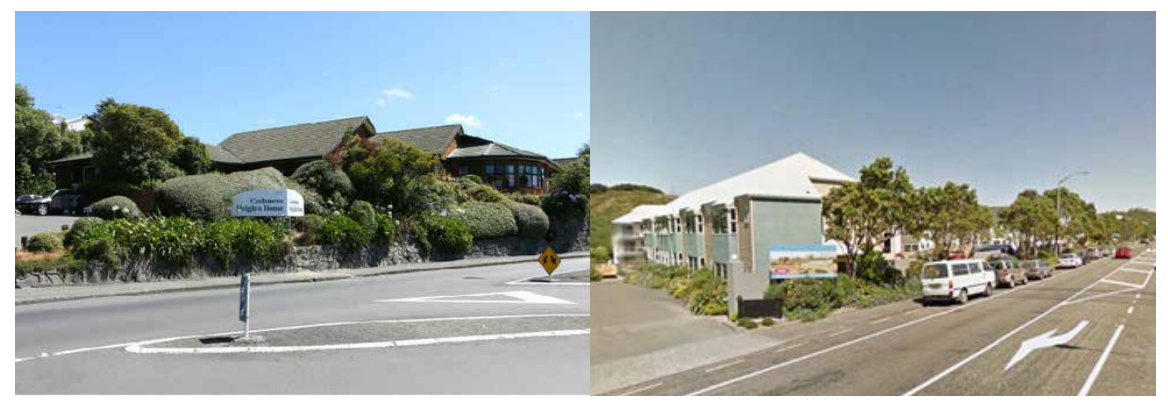

Fig 2.3. Thestereotype of rest home being homogeneous constraints seniors to be socially involved, which is also suggested by their urban setting to the surrounding.

and Social Care at The Open University. Peace concludes that "attitudinal, structural, and environmental barriers prevent people from participating in aspects of everyday life" (27). She examines a number of researchers' works, which gives a more defined understanding of the contributors of such phenomenon. Peace also clarifies that, as social problems, they cannot be fixed simply through architecture. However, she argues that architecture has crucial impact on older people's wellbeing.

To attempt to make a difference, it is important to realise that older people are "normal" just like other community members(Machielse and Hortulanus 11). They have diverse health conditions, mobility, personality, interests, as members of the community. Over-simplifying their diversity of ageing conditions not only misleads the public into certain stereotypes of older people, but also limits the possibility for seniors to remain active and involved in their community (fig 2.2.). According to Boys, these notions prevent enhanced social understanding of the inter-relationships between material spaces and its occupancies (2). 


\subsection{2 [ELDERIY IN}

Public spaces and seniors' psychological wellbeing

Public spaces are where we meet people. They provide common ground for everyone to encounter and interact in various ways. Dr. Caroline Holland, a senior researcher at The Open University and coeditor of Ageing \& Society, states that,

"Public spaces allow people to meet on ostensibly neutral ground in planned and unplanned ways, to interact with others within the context of the whole community." (ix)

This "neutral ground" ensures certain freedom and restriction given to individuals to perform their social behaviour and daily activities (fig 2.3.). It provides a safe and accessible environment for individual to execute autonomy to their physical competence. The quote also draws attention to the underlying social relations of power in public spaces, and its influence on the users of spaces. These power relations define invisible territories and rules of using space, which determine who is privileged or excluded (McDowell 4). In line with this notion, Rowles and Bernard suggests, 


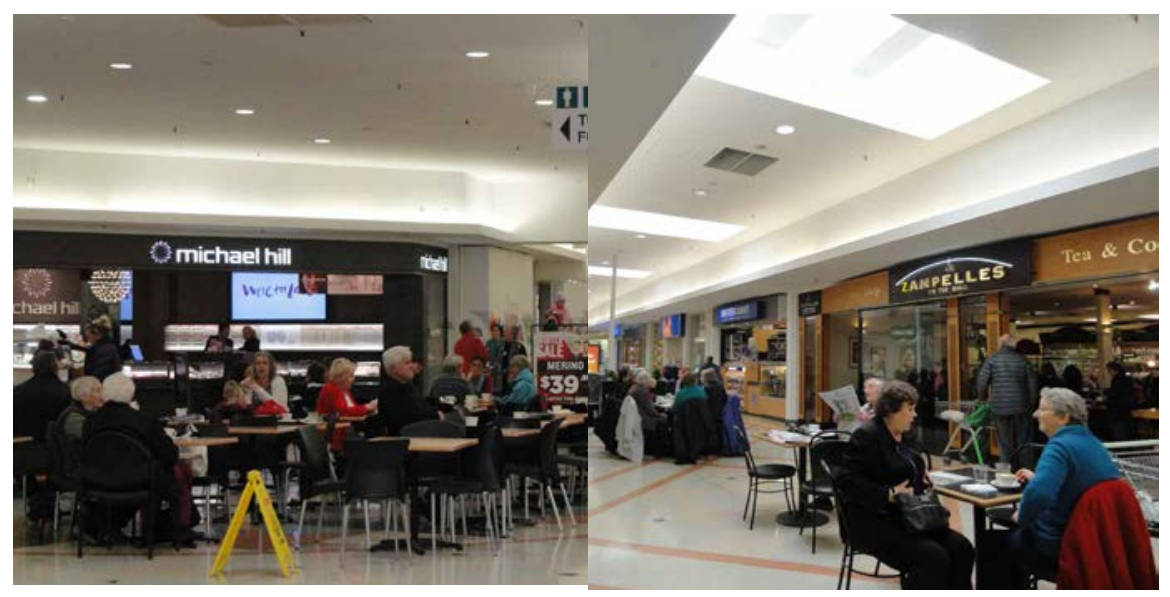

Fig 2.4. Public spaces provide safe common ground for the elderly to social and spend time in.

"the design and ambience of these spaces is a critical element in determining our ability or willingness to venture forth from the relative security of our residence... how does the physical form of our environment, the objects it contains, and the social context it provides, reinforce or threaten identity and a sense of being in place"(6).

It is believed that Public spaces are the significant mediator between these social power relations and the spatial users. The design and ambient qualities of the space are actually subliminally manipulating the intertwining relationships among occupants. Similarly, Peace comments on public places, “...for different individuals or groups, boundaries in place can be overlapping or distinct, and can influence different levels of spatial mastery or... levels of connectivity"(27). We are born connected to our family in blood, however, public spaces expose us to a web of much wider connections to people. 
Fig 2.5. A typical daily view in Johnsonville Mall.

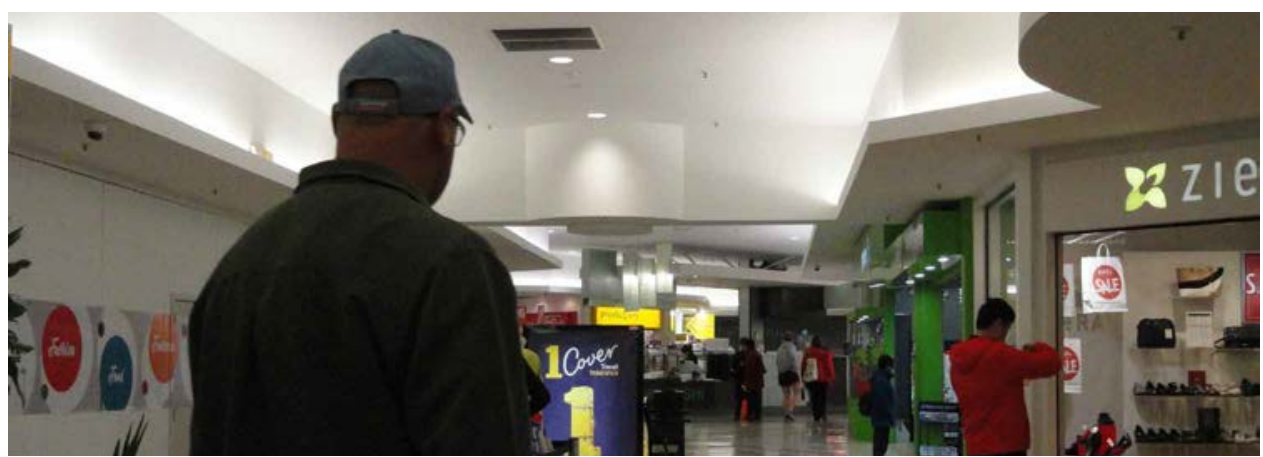

"The degree to which people are capable of finding a good balance between individual autonomy or independence and connectedness with meaningful others is crucial; ageing well means attaining such a balance"

(Machielse and Hortulanus 131)

\section{[AUTONONIY/INDEPENDENCE]}

According to Dr.Phillips, Ajrouch and Hillcoat-nalletamby, the word independence is defined as "a sense or state of physical, psychological and spiritual autonomy, self-identity, self-respect, control and degree of functional capacity" in social gerontology (131). In Professor Mary M. Ball's paper, she clarifies definitions of autonomy based on a selection of previous research on psychology wellbeing with an emphasis on Hofland's framework. It views autonomy as board concept composited by physical, psychological and spiritual dimensions (468).

The physical dimension refers to "the freedom of mobility, physical independence, and the use of the least restrictive environment" and the spiritual 
dimension points to one's sense of identity, long-term values and life meaning. Whilst the psychological dimension highlights one's control over environment and choice of options. This thesis focuses mainly on the psychological dimension due to the complexity that spiritual dimension embeds. Autonomy discussed in this thesis refers to the sense of control over life, and the choice of options they have to accomplish their personal aim.

In Dr. Hillcoat-Nalletamby's research on autonomy conditions of older people from different residential settings, she reviewed five dimensions of autonomy analysed by Dr. Collopy. These cover the range of autonomy from how elder people practice tasks themselves, to the availability of choices for them to delegate the tasks to others (420). It shows that it is possible for older people to have the sense of autonomy despite varied level of dependency (fig 2.5.). To enable and enhance the realization of different dimensions of autonomy, it reveals the important role environment plays in contribution to a better later life(427).

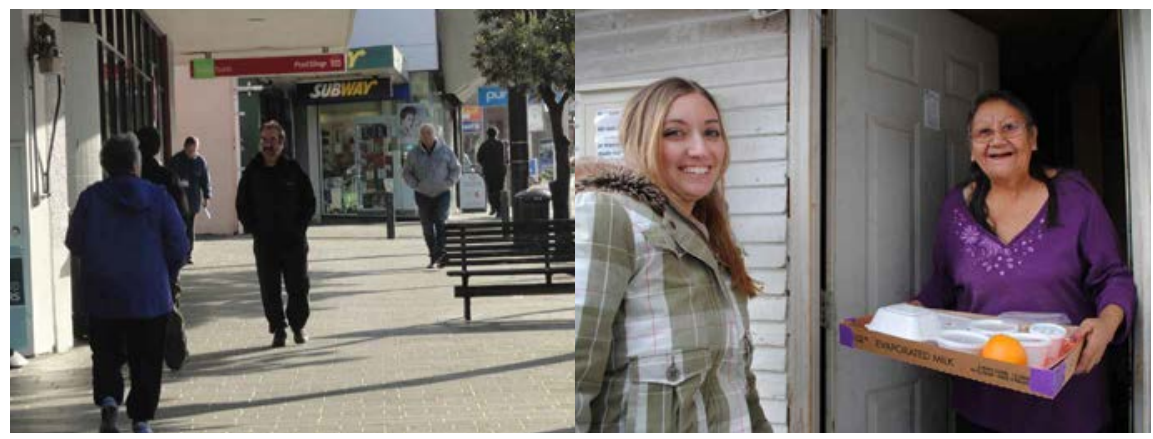

Fig 2.7. Relatively active seniors canFig 2.8. Seniors can also gain the sense execute their autonomy with their ownof autonomy through delegation of physical competence. selected tasks. 

Fig 2.9. A $\quad$ finger-
painting activity from
intergenerational program.

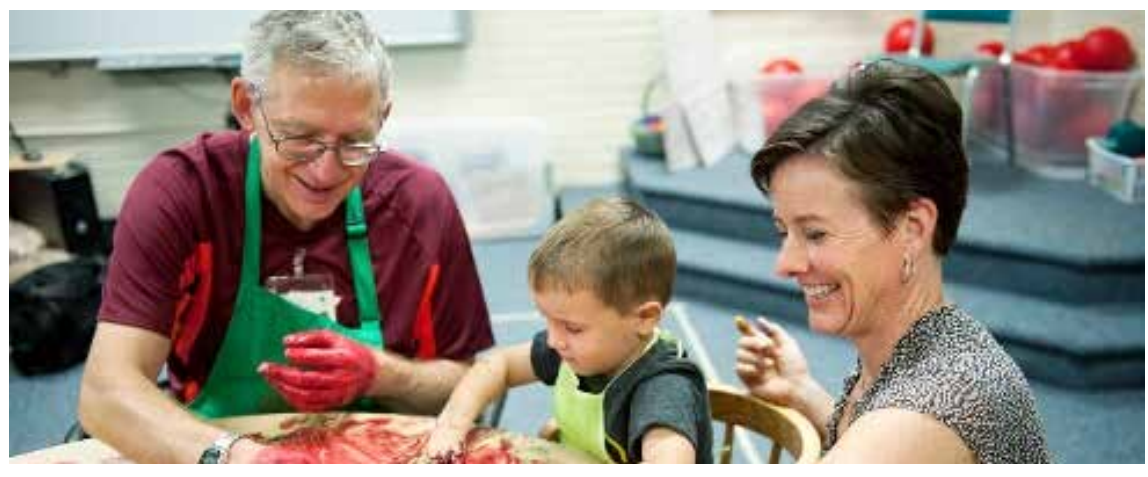

[CONNECTEDNESS]

"...the people who fared the best were the people who leaned in to relationships, with family, with friends, with community..."

---from Dr. Robert Waldinger,

Clinical Professor of Psychiatry at Harvard Medical School in TED Talk

"What makes a good life? Lessons from the longest study on happiness"

Humana are sociable by nature and the ability to connect with others is one of the basic human needs. Growing up as a member of society, we are woven into relationships with our family, friends, and other members of the community such as our neighbours, school mates, colleagues and co-workers. These connections which used to be embedded in our usual daily routines become much more demanding to maintain in retirement and elderly age.

According to Föbker and Grotz from University Bonn in German, who 
have completed extensive studies on elder people and their relations to urban environment, there are two gerontological theories which make fundamental propositions regarding successful ageing. One is activity theory which argues that "psychological well-being in old age is based upon the level of activity and social contacts which are maintained". On the contrary, the disengagement theory debates that deliberate disengagement from some activities can contribute to overall life satisfaction for elder people due to its relieving effect (Föbker and Grotz 101; Havighurst and Albrecht).

Even though disengagement theory starts from the consideration of physical decline in old age, it overlooks the diversity of conditions that elder people age in. Soon after, it was overshadowed by the appealing visions in old age depicted by activity theory (Johnson and Mutchler 94). Through participating in various activities, elder people benefit in the sense of connectedness, achievement and competence, which satisfies a range of psychological needs (Oerlemans, Bakker and Veenhoven 66566). Thus, psychological health of the seniors is strengthened through these social connections and becomes more resilient in later life. 


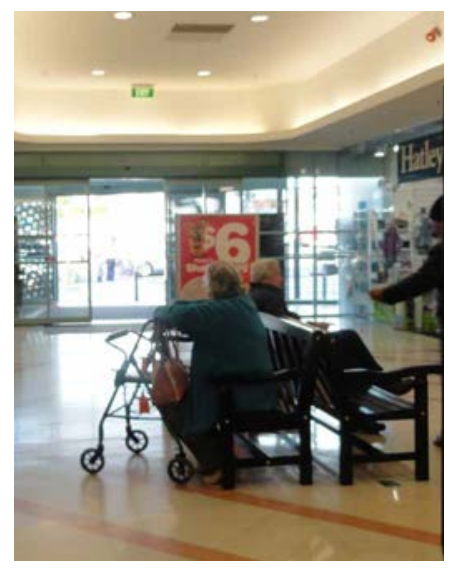

Fig 2.10. The particular arrangement of seating prevents people from interacting.
2.1.3 [DIEEMMMS] Elder people in public spaces and their psychological health

As we discussed previously that public spaces are essential for connectivity, the quality of these spaces is critical to the social behaviour of the senior, who are much more sensitive and dependent to external conditions based on Rowles and Bernards' research (6). Under the pervasive ageing-in-place policy around the world, the majority of older people are aging at their own homes instead of retirement home or institutional care facilities. Compared to the advantages in proximity and convenience of the institutional, for seniors to age well, local communities have to take on the task of satisfying various needs of the seniors what institutions provide as services. Although local communities have the opportunities to provide a better variety of social connections and activity options, if the community fails to cater their needs, older people would have to venture much further out from their own community or be forced to become homebound because of the restraints of the environmental context (Rowles and Bernard 6). 
A community filled with these environmental restraints can be potentially threatening to seniors' psychological wellbeing significantly. It brings in unnecessary difficulties into senior's daily life, making it much harder to complete simple tasks for the elderly when they are experiencing physical transition of ageing body. Living with limited physical competence can deteriorate one's sense of autonomy significantly, especially for someone not socially competent neither (Machielse and Hortulanus 132). These obstacles in public spaces reduce the chances that the elderly venture out as well as their willingness to do so, which makes their social connection deteriorates gradually.

Although the discussion on aging population has been around for decades and the criticism on architecture barriers has never stopped, dilemmas that older people facing in built environment are yet brought enough awareness to. From as small as a slippery bathtub, to as big as the planning of public transport, there could be countless challenges for the elderly to come across throughout the spectrum of scale in daily life (Peace 28). As our population aging and the tendency of older people stay active for longer period of time, it is necessary for designers and architects to optimise our environment for the elderly to remain autonomous and connected in public space.

Certain bias embedded in the built environment imposes the value that conceives older people as burden or merely opportunity for profit, which dims their sense of identity. 


\subsection{4 [CASESTUDIES]}

\section{Case studies of the current situation of seniors in common public spaces}

In the following part, we are going to look into a few different typologies where a lot of seniors maintain their social connections, and discuss what kind of roles are these places play for seniors' psychological wellbeing and the inadequacy of their performances.

Fig 2.11. Johnsonville Mall is one of the most popular places to hang out for the elderly living around.

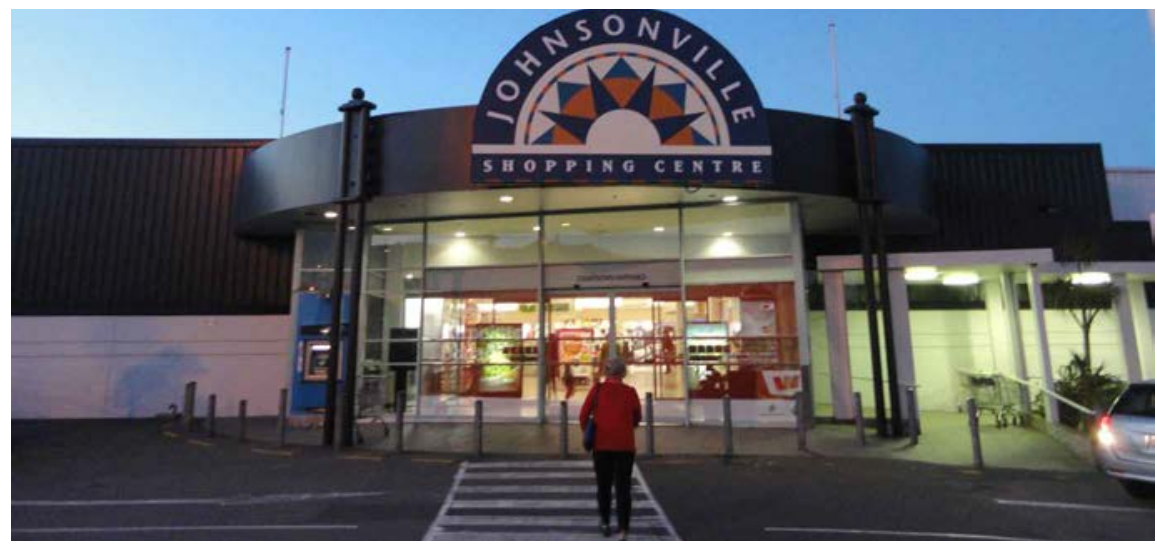

[SHOPPING MAL]

Due to the particular spatial characteristics of shopping malls, it is one of the most favoured places for the elderly to spend their day. In a majority of suburb area in New Zealand, shopping mall is always one of the most dominant buildings in town centre, with other public facilities scattered around it. This typical setting ensures that shopping mall has the advantage of convenience and proximity to nearby transportation and facilities. It is essential to seniors for accessibility to enhance the sense of autonomy. Besides that, the consumptive nature of shopping mall sets out a safe territory under surveillance for the 


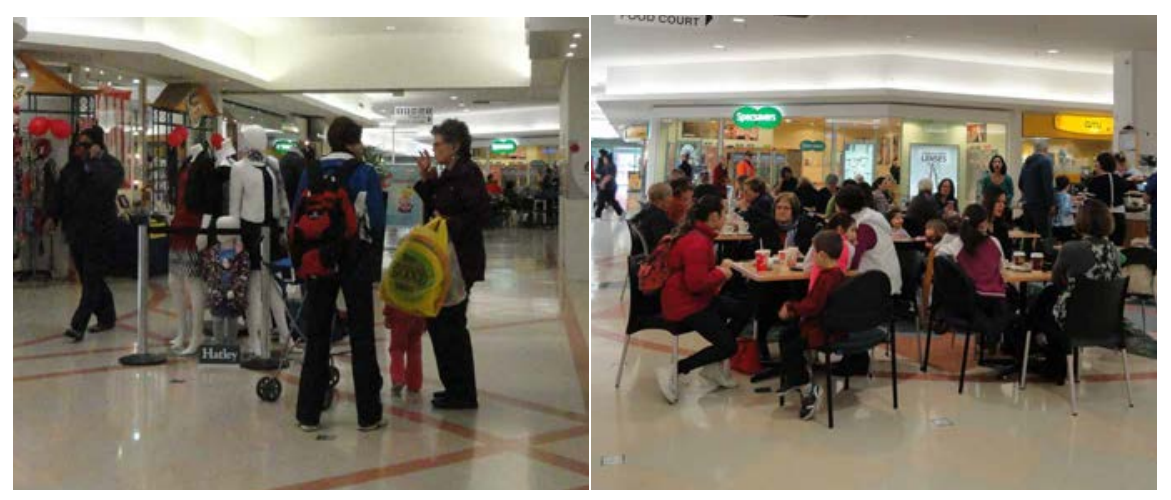

elderly and excludes unpleasant or threatening factors, such as weather, beggars or dominant user groups. This environment makes the elderly feel secured and comfortable to stay and have social interaction with other people for their sense of connectedness. In the research about the elderly and shopping malls, which led by Professor Rob White, who specialises in environment and justice at University of Tasmania, actually states that shopping malls have become more favoured for their non-commercial aspect and being common meet-up places (White, Toohey and Asquith 593). It values shopping mall as a significant public space for enabling seniors to maintain their social connection.
Fig 2.12. Various ways of interactions housed in Johnsonville Mall. 
As much as shopping malls play a decisive role in the quality of daily life of the elderly living in suburbs, we cannot say that shopping malls are the most considerate for the elderly in return for what they are counted on. In the research mentioned above, it is found that there are certain exclusions introduced by the environment deteriorating the experience of autonomy and connectedness for the elderly(White, Toohey and Asquith 590-91). For instance (refer to diagram), access between different transport modes to/from shopping malls might not be linked for varied mobility conditions, or designed to pay equal respects for, which could become the obstructions of seniors' venturing out for social life and eventually affects their psychological wellbeing negatively. 


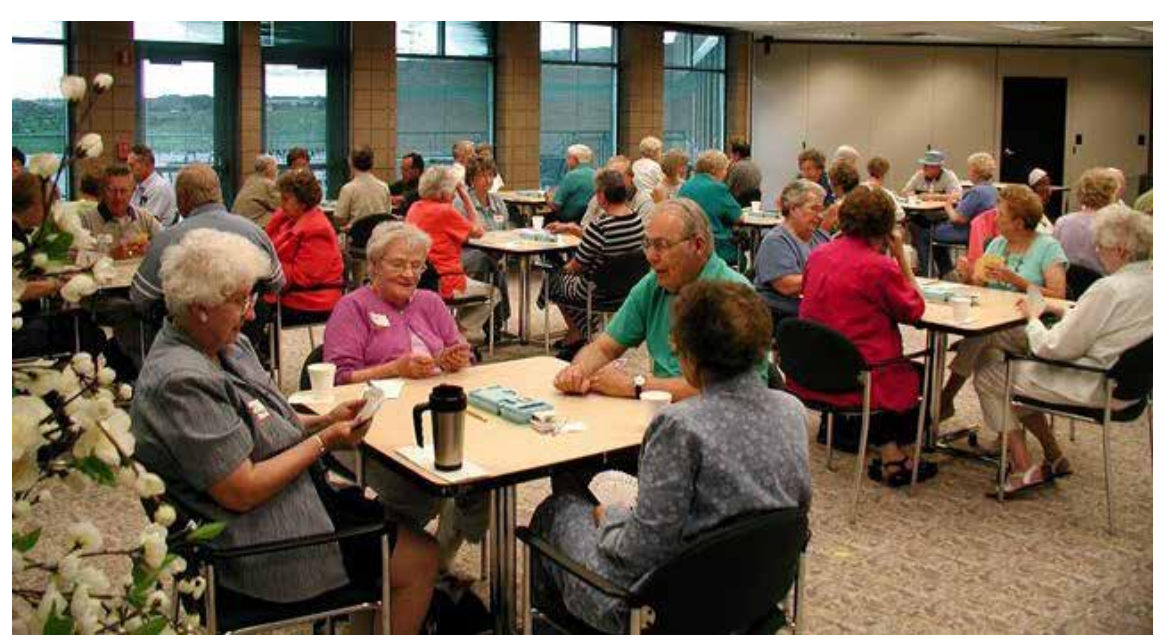

[SENIORS CENTRE]

Senior centre is a specific typology that developed to accommodate seniors' social life. Even though it is much more common in the US, Europe and even Australia than in New Zealand, there are various forms of substitutes taking on similar roles. As its senior-specific nature, senior centres are meant to be designed to the particular physical and social needs of the elderly. According to Dr. Rosenberg from University of Melbourne, “seniors' centre have long been providing space in which senior citizens could seek support and social
Fig 2.13. Photo of seniors playing bridge in one of the seniors centre in the United States. 
contact"(Rosenberg 464). In his paper, it is recognized that seniors' centre's contribution to provide opportunities for social integration, friendship, feelings of self-worth and community belonging, etc. It becomes an essential, sometimes singular, setting for social connection for them. However, it is obvious that as this kind of homogenous settings, they may become less attractive to some elderly or other citizens because they are labelled as "for old people". Hence, it could cause isolation for the elderly as it eliminate possible social contacts they could have with wider society members. 


\subsection{Autonomy \&}
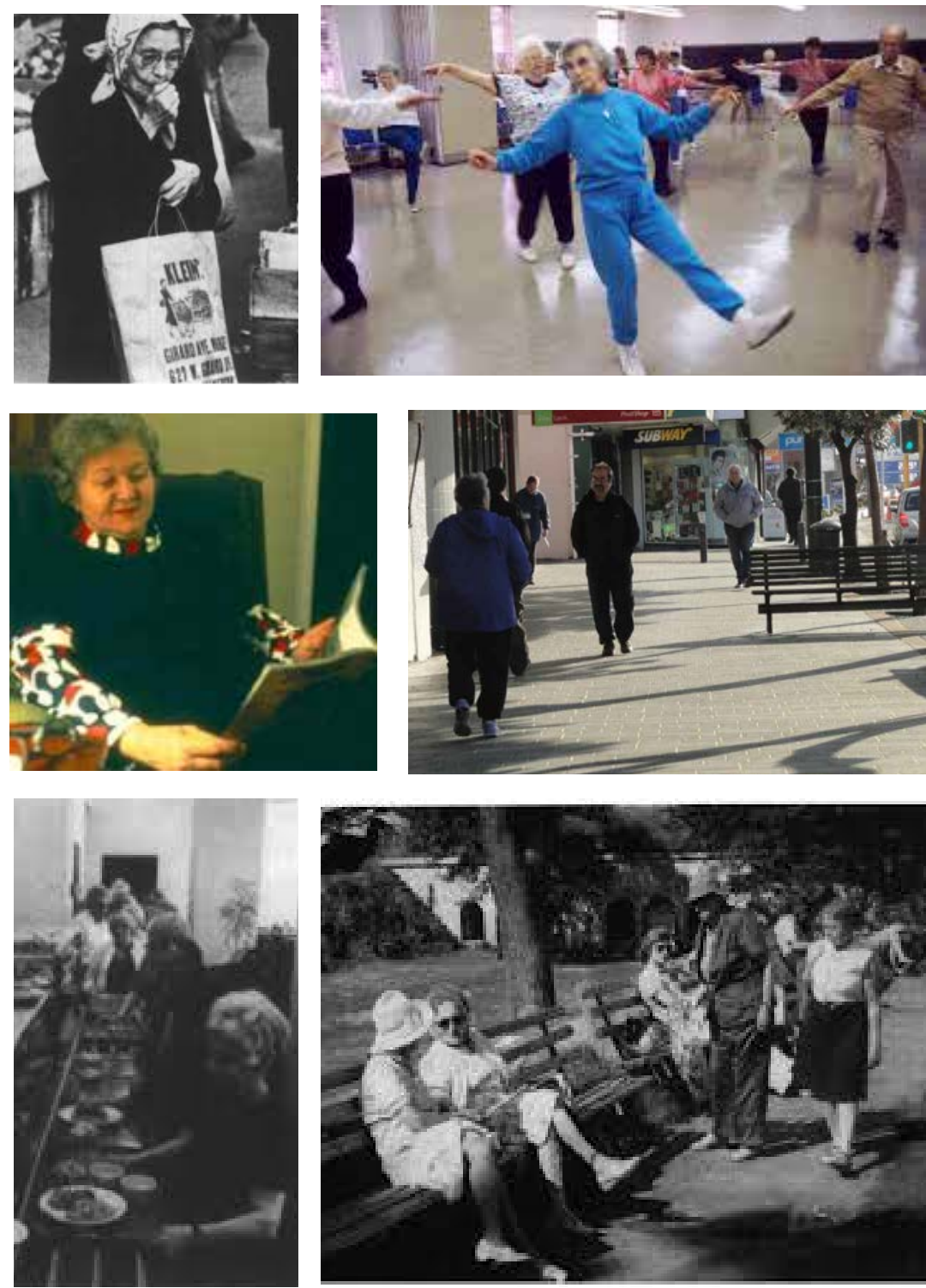

Fig 2.14. Collage images showing seniors' living condition in various background.

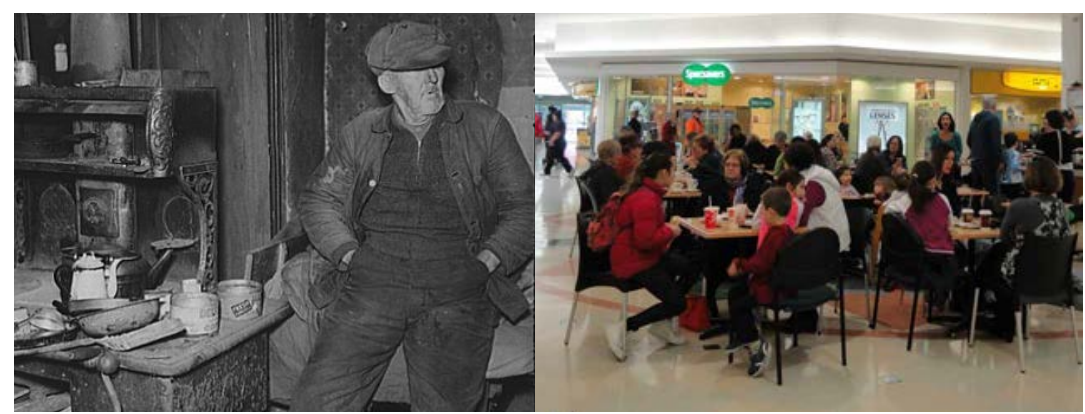




\section{[ENVIRONMENTAL 2.2.1 GERONTOLOGY]}

According to Key Concept in Social Gerontology published in 2010, environmental gerontology refers to "the interaction between the older people and their environments". Considering the complexity in the varied layers of environment, identified by Dr. Peace and a few fellow researchers, the scope of the thesis is limited within the intersection of the macro, and the social and public environment (Phillips, Ajrouch and Hillcoat-Nalletamby 83).

The dynamic interrelationship between the elderly and their sociophysical environment has always been the focus in the discourse of environmental gerontology. Since the 1920s, under the primary influence of the Chicago School of Urban Sociology, the field has been dominated by American researches due to particular social and political drivers. The Press-Competence model developed by Dr. Lawson and Dr. Nahemow in 1973 has been widely recognized in the field. It illustrates that there are adverse correlations between elder individuals' competence and the environment's impact on them. It was later modified into the PersonEnvironment Fit model, which prioritizes personal needs of the elderly over their competence. This modification advanced environmental gerontology to the acknowledgement of seniors' ability to shape the environment to their needs. It highlights the autonomy of elder persons to actively interact with the environment (Altman, Lawton and Wohlwill 198; Phillips, Ajrouch and Hillcoat-Nalletamby 83) 


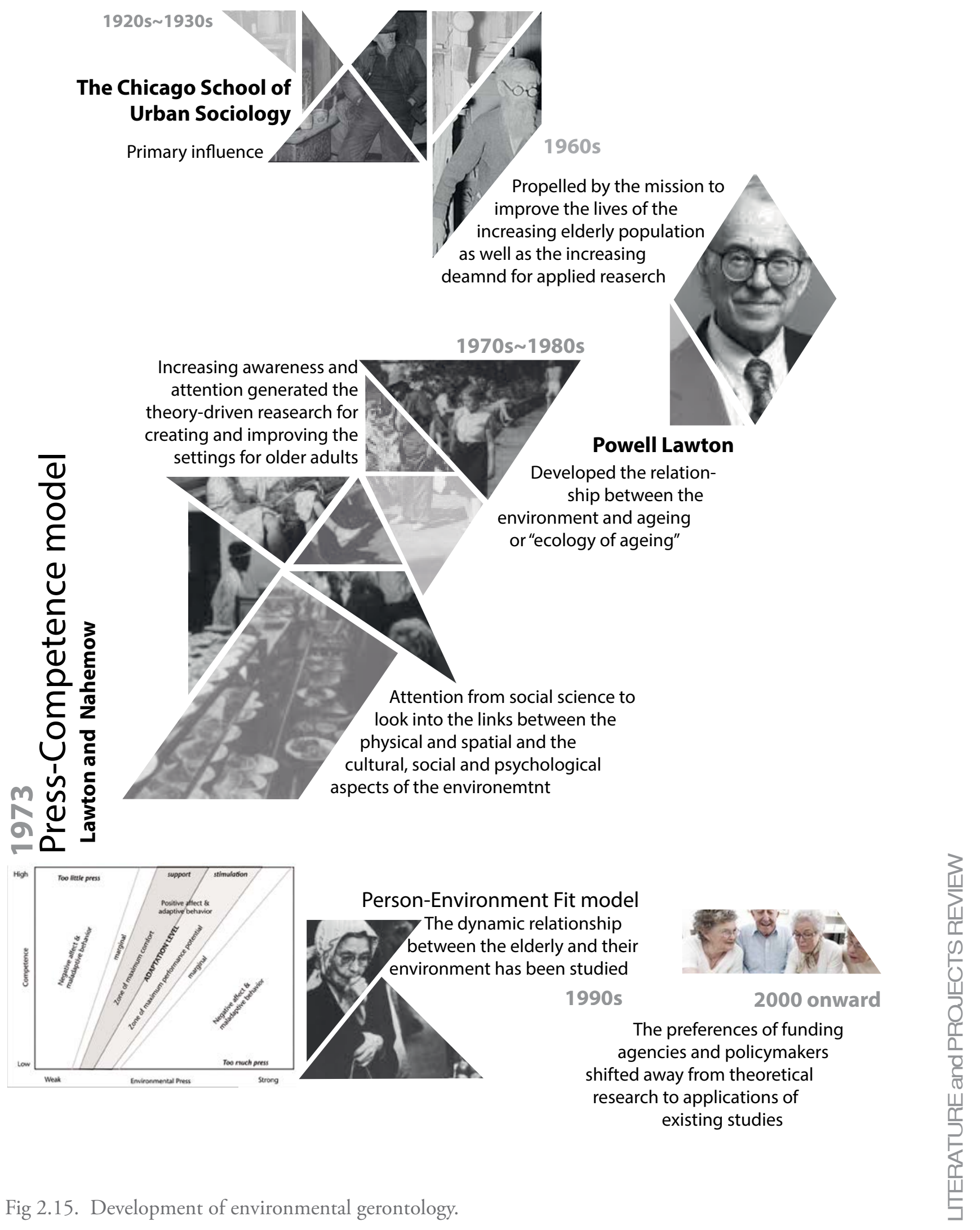




\subsection{2[UNIIVERSALDESIGN]}

\section{Enabling persons' autonomy from a physical perspective}

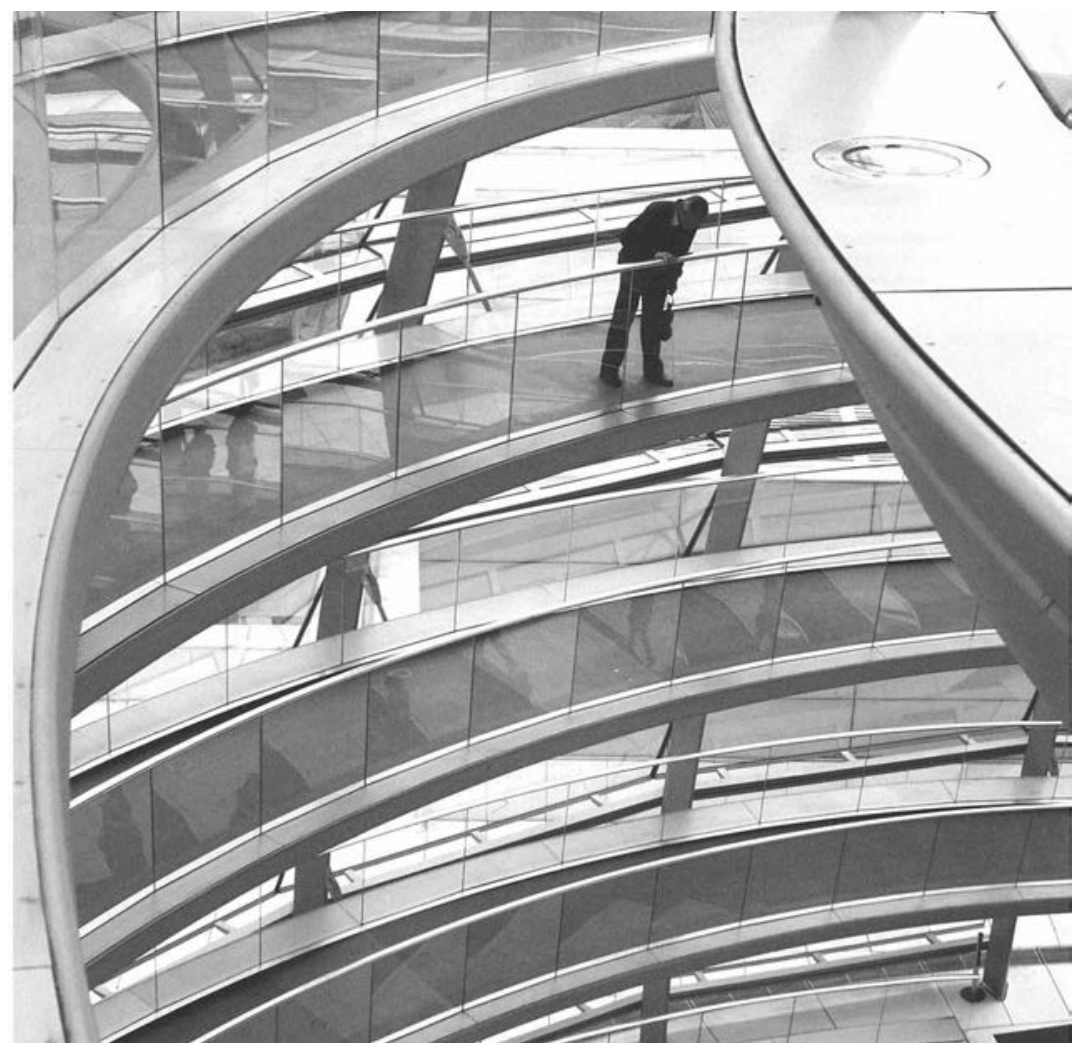

Universal Design is a term coined by architect and designer Ronald

L. Mace, which means "simply designing all products, buildings and exterior spaces to be usable by all people to the greatest extent possible" (Mace, Hardie and Place).
Fig 2.16. Example of architectural application of Universal Design. 
To maintain elder people's sense of autonomy and connectedness, it cannot happen without the empowerment from the physical world. In the architecture field, there have been ongoing discussions from the point of view of disability considering the relationship between older people and the environment they age in $\neg$. There has been increasing awareness from researchers and practices looking into the applications of universal design, accessibility and visitability within public spaces in response to the discourse of spatial equality. (Imrie; Hillcoat-Nalletamby and Ogg; Ball; Kendig et al.; Ozanne, Biggs and Kurowski). These studies extend from city development to local neighbourhood, to details in residential setting to investigate the relationship between spaces and the development of social roles in later life. According to influential gerontologist Glenda Laws, several dimensions of spatiality are valid for studying the relationship between spaces and older people, which are accessibility, mobility, motility, spatial scale and spatial segregation (Laws 93). These dimensions are going to be aspects of design exploration to create age-friendly spaces. 


\section{Special needs of older people}

Despite the varied kinds of physical decrement that come with ageing, manual dexterity (mobility), vision and hearing are the emphasis in this section, as they are most relevant to and affected by the environment. Manual dexterity refers to the changes in muscle and bone structure with age which leads to discomfort or pain in joints (Dougherty 21). This weakens one's ability to move around or perform tasks that require precision and strength. Universal Design aims to facilitate such physical decline in a way that the environment is friendly and less physically and mentally demanding (fig 2.17). Dougherty also mentioned that the elderly experience changes in their vision which make them become more sensitive to glare, have difficulties distinguishing shorter wavelength colours, experience decreased visual field and diminished sensitivity to low quantities of light. In addition, loss of hearing for high frequencies and ability to discriminate pitches and tinnitus (ringing in the ears) can occur as our body ageing. Catering these aspects of sensitivity for the elderly not only enables them to remain involved in public spaces, but can also be beneficial for everyone.

Fig 2.17. Diagram showing three main physical decrements elderly may experience. 


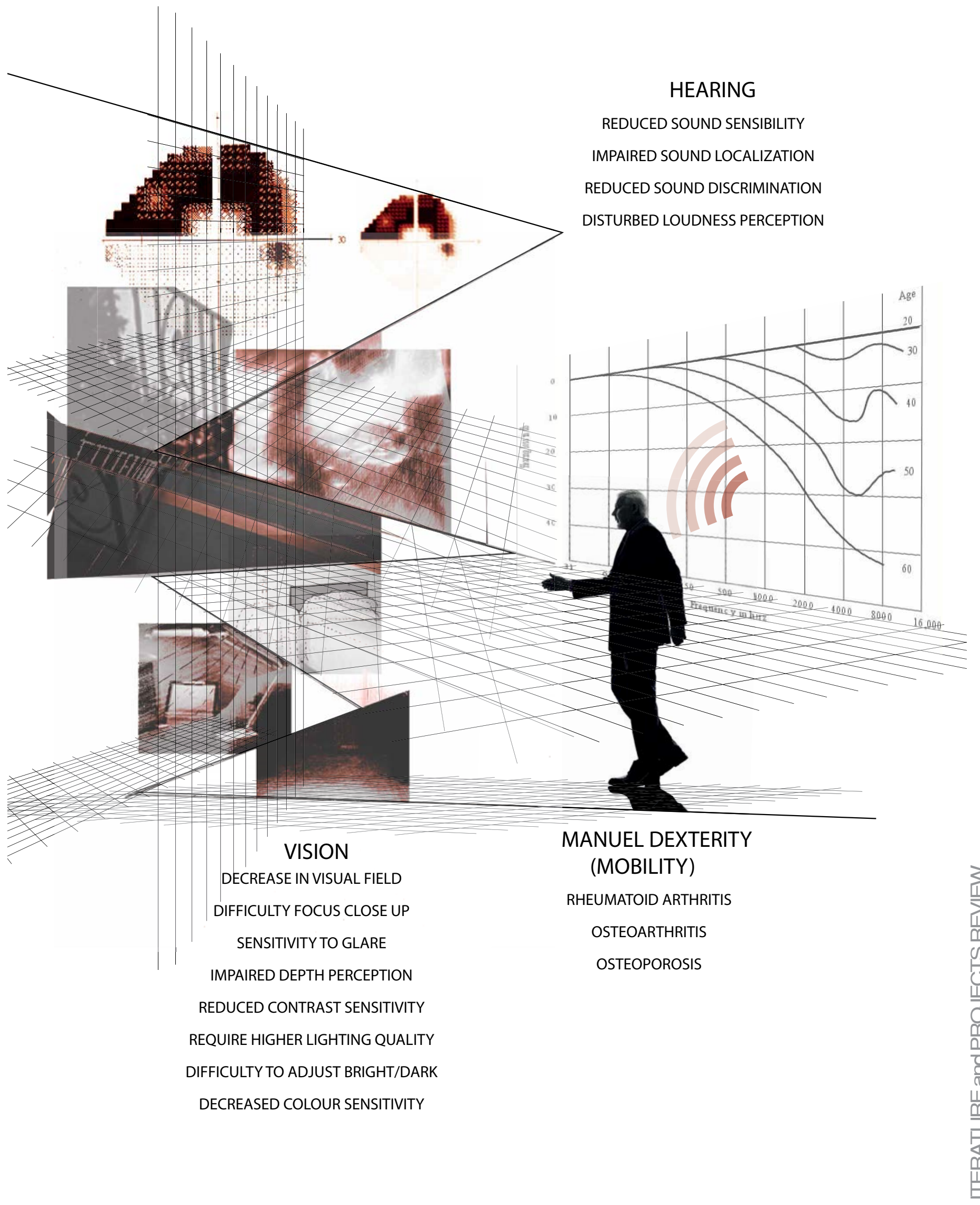




\section{Seven Principles of Universal Design}

The concept of Universal Design was crystallised by Mace and fellow researchers into seven principles:

i. Equitable use. The design is useful and marketable to people with diverse abilities.

ii. Flexibility in use. The design accommodates a wide range of individual preferences and abilities.

iii. Simple and intuitive use. Use of the design is easy to understand, regardless of user's experience, knowledge, language skills or current concentration level.

iv. Perceptible information. The design communicates necessary information effectively to the user, regardless of ambient conditions or the user's sensory abilities.

v. Tolerance for error. The design minimizes hazards and the adverse consequences of accidental or unintended actions.

vi. Low physical effort. The design can be used efficiently and comfortably and with a minimum of fatigue.

vii.Size and space for approach and use. Appropriate size and space are provided for approach, reach, manipulation and use regardless of the user's body size, posture or mobility. (Lazzaro; Persson et al.)

This manifesto set up the foundation of Universal Design, which is adopted selectively for following design interventions. 


\subsection{3[PHENOMENOLOGY]}

Why Phenomenology?

Fig 2.18. C o n c e p t u a l drawing by Steven Holl for Kiasma Museum of Contemporary Art.

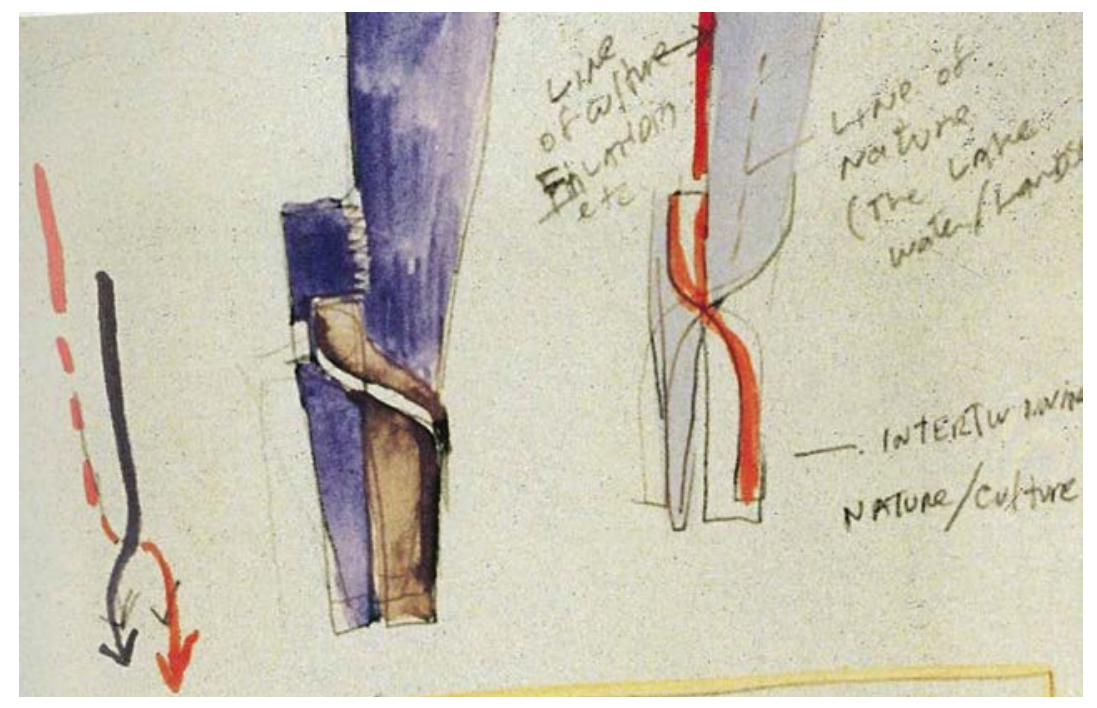

As Pallasmaa addressed, "as architects, we do not design buildings primarily as physical objects: we design with regard to the images and emotions of the people who live in them...the effect of architecture stems from more or less shared images and basic emotions connected with building"(244). Pallasmaa extends notions of phenomenology to an architectural context. By defining it is as the study in the phenomenon of the consciousness experiencing architecture. 


\section{Phenomenological approach in environmental gerontologist}

According to Dr. Scheidt and Dr. Schwarz, within the field of environmental gerontology, there has been constant debate between two dominant approaches. While the positivist build their belief on scientific and quantifiable measurements, the interpretivist pay attention to "the subjective experience of the ageing individual and his or her interaction with the environment". As elderly are the focus of this research in environmental gerontology, the positivist approach is questioned in regard to whether elder people are well represented and benefit from its deals. It is argued that the positivist approach neglects the subjective measure from the seniors' perspective (16-18). The interpretivist approach is adopted as theoretical foundation to develope the potential of the built environment to fulfil the elderly's sense of autonomy. It leads to the study of the complex and multifaceted transaction between the elderly and their environment through a phenomenology perspective focusing on the spatial experience of the elderly. 


\section{Sense of Place Attachment in phenomenological approach}

Constant transactions between person and environment, and the sense of place attachment, have significant contribution to facilitate successful adjustments in old age. Sense of place is believed to "help to maintain a sense of identity and wellbeing", according to researchers from the University of Auckland and University of Otago (Wiles et al. 664). Such place attachment can be physical, cognitive and psychological. This attachment could be traced back to familiarities that ease maintenance and function. The familiarities can be understood as the mental constructs the persons has made with the environment, embodying the meaning, memory and experience the person associates with the place(HillcoatNalletamby and Ogg 1772). As Di Masso, Dixon, and Durrheim argued that, "place attachment can be understood as a phenomenon that is linguistically constructed through interaction as individuals co-construct the meaning of places and person-place relationship" (Cross 495).It is this interrelationship contributing to the sense of belonging and identity, which can be easily lost after one's retirement (Hernández et al. 310). Thus, place attachment enhances one's feeling of being in control of 
familiar environment and therefore sustains elderly's sense of autonomy. This sense of familiarity and being in place make the elderly feel safe and comfortable to maintain their connection.

Professor Cross argues that place attachment “... is the positive experiences which create attachment, the desire to maintain connection to a place and the senses of safety and comfort" (Cross 495). Despite decades of separation, Cross shares very similar views with Pallasmaa on the impact of spatial experience on people.In her recent paper, she proposes that to construct place attachment, there are seven common processes including sensory, narrative, historical, spiritual, ideological, commodifying and material dependence(Cross 501). Considering the relevance between each process to architecture (table 1.), sensory and narrative will be the focal points of the design experimentation. 
TABLE 1. Interactional Processes of Place Attachment

\begin{tabular}{|c|c|c|c|c|}
\hline Processes & $\begin{array}{l}\text { Nature of } \\
\text { Process }\end{array}$ & $\begin{array}{l}\text { Action } \\
\text { (individual or } \\
\text { interactional) }\end{array}$ & $\begin{array}{l}\text { Meaning } \\
\text { (individual } \\
\text { or cultural) }\end{array}$ & $\begin{array}{l}\text { Change over } \\
\text { Time }\end{array}$ \\
\hline Sensory & $\begin{array}{l}\text { Experiencing the } \\
\text { place through } \\
\text { the five senses }\end{array}$ & $\begin{array}{l}\text { Individual } \\
\text { experience }\end{array}$ & $\begin{array}{l}\text { Personal } \\
\text { assessment and } \\
\text { meaning: } \\
\text { aesthetic value } \\
\text { judgments based } \\
\text { on personal } \\
\text { preference, } \\
\text { interpersonal } \\
\text { interaction, and } \\
\text { cultural values }\end{array}$ & $\begin{array}{l}\text { Expands and develops } \\
\text { over time, } \\
\text { meanings shift with } \\
\text { interaction and } \\
\text { reinterpretation }\end{array}$ \\
\hline Narrative & $\begin{array}{l}\text { Practice of telling } \\
\text { stories about } \\
\text { the place, } \\
\text { individuals in } \\
\text { place, and } \\
\text { cultural stories } \\
\text { of place }\end{array}$ & $\begin{array}{l}\text { Interpersonal } \\
\text { story-telling, } \\
\text { cultural stories } \\
\text { of place }\end{array}$ & $\begin{array}{l}\text { Individual, family, } \\
\text { group, cultural }\end{array}$ & $\begin{array}{l}\text { Continually evolving } \\
\text { as people select } \\
\text { which stories to } \\
\text { retell and which to } \\
\text { overlook and what } \\
\text { personal and } \\
\text { cultural meanings } \\
\text { to emphasize }\end{array}$ \\
\hline $\begin{array}{l}\text { Historical } \\
\text { (Biographical, } \\
\text { Genealogical, } \\
\text { Ancestral) }\end{array}$ & $\begin{array}{l}\text { Personal life } \\
\text { experience, } \\
\text { family history, } \\
\text { cultural history }\end{array}$ & $\begin{array}{l}\text { Accumulation of } \\
\text { life history and } \\
\text { events in a } \\
\text { place, family } \\
\text { history, cultural } \\
\text { history }\end{array}$ & $\begin{array}{l}\text { Association of key } \\
\text { life events with } \\
\text { place, and } \\
\text { association of } \\
\text { place history to } \\
\text { personal } \\
\text { biography }\end{array}$ & $\begin{array}{l}\text { Progressively } \\
\text { expanding over } \\
\text { time in place }\end{array}$ \\
\hline Spiritual & $\begin{array}{l}\text { Deep feeling or } \\
\text { sense of } \\
\text { belonging }\end{array}$ & $\begin{array}{l}\text { Ongoing feeling } \\
\text { of deep } \\
\text { "oneness" with } \\
\text { place }\end{array}$ & $\begin{array}{l}\text { Deeply personal, } \\
\text { difficult to share, } \\
\text { often creates } \\
\text { conflict over } \\
\text { "authentic" } \\
\text { attachment }\end{array}$ & Usually constant \\
\hline Ideological & $\begin{array}{l}\text { Moral, ethical, } \\
\text { legal } \\
\text { commitment to } \\
\text { place }\end{array}$ & $\begin{array}{l}\text { Individual, group } \\
\text { or cultural } \\
\text { commitment }\end{array}$ & $\begin{array}{l}\text { Individual, } \\
\text { interpersonal, } \\
\text { cultural }\end{array}$ & $\begin{array}{l}\text { Requires ongoing } \\
\text { commitment/ } \\
\text { adherence to code } \\
\text { and related action }\end{array}$ \\
\hline Commodifying & $\begin{array}{l}\text { Cognitive act of } \\
\text { assessing place } \\
\text { based on a list } \\
\text { desirable traits }\end{array}$ & $\begin{array}{l}\text { Individual, } \\
\text { interpersonal }\end{array}$ & $\begin{array}{l}\text { Individual, } \\
\text { interpersonal, } \\
\text { cultural }\end{array}$ & $\begin{array}{l}\text { Often diminishes as } \\
\text { other processes } \\
\text { develop }\end{array}$ \\
\hline $\begin{array}{l}\text { Material } \\
\text { dependence }\end{array}$ & $\begin{array}{l}\text { Reliance on a } \\
\text { social } \\
\text { resources, or } \\
\text { features of } \\
\text { place }\end{array}$ & $\begin{array}{l}\text { Individual, } \\
\text { interpersonal, } \\
\text { cultural }\end{array}$ & $\begin{array}{l}\text { Individual, } \\
\text { interpersonal, } \\
\text { cultural }\end{array}$ & $\begin{array}{l}\text { Changes as material } \\
\text { conditions change } \\
\text { (e.g., life-course), } \\
\text { and as personal } \\
\text { requirements } \\
\text { change (e.g., } \\
\text { new attitudes, } \\
\text { experience) }\end{array}$ \\
\hline
\end{tabular}




\section{Sensory}

Sensory is one of the initial interaction humans have with places. Hence, a sensory-enriched space can be highly effective in developing place attachment. Based on her research, Professor Cross concludes that "Places that a person can rely on for restorative experiences are thus more likely to be places for which attachments develop". As they spend time in these spaces, these positive sensory experiences start to entangle with the place identity and attachment has potential to be developed.

\section{[CASESTUDY]}

Kiasma Museum of Contemporary Art
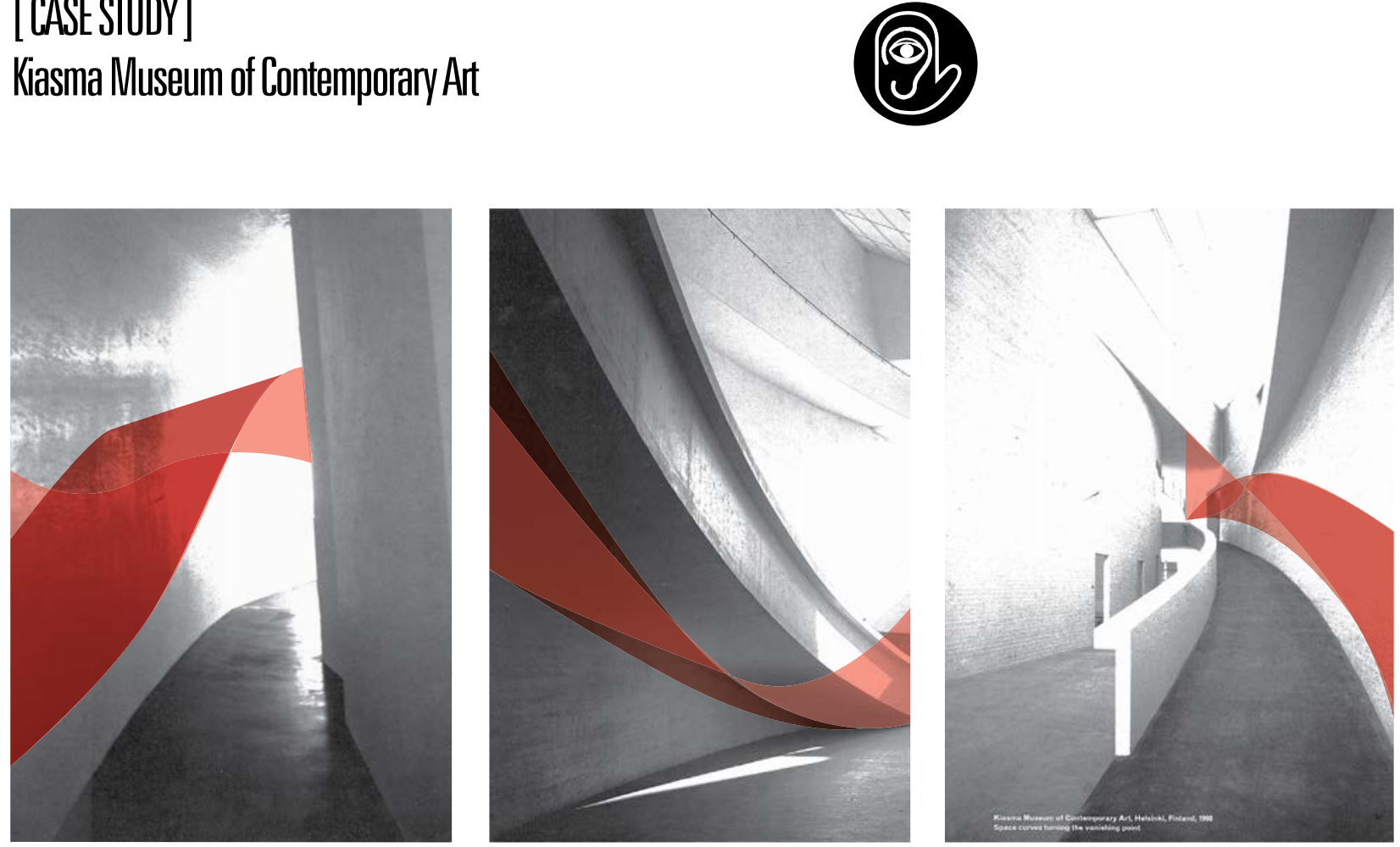
Fig 2.20. [Opposite page] The twist and turn of body with the rhythm of the geometry of architecture.

Fig 2.21. [Right] Analysis of the dynamic of visibility and movement introduced by the architecture.

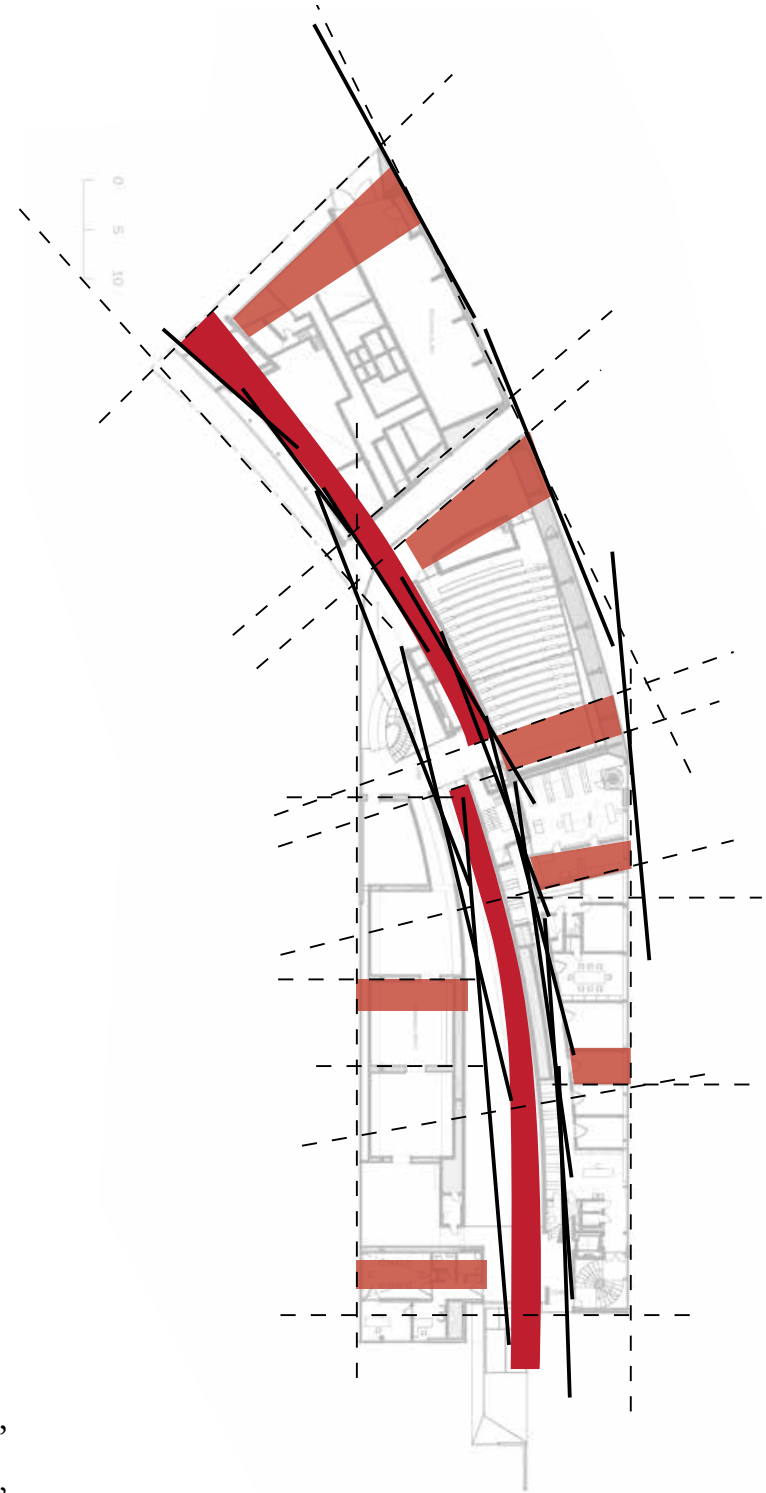

Kiasma Museum is designed to fully engage visitors' senses for a "radiant" experience which refers to the phenomenon created by intense spatial quality. As visitors twist and turn their body with the rhythm of the space, these movements create a dynamic sensory experience in visitors' perception. 


\section{Narrative}

Narrative, as the foundation of human interaction, can have its contribution to the building of place attachment. As Professor Cross demonstrates in her paper, "the narrative process of place attachment is learning about place and developing bonds to place through the telling and hearing of stories" (504). Through this story telling and retelling, people associate the place with their life and experience, slowly creating the narrative about them and the place, thus the sense of attachment and belonging is developed. Other than being the subject of this storytelling, architecture can also be the story teller. According to Professor Psarra's research on Tschumi's view on the perceptual aspects of architecture, architecture tells story through the sequences of spaces and events (4). 


\section{[CASESTUDY] \\ Louisiana Museum of Modem Ait}

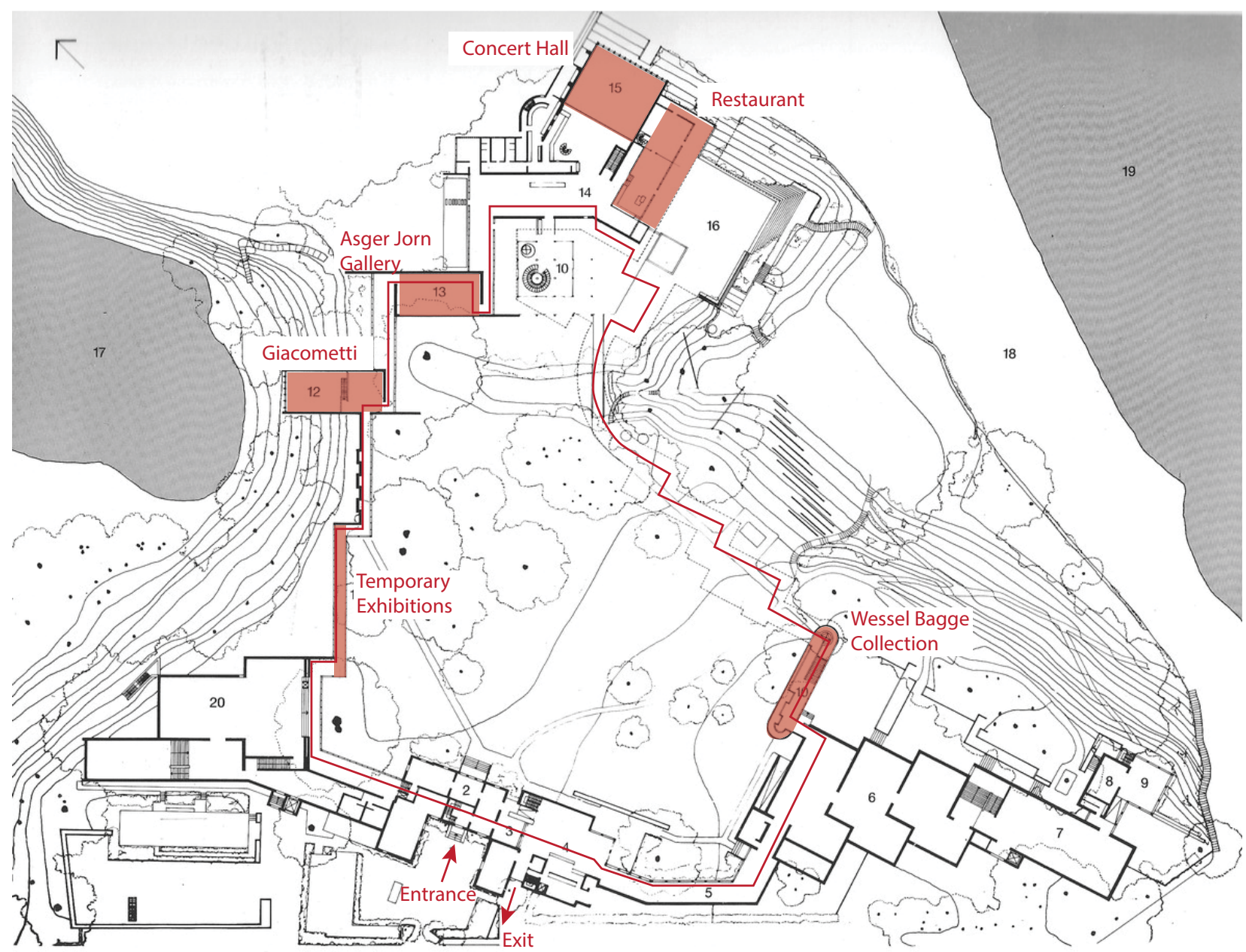

Fig 2.22. Ground floor plan showing the "threading" of spaces and the locations of spaces that are analysed in following diagram. 
In Louisiana Museum of Modern Art, the architects create a fascinating narrative through their careful threading of spaces. The story of the museum is revealed as visitor move along the looped journey composed of buildings developed sequentially. In the theme of "promenade", visitors are presented with a range of spaces with various widths, height, depth, lighting, material and others.
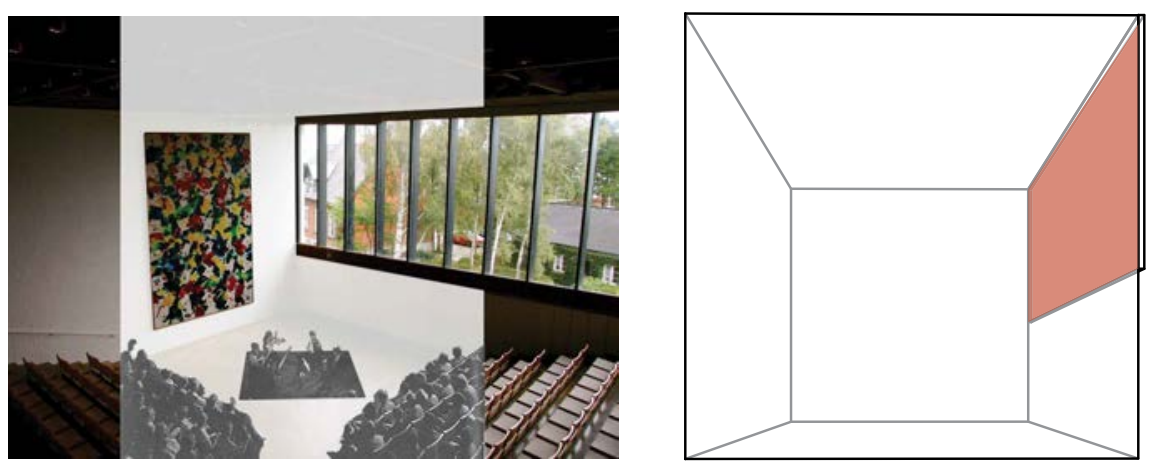

Fig 2.23. D i a g r a m s highlighting the interactions among art works, nature and people in relation to the volume and composition of opening in various spaces.

a). Conference room
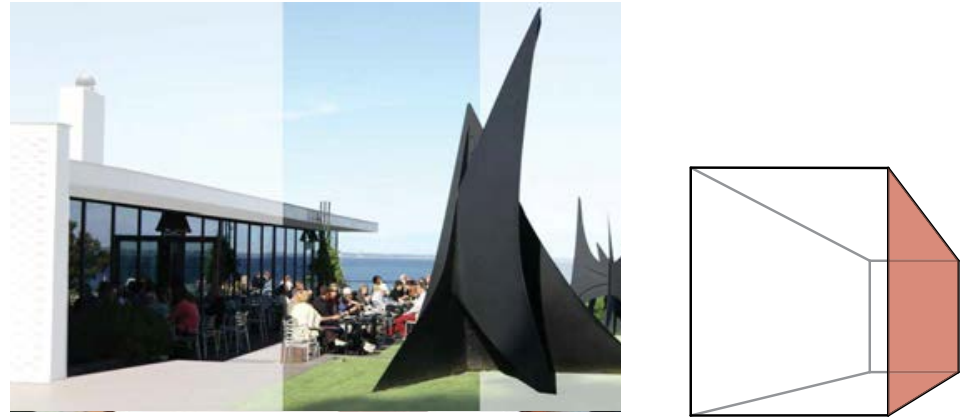

b). Restaurant and sculpture terrace

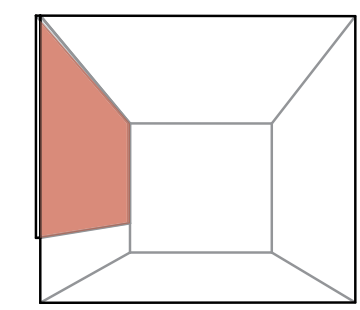

c). Wessel Bagge Collection

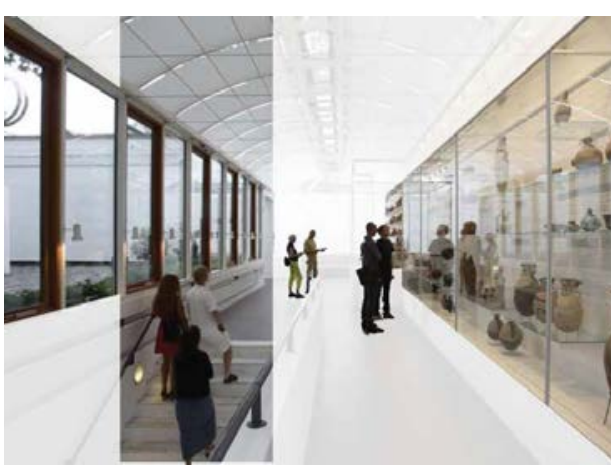


Within these spaces, the architecture is a humble mediator between people, art works and landscape. It brings all these elements together without over-announcing its own existence. The pause to the nature from art works allows people to reflect and interact with each other. Rather than overwhelming formal manifesto which people can hardly feel related, Louisiana Museum creates experience. An experience is about immersing oneself among arts, nature and connection with other people (Grabow 122-32).

d). Giacometti gallery
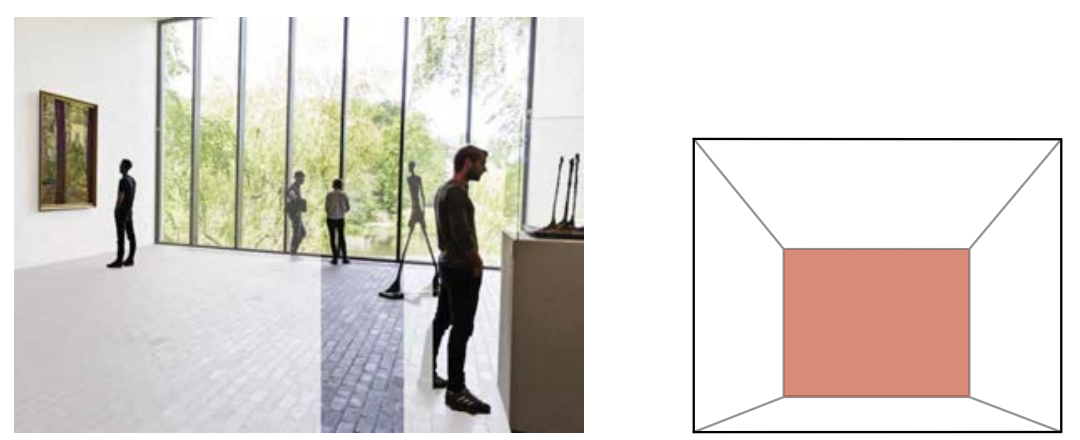

e). Temporary exhibitions
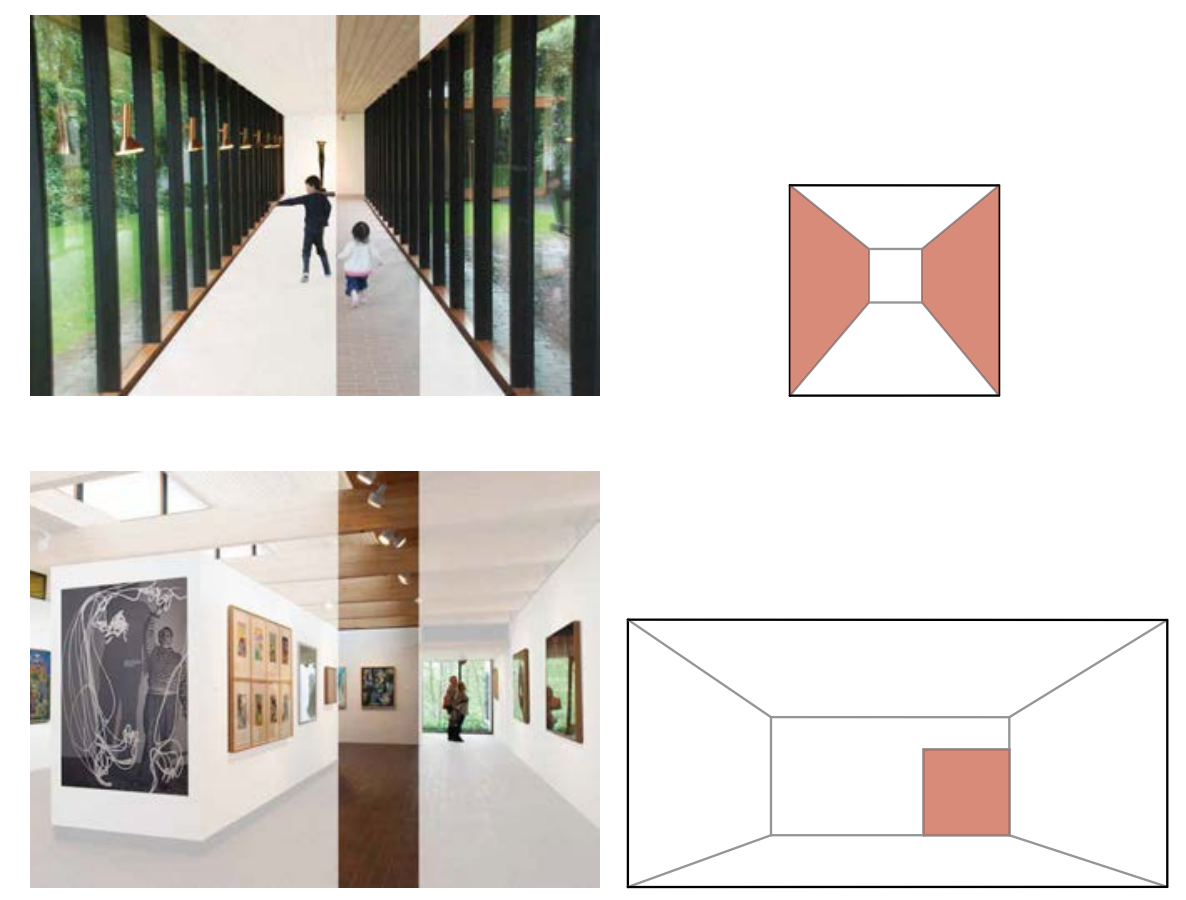

f). Asger Jorn gallery 
Ageing

2.1 Validity of Problem

Mindset

Elderly in Public Spaces

Dilemmas

Case studies:

Shopping Mall

Senior Centre
2.2 Autonomy \& Connectedness

Environmentle Gerontology

Universal Design

Case studies

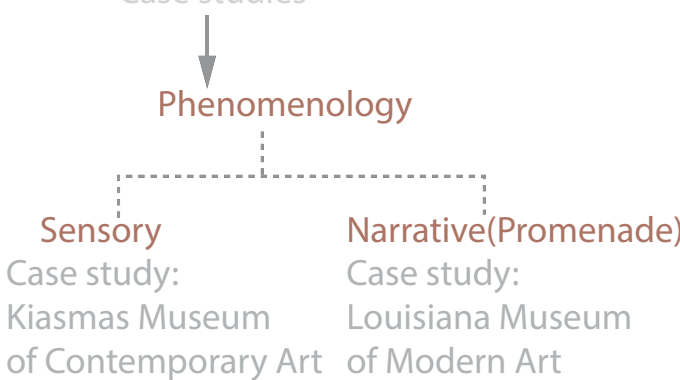

Johnsonville

3.1 The Suburbia

Situating ageing

in context of Contemporary Art of Modern Art 
$\Gamma$

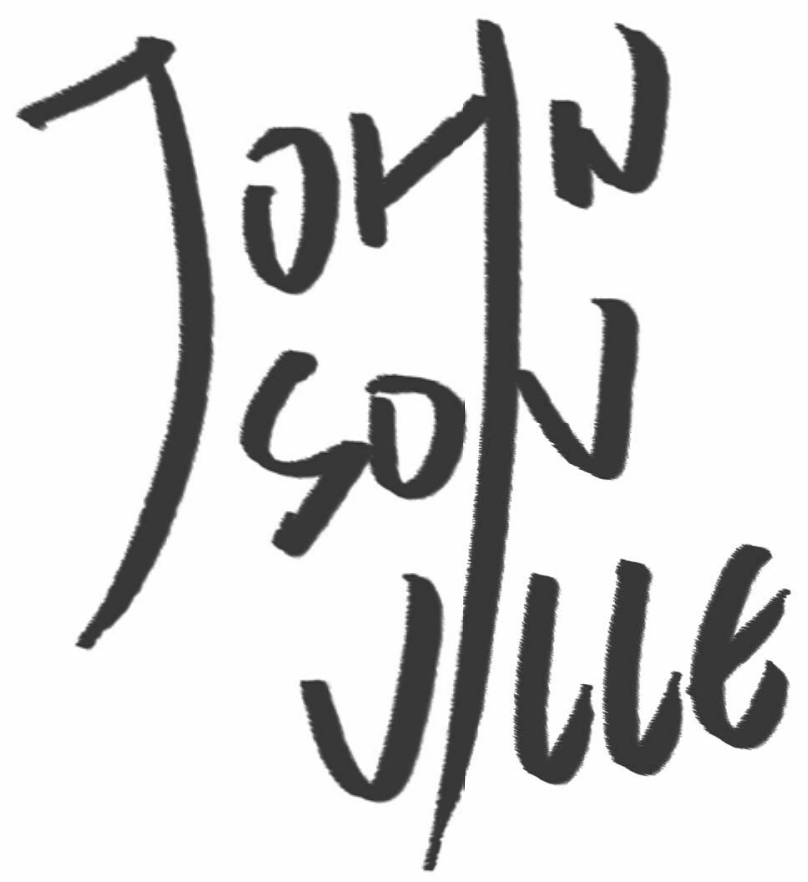

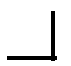


Fig 3.1. Busy traffic on

Broderick Road at peak time.

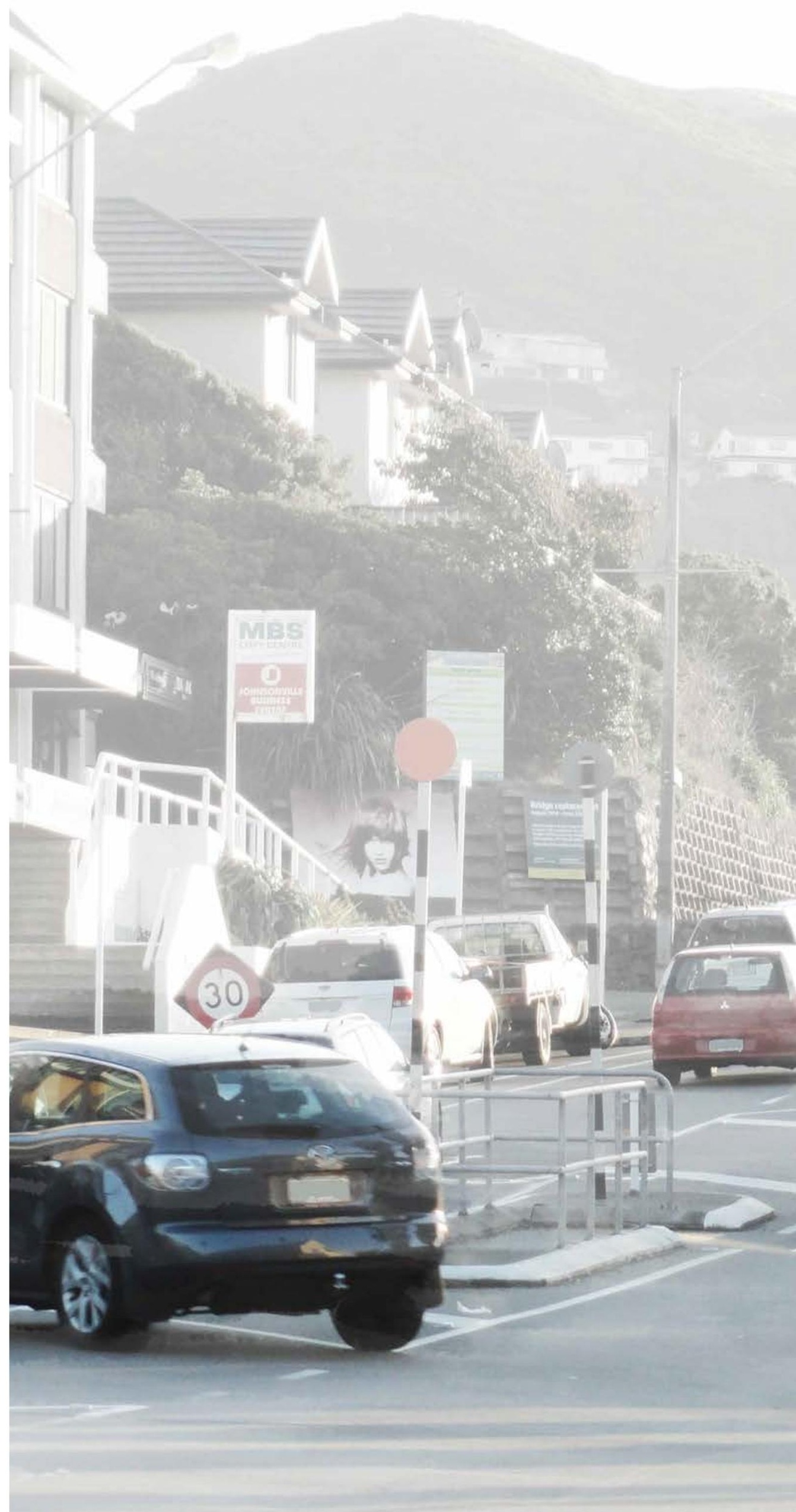


In this chapter, the problem of elderly accessibility is situated in a New Zealand suburban context - Johnsonville. Through analysis on the spatial experience of the elderly from the overall suburban setting to the specific focus on the town centre, a collection of conceptual models were made as statements responding to the site-specific problems. 


\section{The Suburbia}

Situating ageing in Johnsonville

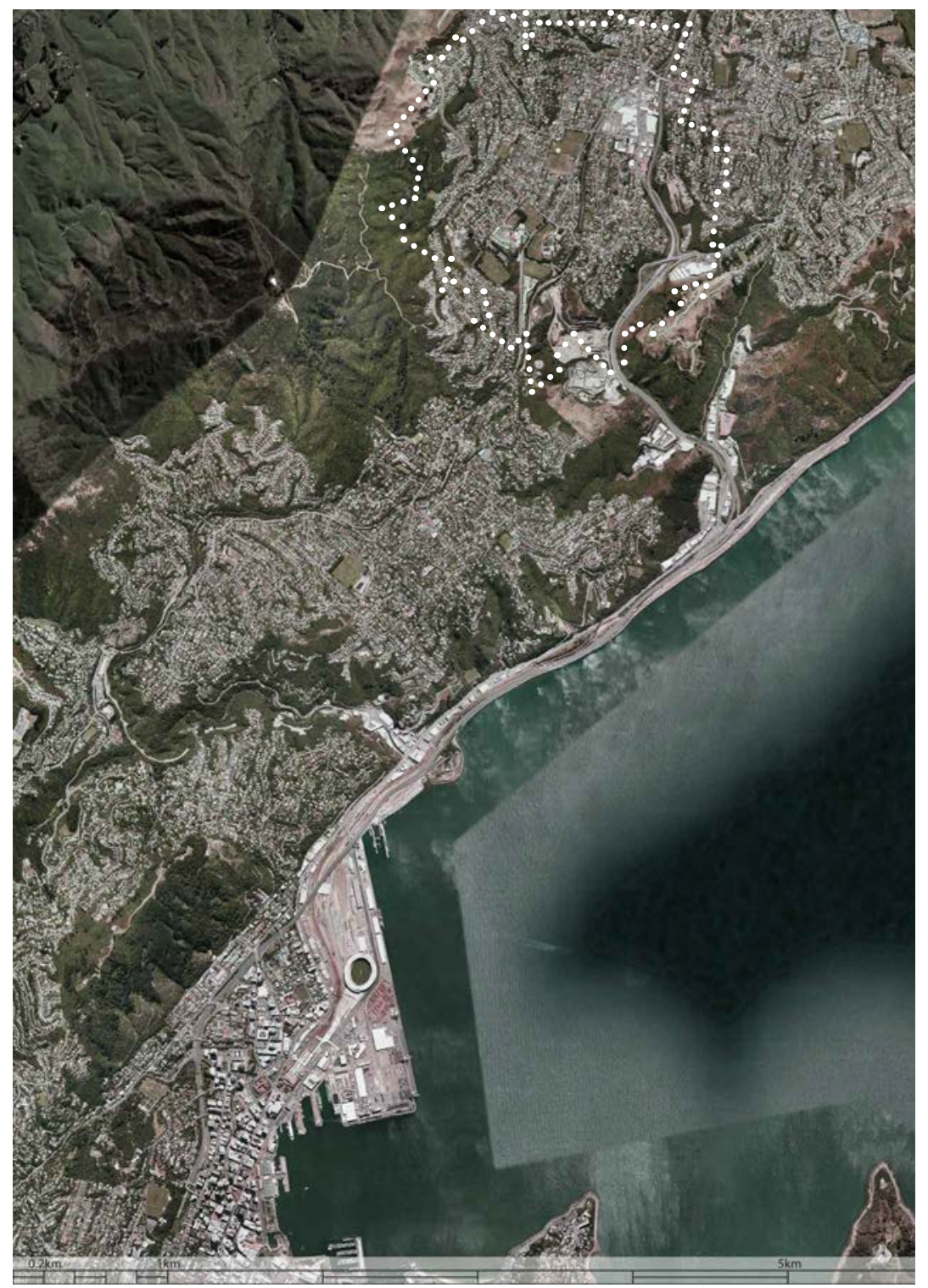

Fig 3.2. JohnsonvilleJohnsonville in relation to Wellington City. The proximity to Wellington Central attracts increasing number of people to settle in Johnsonville. 


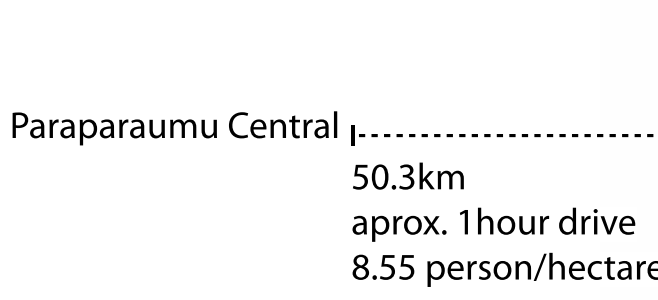

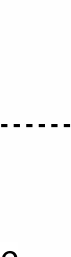

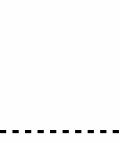


Amongst three candidate sites, all expecting significant population growth (Mead; Harris). New Town shows the major increase in the age group of 20 to 40 years old and most of people moving into Paraparaumu are above 65 in recent year (fig 3.3, fig 3.4). Compared to these two suburbs, Johnsonville has a relatively balanced growth among all ages. It suggests that Johnsonville has greater demands on an age-friendly yet all-age-welcome public space rather than prioritising or isolating (out of over-protection) any age group.

Fig 3.3. [Left] Proximity to Wellington city central and population density of three site candidates.

Fig 3.4. [Next page] Age structures of three candidate sites from 1981 to 2013. It illustrates the trends of different age groups throughout recent decades in candidate sites, some of which display strong attraction to certain age groups. 


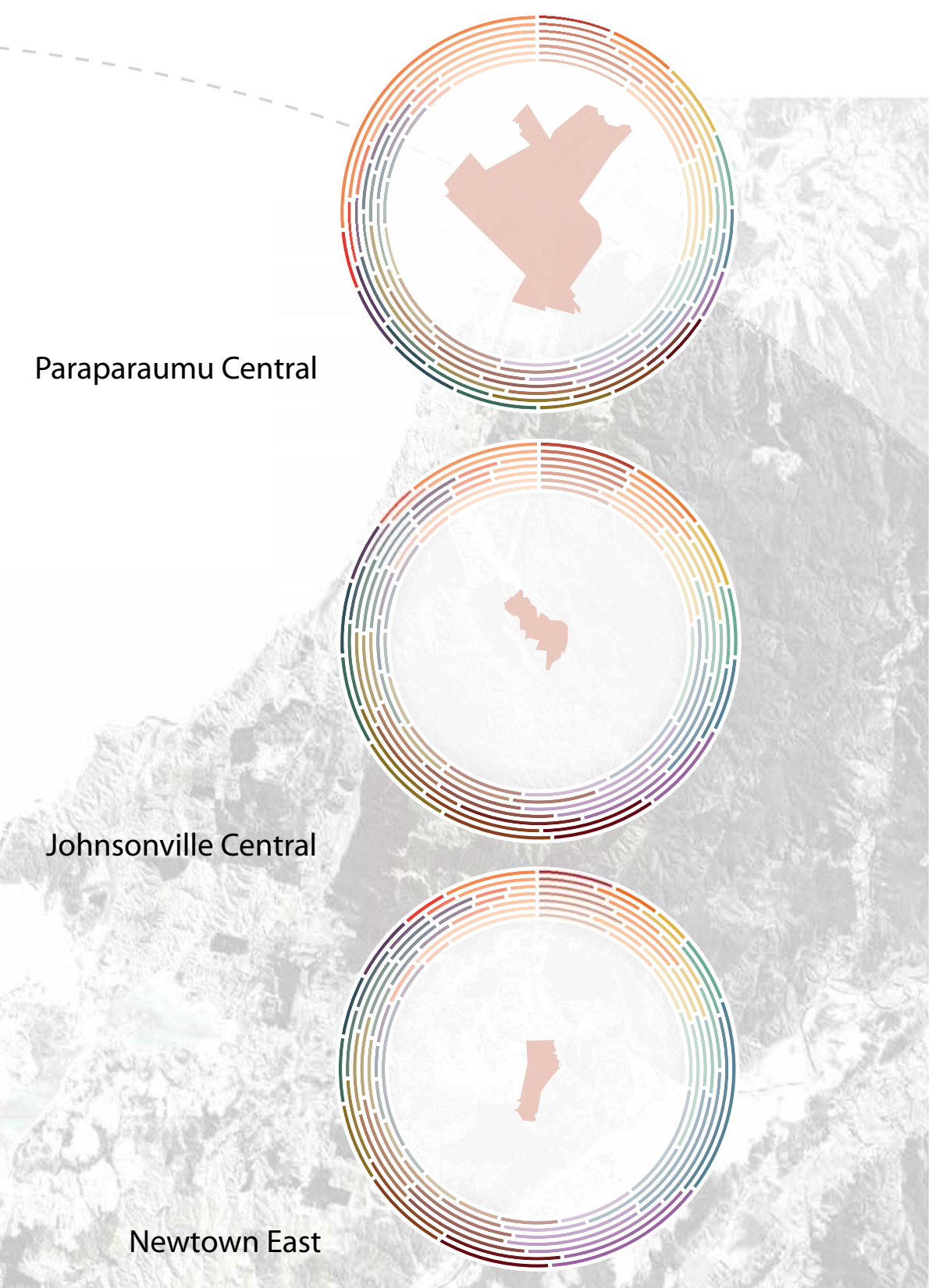

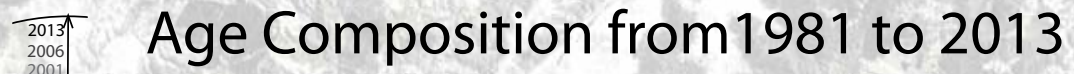

\section{Wellington - Lambton}


First church established.

SERVICE CENTRE

for growing rural population surrounded Wellington.

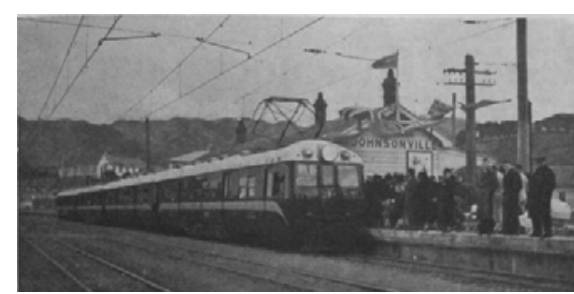

New eletric train service link

the area to Wellington.

State housing expanded.
Road and railway
development

Name after early settler

\section{Frank Johnson}

who built a timber mill in

the area to supply wood

to Wellington.
1842

1866

1

Rest stop

when Cobb and

Co began a

coach service to

Wanganui 1920s 1930s 1953
Fig 3.5. Timeline of the development of township of Johnsonville. The history of Johnsonville's development reveals its relationship with the development of transportation from the origin.
Johnsonville is situated about seven kilometres north of Wellington city. Being slightly tucked behind mountains, transportation between Johnsonville and Wellington city is heavily relies on the motorways. Benefited from its critical location of connecting Wellington city and northern regions, the development of Johnsonville township is significantly influenced by the development of road through the Ngauranga Gorge and the railway(Chapman). Tracing the history of Johnsonville (see fig 3.5), it become obvious how its urban configuration is mainly shaped by the press of transportation. 


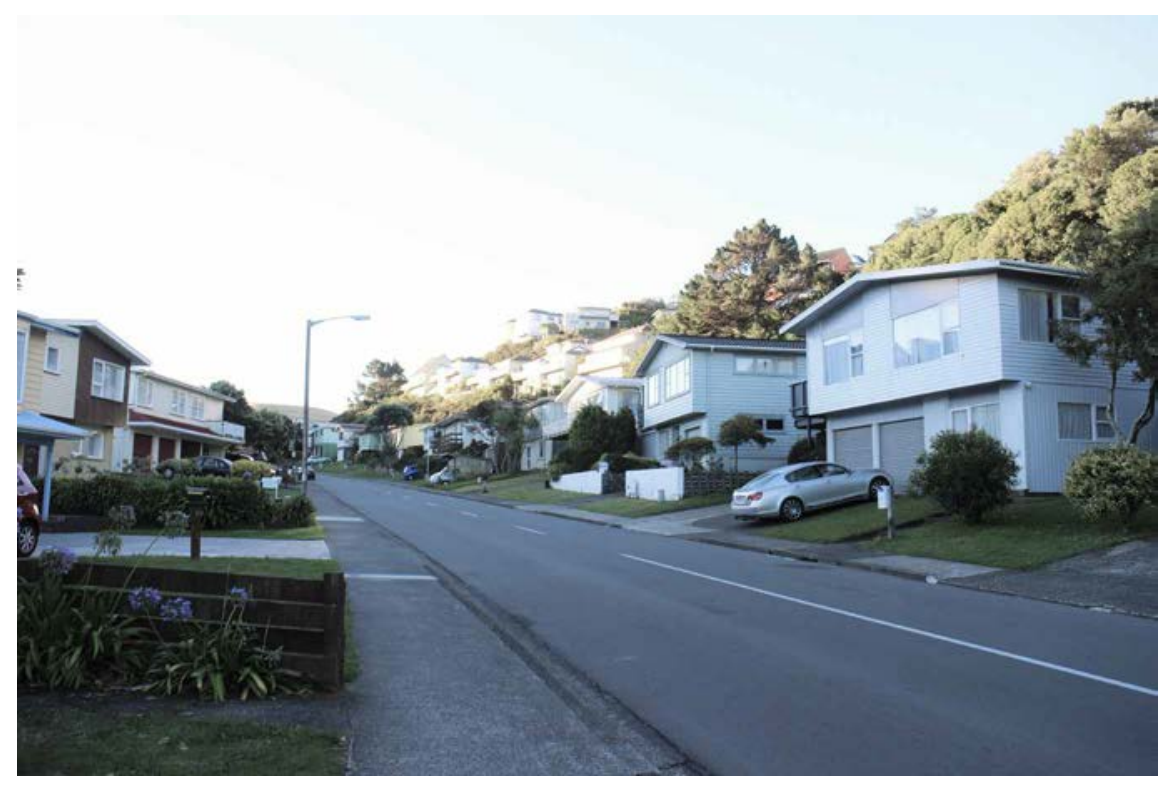

(5)

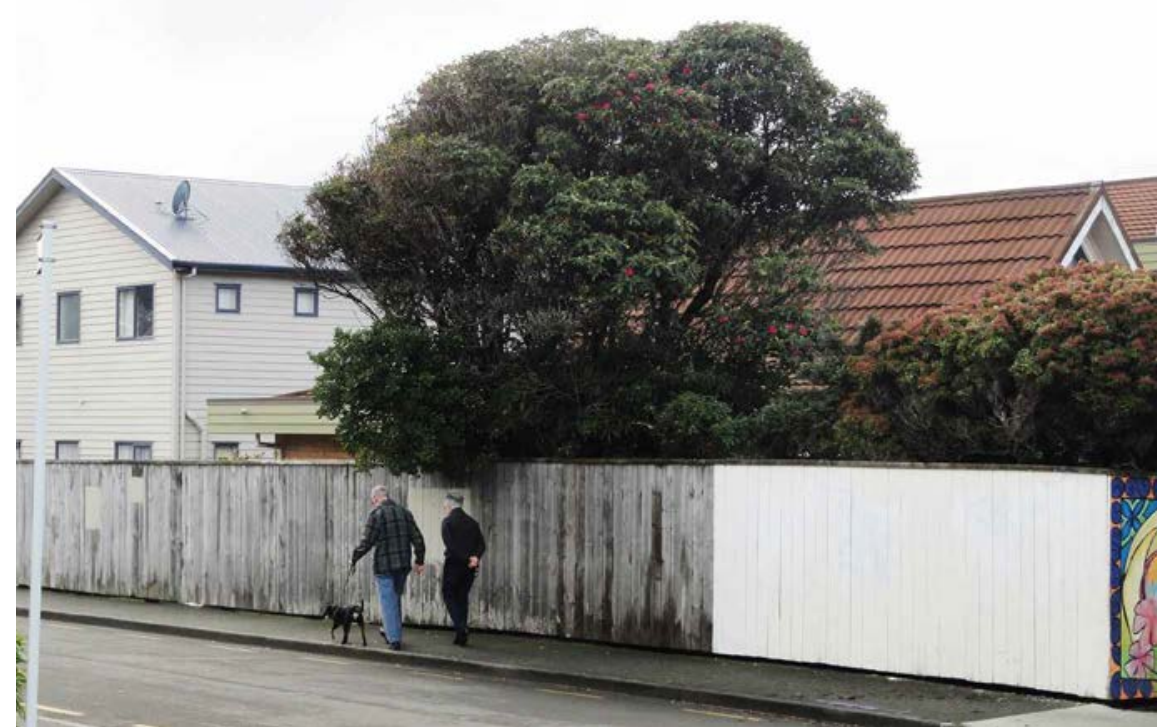

Fig 3.6. View on Cortina Avenue. A single-detached houses with cars parking at the front is a typical scene in Johnsonville.

Fig 3.7. Two seniors taking a walk with pet on Frankmoore Avenue. People in Johnsonville enjoy walking if they are provided the option to. 
Fig 3.8. The boundary of Johnsonville in aerial view. It illustrates the configuration of the township is highly centralized and carved out from the residential by roads.

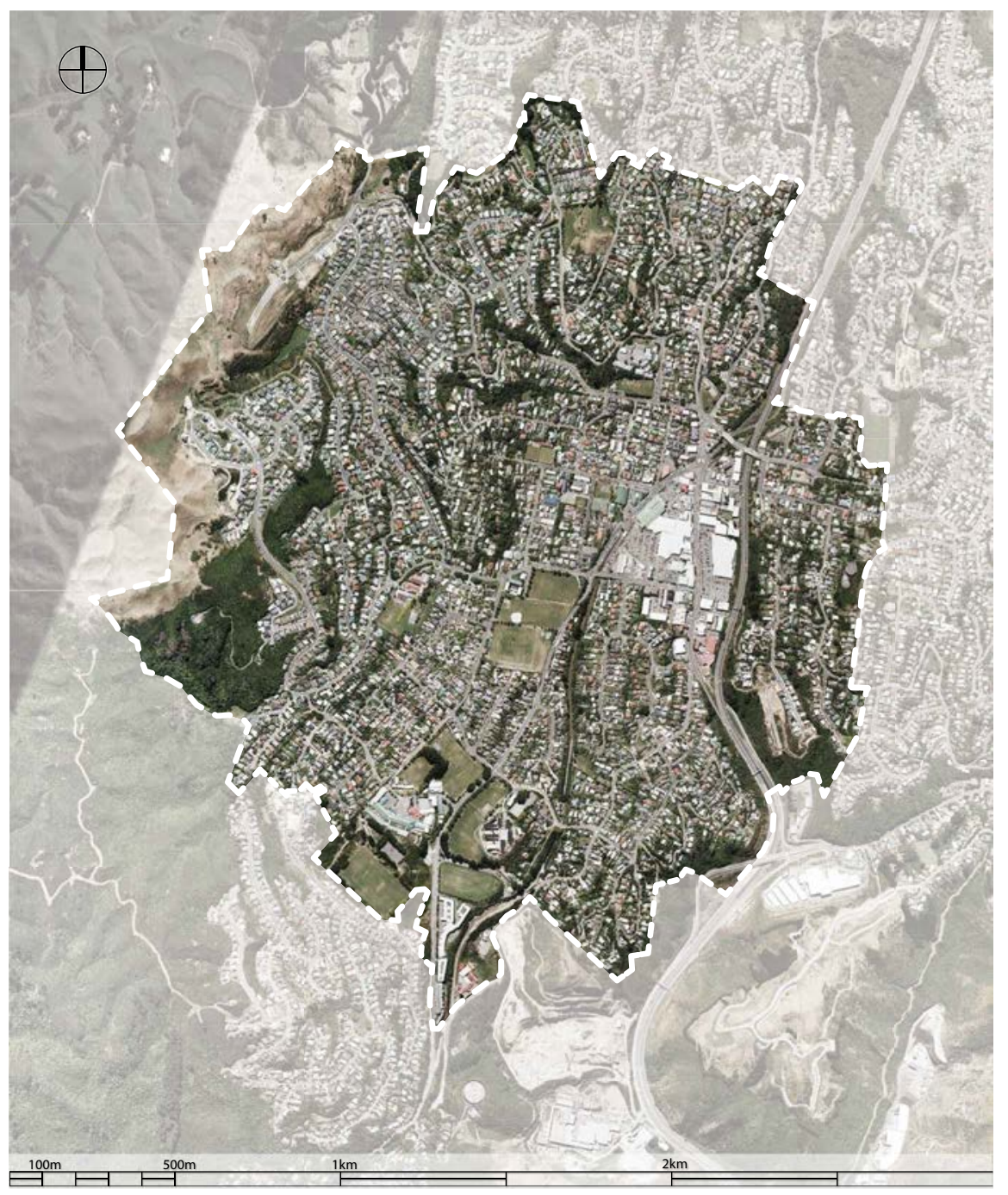

Aligned with the American pattern of suburban development, the settlement of Johnsonville originates from the main roads and spread out gradually. Single-detached houses sprawl as far as $2 \mathrm{~km}$ from the town centre, which takes at least half an hour to walk and even longer for seniors who are less mobile. As recognised by a number of researchers, the difficulty of accessing transportation is one of the biggest problems of ageing in suburbs (Davis 3; Taylor and Buys 56). Individuals' mobility in suburbs is highly, sometimes solely, depended on their access to private vehicles if public transportation is 

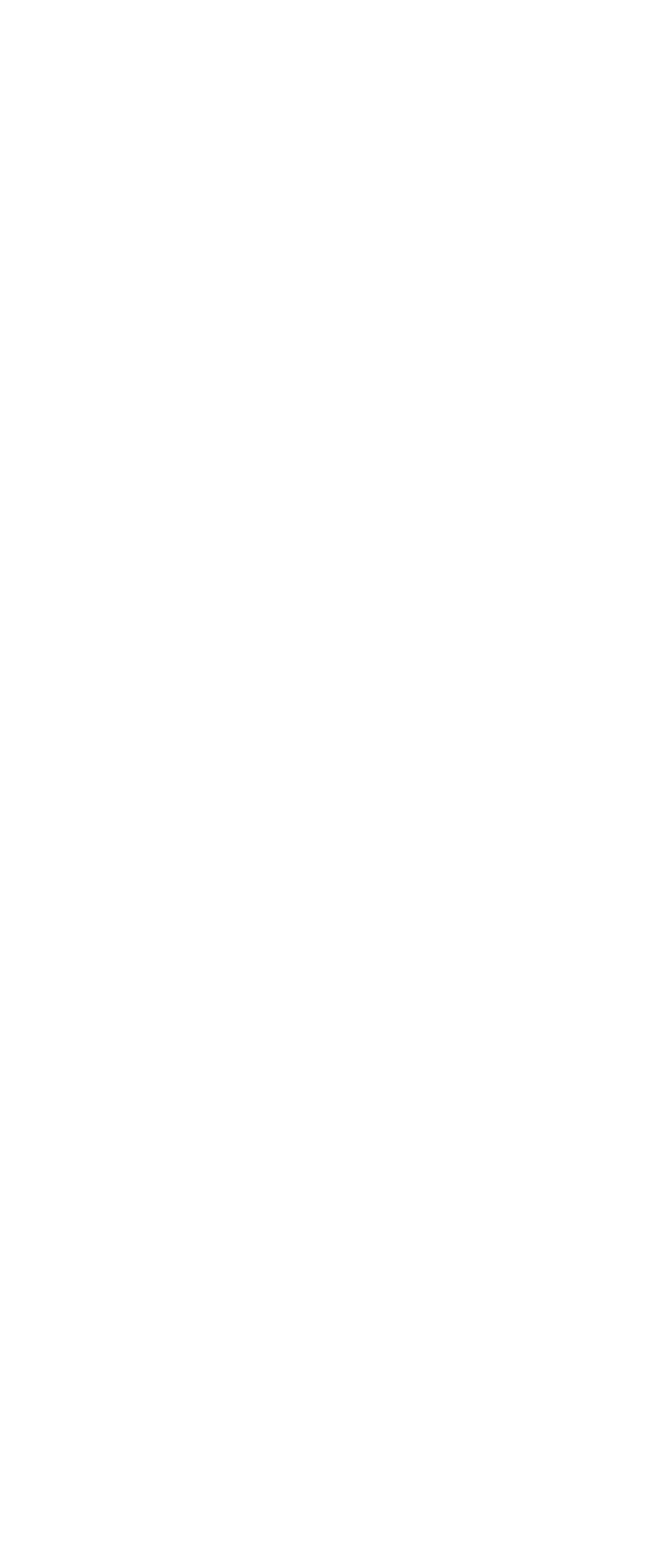


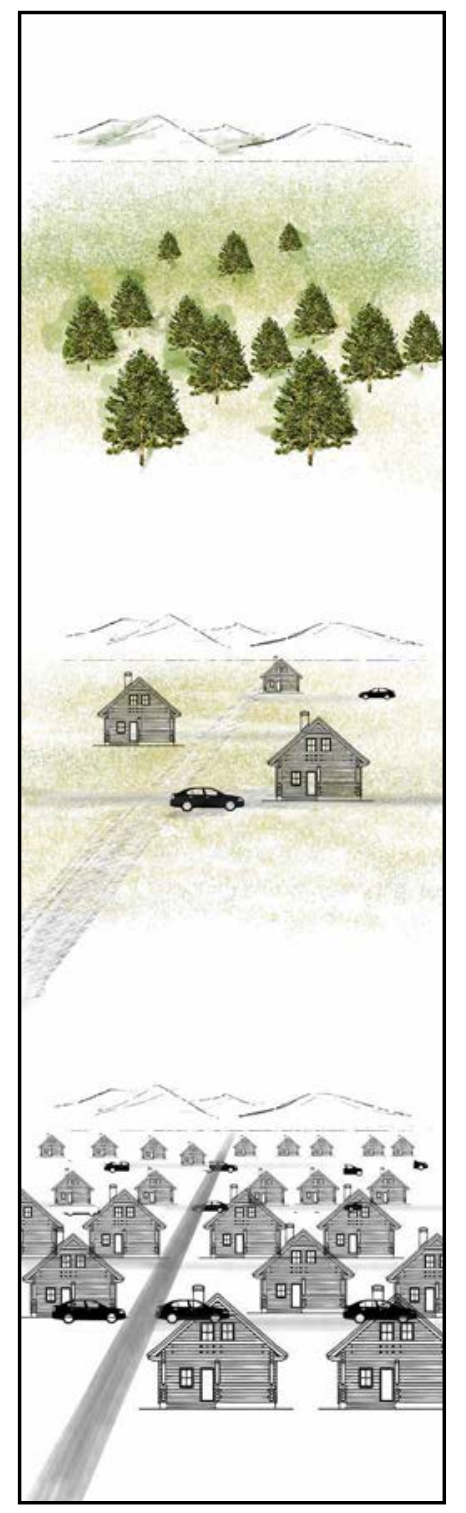

Fig 3.12. [Left] Model of development of suburban sprawl.

Fig 3.13. [Right] View from the car park area overlooking the houses on the hill in distance. How easy is it for the elderly live in those houses to come to the mall to just do grocery?

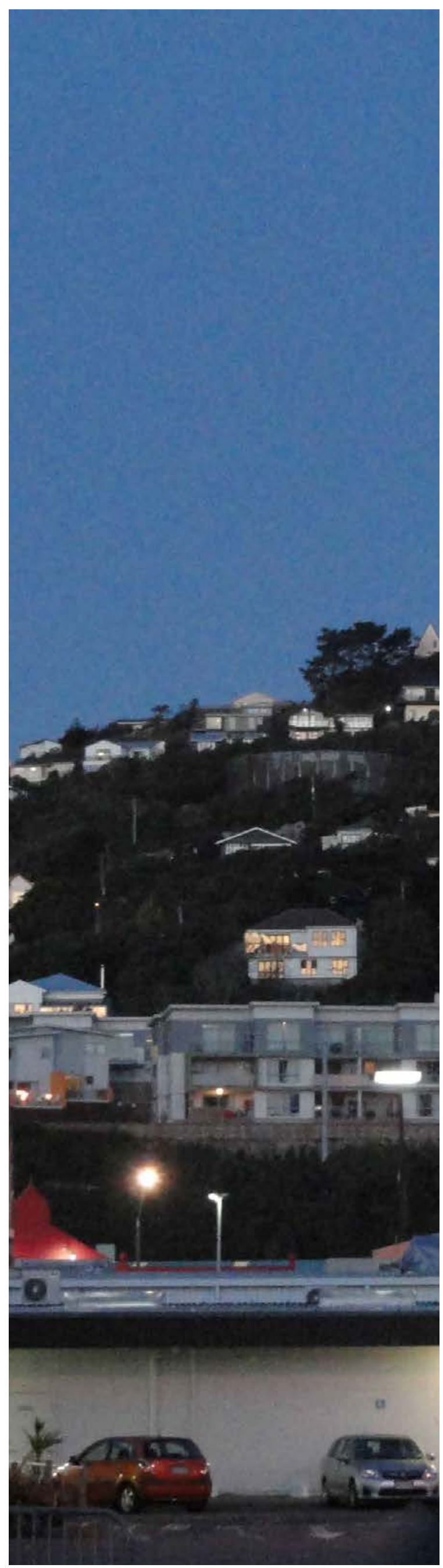


As illustrated in the diagram below (fig 3.14), most of the town centre is approachable for the elderly within five-minute-walk departing from the bus stop. For average pedestrian, the five minutes walking radius covers the whole town centre. Even though the town centre is dominated by vehicles, the centralised configuration of Johnsonville town centre shows its potential in walkability in terms of the size. However, the majority of residential area can be a challenge for the elderly to travel on foot, meaning for people live in those areas have to rely on public transport if they have no easy access to car, otherwise, their activity space will be highly restrained.

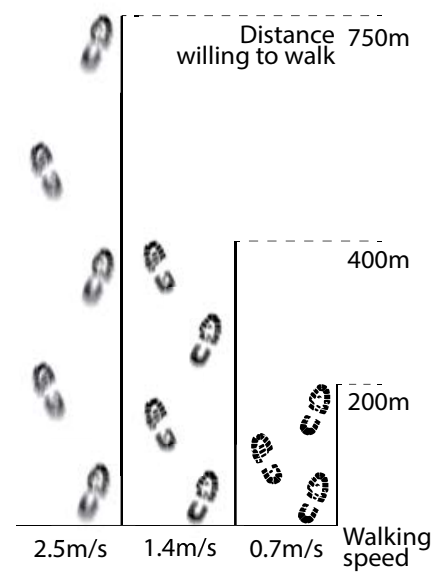

Fig 3.14. Comparison of walking speeds. Variation of walking speed implicates the difference in the distance people are willing to walk. 


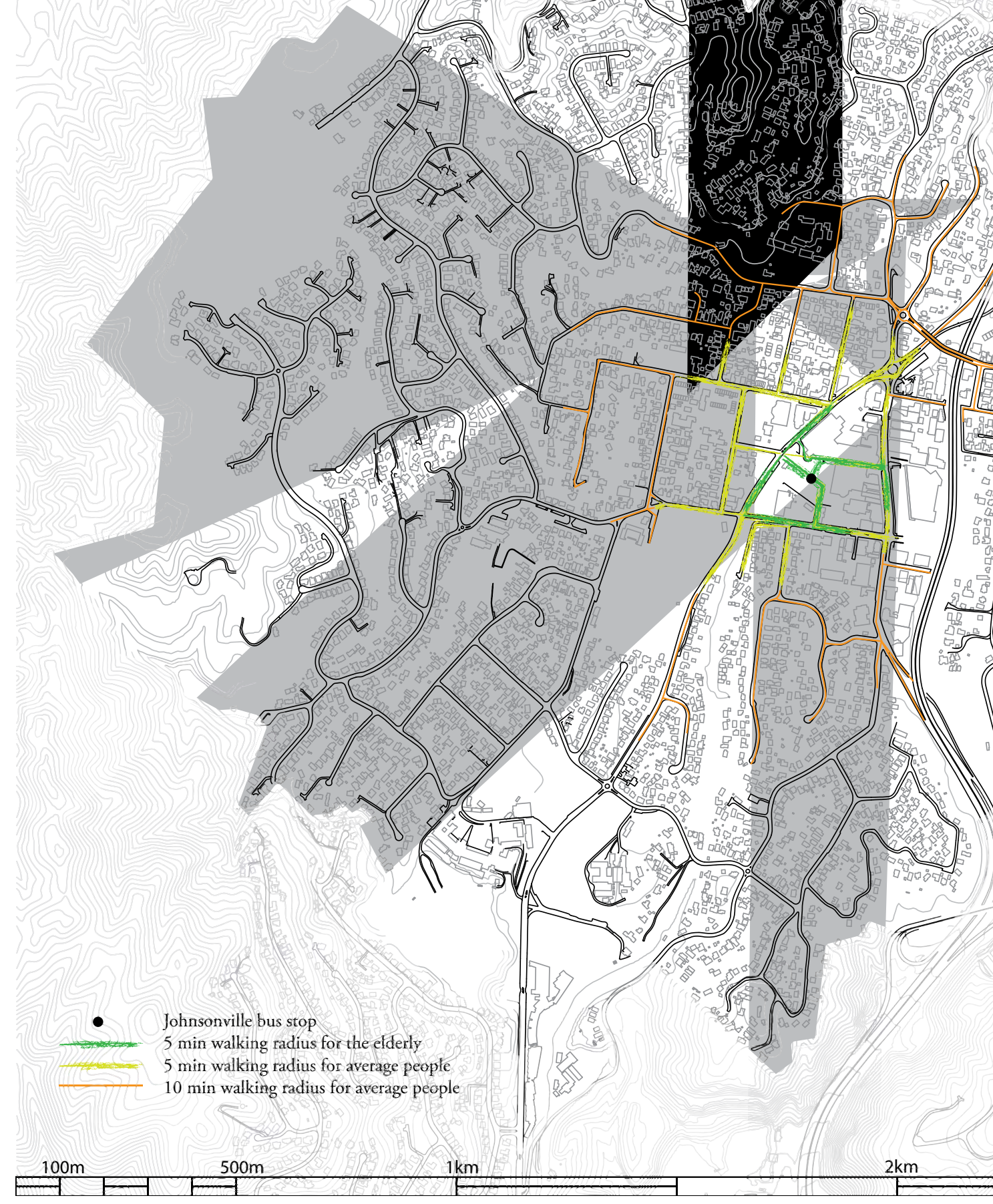


Through a study of bus route coverage, it is revealed that Johnsonville actually has a decent bus network in terms of bus stop distribution, however not in the timetable. In most areas of Johnsonville, residents have access to a bus stop in less than a five-minute walk. However, this coverage can reduce to less than its one third for individuals with slower walking speed and on weekend schedule, which affects the mobility of the most reliant people greatly. 


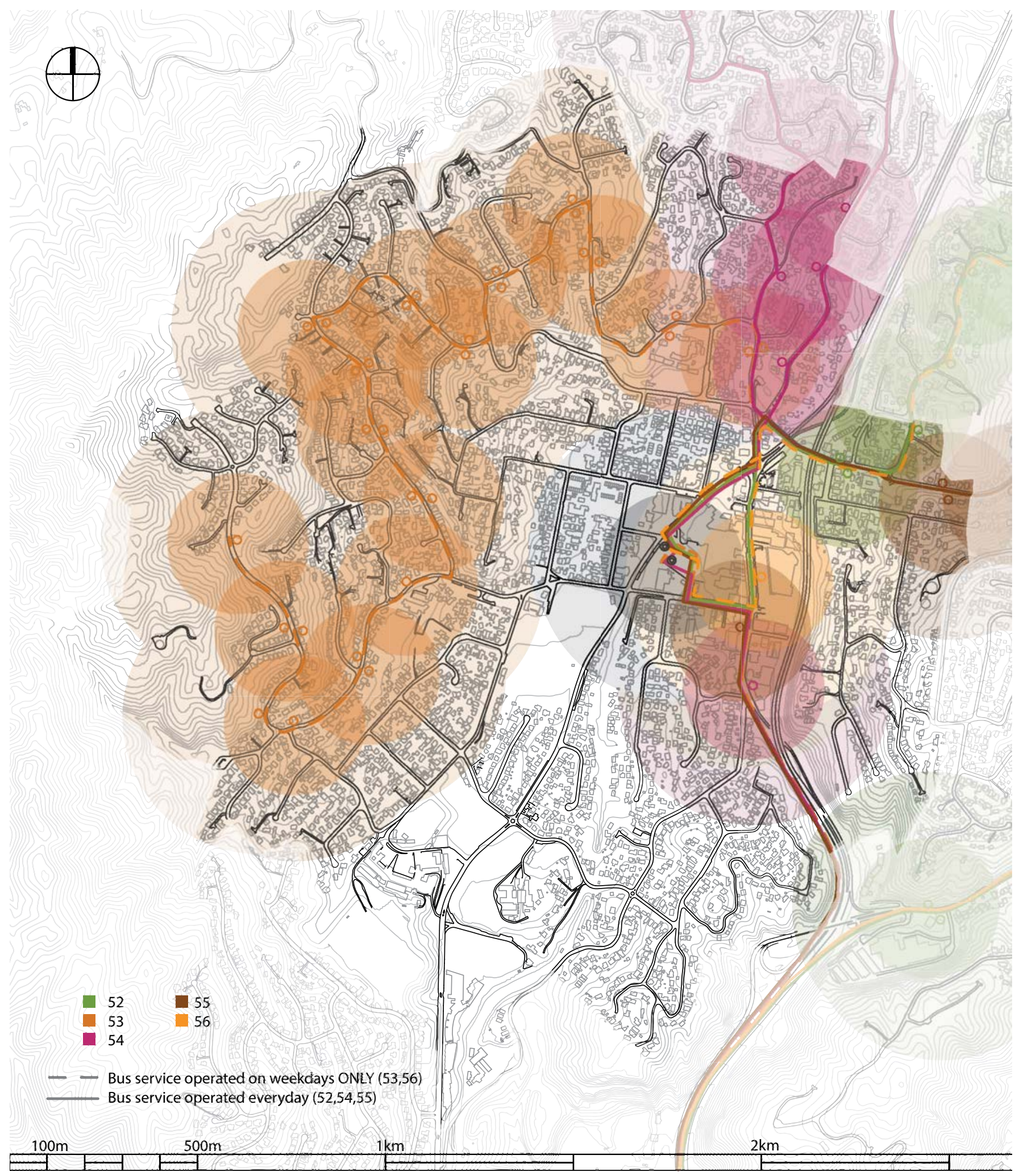

Fig 3.16. Study of bus route coverage. The approachability of buses can be significantly reduced to the elderly. 


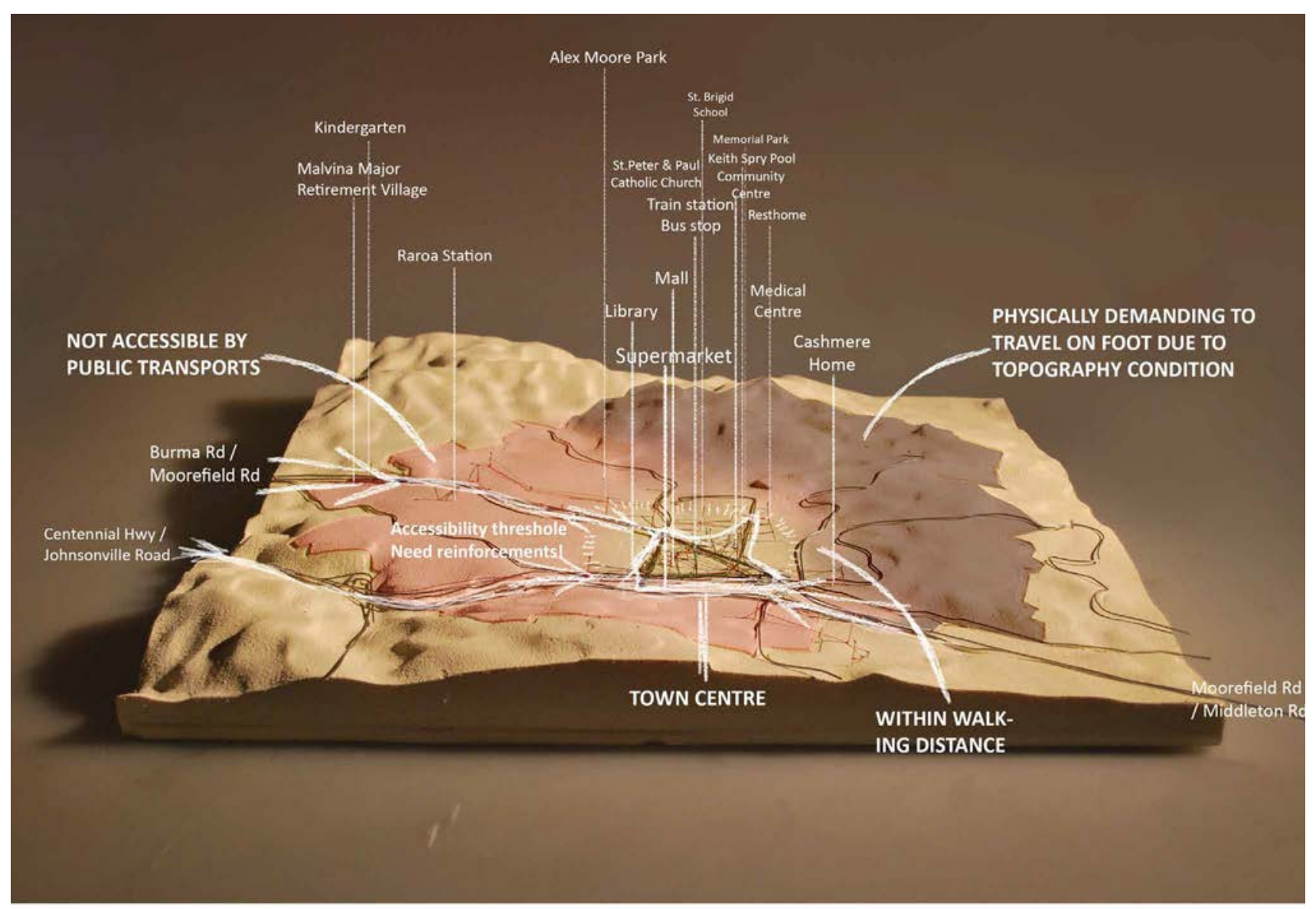

Fig 3.17. Sandbox model of activity spaces network for vehicles and pedestrian with walkability analysis overlay. The suburbia configuration might not be the best place for the elderly to age in.

To analyse how age-friendly Johnsonville is overall, a sandbox model is used to synthesise the conditions of Johnsonville from the perspective of the seniors. By marking up venues of daily activities based on site visits, the hidden activity spaces networked within Johnsonville is revealed against the topographic backdrop. Through overlaying with the studies of walking radius and bus services, zones of varied accessible levels are identified. It is evident that activity spaces for the elderly are highly centralised in the town centre, where most of pedestrians and traffic are 
attracted to. The suburban sprawl model requires vehicles to help people get around places while public transport in Johnsonville yet to improve. At the same time, the vehicle-orientated layout in the town centre is limiting the approachability of the town centre for the seniors to fully utilize it as a social hub. At the edge of walking radius, there is potential to extend the activity space for the elderly through adding community cyclic buses, rest points amenities, and/or mobility scooters renting stops and other means.

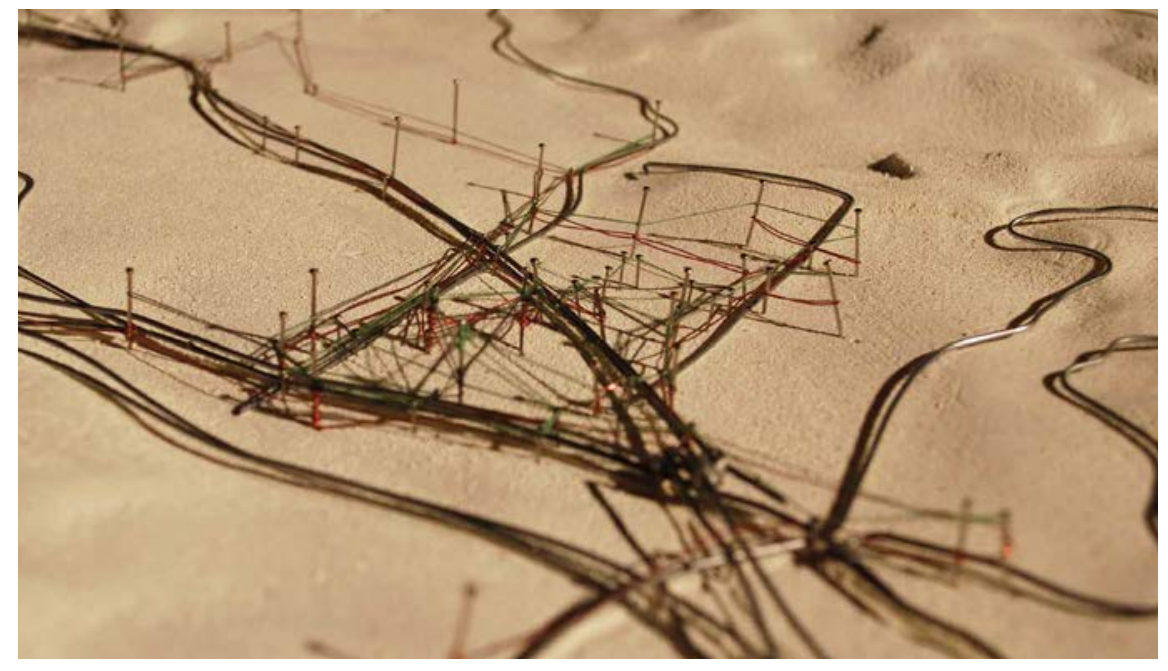

Fig 3.18. Close-up of the activity spaces network. Some facilities are far spreaded out although the major of them locate around town centre. 


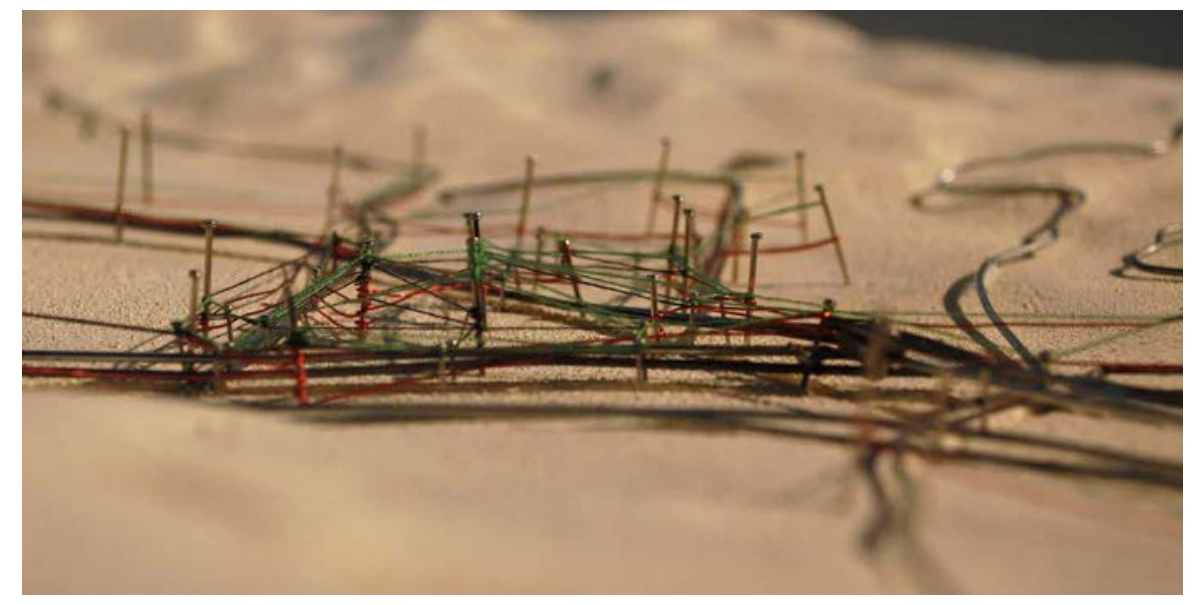

Fig 3.19. Activity spaces network in the town centre. The intertwining networks of vehicles and pedestrian represents the conflict between them in the suburban context.

As we can see in the sandbox model, most of public activities are highly centralised around the town centre triangle, which means it is the most common venue for the elderly to interact and socialise with others outside home. Hence, it is necessary to analyse the urban environment of the triangle. 

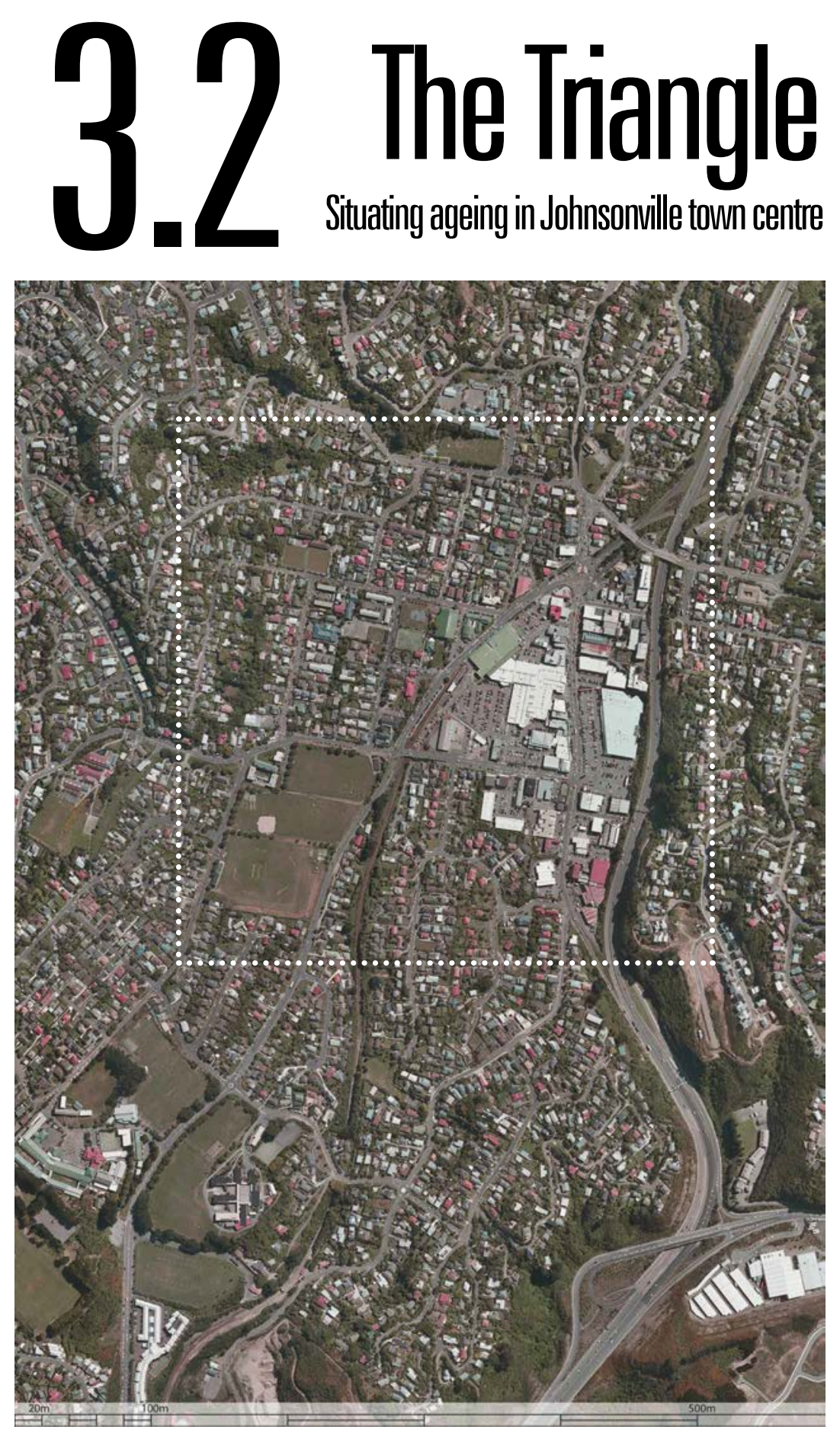

Fig 3.20. Urban context of central Johnsonville. 
As a suburban town centre, most of social interactions outside home happen here for the elderly living in the suburb. The spatial experience in the town centre determines their willingness to venture out and socialise. To investigate the seniors' experience in the town centre, multiple field visits were made in varied time of a day/week to grasp a comprehensive picture, which is recorded as the form of a psychological map (fig 3.21.). There are a selection of key areas stand out in terms of facilitating an autonomous and connected life for the seniors, which are discussed respectively.

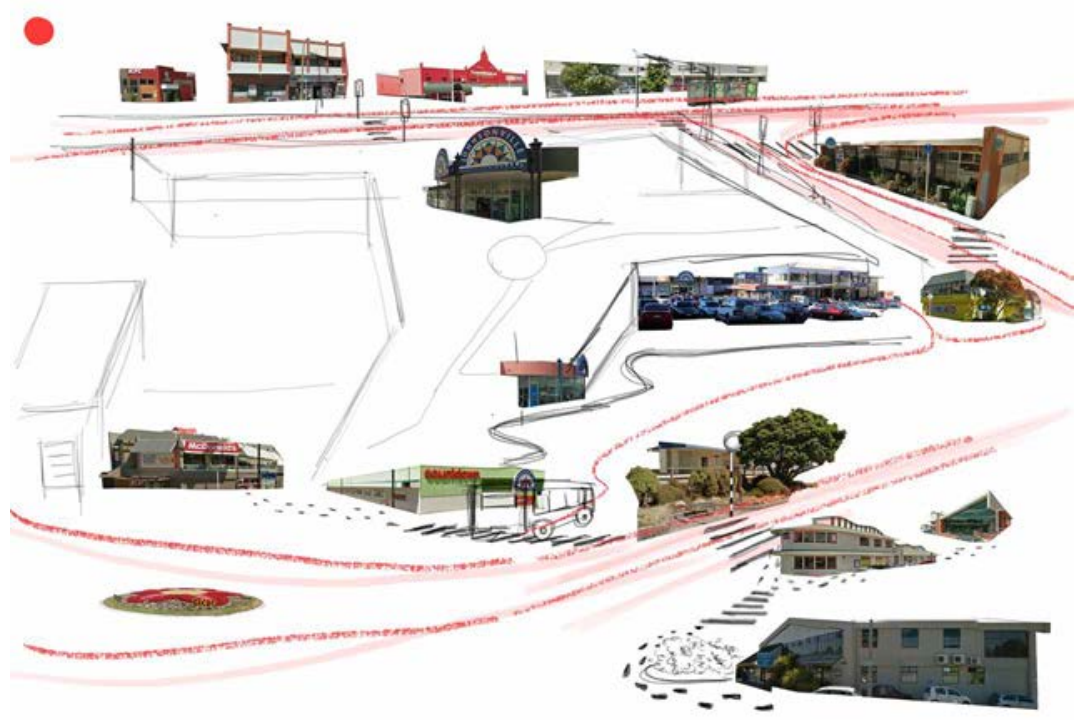

Fig 3.21. Psychological map to analyses seniors' spatial experience in Johnsonville town centre. 
[Visibility] Visibility in the urban context is crucial for people to navigate through spaces as it contributes immensely to the sense of orientation. It can become even more critical for the elderly due to lower competence. However, in the town centre of Johnsonville, the sense of disorientation is strongly noticeable due to a low level of visibility in the urban setting, despite its modest size. From the diagram (fig 3.22), it is made obvious that the continuous row of shops on Johnsonville Road and Johnsonville Mall create a large visual barrier preventing people to get the sense of orientation across the triangle. In addition, the mall interrupts an occupant's vision to form a coherent sense of orientation in the town centre. Such sense of disorientation disables the seniors' sense of control of the space, which often leads to the lost of the sense of autonomy.

Fig 3.22. Visibility analysis of the town centre. The visibility of the town centre is fragmented by the mall and the changing ground level.

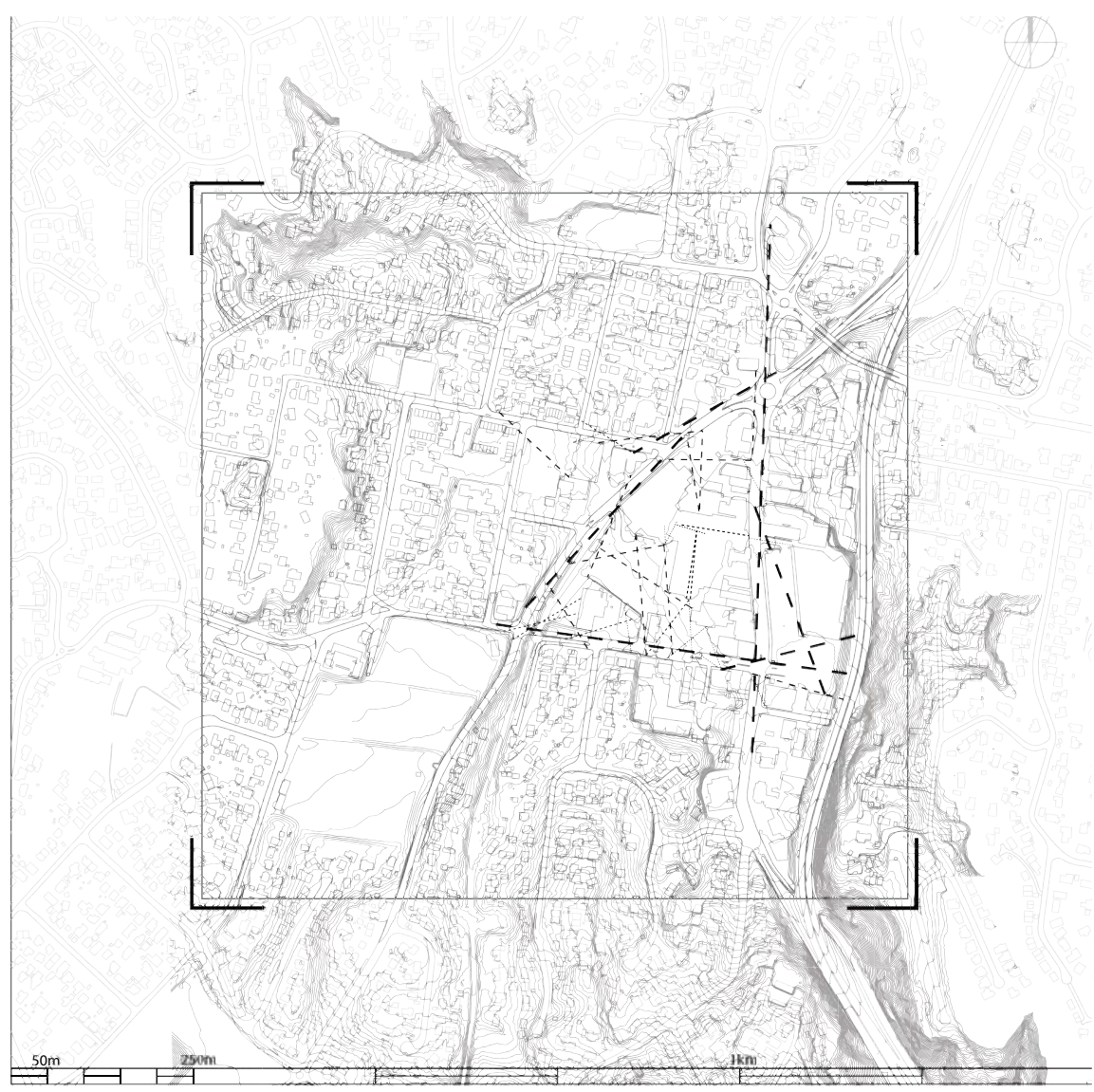



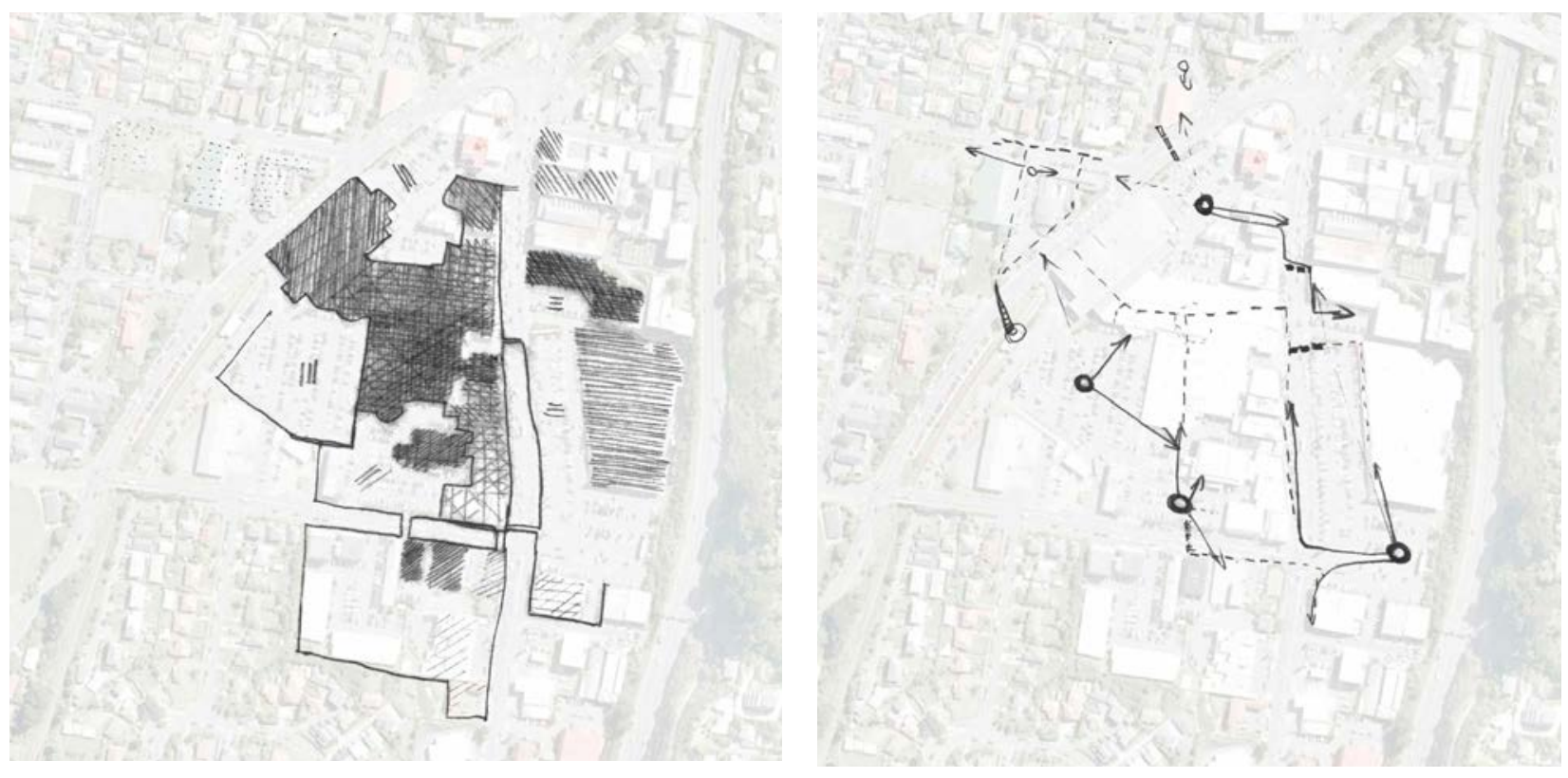

[Mobility] The convenience of pedestrian and the benefits of a walkable town centre are overlooked in Johnsonville as it has been designed to prioritize private vehicles. As evidenced in the diagram (fig 3.23, fig 3.24) that every amenity has access to car park in close distance, which does provides great convenience for vehicle users. However, for the elderly who have varied competence, such setting lack of options in consideration of their access to cars. For an instance, at the core of the triangle where the train station and bus stop are located, even though there is a large number of people transit or pass through, there is no effective pedestrian-friendly area across the whole
Fig 3.23. [Left]Diagram of car park in the town centre and their serving area. Most amenities have available car park nearby.

Fig 3.24. [Right]Car parks in the town centre and the dominant directions people walk to from their cars. 
car park but token traffic markings. Additionally, The frequent presence of people jaywalking around the triangle suggests the inadequacy and inefficient placement of the existing crossings. These environmental constrain limits the seniors' mobility to execute daily activities and socialise

Fig 3.25. Diagram of available car park and open public space in the town centre.

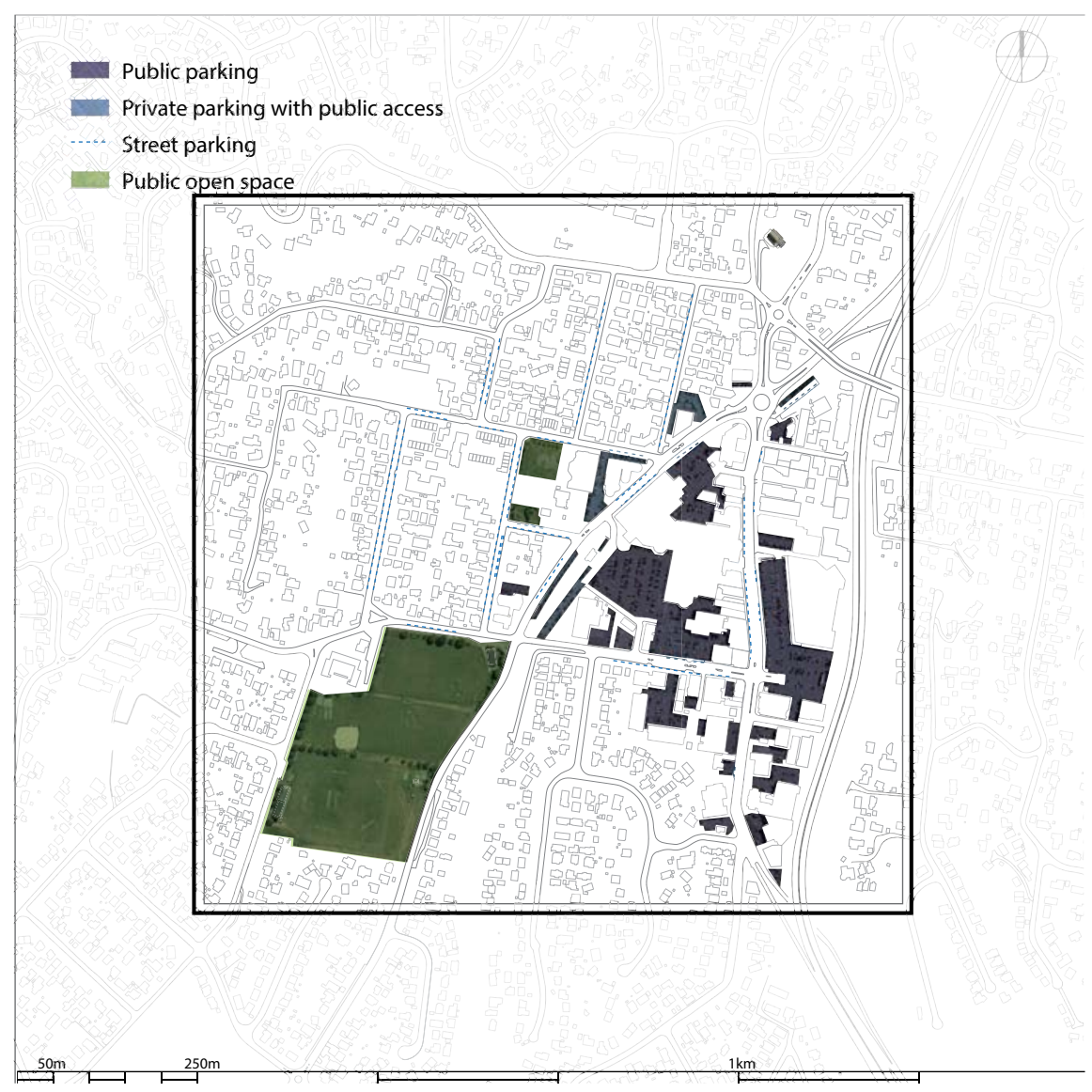




\section{Analysis of main existing facilities in the town centre}

At the moment, in Johnsonville town centre, there are only limited facilities accommodating this kind of social model.

Johnsonville mall always has been one of the most popular places where people in Johnsonville hang out. However, seating for cafe and food court surrounded by shops is losing its attraction to other newer malls in the region.

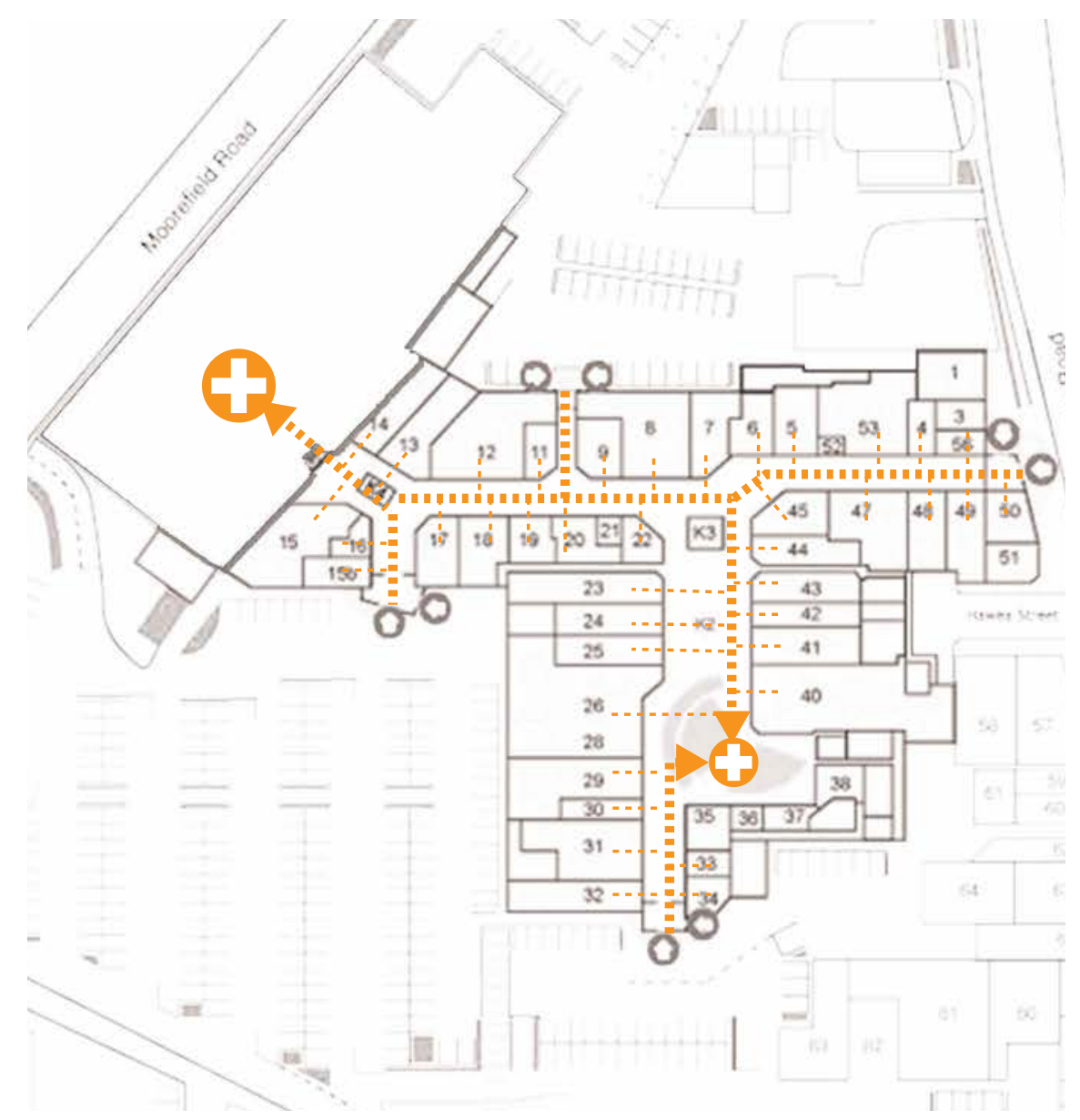

Fig 3.26. Analysis on the planning strategy of Johnsonville mall. 
Fig 3.27. Plan

Johnsonville Community

Centre showing the

segregation between

programmes. f y

n

Although community centre has a range of activities for varied age groups, they are mostly designed for small groups in particular classes, meetings and events. Such premise determines that the community centre is only used by people involved in those events and less open to others. 
The library is the most open in this sense, judging from the frequent presence of users of all ages. With the assistance from librarians, the library accommodate reading, playing, socialising for community members from kids to seniors. The only downfall is that the disproportional size of the library to the growing population significantly restrains people's use of the space.

Fig 3.28. C o m p a ris o $n$ of the size of public libraries domestically and internationally. 


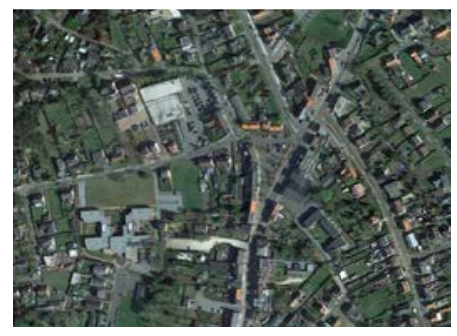

New Public Library Zoersel Zoersel, Belgium

534 inhabitants per $\mathrm{km}^{2}$
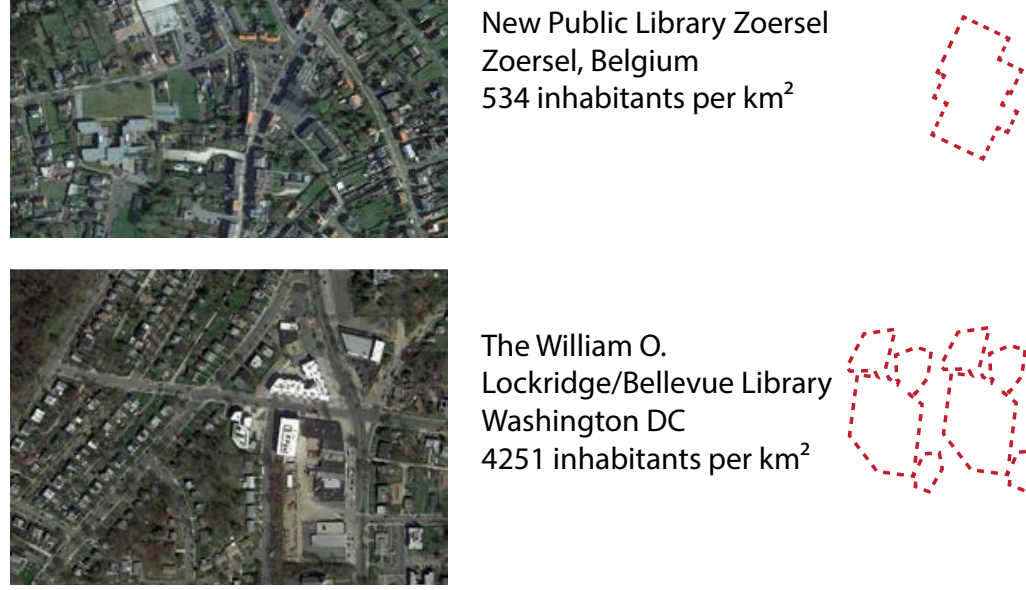

The William O.

Lockridge/Bellevue Library Washington DC

4251 inhabitants per $\mathrm{km}^{2}$
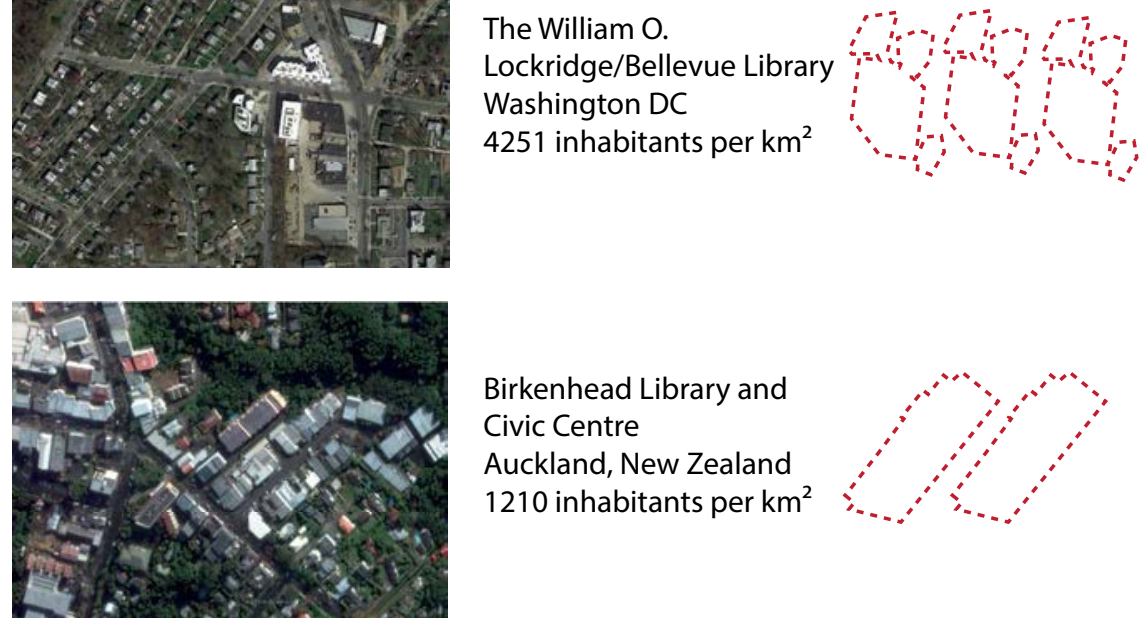

Birkenhead Library and Civic Centre

Auckland, New Zealand

1210 inhabitants per $\mathrm{km}^{2}$
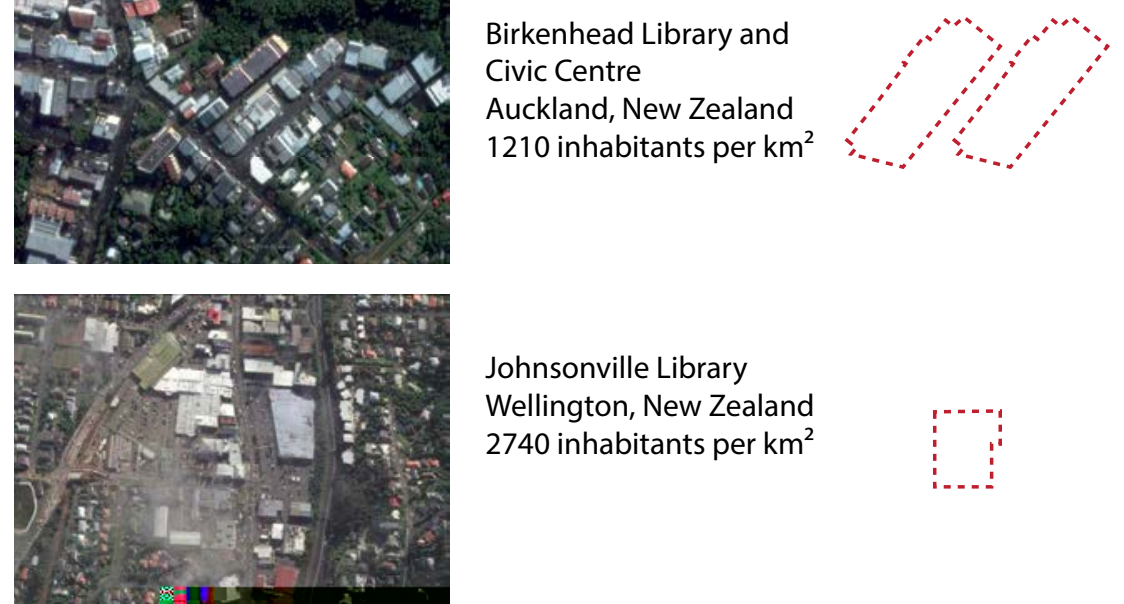

Johnsonville Library

Wellington, New Zealand

2740 inhabitants per km²

Aerial map images

Projects/location

/population density

Area 


\section{SWOT Analysis of the Town Centre}

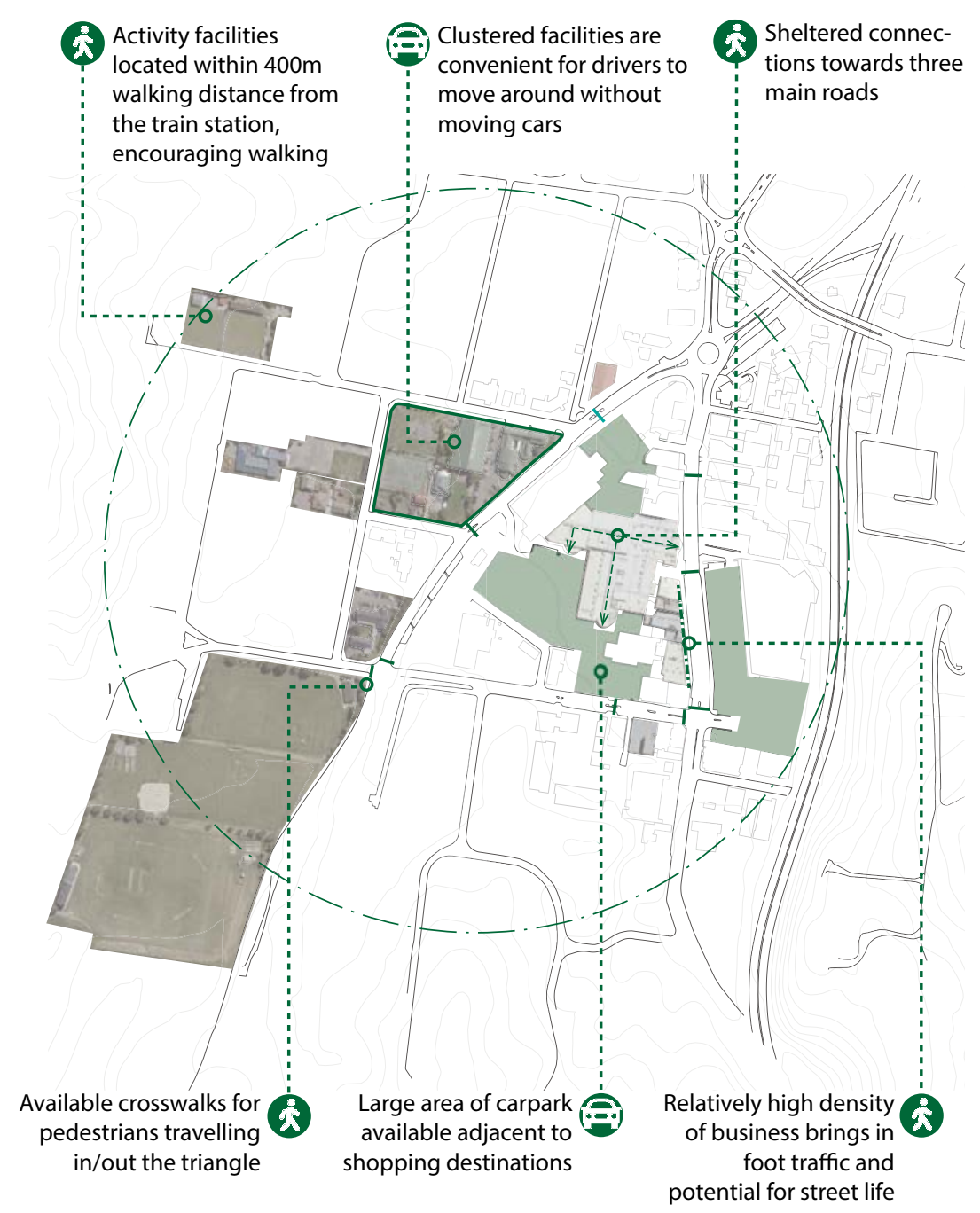

Strengths

Fig 3.29. Overall SWOT analysis of the town centre considering seniors in varied modes of transportation. 


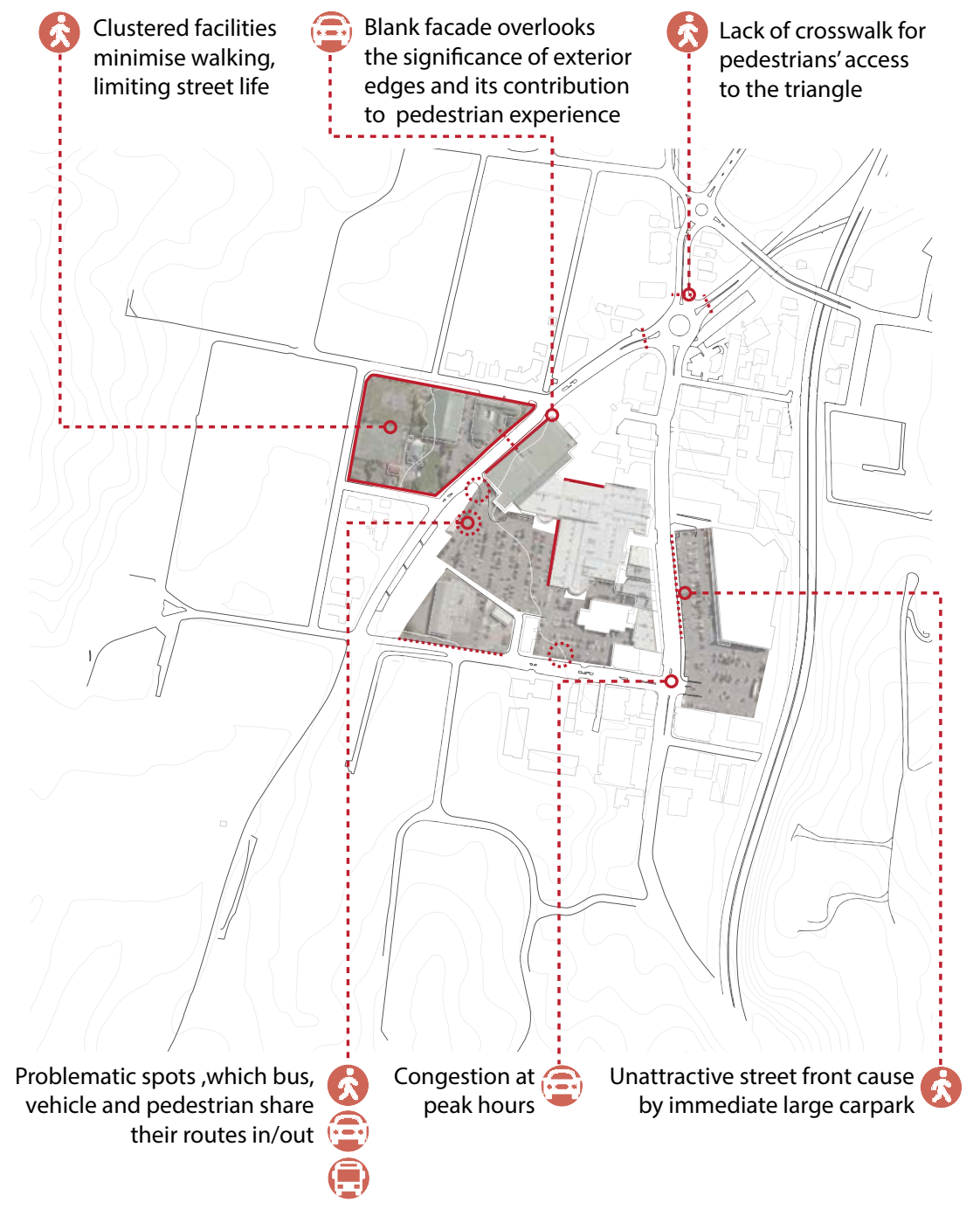

Weaknesses 


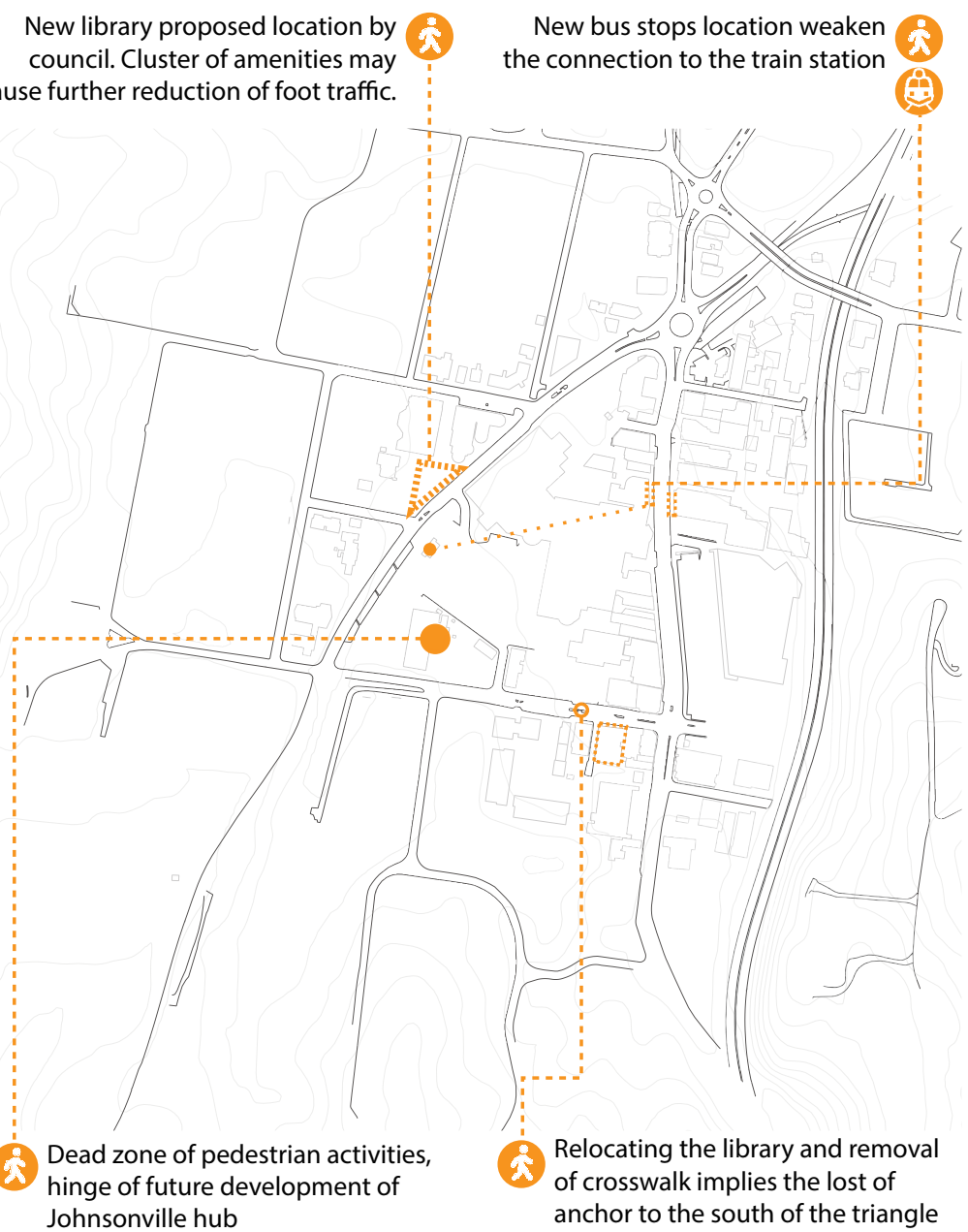

Threads 


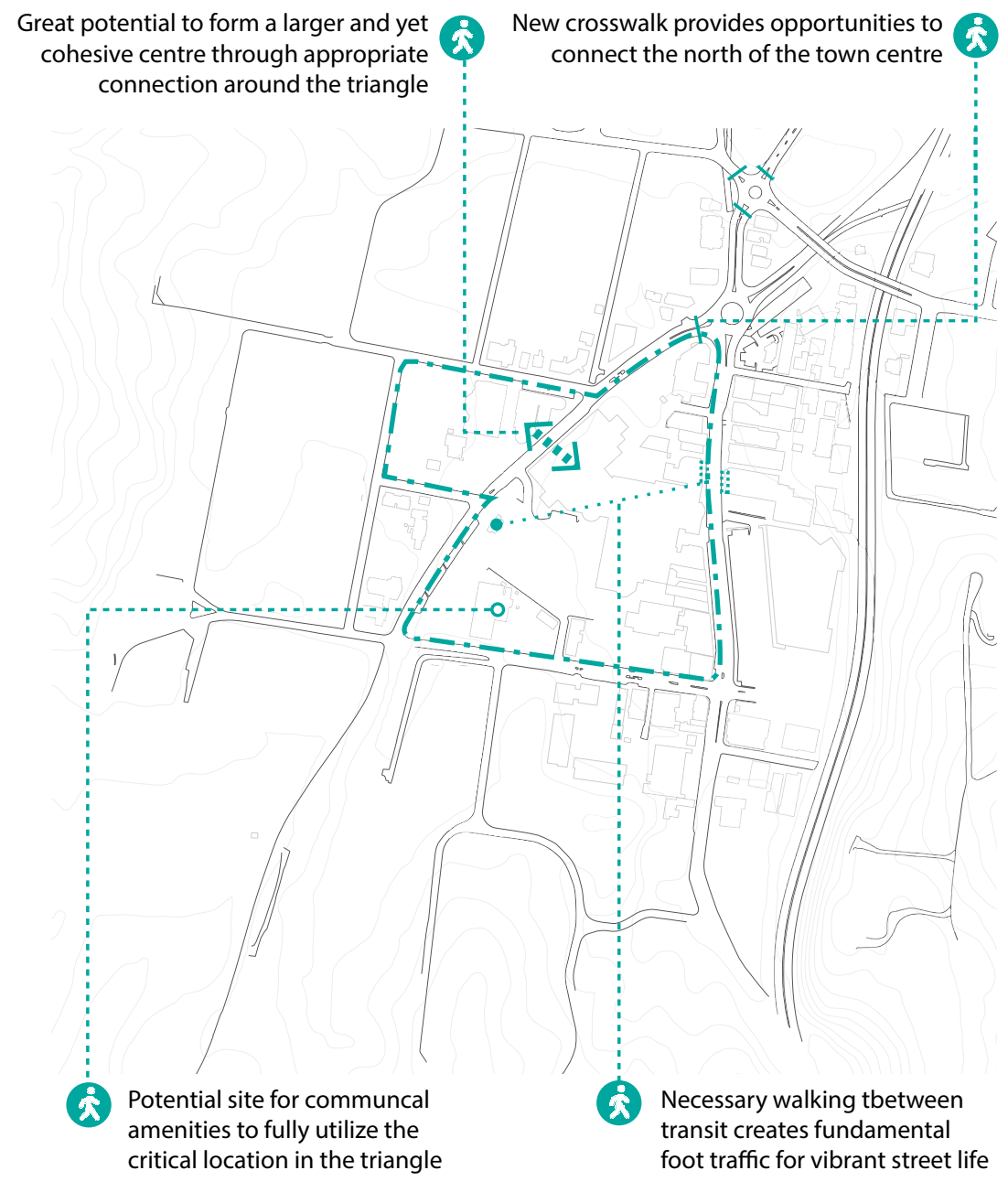

Opportunities 
To deepen the understanding of the site condition of the town centre triangle, the method of maquette was adopted to make statements in response to site analysis. Without consideration of particular assigned programmes, the function of pedestrian express is a radical counter attack towards the limitations of the public infrastructures and facilities on people's mobility.

As the population in Johnsonville is rapidly growing, it puts increasing pressure on the existing road network, as well as nearby crossings and intersections where vehicles meeting pedestrians. From a SWOT analysis of the triangle for different occupants, there is obvious disconnection between the triangle and the community precinct (fig 3.29). 


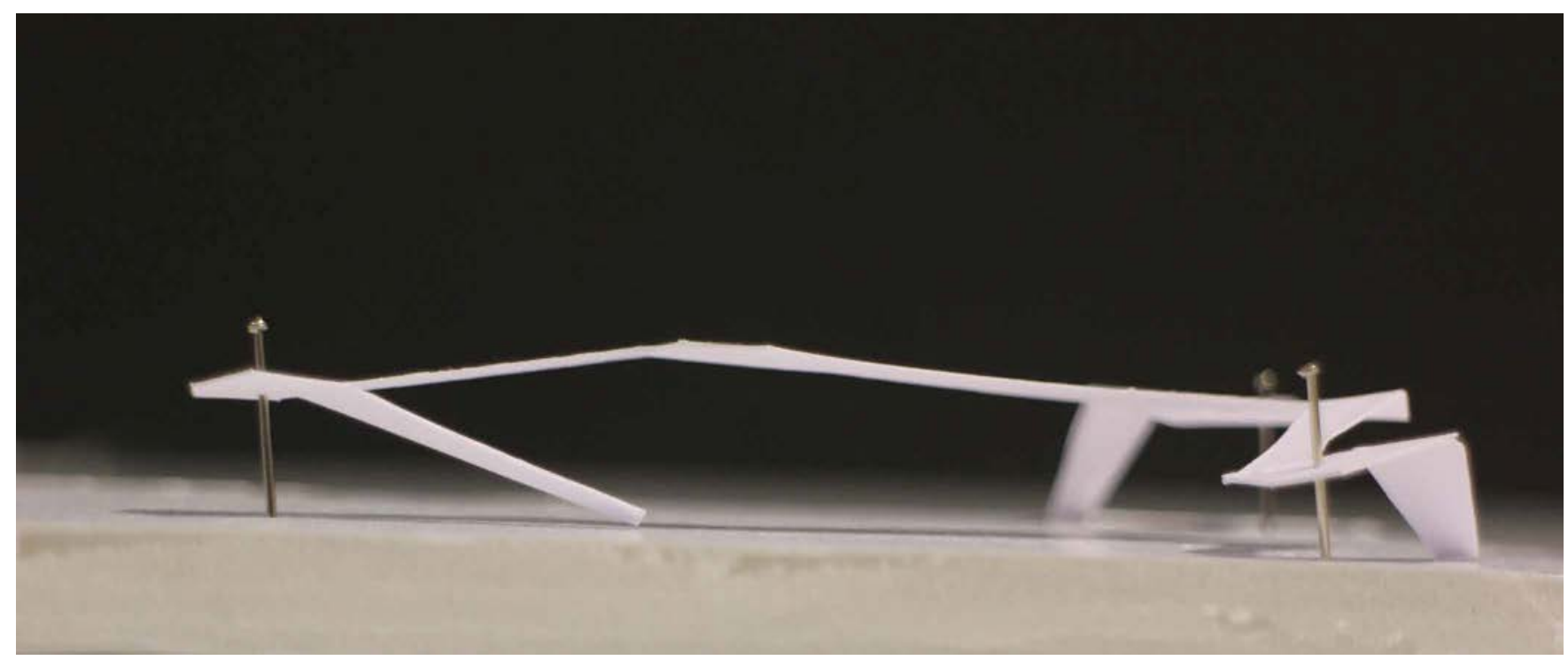

Fig 3.30. [Above] Viewing the conceptual model of the pedestrian express from the side showing the relationship between levels.

Fig 3.31. [Below] A plan view of the conceptual model highlights its connectivity.

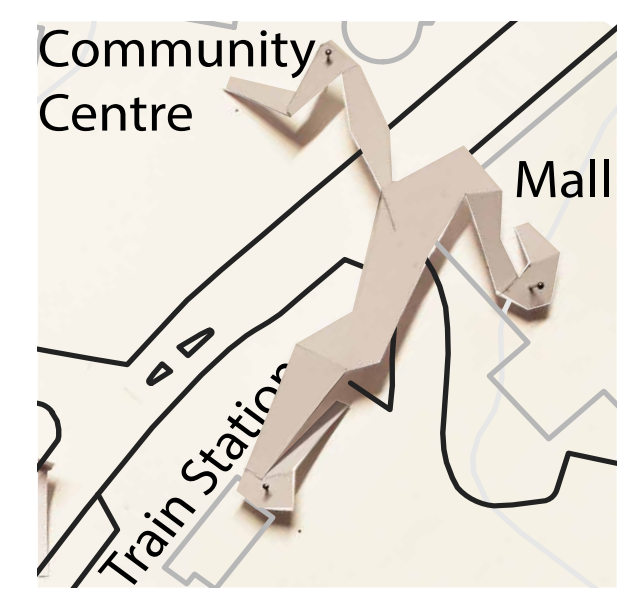

\section{Pedestian express:
for mobility diversity untangle the tangle for mobility diversity}

To create an uninterrupted traffic flow for vehicles and pedestrians, a pedestrian express which links up the mall, train station, and community centre over Moorefield Road and the entrance into the car park area, is proposed. The introduction of pedestrian express provides safe access among amenities yet minimises the number of crossings for fluent traffic flow. In addition, to make the pedestrian express accessible, it needs to be equipped with lifts or escalators to enable seniors with varied mobility travel between levels. 


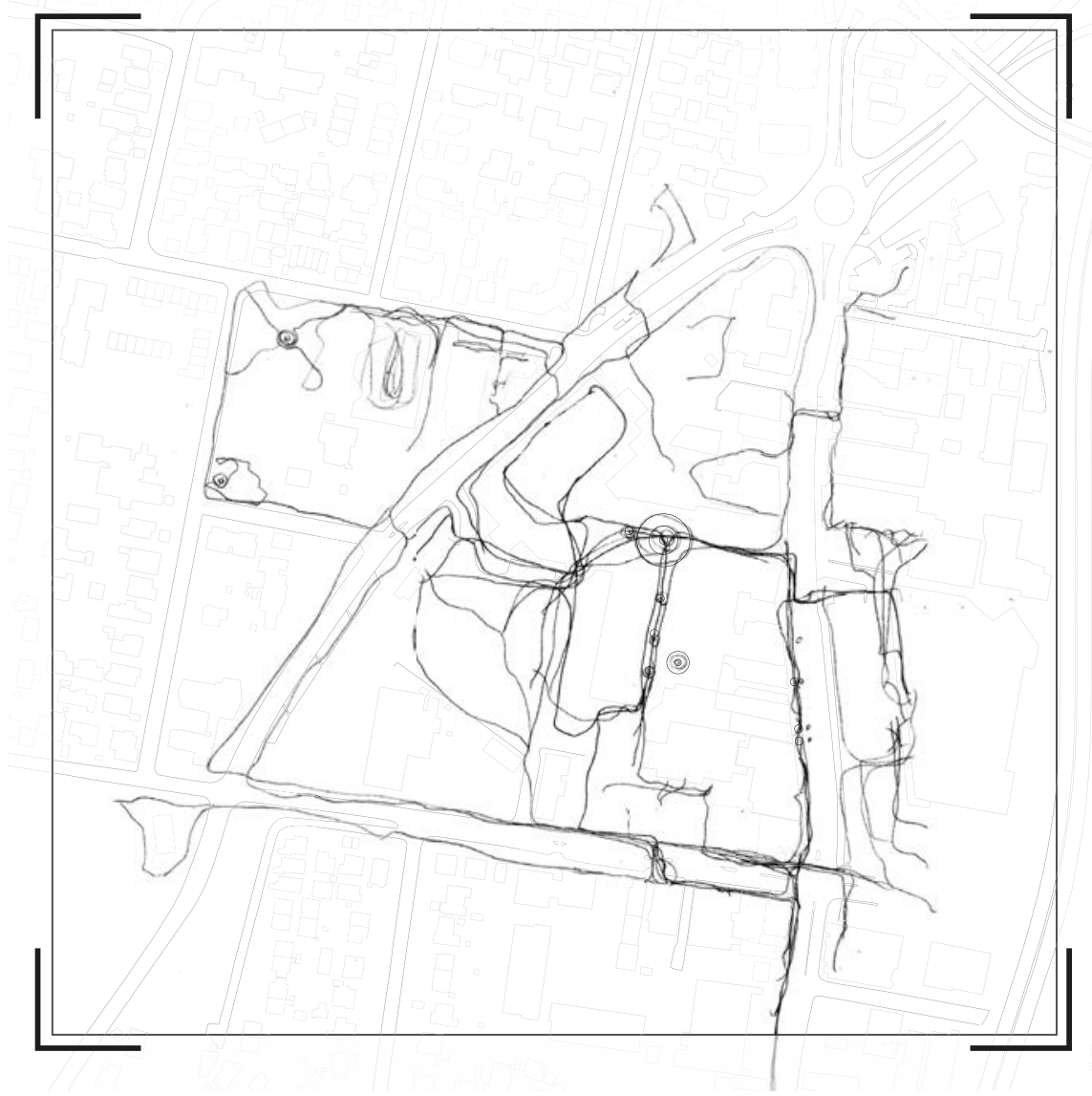

[Events] movement/stationary activities

Apart from Johnsonville Road displaying relatively more human activities, there is little stationary activity on Broderick Road and, on Moorefield Road, even the presence of pedestrians is very limited. Although there is decent amount of foot traffic from the train station, bus stop and the mall, the only place allows stationary activities to occur is inside the mall. Even there, the
Fig 3.32. Study of human movements in the town centre reflects how well the urban environment is facilitating social life. 
provision of seating is commercialized and the surrounding has a lack of activities as interest focal point to make the stay pleasant. As Jan Gehl argues it is needed to create an urban environment for staying and meeting (Gehl 25). As a suburban centre, it does provide the connection between train/bus to car park. Nevertheless, the lack of public meeting places turns the town centre into merely a transit point, which leads to a crucial part of public life missing for Johnsonville residents.

Fig 3.33. Diagram showing hierarchy of purposes in buildings in the town centre. It determines people's movement to a certain degree.

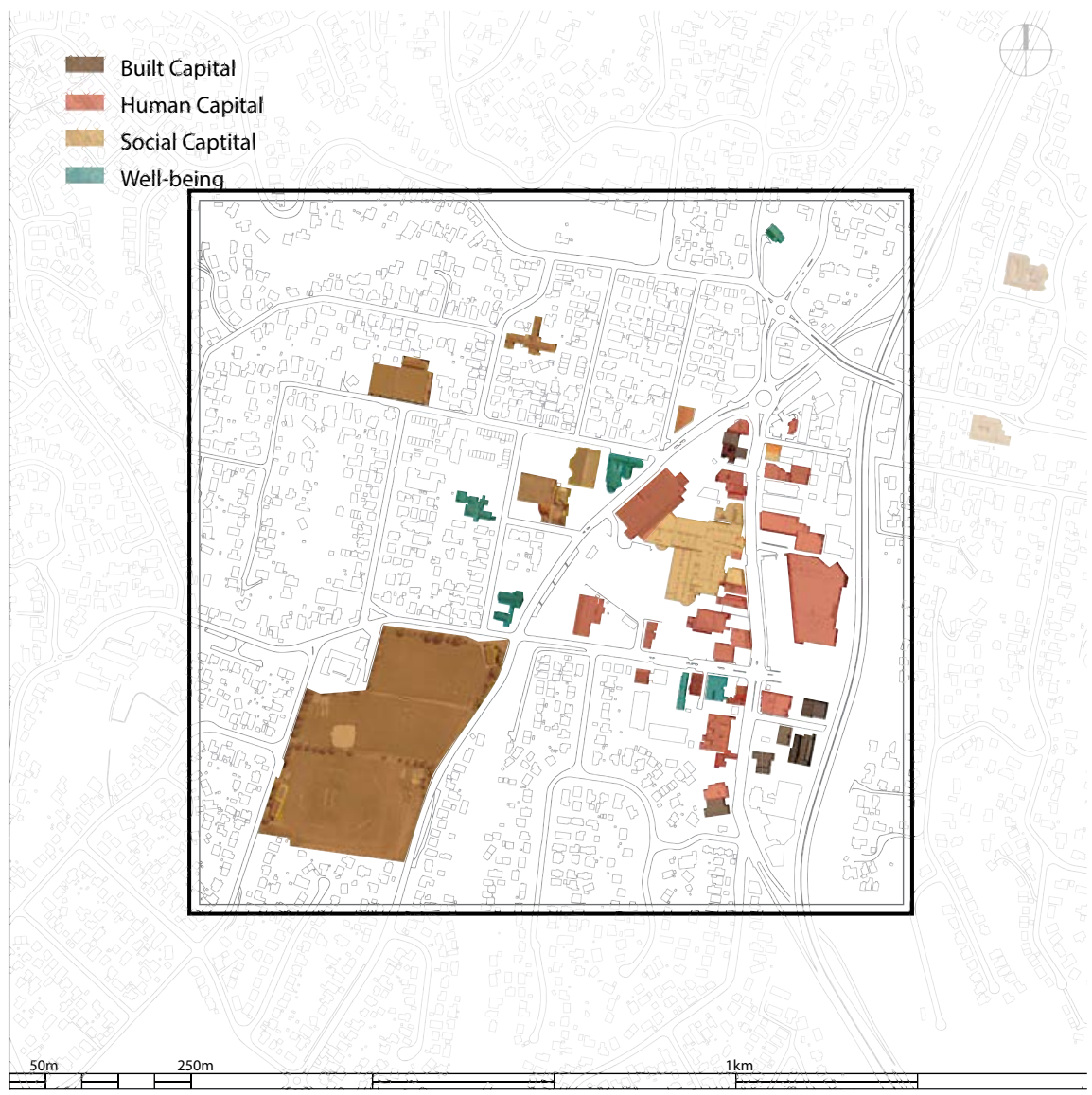




\section{Pedestrian express with shelters: community casual meeting place to encourage unban stationary activities}

Considering the lack of shelters for stationary activities in the town centre for people to stay and meet. There are a selection of pocket spaces along the pedestrian express that have potential to be developed into shelters and rest areas as an extension of streetscape for seniors to increase the opportunities for social connection. 


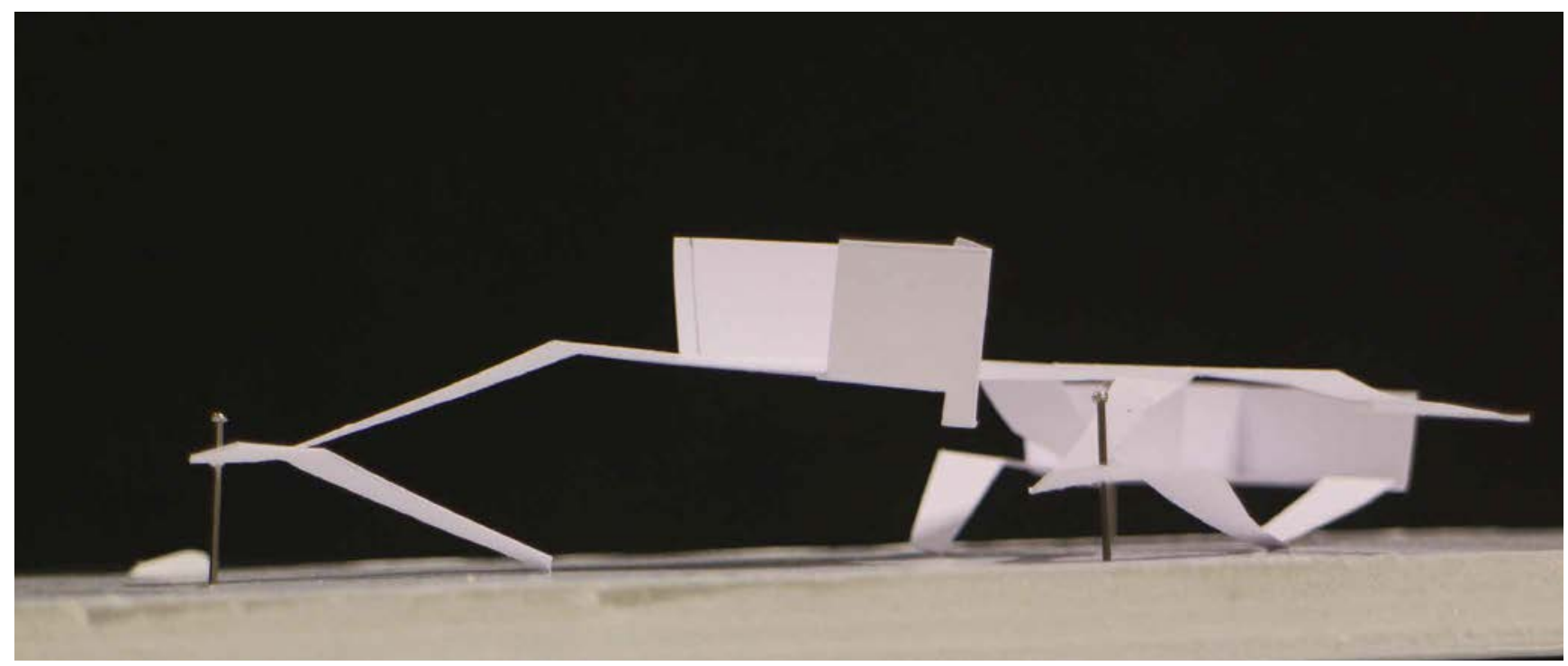

Fig 3.34. [Above]Viewing the conceptual model of the pedestrian express with shelters from the side showing the relationship between levels.

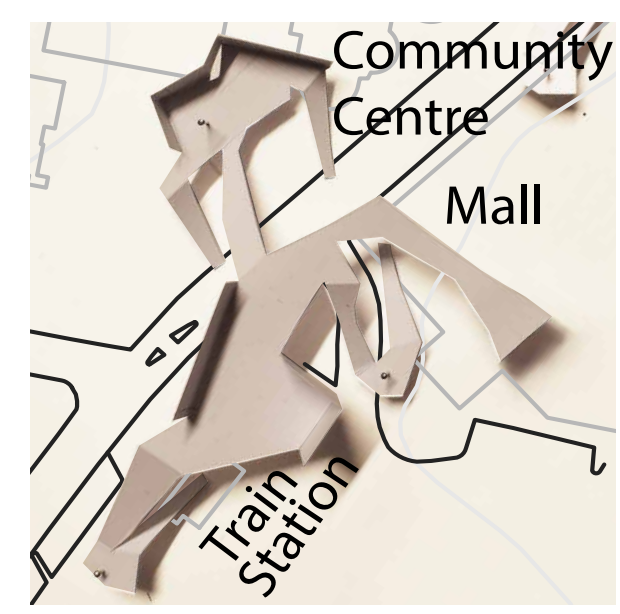

Fig 3.35. [Left] A plan view Fig 3.36. [Right] Pocket of the conceptual model spaces along the pedestrian highlights its connectivity. express for casual social purposes.

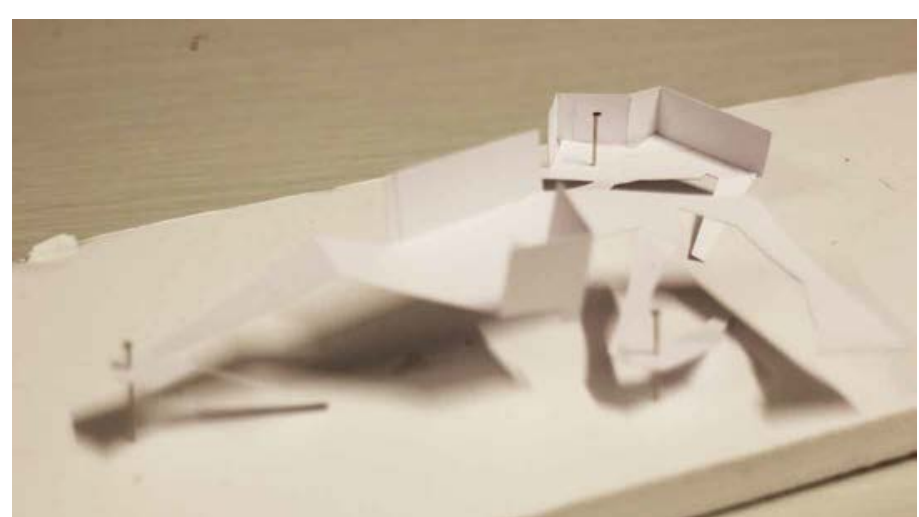




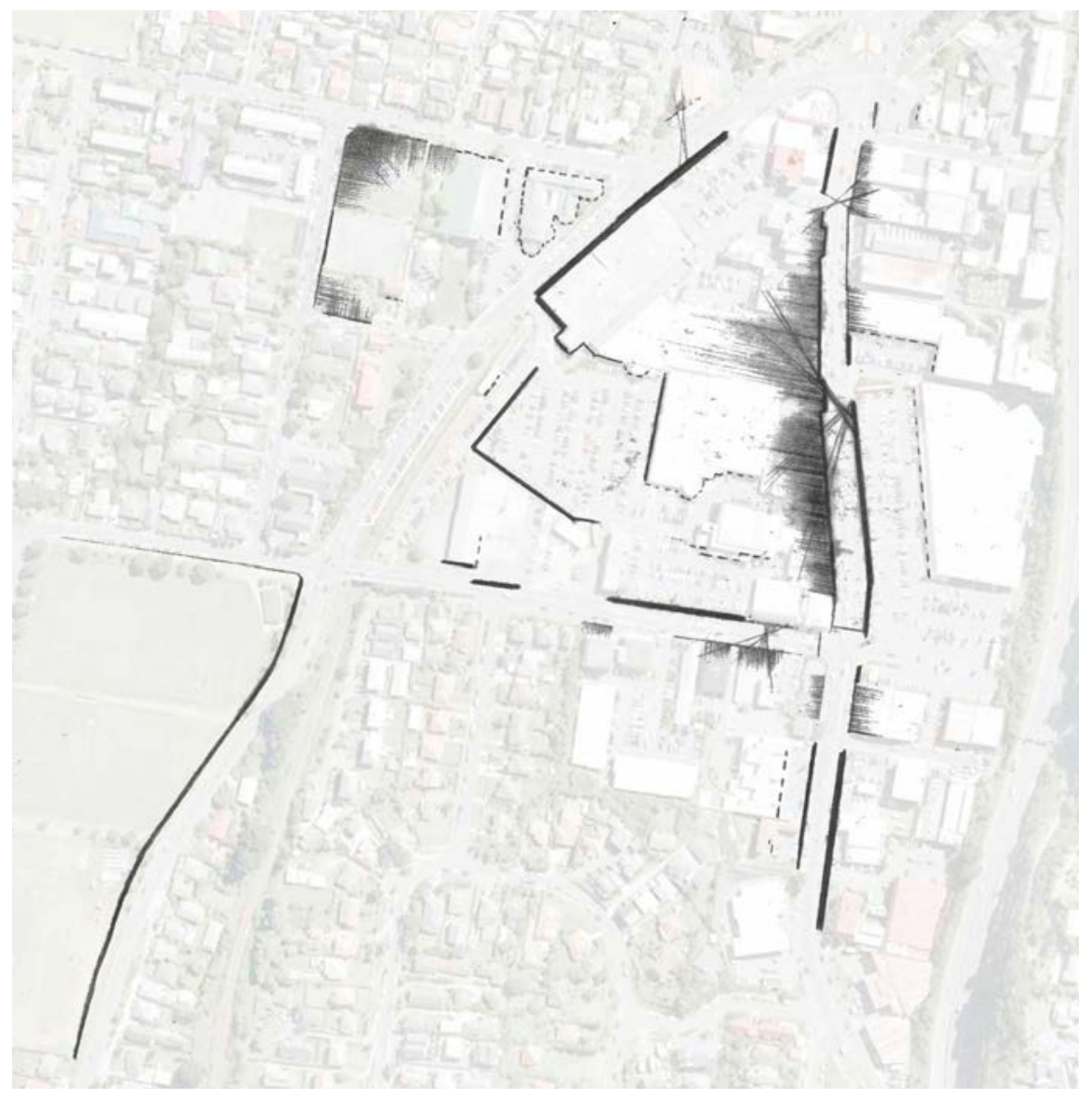

[Place identity]

Arriving into Johnsonville town centre, one is faced with generic suburban image composed of a mass of car park space, take-away shops and large retailers. Similar to many suburban centres, Johnsonville's town centre performs mainly as a service stop lacking of potential character and place identity. As a result, residents often have little sense of attachment of the space and community. This might not be a problem for a fully competence
Fig 3.37. Study in density of interaction at street edges. Soft edge encourages more human interactions, which contributes to a place identity that seniors can relate themselves to. 
individual, however for a "stay-put" elderly, the local community should be the most accessible place to socialise outside the home. The absence of place identity can potentially diminish the positive influences of a local community could have on seniors, intensifying the environmental restraints for them to become homebound.

Fig 3.38. Study in the attractiveness of street front. The correlation between the quality of street front and human interactions occur can be seen

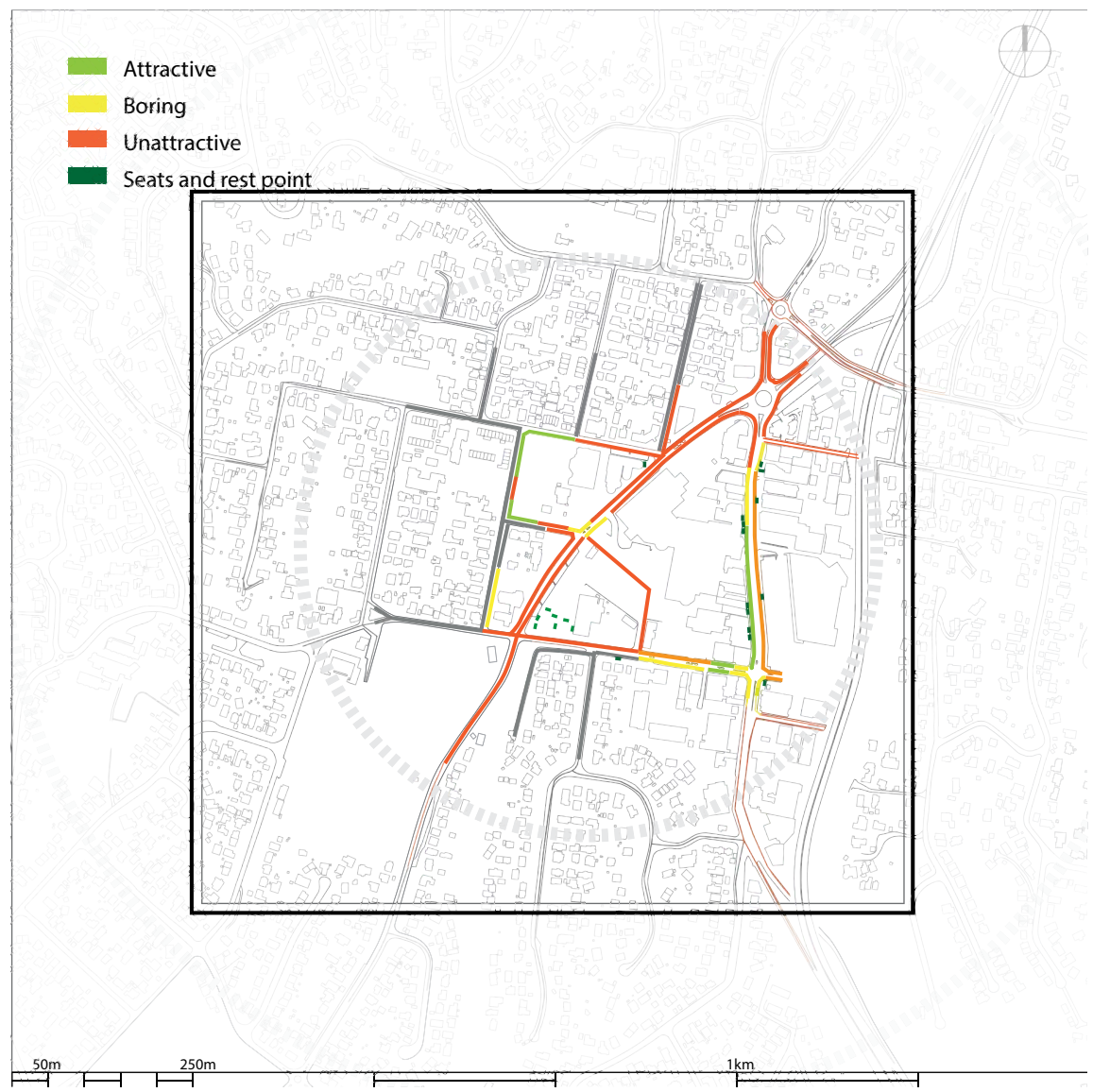




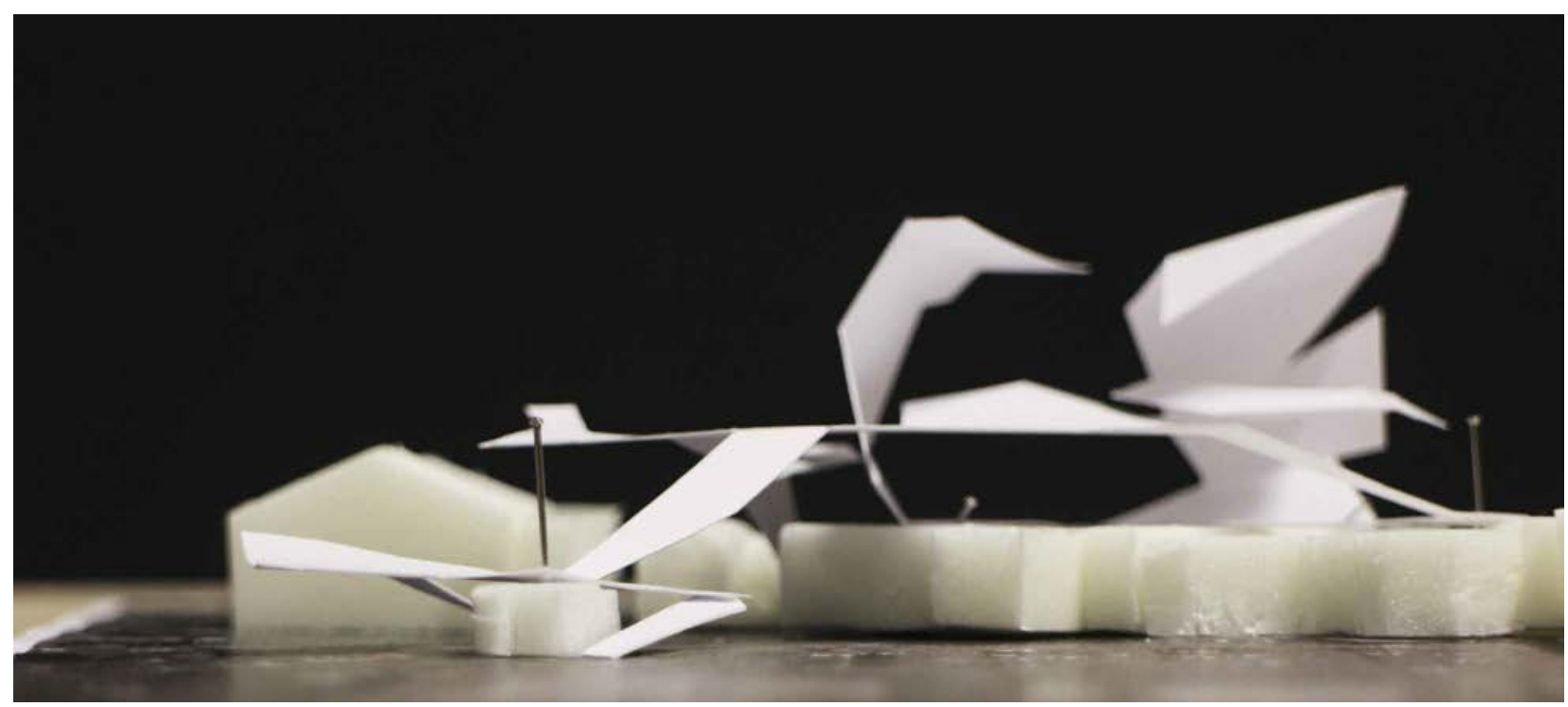

Fig 3.39. [ $\mathrm{A}$ A Conceptual model of the pedestrian express with amenity and its relation to the urban context.

Fig 3.40. [Right] The insertion of pedestrian express with amenity anchors a focal point for the town centre,

\section{Pedestrian express with amenity:} advocating an autonomous and connected lifestyle as place identity

Pedestrian express with amenity insertion: It is demonstrated in previous diagrams that the Moorefield Road side of the triangle along could be developed to optimise the urban experience. By inserting amenity on top of an existing supermarket, on one hand, anchors the connection between the triangle and other community facilities on the west; on the other, enhances the identity of Johnsonville as a cohesive community, shifting the focus of pedestrian experience to amenities on the upper level from barely a drivethrough town below

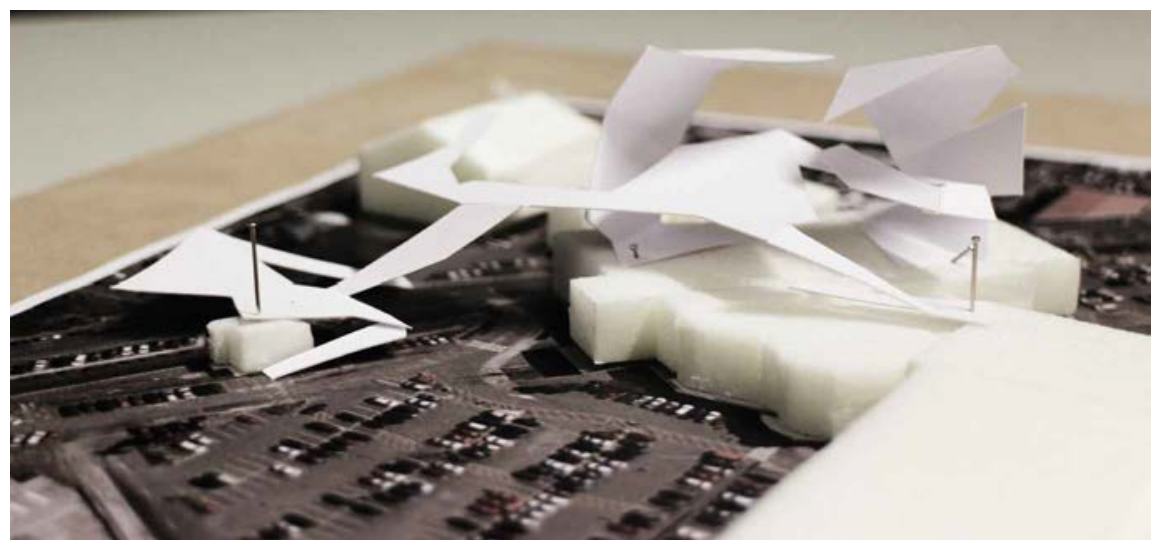




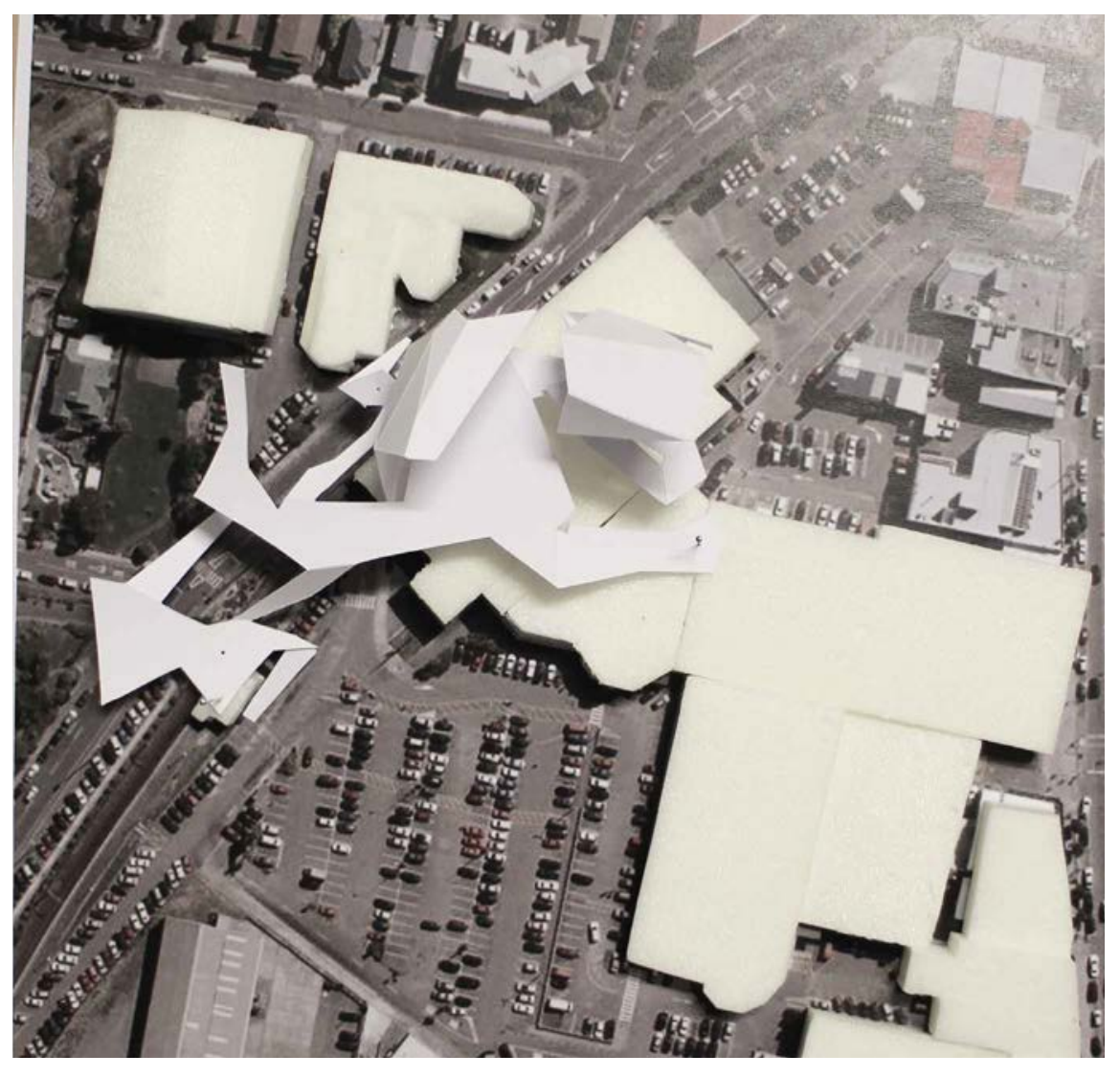

Fig 3.41. Plan view of the conceptual model demonstrating the connections it creates.

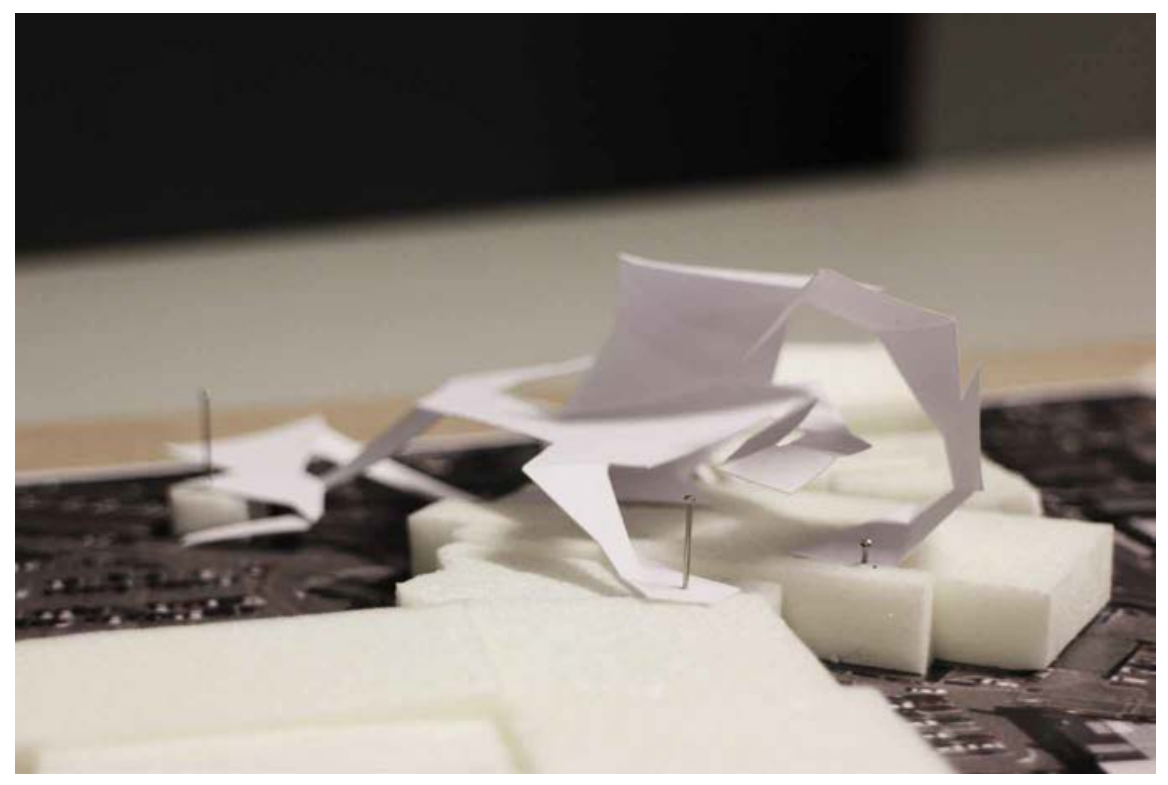

Fig 3.42. View into the amenity. The anchor amenity draws the attention to the community life of the suburb.

Fig 3.43. [ O p p o s i t e page] Bird-eye view of the conceptual model. 


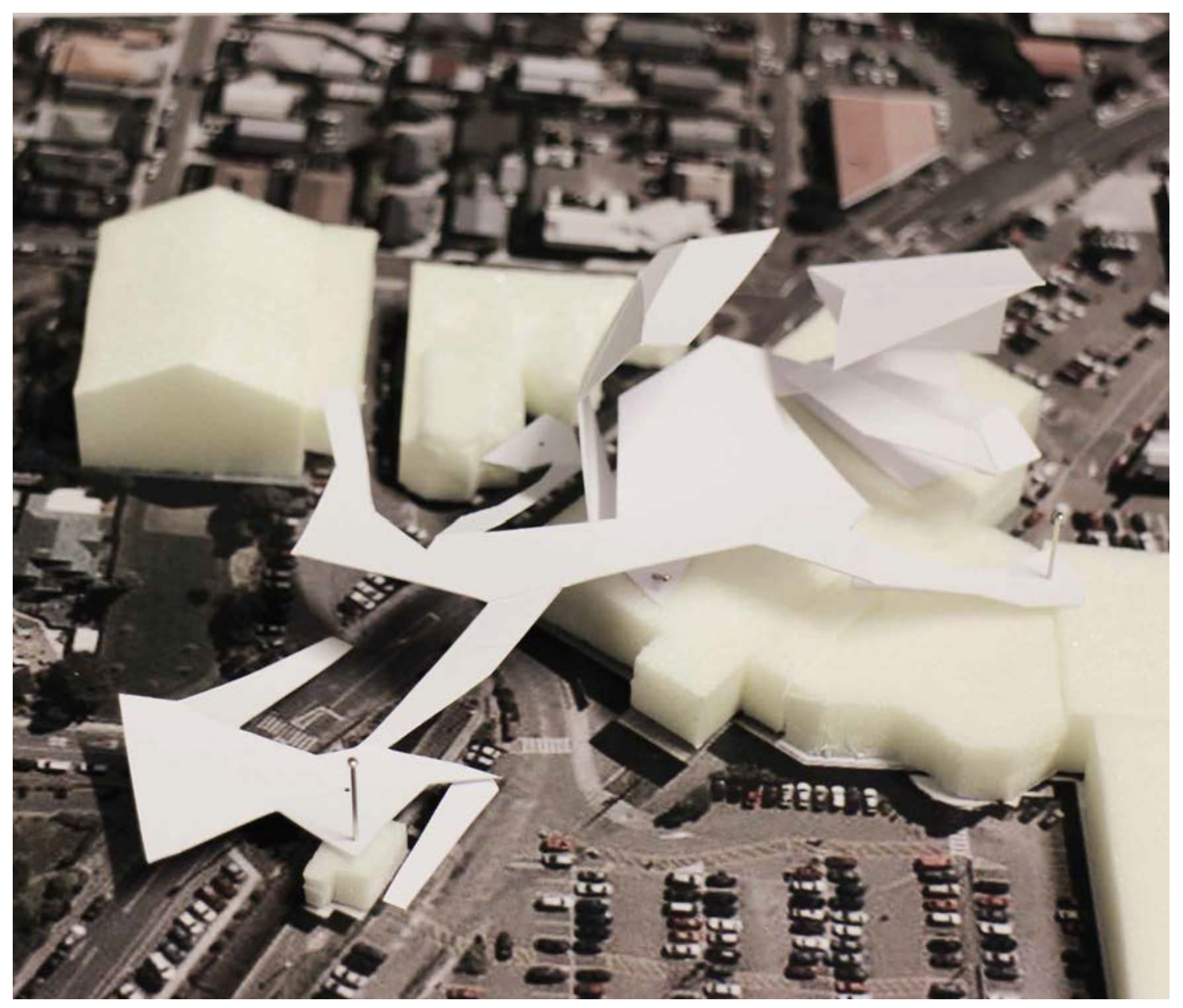


Reflection: This radical approach to the problem requires further feasibility studies to be practical. However, it extends the focus on the issue of elderly accessibility to the public domain from the domestic environment. The use of communal amenity as an anchor project provides a public space for seniors to socialise with other community members without segregation. The proposal of separating pedestrian and vehicles can effectively improve the efficiency of transport networks. It may involve issues of building ownership and gaining funding for an additional structure to the existing buildings below. The exposure to weather might further diminish the effectiveness of the express. There is potential of introducing amenity as an attraction anchor, however, the specific programmes facilitated would need to be studied to fit the seniors need in Johnsonville as the specific targeted demographic. 
Ageing

2.1 Validity of Problem

Mindset

Elderly in Public Spaces

Dilemmas

Case studies:

Shopping Mall

Senior Centre
2.2 Autonomy \& Connectedness

Environmentle Gerontology Universal Design

Case studies

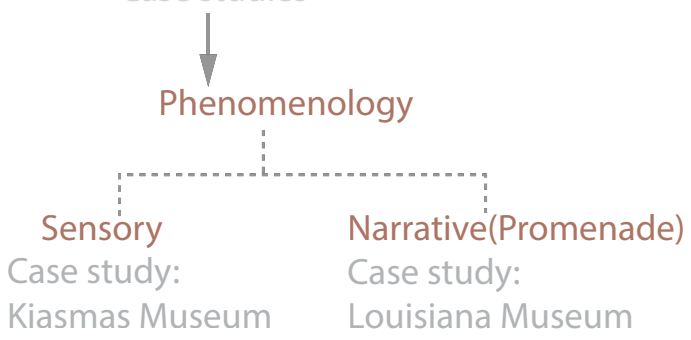

of Contemporary Art of Modern Art

Johnsonville

3.1 The Suburbia

Situating ageing in context

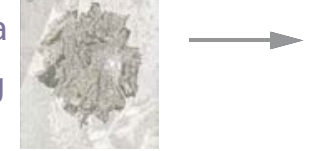

Agora

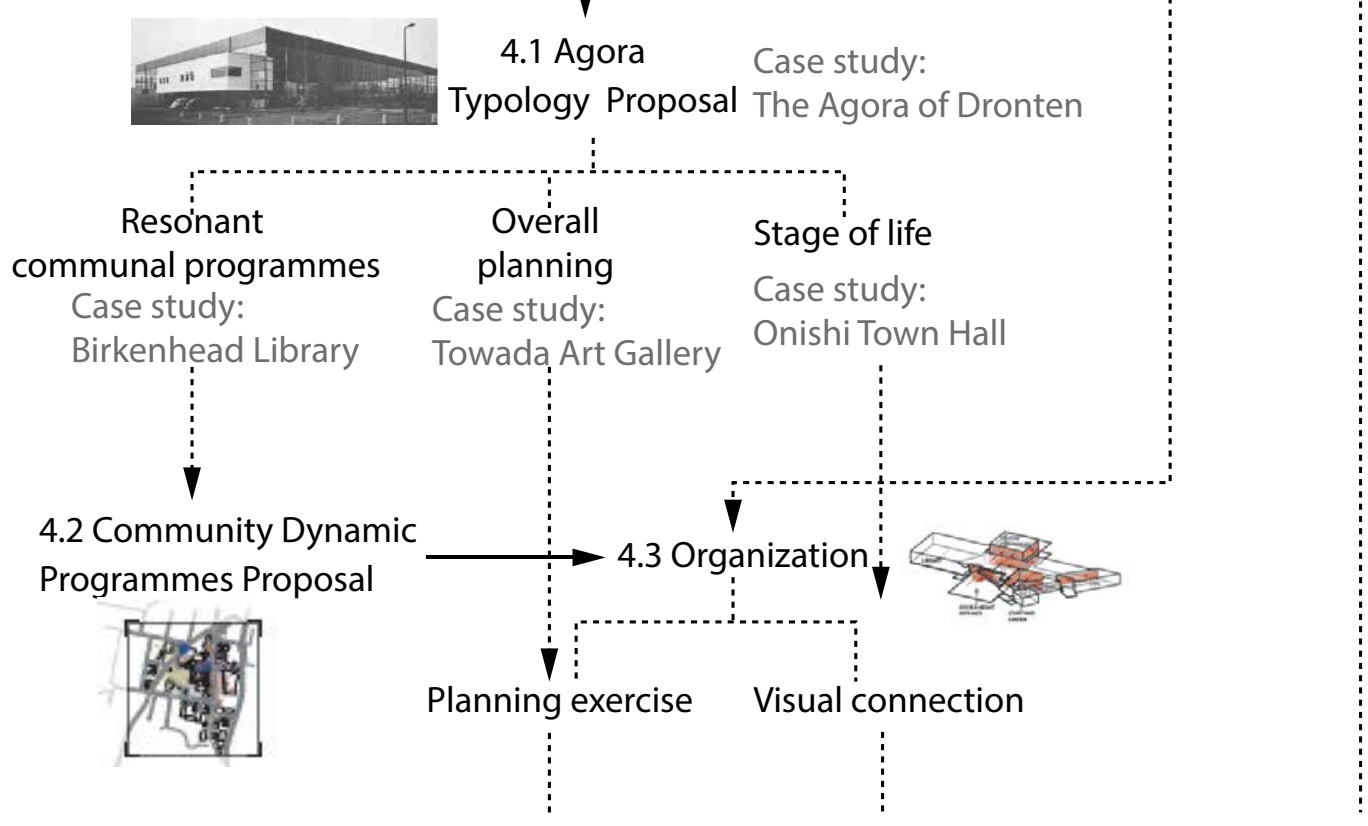

3.2 The Triangle

Project Site Selection
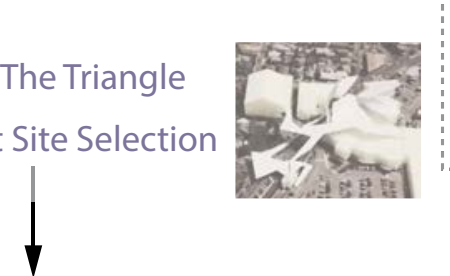
communal programmes

Case study:

齐

4.2 Community Dynamic Programmes Proposal

Case study: 


$$
\text { Papas }
$$




\section{What better public meeting place can suburb offer?}
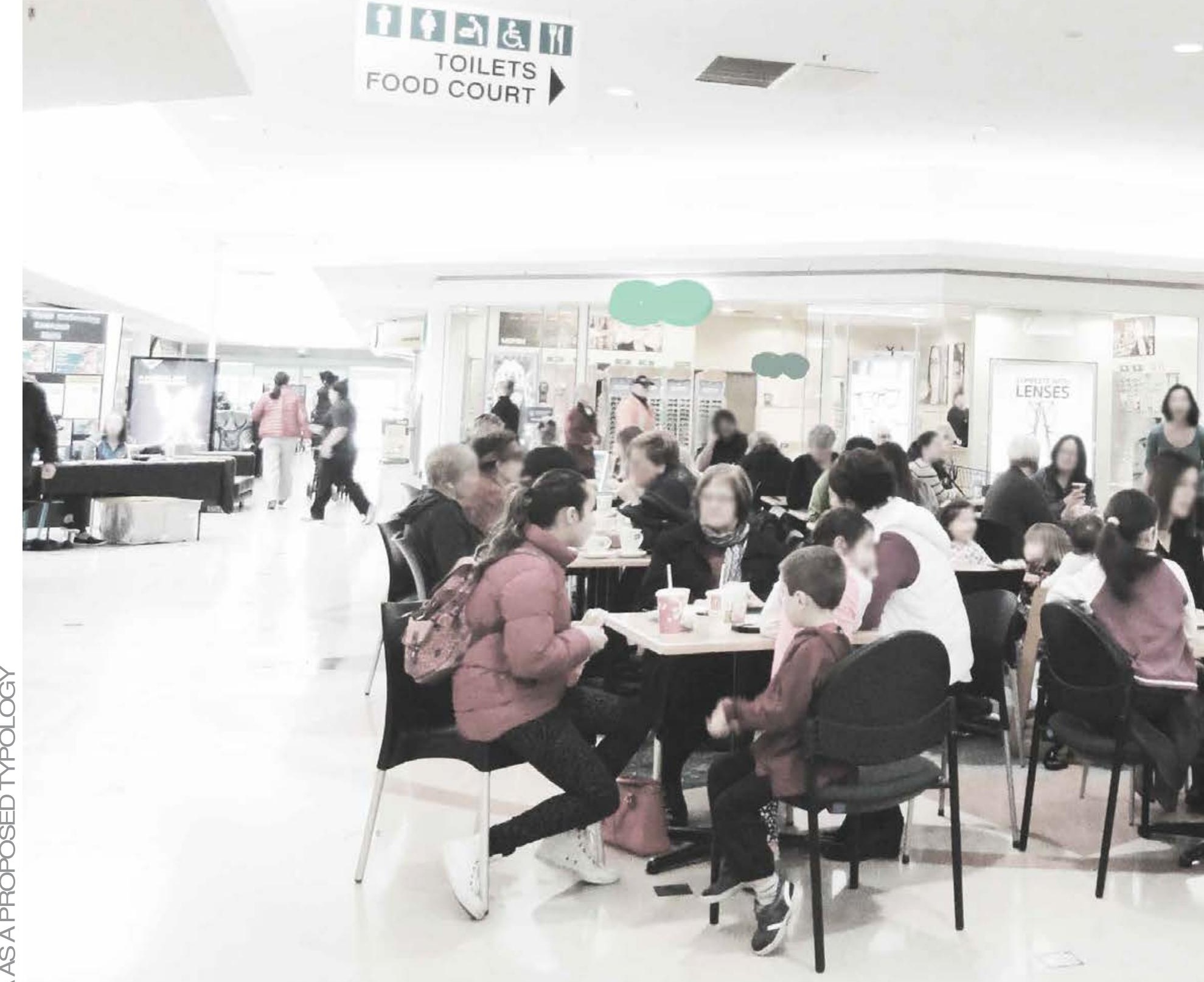
Fig 4.1. View of people meeting at the cafe in Johnsonville mall.

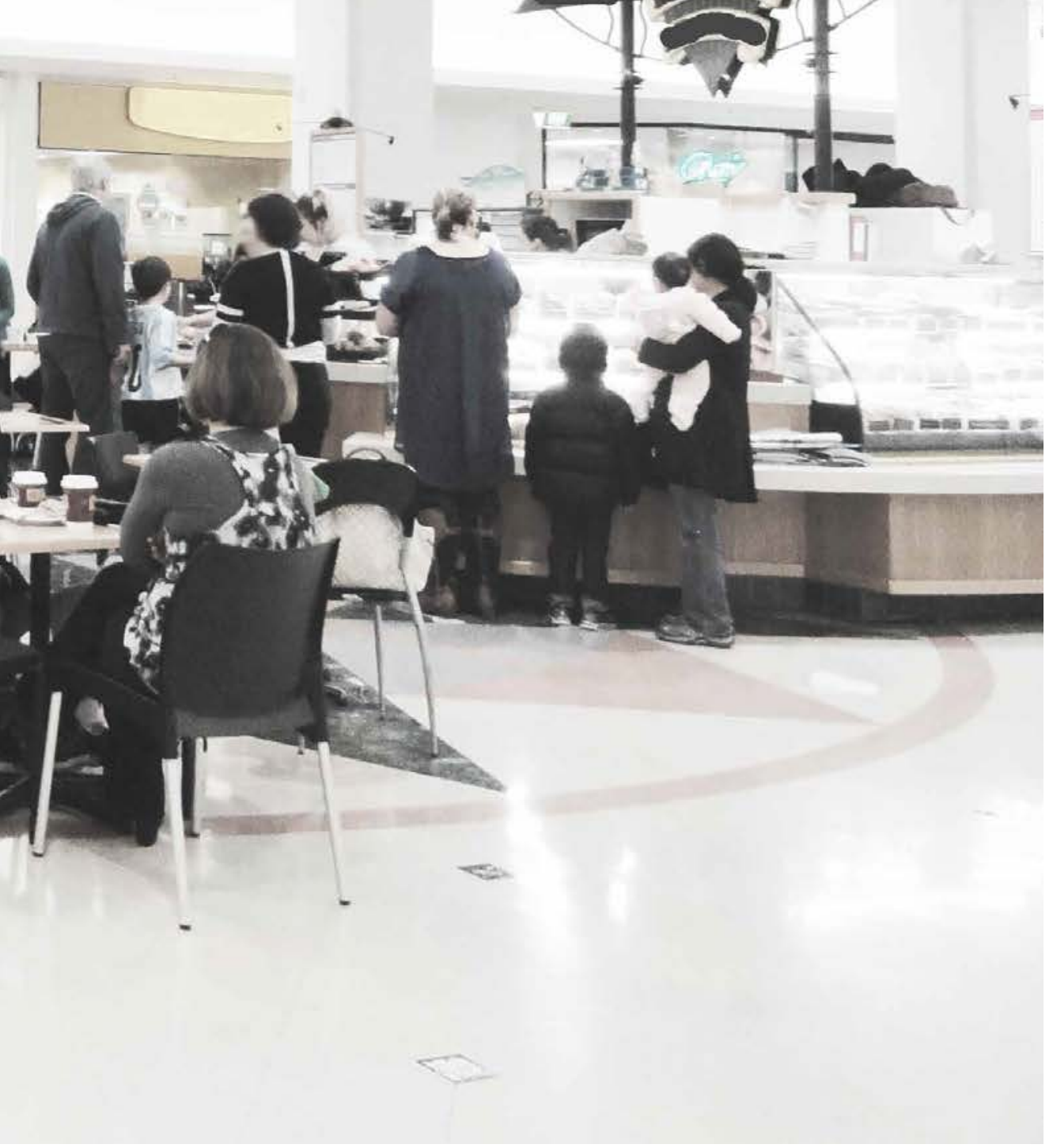


In this chapter, agora is proposed as a typology to help construct seniors' autonomous and connected life. Through analysis based on the dynamic of current community and the models of existing community facilities, agora is considered to valid to improve the community experience of the elderly in Johnsonville. Specific programmatic requirements are studied for the development of design. 


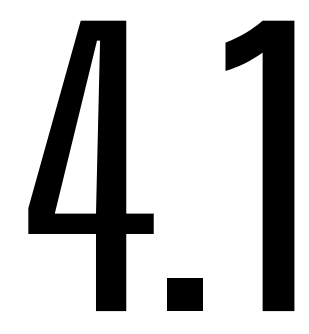

\section{AGORA}

\section{Agora as a typology exemplar}

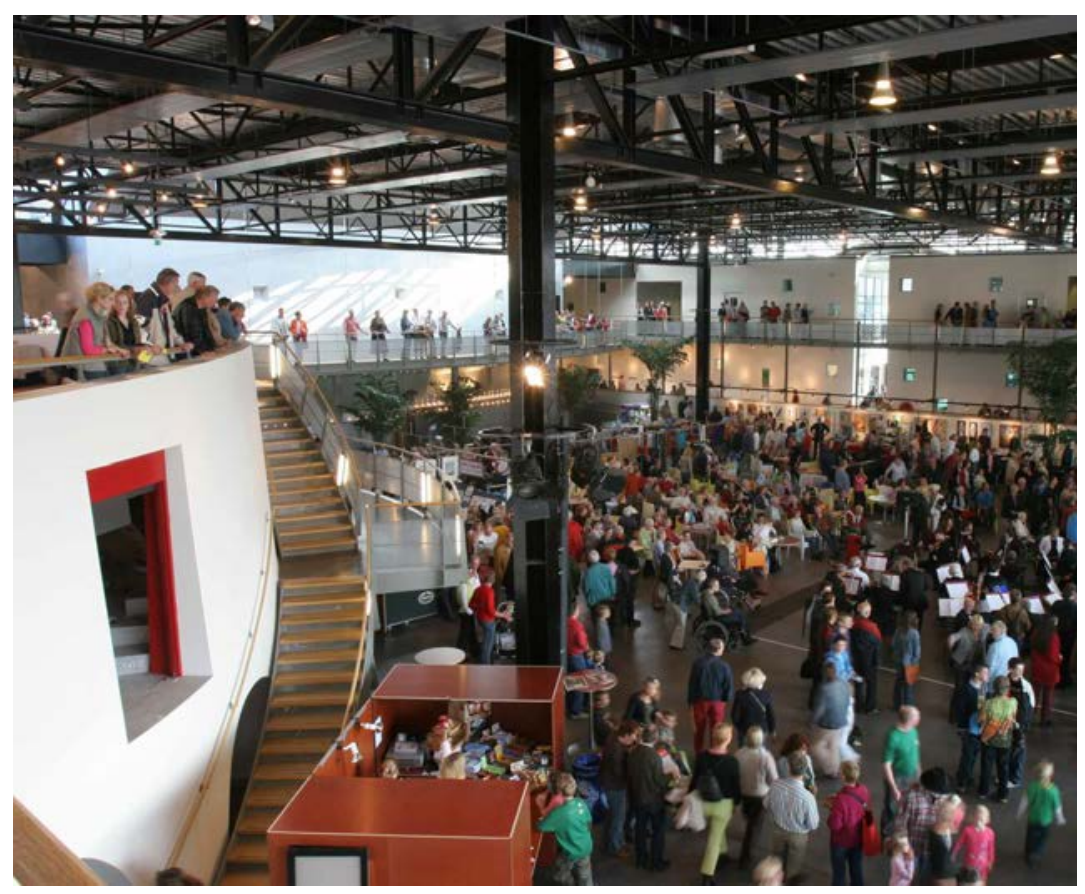

Fig 4.2. The Agora of Dronten on its re-opening day.

Agora, meaning "gathering place" in ancient Greek, is one of the architectural objects emerged from the booming urbanism in France during the "Thirty Glorious Years" (Ring, Salkin and La Boda 66). The rise of agora can be seen as a "counter-model" of a new kind of social and cultural amenities for suburban centres that are dominated by commercial activities, in the doubt that a space prioritised business could also serve the public good (Orillard 121-23). 
Against this backdrop, Agora of Dronten by Frank van Klingeren was designed to be "the focus for the construction of a local identity", creating a "relaxed, open-ended and democratic" public space for its user. As James Madge analysed, "there is a relaxed and inviting suggestiveness in the ordering of its 'landscape' that is convincingly juxtaposed with the forceful directness of the covering structure and enclosure"(33). After decades of tests by generations of visitors, the Agora of Dronten has been the close-to-perfect exemplar of architecture of this kind.

Fig 4.3. Exterior view of the Agora of Dronten not long after it was built.

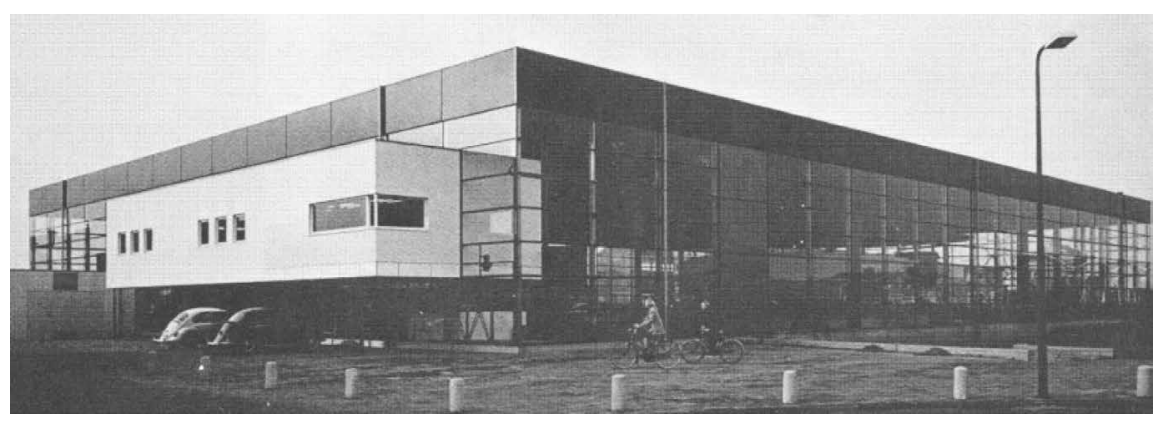

\section{Case study: The agora of Dronten (De Mleepaal)}

In this section, the agora of Dronten which also refers to De Meerpaal is investigated as a valuable lesson of constructing a successful public space to better facilitate seniors social needs. A selection of characters will be studied closely and contributed to the design outcome. 


\subsubsection{Resonant communal programmes - constructing social encounter}

Klingeren has a vision of open-ended programmes of the agora, which makes the design was aiming to accommodate various activities for different users. It is the capacity of agora in catering diverse users makes it successful as a public space where "everyone meets everyone" (Hughes-Stanton 42).

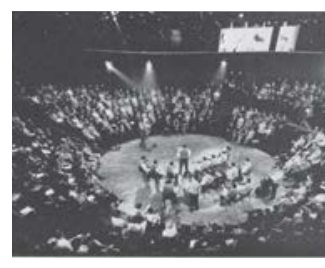

Congresses Musical events Cabaret

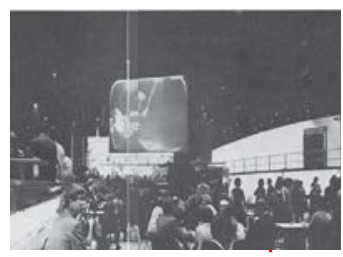

Movies' Sports

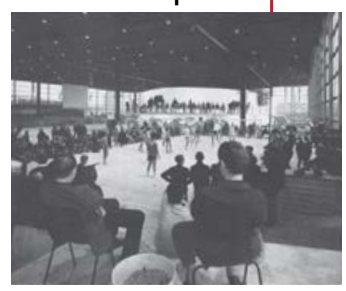

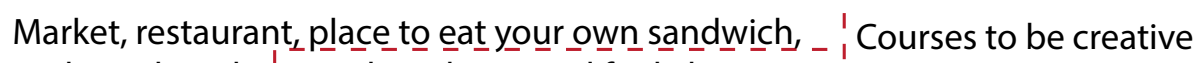
to do nothing but watch and wait and fool about

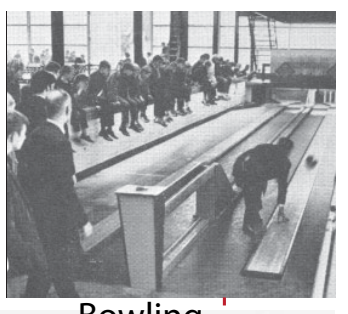

Bowling Clubs

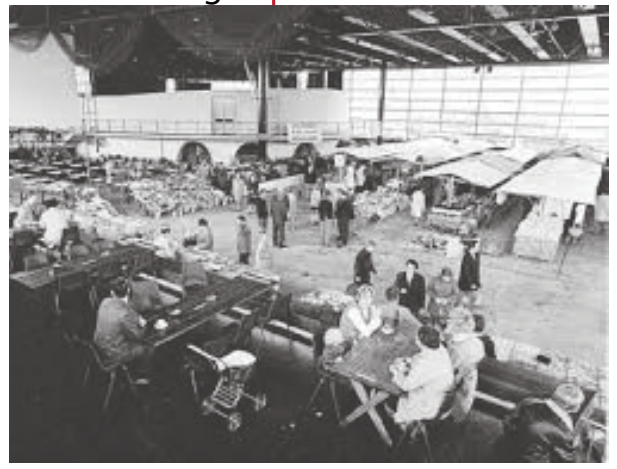

Fig 4.4. Diagram studying the diversity of programmes the agora houses and their relationship among each others. 


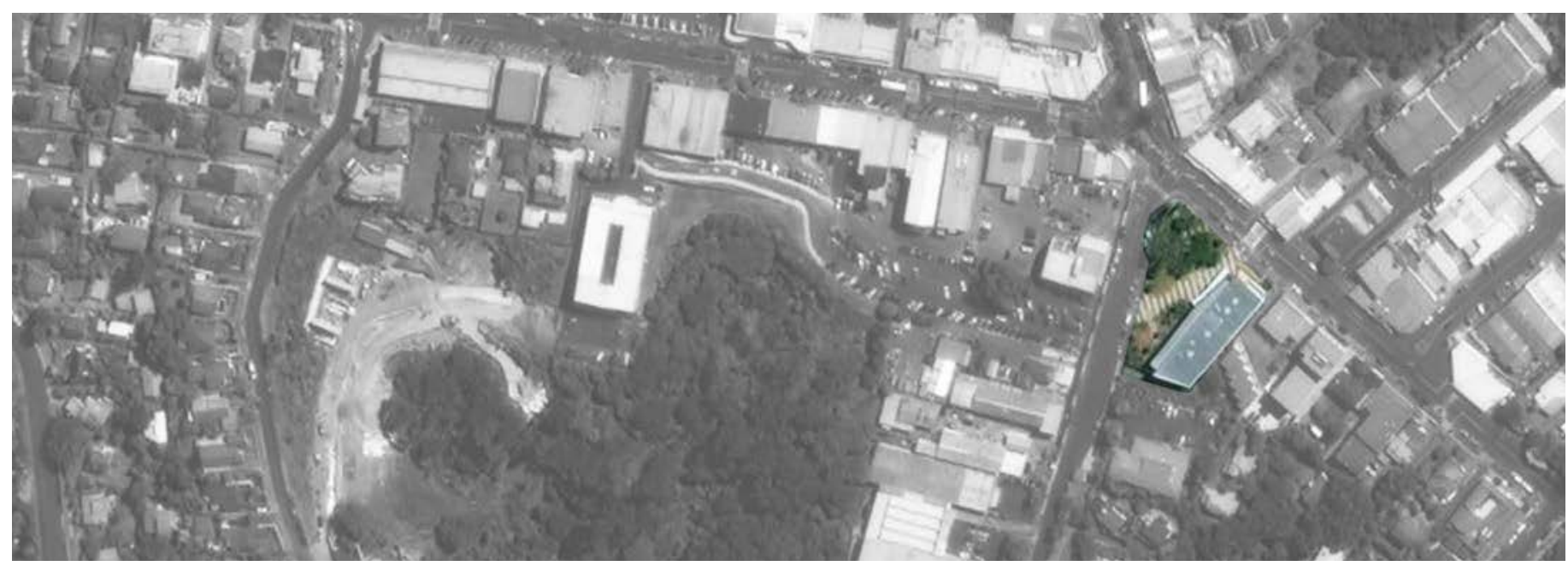

\section{Comparative case study: Birkenhead library and Civic Centre Open plan verser interlocking}

Fig 4.5. Contextual map of Birkenhead Library and Civic Centre.

Fig 4.6. Bird-eye view of Birkenhead Library in relation to its surrounding.

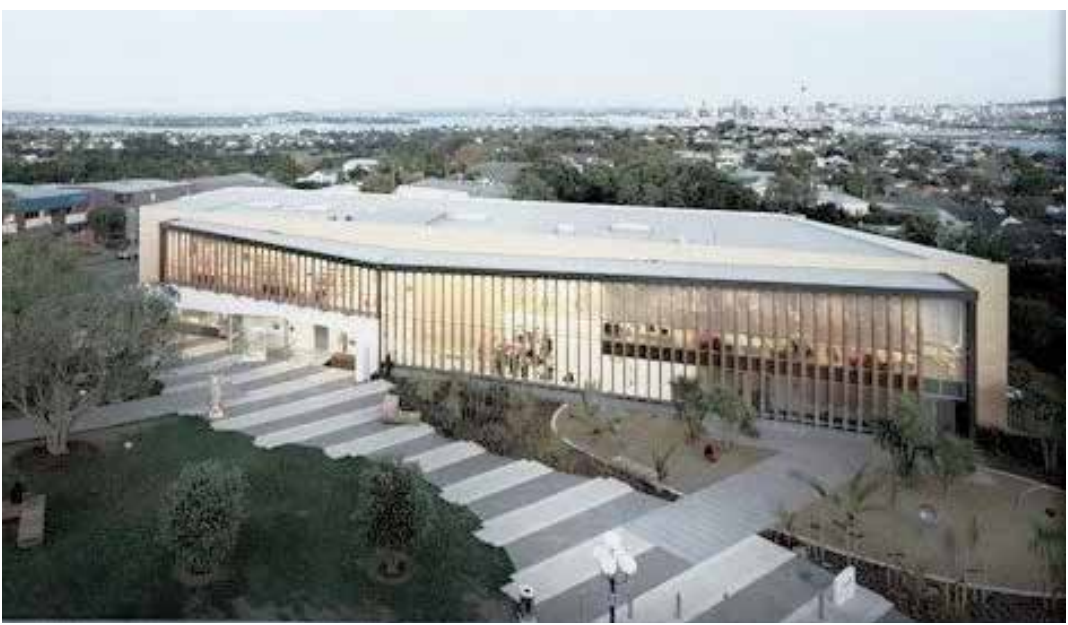

Similar to the Agora of Dronten, Birkenhead Library and Civic

Centre houses multiple programmes for the local community. While the open plan layout of the Agora of Dronten advocates uninterrupted interactions among different programmes, Birkenhead Library was 


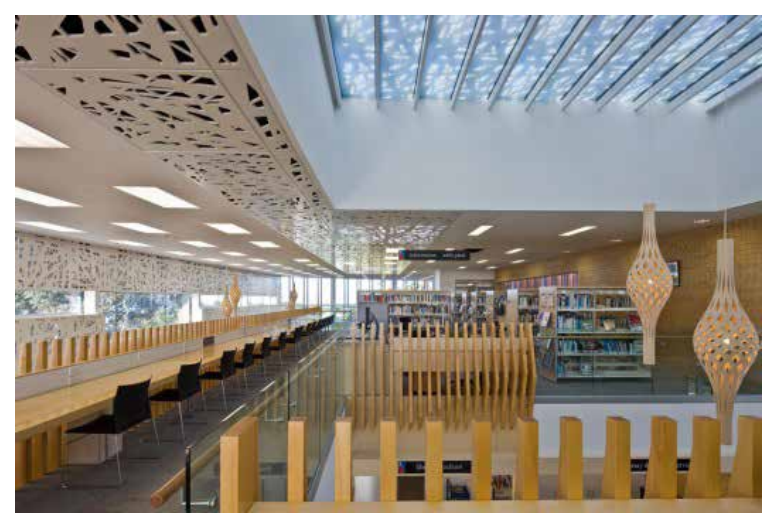

Fig 4.7. Mezzanine floor creates a space that is connected to ground floor through the double height space and yet remains relatively private.

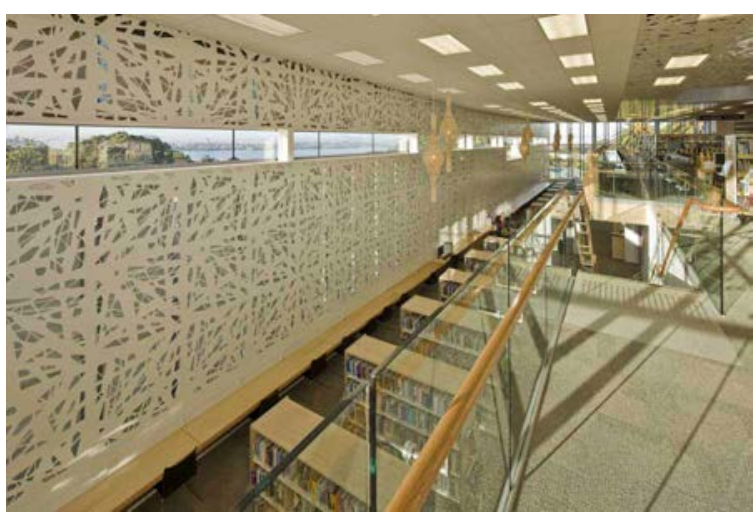

Fig 4.8. Visibility through different floors and across inside and outside create the sense of publicness in a modest scale.

designed to create the sense of connectedness through a more controlled manner. Masses of varied programmes subtly interlock into each other. Spaces are either visually or acoustically connected and yet remaining privacy and safety certain programmes required.

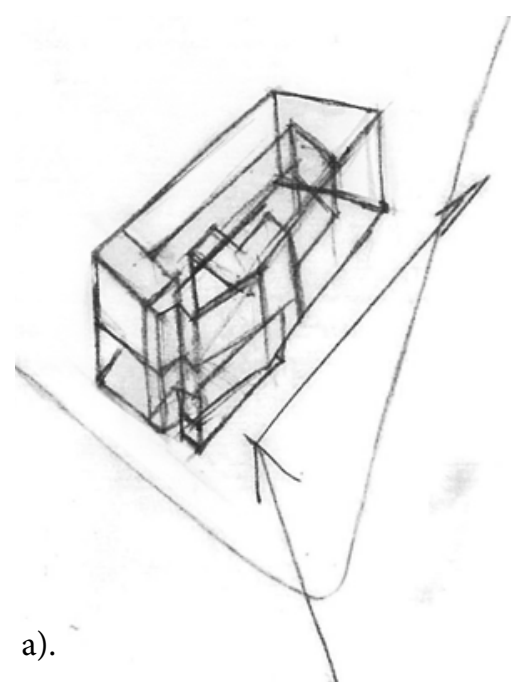

b).

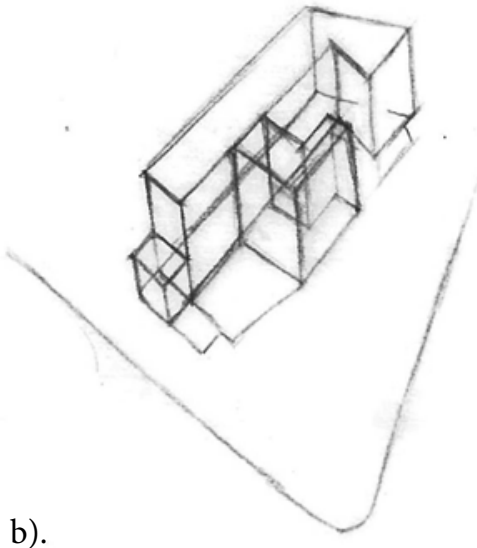

c).

Fig 4.9. Diagrams of a).overall mass of the entire building in relation to street; b). the volume of library area; c). the volume of communal function area. 


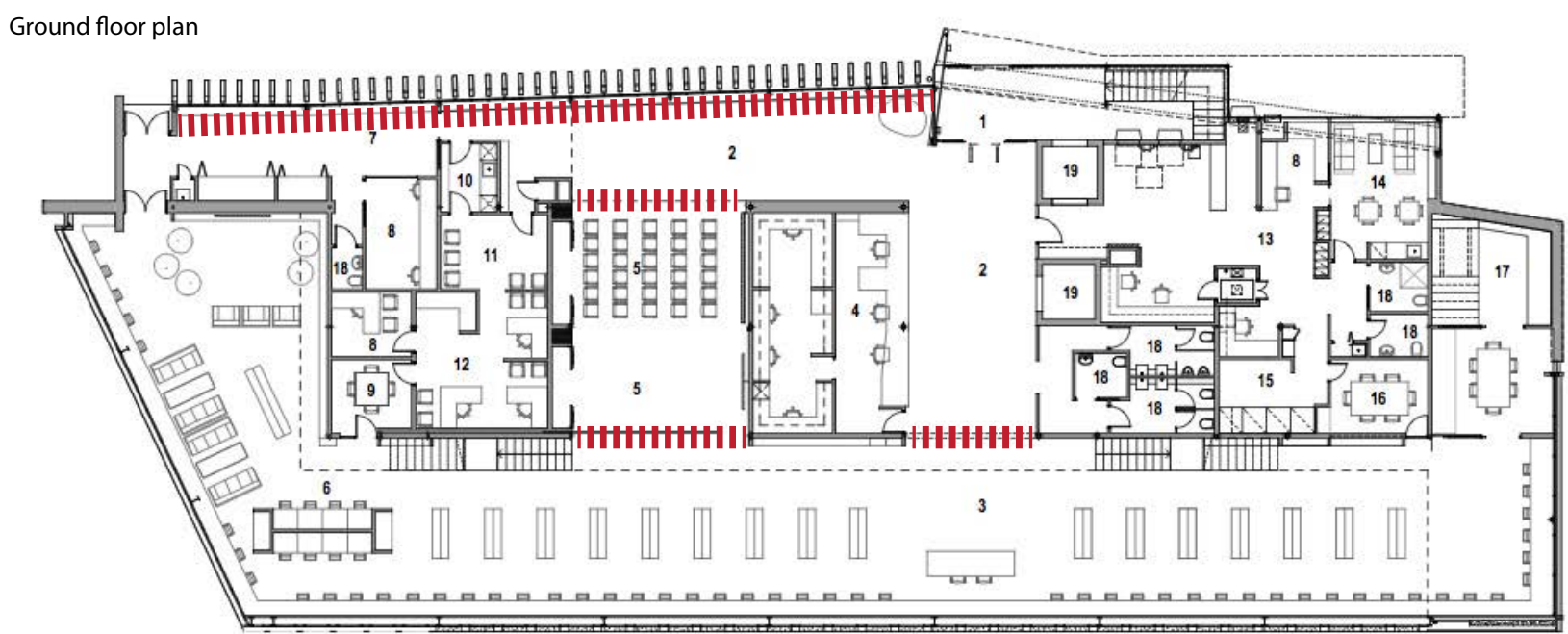
1. Main Entry
2. Lobby
3. Library
4. Customer Services
5. Community Meeting Room
6. Learning Centre
7. Plunket
8. Office
9. Meeting
10. Kitchen
11. C.A.B
12. C.A.B Waiting
13. Workroom
14. Stafftoom
15. Resource Area
16. Staff Meeting Room
17. Local History/Archives

18. WC

19. Lift

20. Childrens Area

21. Library Support

22. Store

23. Basement Carparking

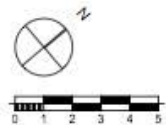

Mezzanine floor plan

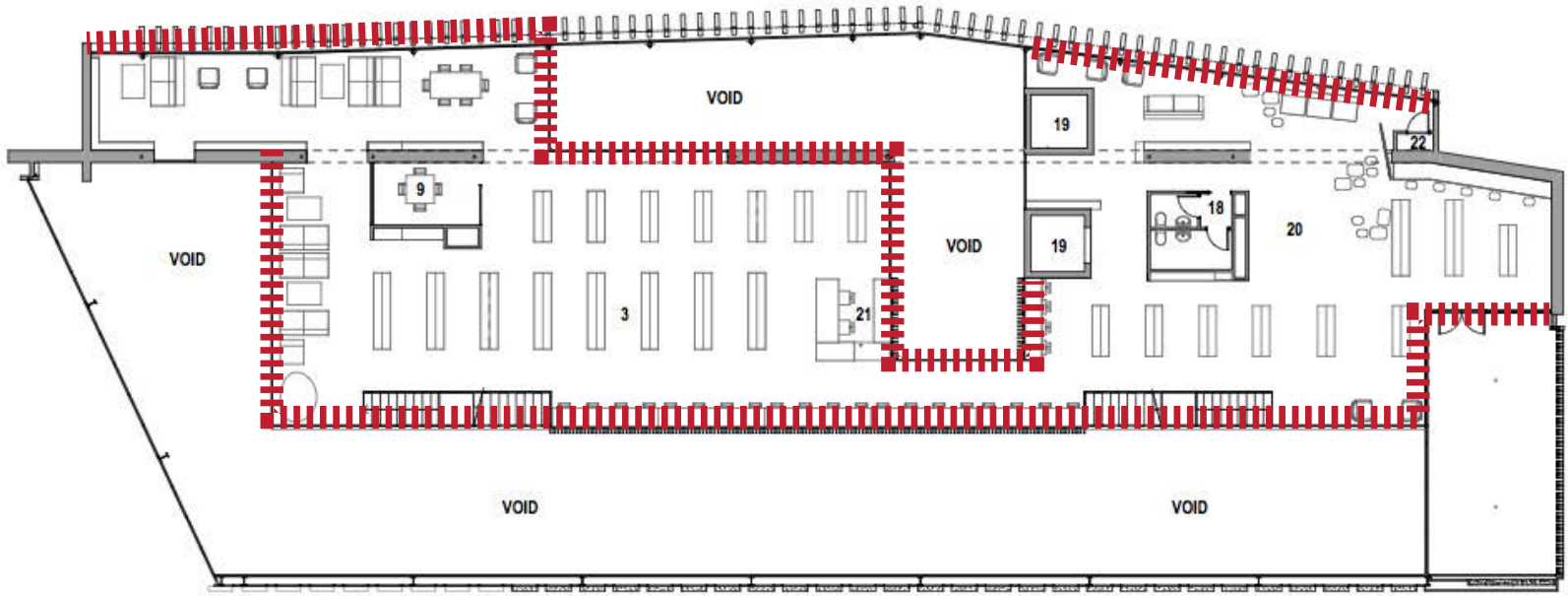

Fig 4.10. Diagrams highlighting edges where varied programmes meet on plans. 


\subsubsection{Overall planning - make sense of public amenity}

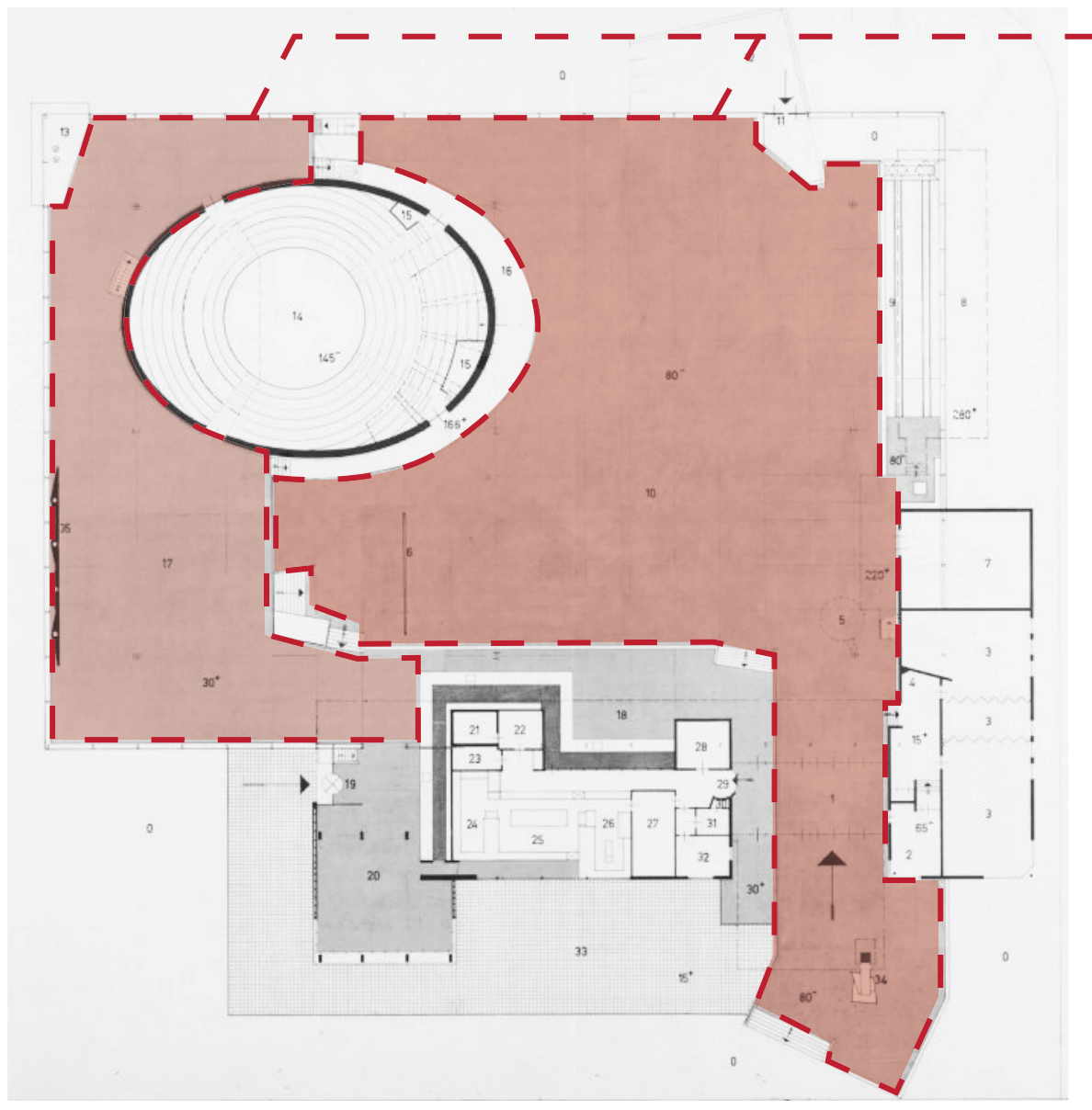

To build for a fast-growing suburban community, Klingeren comes up with the idea of "to build for the future", meaning that leaving a great deal unbuilt for the future community to finish. Through the provision of a gigantic structure as shell and leaving most of the internal open, the agora is able to facilitate the flexibility required for diverse activities and users.
Left for the future to build

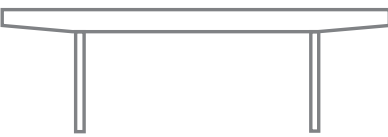

Large structure provides shelter for the programmes

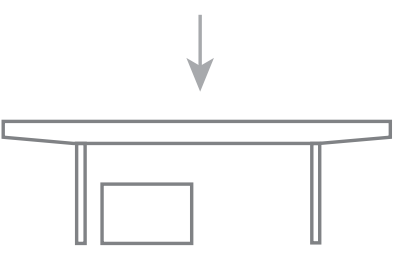

limited built components

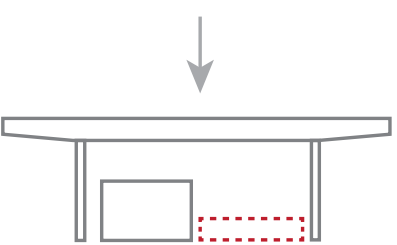

flexibility allowing various communal activities to happen in the unbuilt area

Fig 4.11. [Left] Plan of the Agora of Dronten highlighting the large "unfinished" area.

Fig 4.12. [Right] Diagram studying the idea of providing a frame and limited built component and inviting the community to "finish" it. 


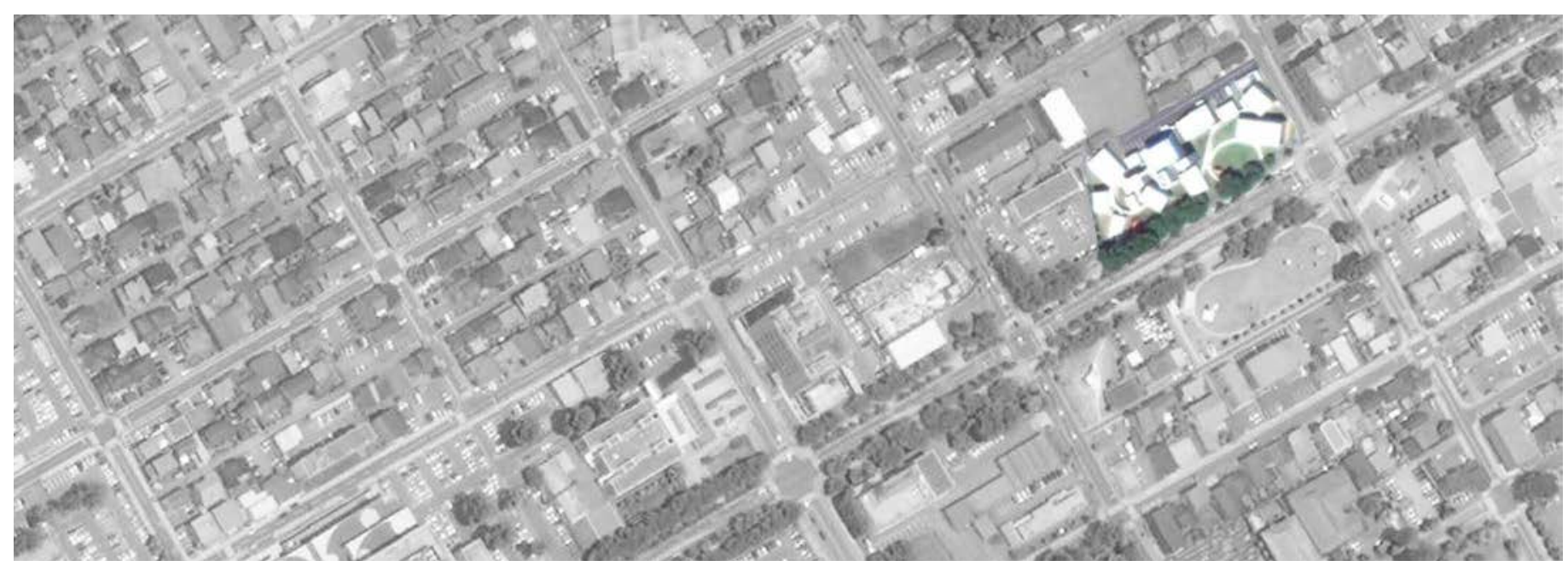

\section{Comparative case study: Towada Art Centre one big box versus lots of small boxes}

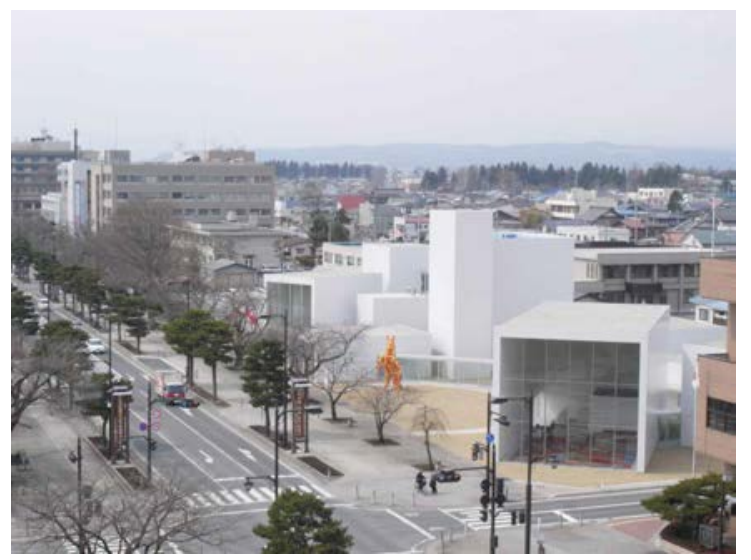

Fig 4.13. Contextual map of Towada Art Centre.

Fig 4.14. Bird-eye view of Towada Art Centre showing it relation to the site.
Similar to the Agora of Dronten, Towada Art Centre aims to create a public space for the people. However, with the focus on art, Towada Art Centre presents a completely opposite approach to the Agora of Dronten. These two approaches result in environments with their own distinctive atmosphere. 


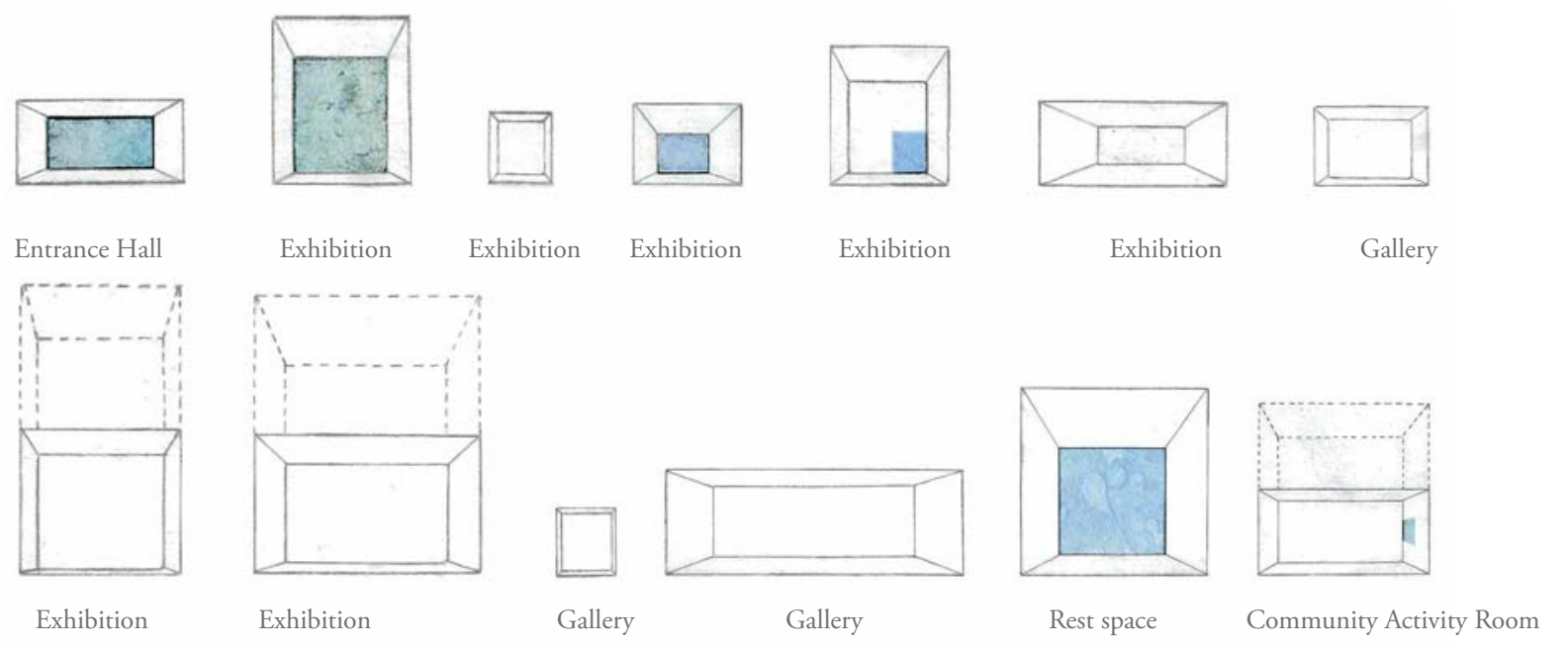

Instead of providing a large box where various activities take place, Towada Art Centre is composited of a collection of smaller boxes containing different programmes. It creates a controlled environment even its still relatively open to public, which is beneficial for safety of both visitors and exhibits.
Fig 4.15. A collection of small "boxes" contain varied programmes.

Fig 4.16. View of landscape outside with sculptures. These pocket spaces with focal points have potential to create more interactive street front.

Fig 4.17. View from a gallery space. In a properly controlled space, the safety of visitors and exhibits is protected.
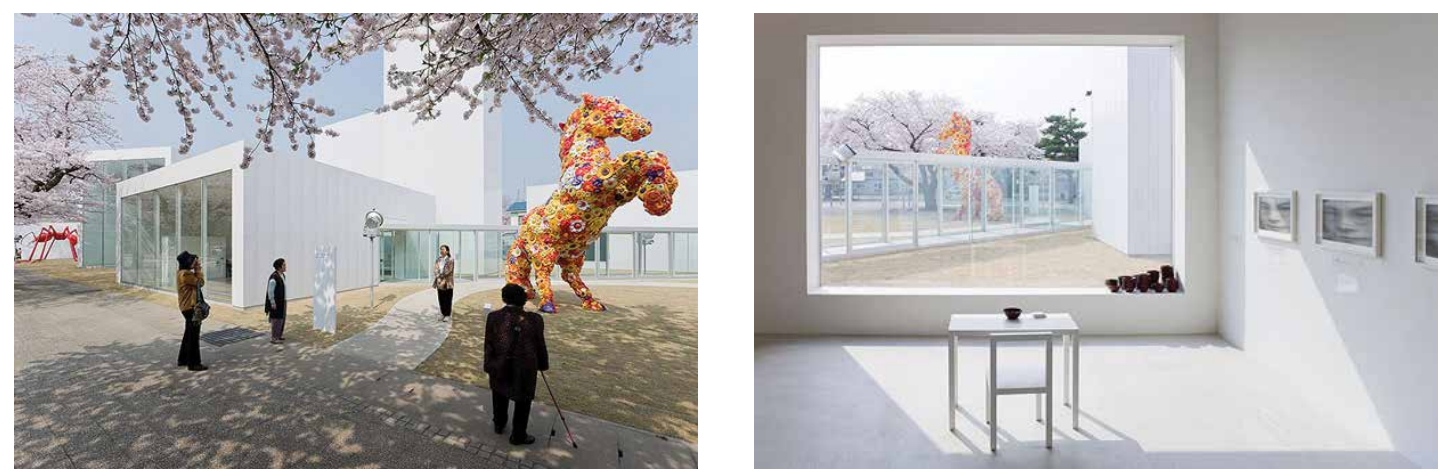


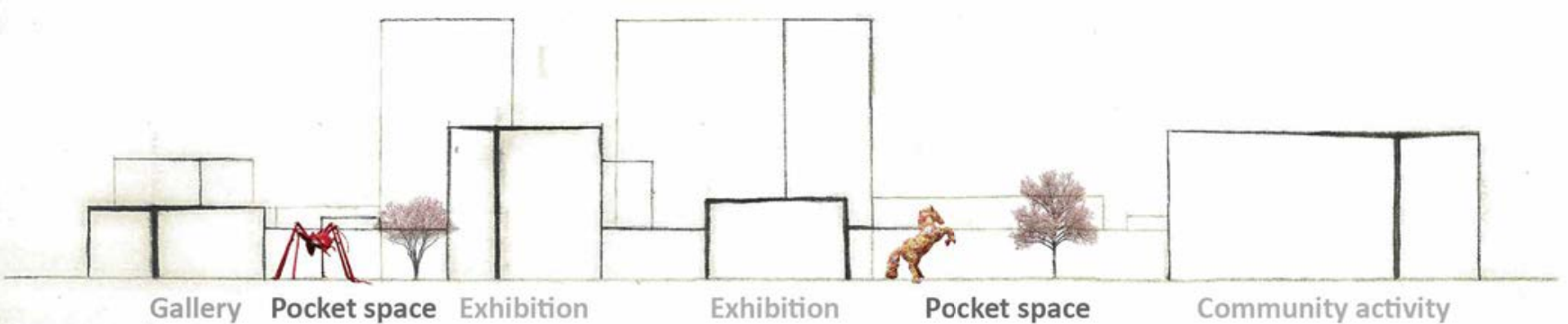

Fig 4.18. Pocket spaces are created by loose edges to encourage social interactions.

Fig 4.19. Ci r culation among building blocks and its relation with surrounding pedestrian access.
Compared to the Agora of Dronten, Towada Art Centre leaves pocket spaces among building blocks to respond to the site context and encourage social interactions even outside of the building. Circulation is in a controlled pattern suggesting certain routes rather than open-plan in the agora advocating free movement.

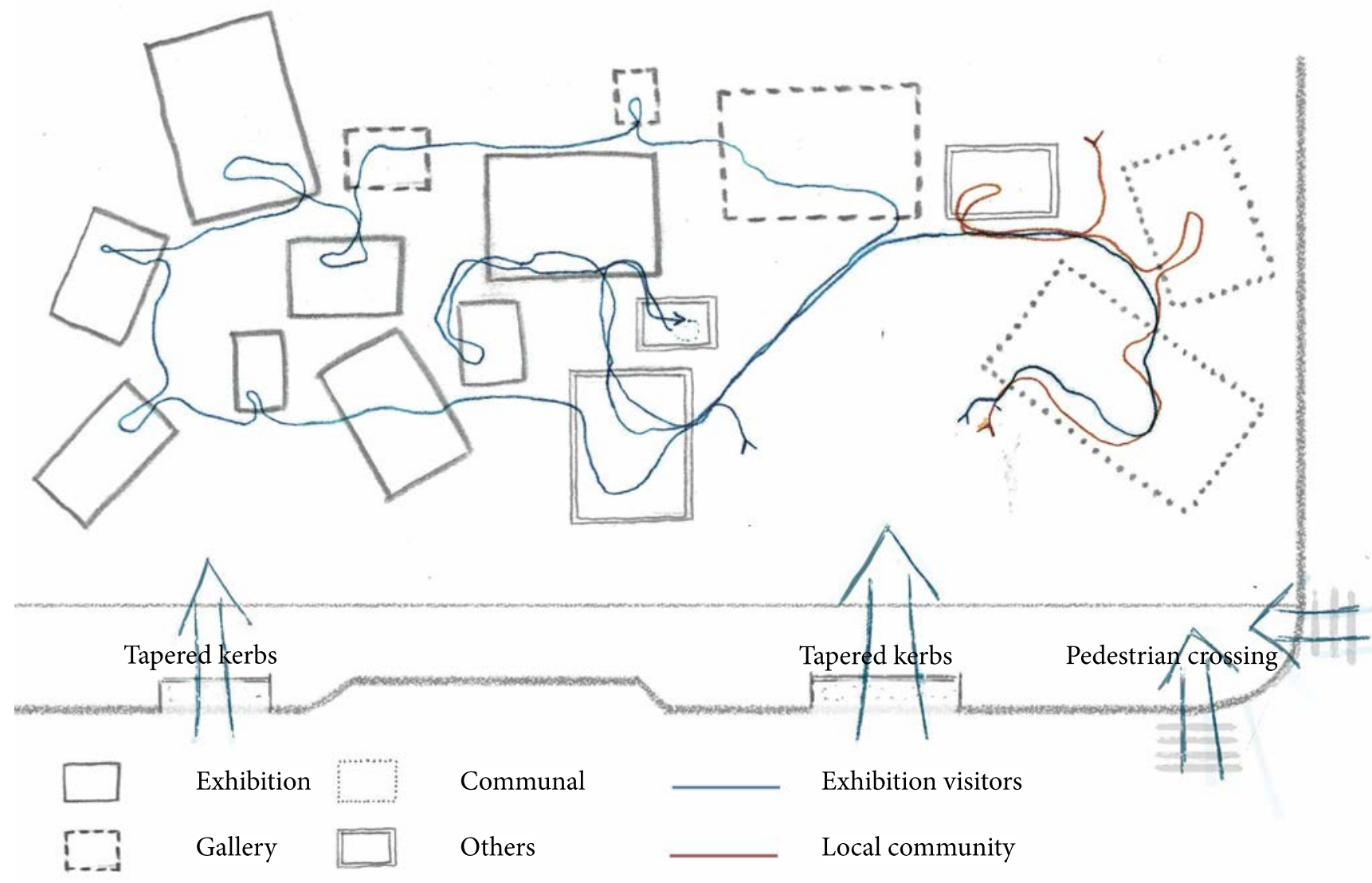




\subsubsection{Stage of life - creating focal points}

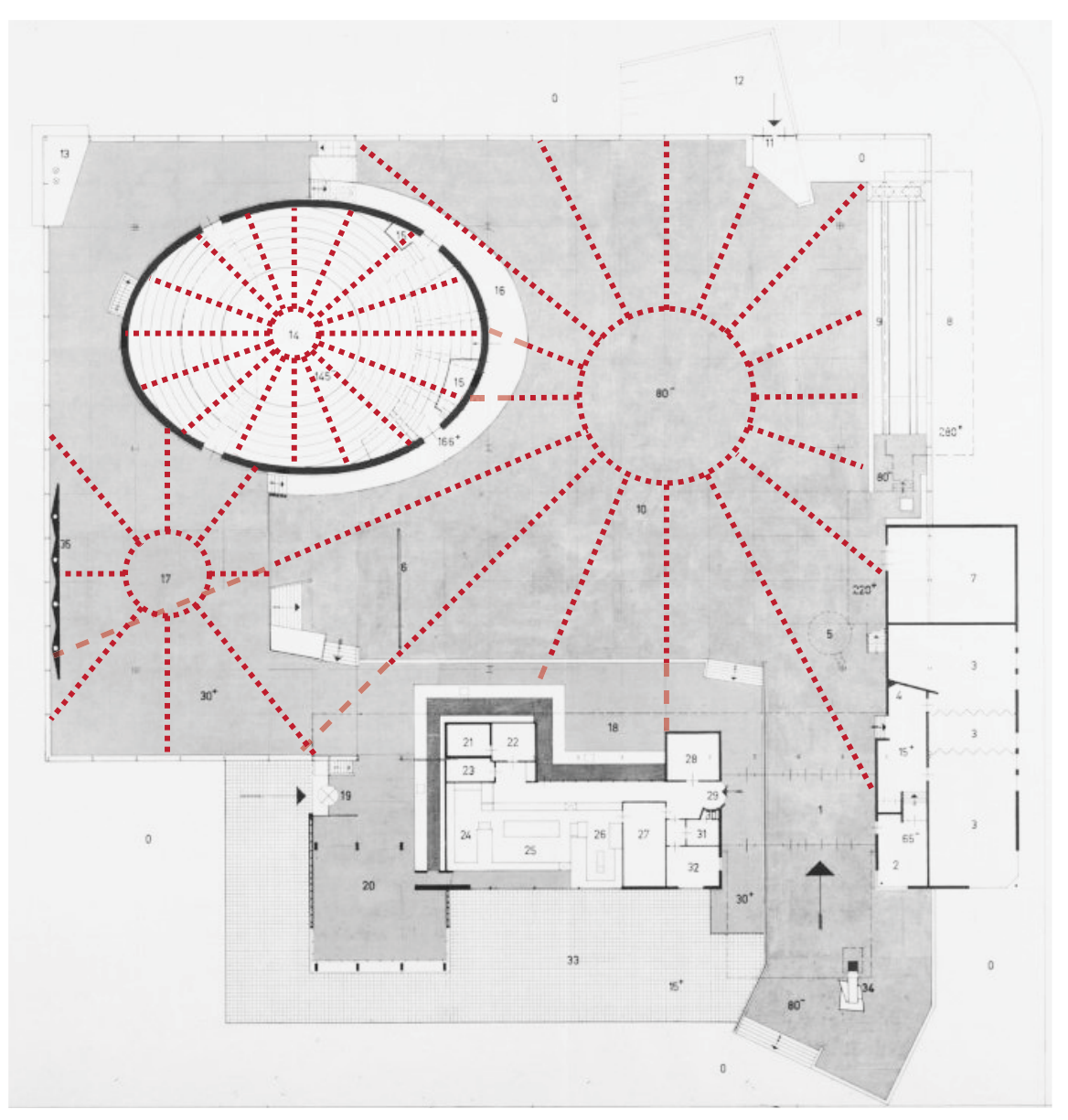

As little as Klingeren design to build in the agora, there is clear provision of focal points in the large open space alongside with viewing points. This notion responds to people's nature of enjoy watching human activities, which is crucial in Jan Gehl's study of creating a vibrant urban environment (Gehl 25).
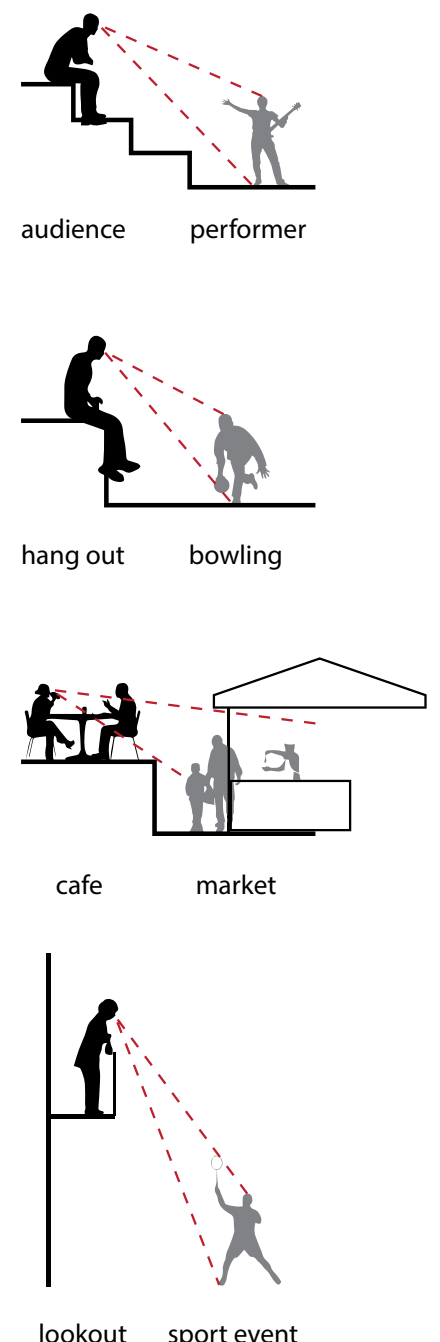

Fig 4.20. [Left] Analysis of potential focal points created from activities.

Fig 4.21. [Right] Diagram studying varied viewing relationship created in the agora. 


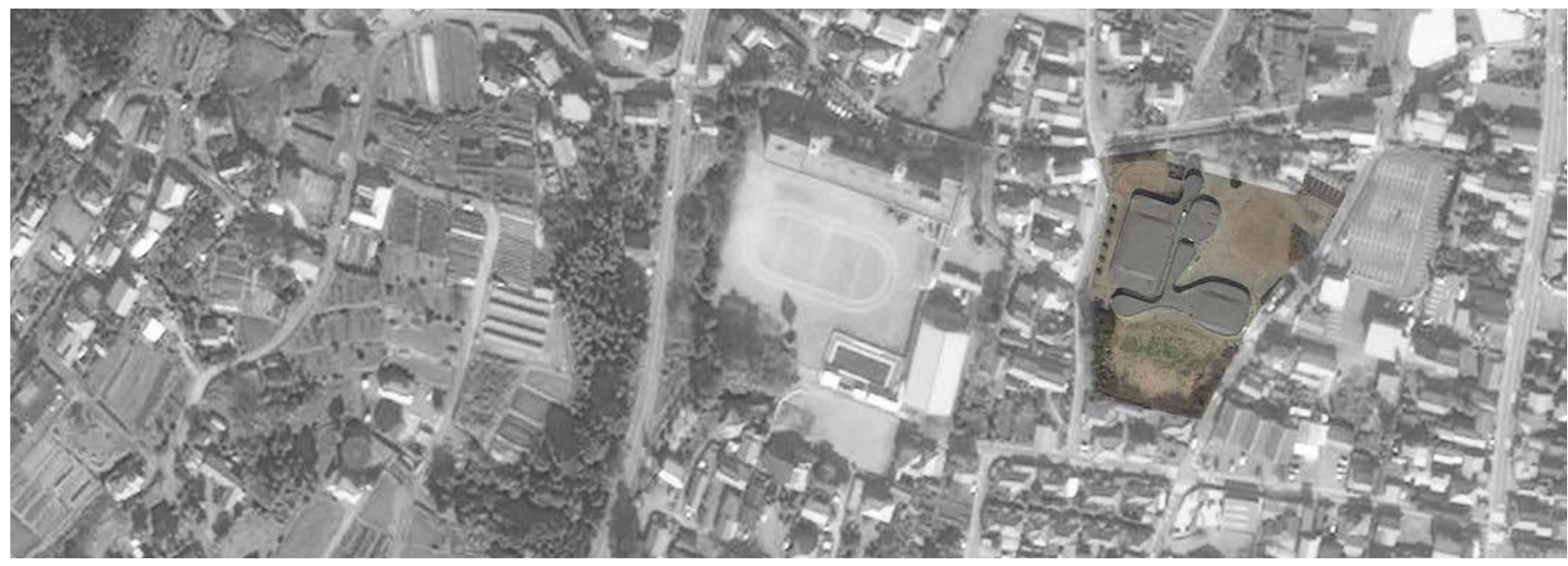

\section{Comparative case study: Onishi Town Hall one great roof versus invisible walls}

Fig 4.22. Contextual map of Onishi Town Hall.

Fig 4.23. Bird-eye view of Onishi Town Hall in relation to its surrounding.

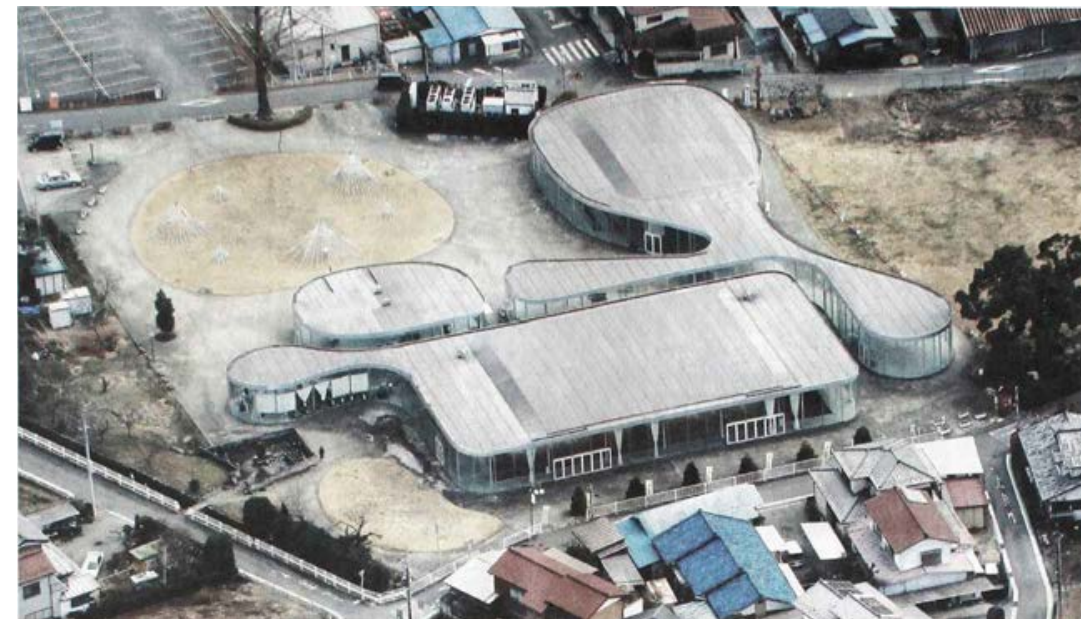

The Agora of Dronten and Onishi Town Hall share the same notion of public space that "everyone can see and hear the same thing"(Madge 33). Klingeren decided to shelter a large open space under one great roof, while SANNA chose to create that sense of publicness through invisible walls. 


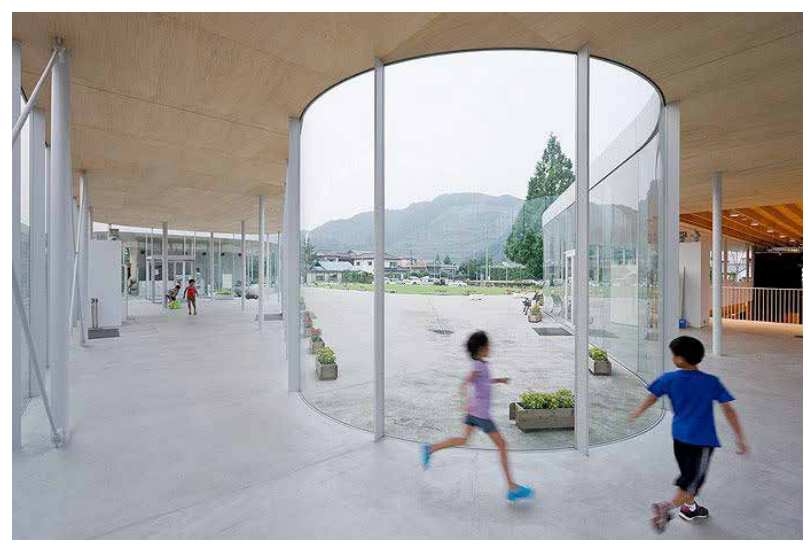

Fig 4.24. The application of glass facade creates a continuousandscape from the inside to the outside.

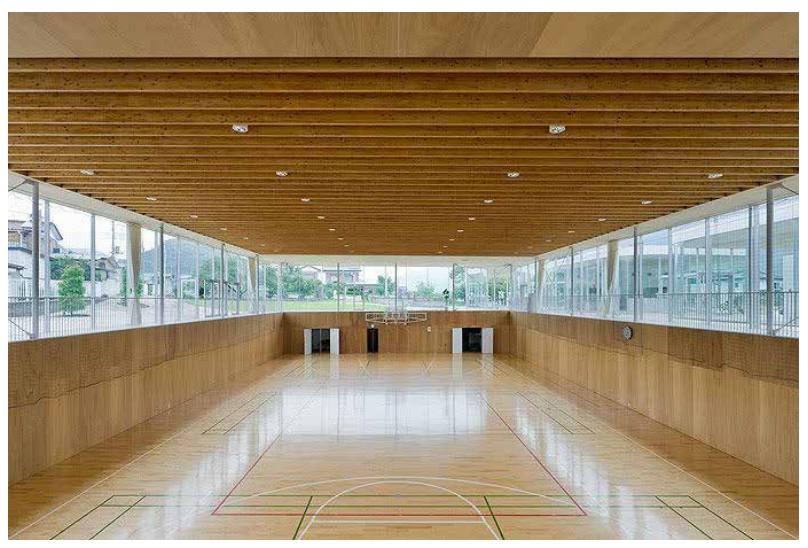

Fig 4.25. View into indoor sport court. The transparancy of upper level invite people to take part in activities passively.

Although the Agora of Dronten provides plenty of opportunities for cross-programme interactions, these interactions are highly limited inside of the building, having little connection to the outside. In comparison, the particular configuration of Onishi Town Hall creates moments where the inside embraces the outside and blends into a continuous "landscape".

Fig 4.26. Analysis of varied viewing relationship created in the town hall.
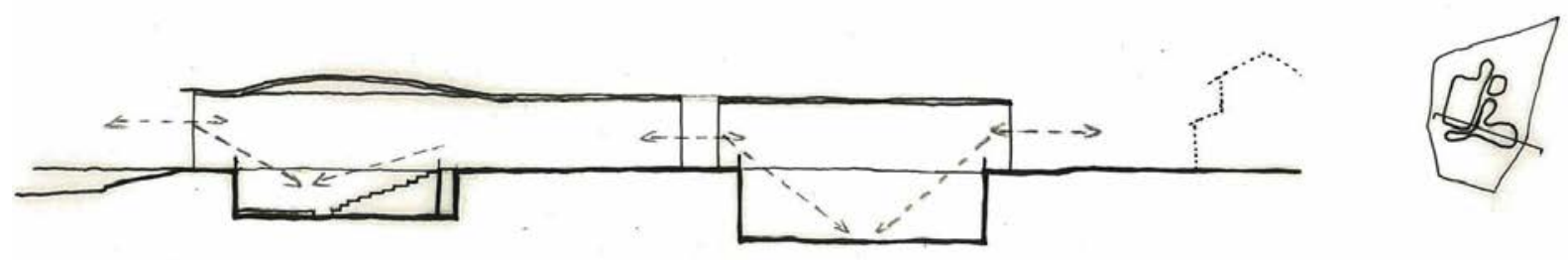

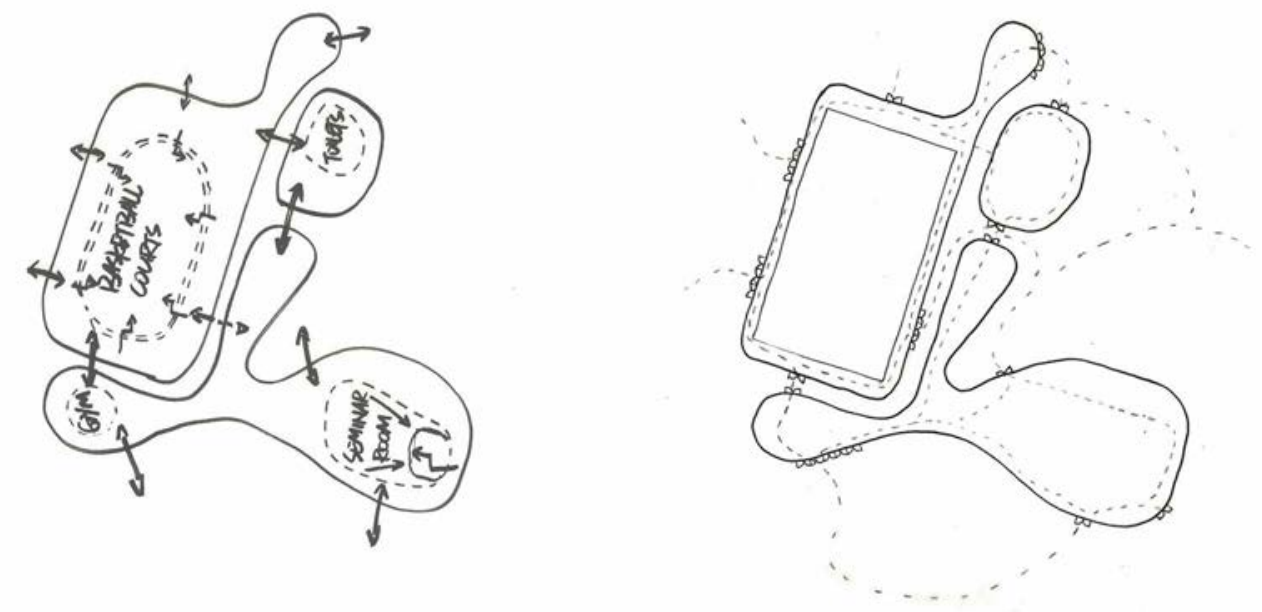

Fig 4.27. [Top

left]

Programmes are separated but yet visually connected due to the transparency.

Fig 4.28. Top

right] Circulation around the town hall.

Fig 4.29. [[Bottom] The building form extends towards adjacent streets, making it approachable for the occupancy.

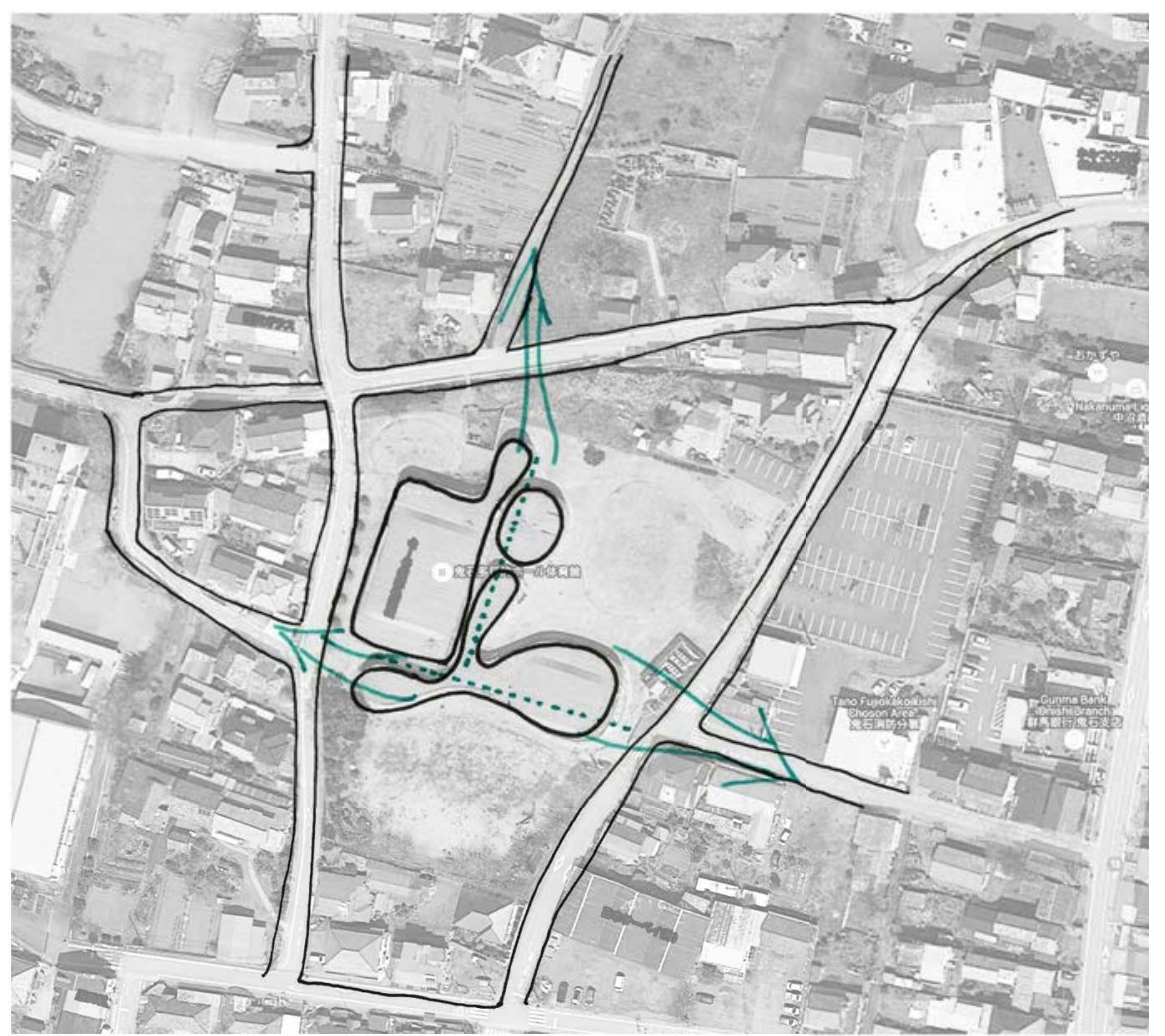




\section{Opportunities agora brings and critics on them}

As a typology of "protected public space", agora is public space that has defined boundaries with shelters, and belongs to the traditional public authorities as well as other actors in the city according to professor Orillard from l'Institut d'Urbanisme de Paris (117). It provides public space that is protected from the weather for citizens, and takes advantage of public-private-partnership. Agora has the potential to resonate with local community's preference of protected environment in Johnsonville, yet opens up the opportunity for City Council to partner with Johnsonville mall to create a cohesive town centre.

Even though the Agora of Dronten is considered as a success by many researchers, there are issues arise during the past almost half a century after it was built. The large structure does allow open-ended communal programmes to happen, however, its utilization also becomes highly reliant on the actual organisers of those programmes. For instance, the agora of Dronten has mainly been used as venue for popular events after 2000 , losing its temporariness from the design intent. It also causes issues of the spatial acoustic performance which results in several modifications subsequently. When introducing agora into Johnsonville, it is important to find the appropriate scale of building to fit the local community, and take the influence of local communal organizations into consideration. 

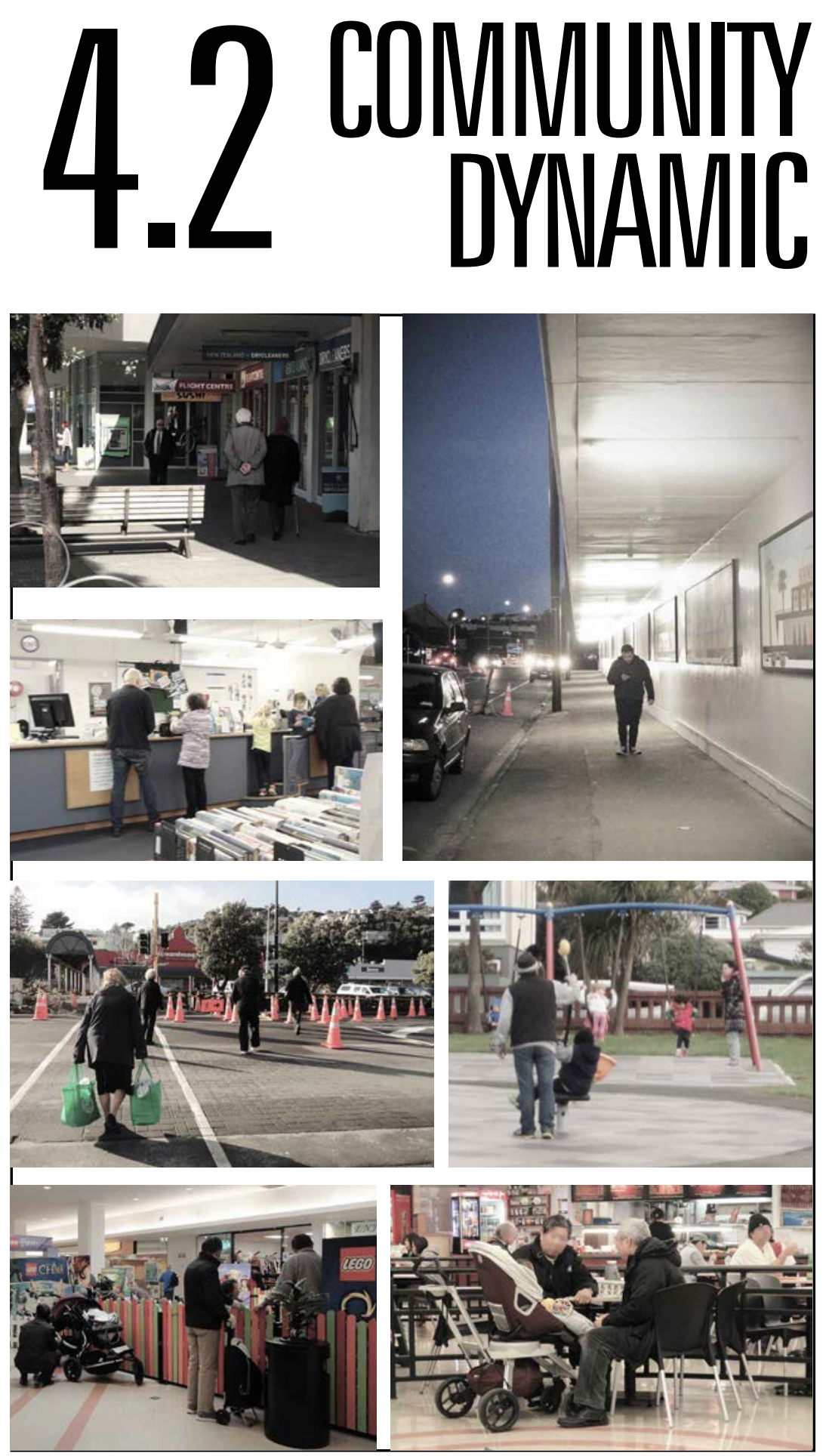

Fig 4.30. Collage of dynamic in the town centre in different time of the day. 
As a public meeting place, it is important to facilitate programmes that resonate with the dynamic of local community. In order to gain a comprehensive understanding of senior's daily life in Johnsonville, a field research was undertaken to investigate the occupancy of different age groups in the town centre.

It is evident in the field research that the elderly is segregated in space and time from other community members (fig 4.31, fig 4.32). To be specific, in terms of space, most of seniors limit their activity space around Johnsonville mall, the library or inside the community centre. Time-wise, they mainly show their appearance from early morning till after lunch on weekdays and slightly later on weekend. It also shows an increase in the number of seniors in town on weekend than weekdays, mostly with their family. It reveals the tendency that the elderly go out more when they can spend time with other community members to socialise, especially through activities that different age members in a family are able to engage.

Fig 4.31. [Opposite page] Dynamic of different age groups in a day (weekday and weekend). 


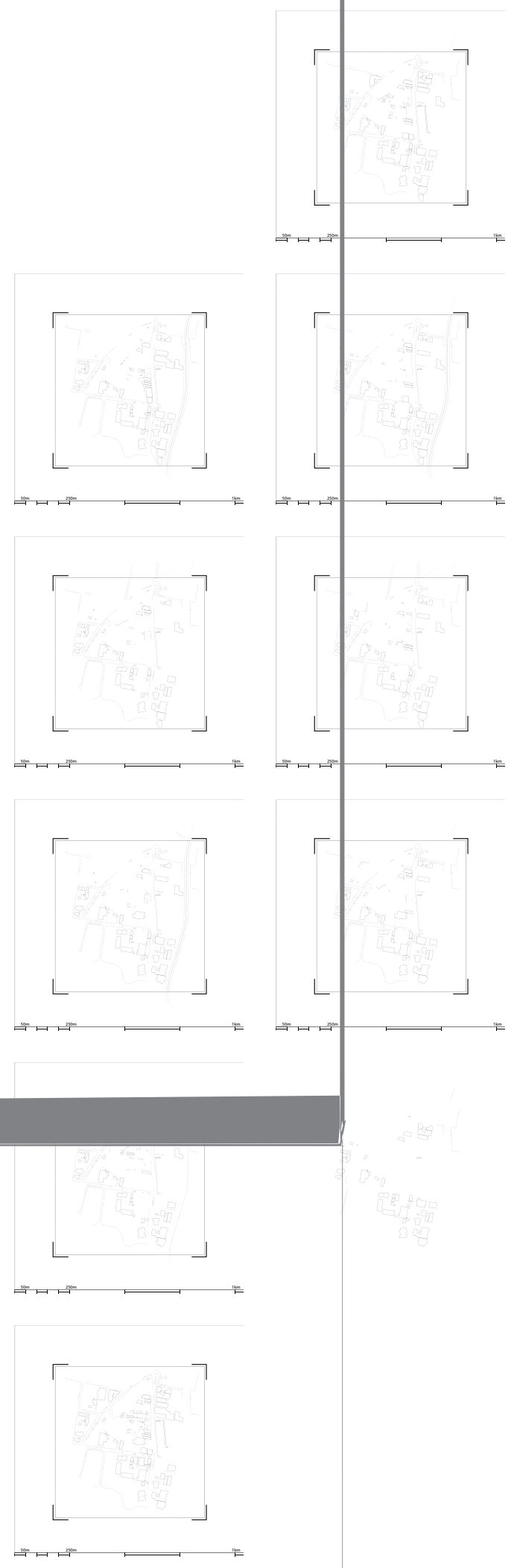




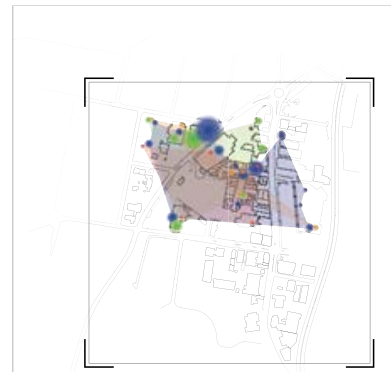

Holiday 10am

Weekdays

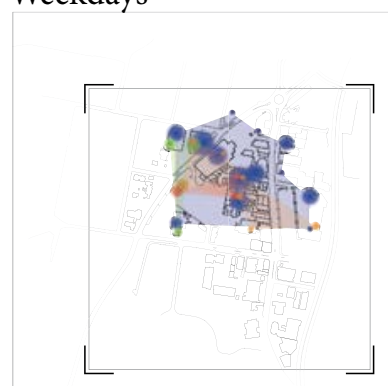

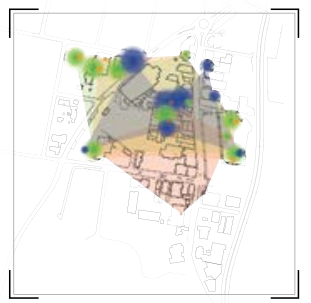

$12 \mathrm{pm}$

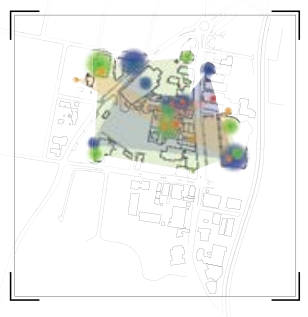

$3 \mathrm{pm}$

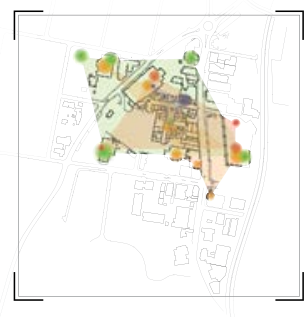

$5 \mathrm{pm}$

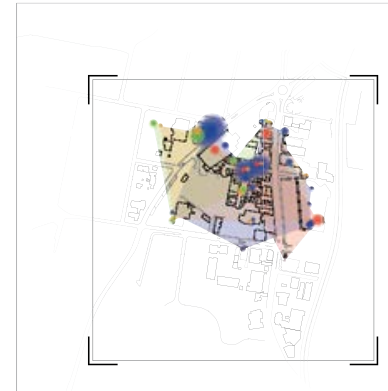

\section{Anchoring community engagement}

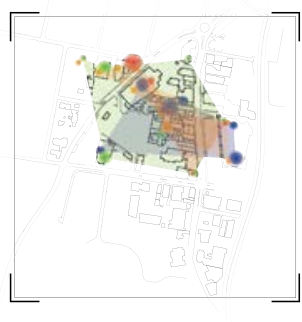

Fig 4.32. P r o j e c t e d demographic dynamic after the anchor project is built throughout a day (weekday and weekend).

From the diagram mapping out activity space of different age groups, it is realized that there is a significant dead zone taking over one third of the triangle at the south-west corner. Considering previous analysis on Johnsonville as a suburb and the town centre, it could be an opportunity to make full use of the critical location of the dead zone. In the proposed incremental plan of the triangle, it is suggested that there is huge potential of the triangle to be developed into a pedestrian precinct with malls and amenities where seniors can enjoy a vibrant community life even in a vehicle-orientated suburban. 

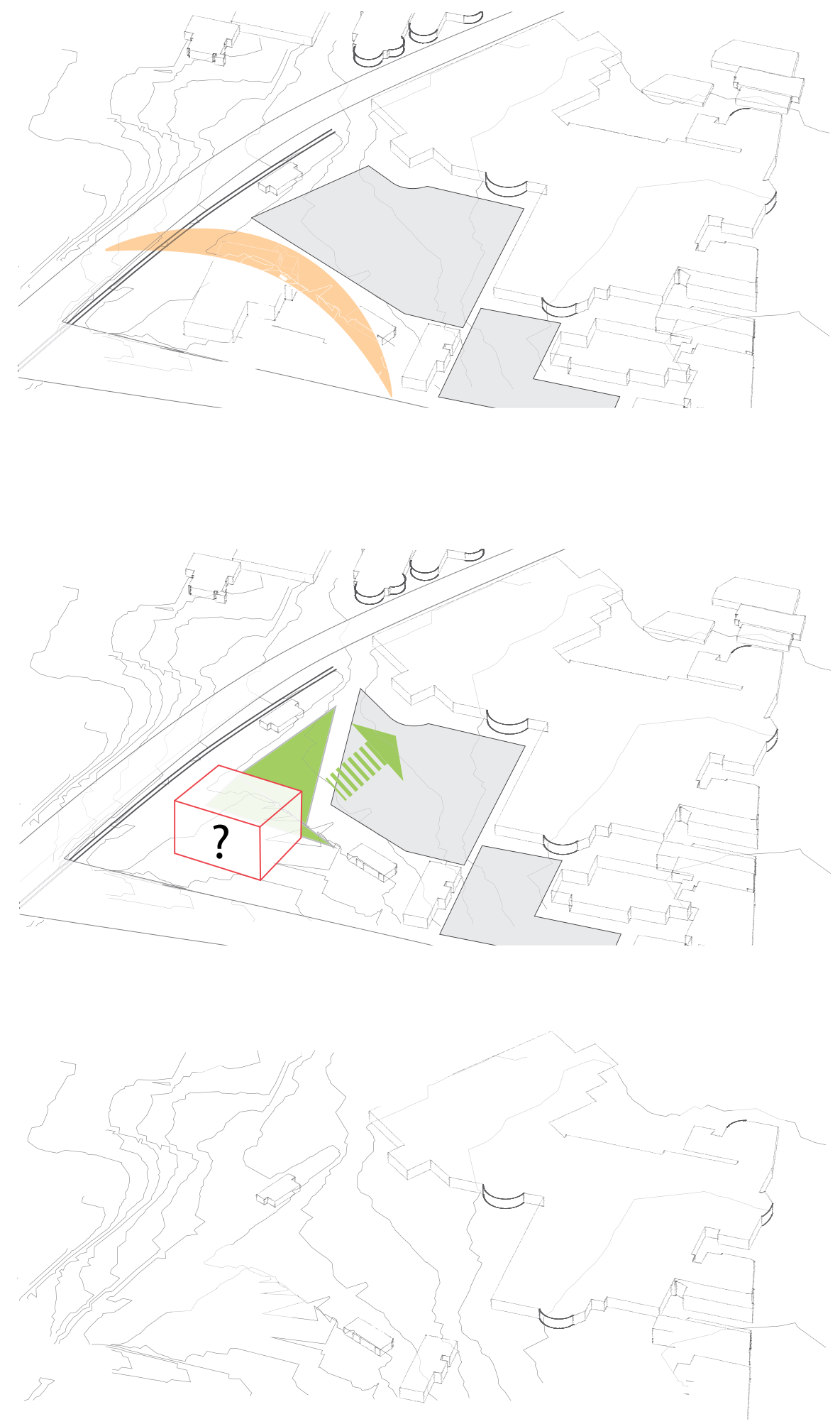

Fig 4.33. Diagramsofcurrent condition and vision of the triangle revitalization. 


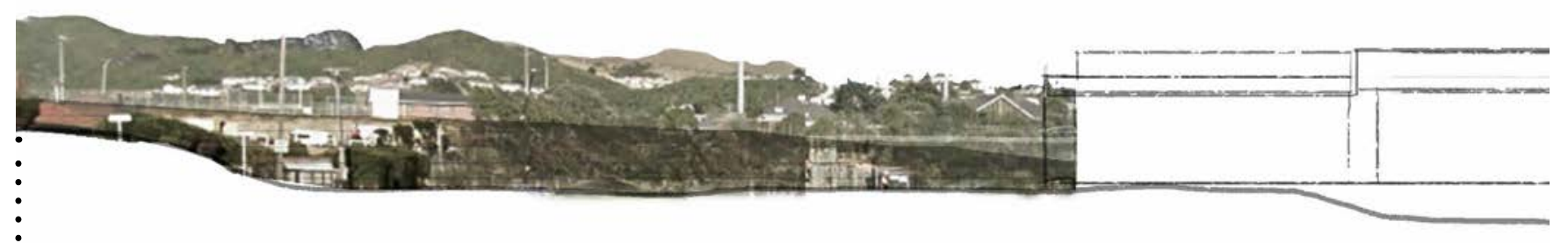

Fig 4.34. [Across spread] Section from Broderick Road to the Mall. The significant drop of the site determined its disconnection from the triangle.

Fig 4.35. [Bottom] Aerial view of the chosen site and section reference.

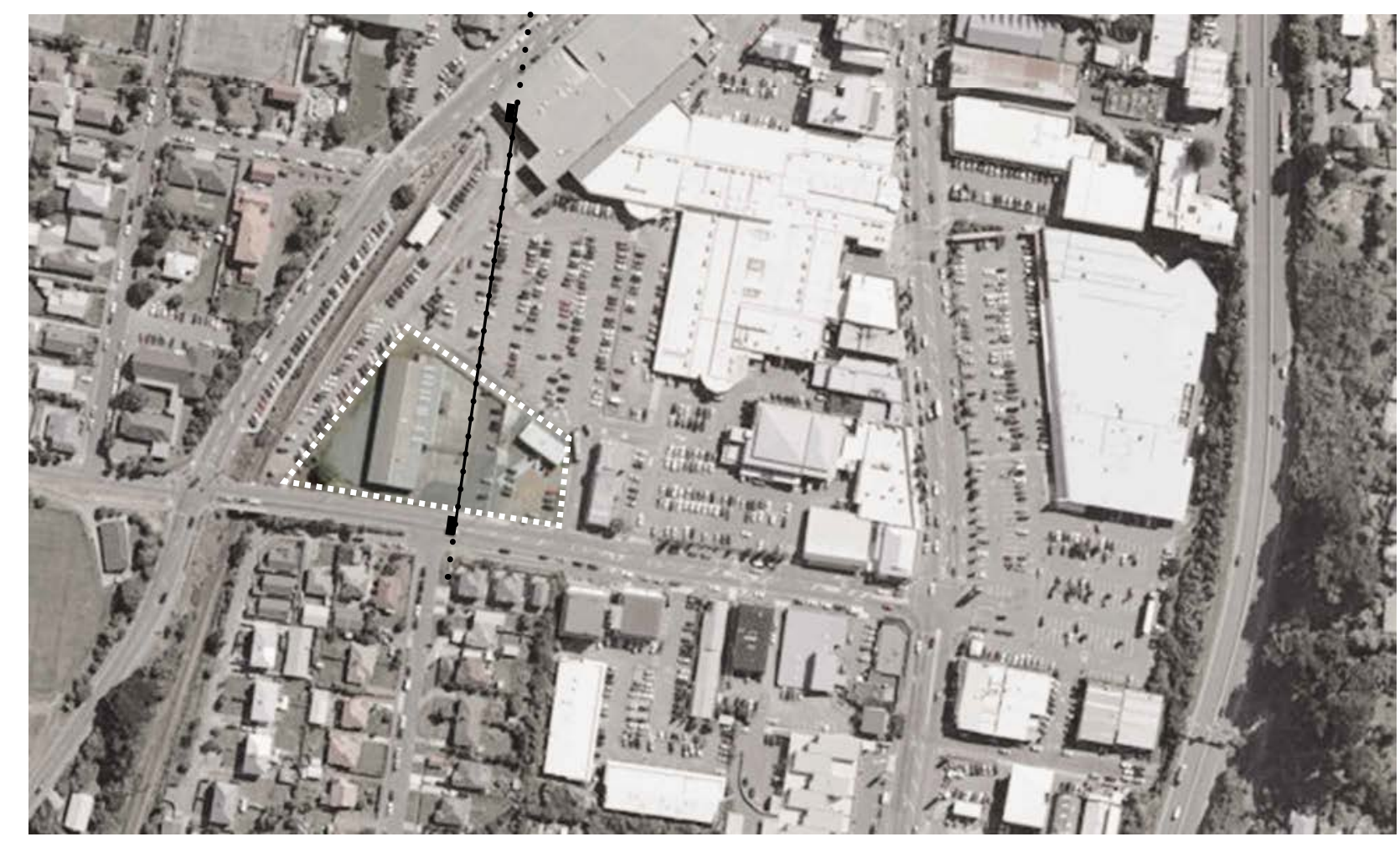




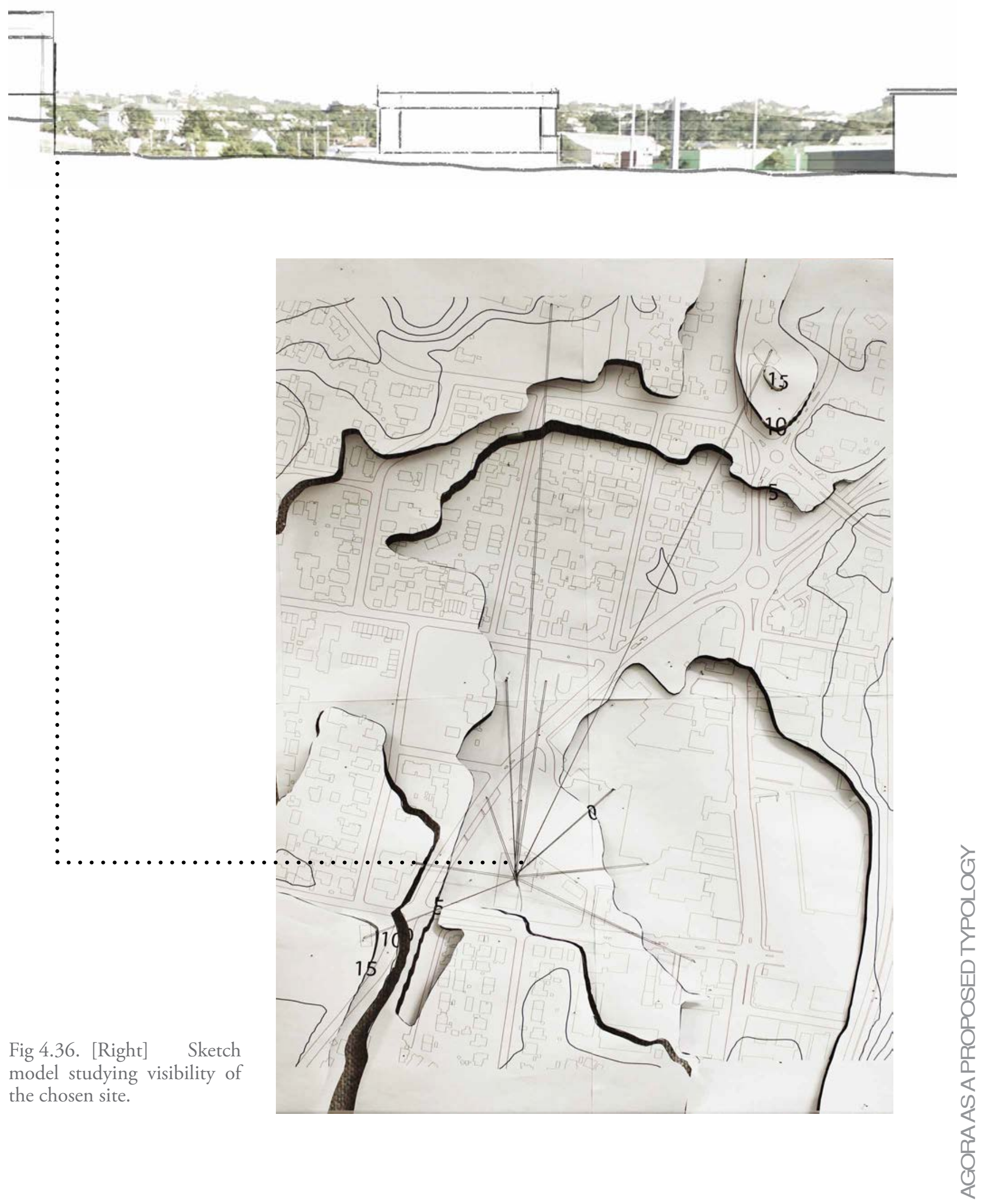



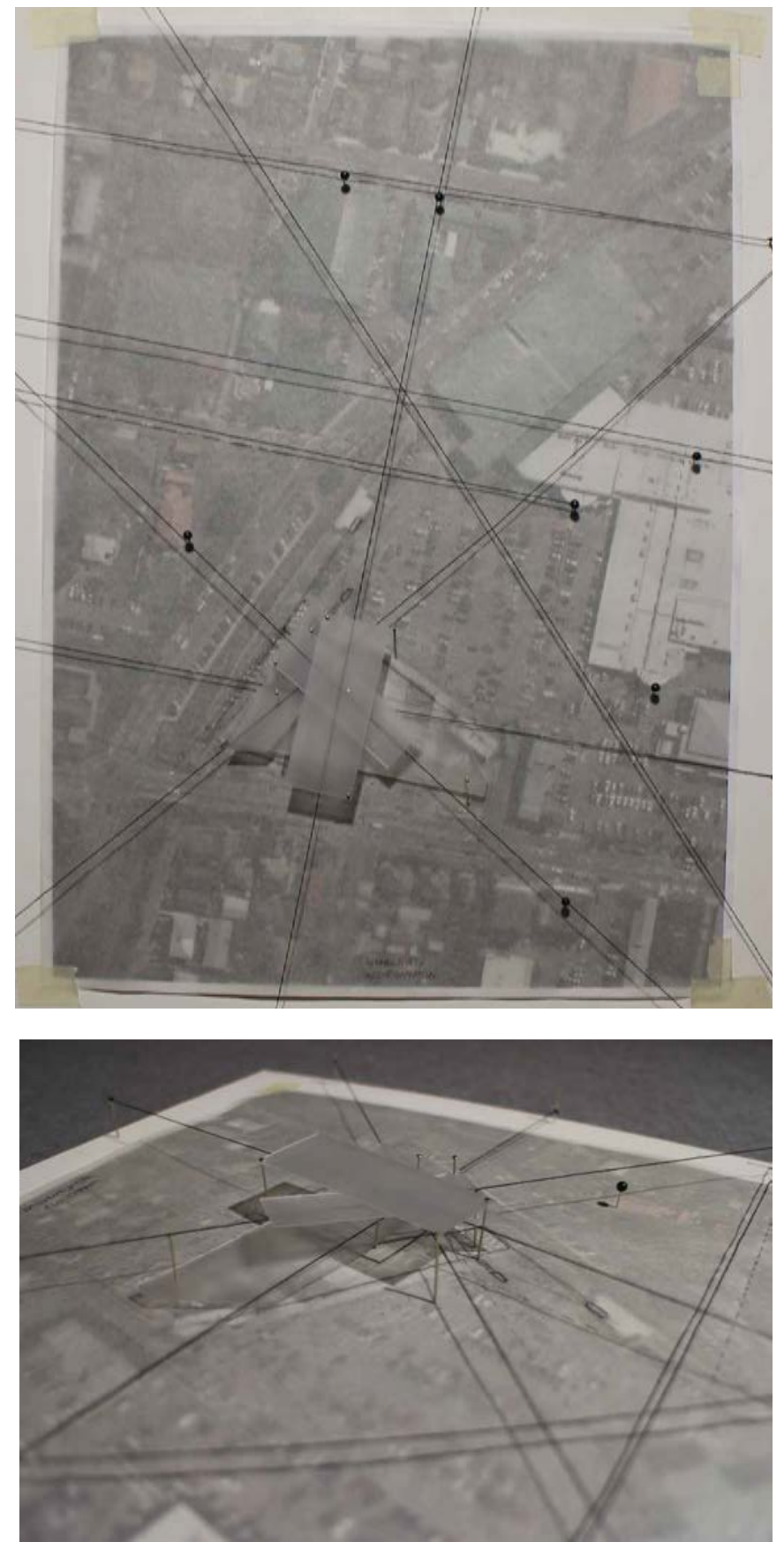

Fig 4.37. Photosofmodelling revealing the underlying visibility axis of the site. 
From the study of the dynamic of local demographic, it is discovered that there is need to revitalise the central triangle to allow people with varied mobility to be able to enjoy public life. The southwest corner is identified as the anchor point to further open up the triangle to Broderick Road. Based on the study of the chosen site, the architecture challenge becomes to create connection across the level difference.

As it is such a critical point for establishing connection, it is crucial that the anchor project to be proposed has great potential to draw in everyone in the community to realize such connection. 


\section{3organIZATION}

\section{Proposed programmes}

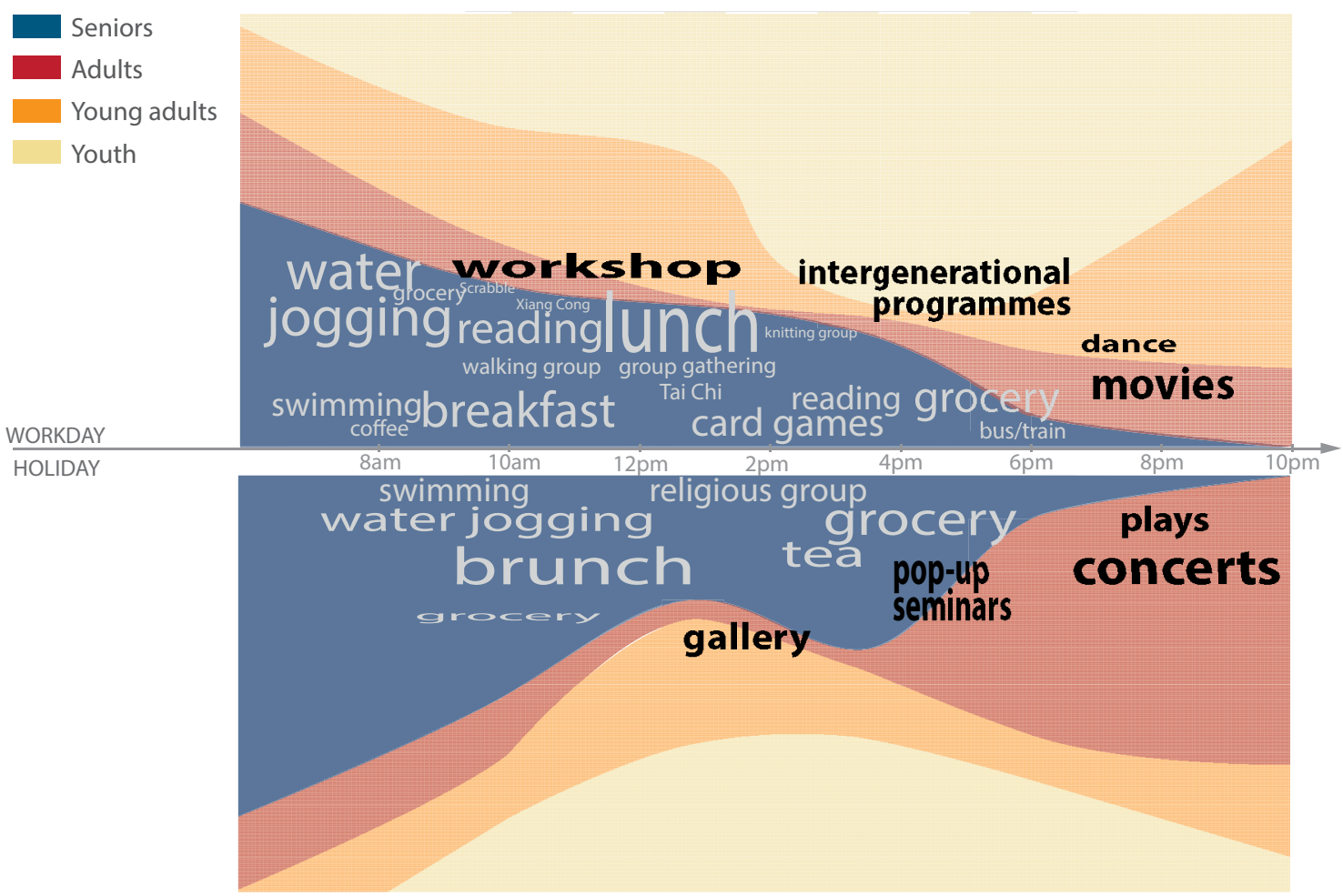

Fig 4.38. Diagram of study on seniors' activities throughout a day in Johnsonville.

Community gallery: Johnsonville has a rich culture in art and craft according to the observation in field studies and conversations with the locals. The provision of a gallery resonates with such character of the Johnsonville and amplifies its influence to the wider region by creating a safe and cultural environment for all members in the community to spend time at leisure and socialise. 
Amphitheatre: The amphitheatre anchors a community focal point in the town centre as. The provision of large civic events has great potential to reestablish the role of Johnsonville as a suburban culture hub. It is considered essential to counter balance the declining attraction as shopping destination due to new developments in nearby suburbs. The amphitheatre also makes it possible to organise a variety of community activities throughout the day, which everyone in the community, from young kids to seniors, is able to engage.

Intergenerational learning centre: The elderly are important members of the community. Their knowledge and experience is valuable and should be made available for others to learn from. The provision of an international learning centre not only makes it possible for senior to continue contributing to the community, but creates opportunity for others to learn from senior's experience. It can also be the case while the younger ones teach the elderly about latest technologies and get experience from the process of teaching. The intergenerational learning centre is designed to facilitate this kind of intergenerational knowledge exchange which is lacking in the current suburban centre. 
Planning

4 TO SERVE A COMMUNITY OF 7000 INHABITANTS

(as Johnsonville )

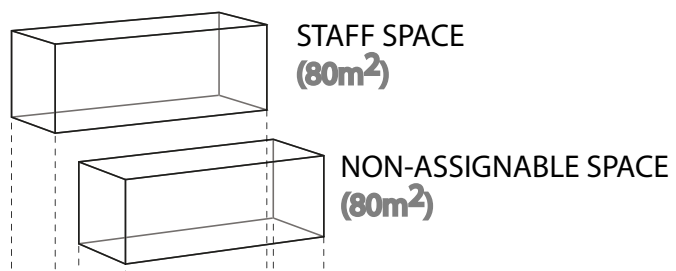

ELECTRONIC WORKING STATION

$\left(40 \mathrm{~m}^{2}\right)$

MEETING ROOMS

$\left(60 m^{2}\right)$

\section{USER SEATING SPACE}

$\left(\sim 120 m^{2}\right)$

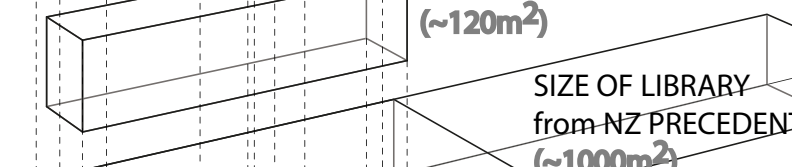
from NZ PRECEDENTS

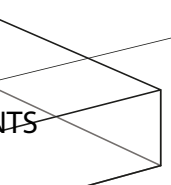

IZE OF LIBRAR̈Y

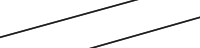
in FLATUNESCO GUIDELINES
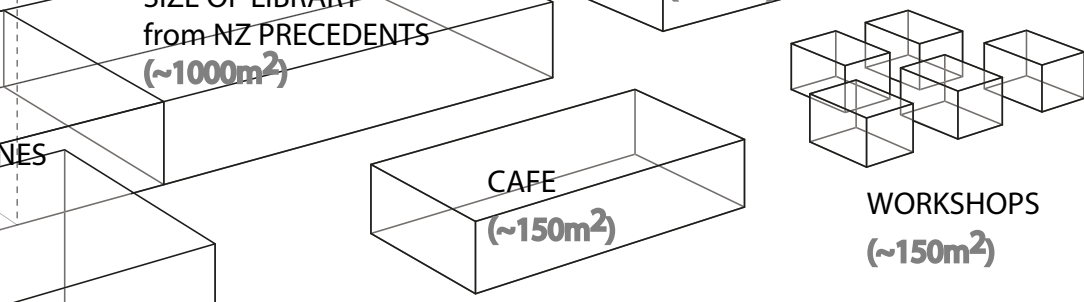

WORKSHOPS

$\left(\sim 150 \mathrm{~m}^{2}\right)$

Fig 4.39. Study of area needed for primary programmes. 
Fig 4.40. Diagrams of exploration of creating the sense of connectedness through viewing relationships.

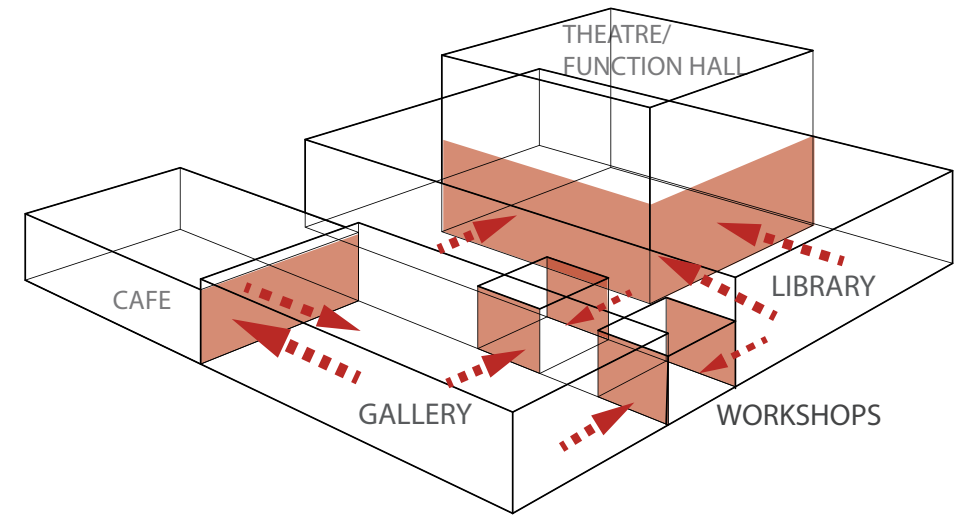

a). Viewing relationships between programme masses are established to create a sense of connectedness through visual focus.

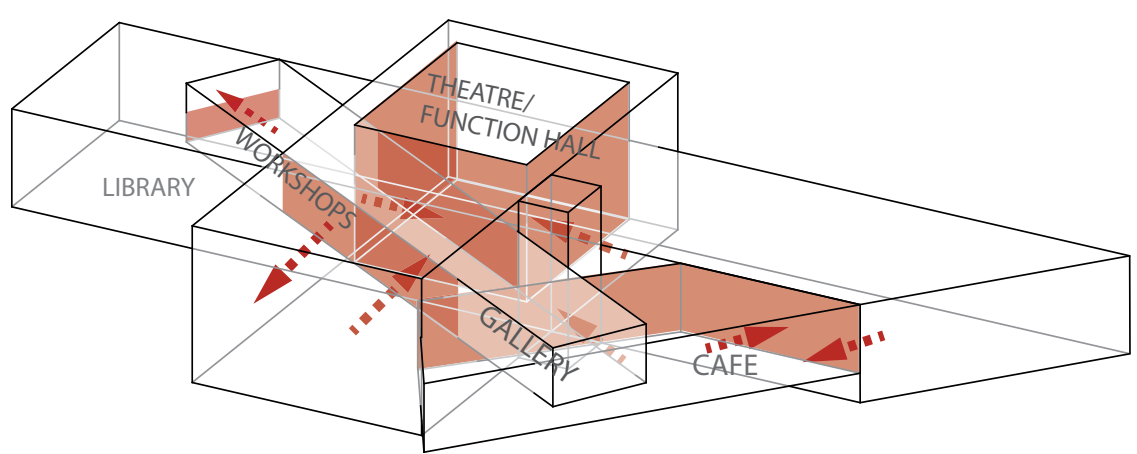

b). Masses are shuffled to respond to the site and level difference is introduced into the variations of visual connections.

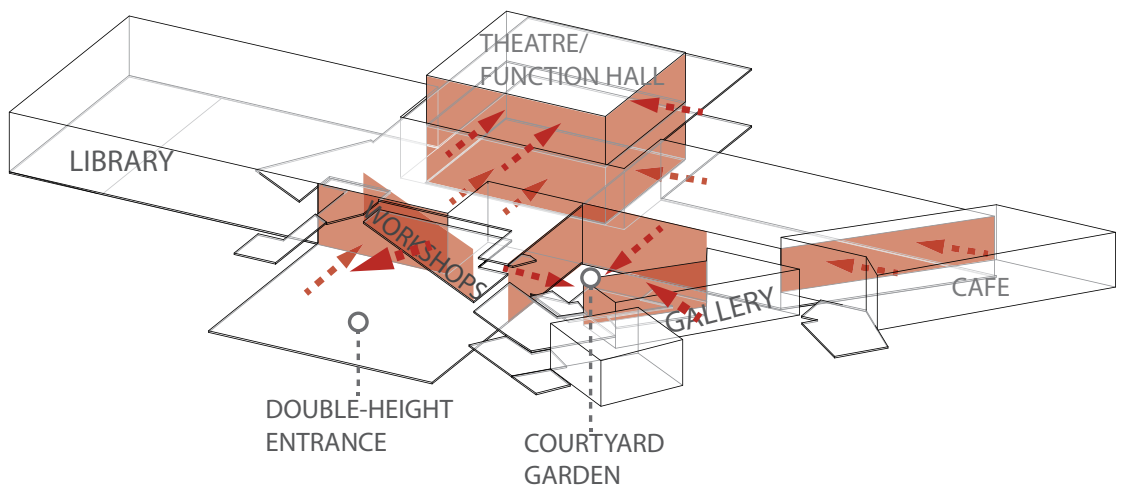

c). Level changes are further detailed and a double-height entrance and small courtyard garden are introduced to create a variety of visibility through spaces. 


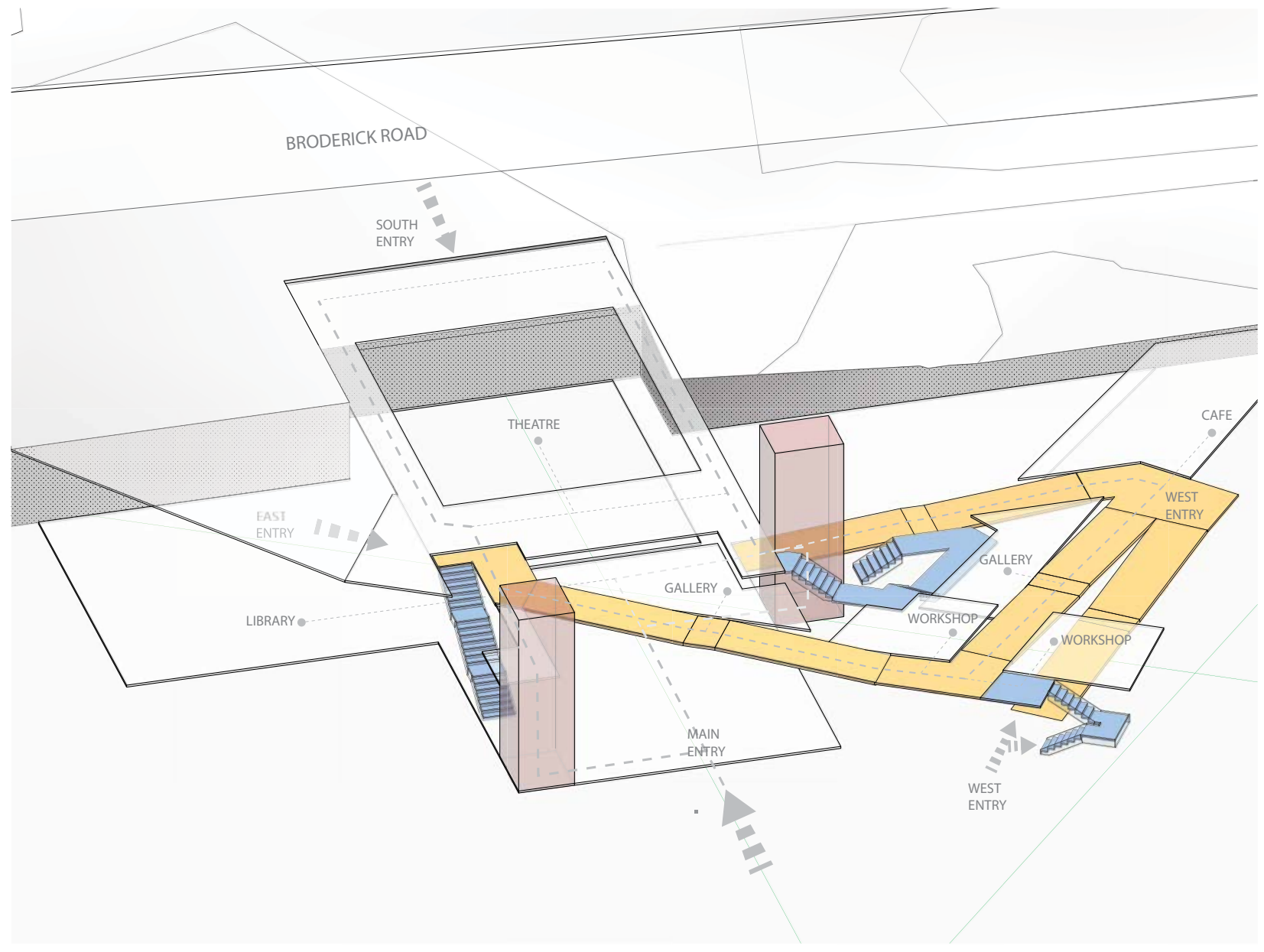

To enable users with diverse mobility to easily move around the agora, there are ramps, stairs and lifts are distributed in the agora. Different programmes are located along the circulation route, accessed from platforms

Fig 4.41. Diagram showing circulation options for people with different mobility and its relation to different programmes.

branched out on varied levels. It creates not only rest points for seniors or others with lower physical competent, but also opportunities for interactions between people on the path and from different programmes. 
Fig 4.42. Plans of each resting platform showing access to them and relation to nearby programmes.
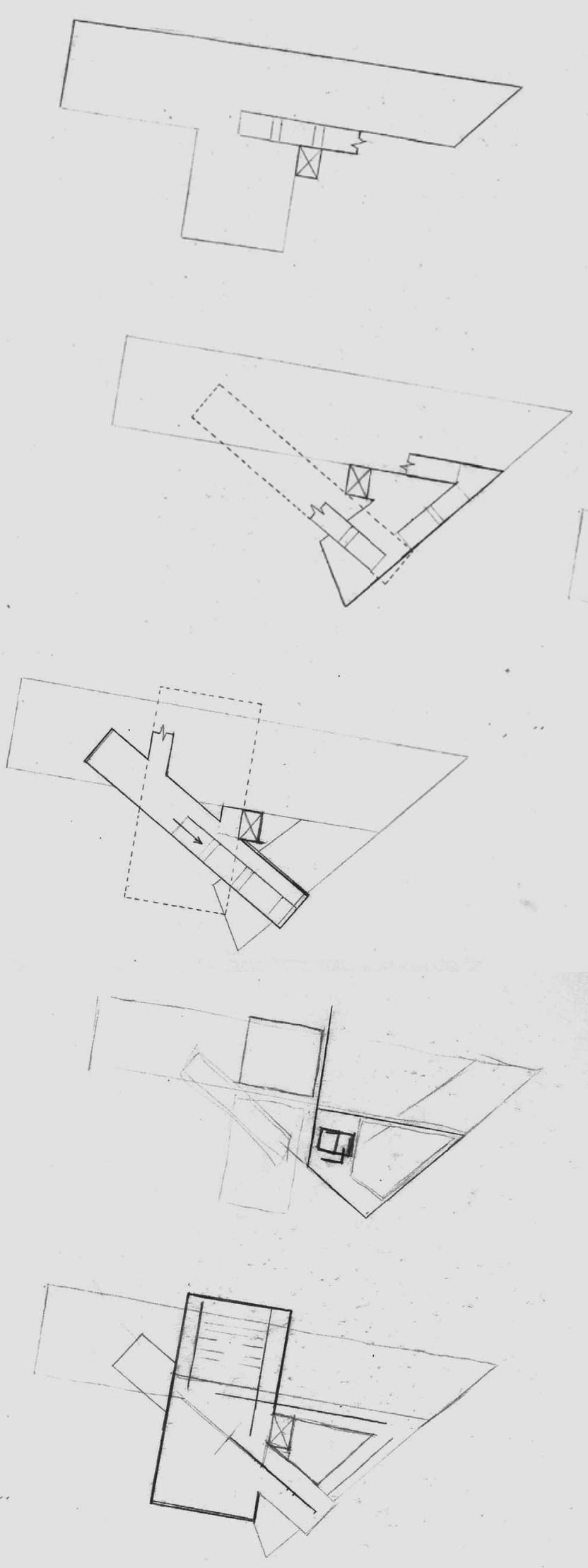
Fig 4.43. Plans of initial concept of the agora showing the organization of programmes and circulation.
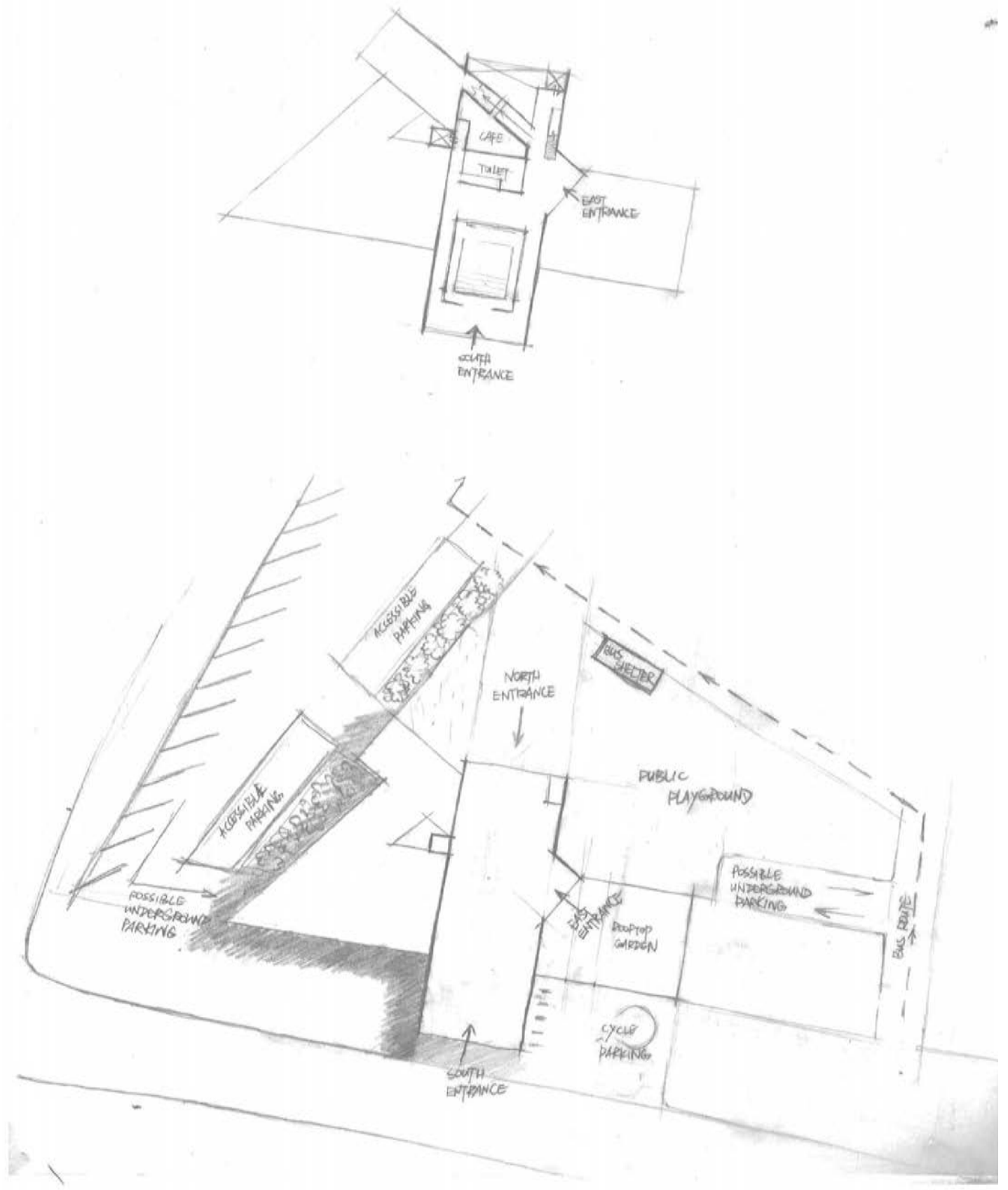


\section{REFLECTION}

The idea of promenade and accessibility of the circulation is coming through the planning exercise. However, the contradicition between the transparency brought by visual connection and the winding of the ramp is raised to cause potential confusions for users. Additionally, the lack of hierarchy of circulation options may still cause segregation between different mobility groups.

To respond to these concerns, it is essential to further study the role of circulation in guiding visitor through the promenade experience through the agora while considering issues of accessibility in architecture. 


\section{Ageing}

2.1 Validity of Problem

2.2 Autonomy \& Connectedness

Mindset

Environmentle Gerontology

Elderly in Public Spaces

Dilemmas

Case studies:

Shopping Mall

Senior Centre

Universal Design

Case studies

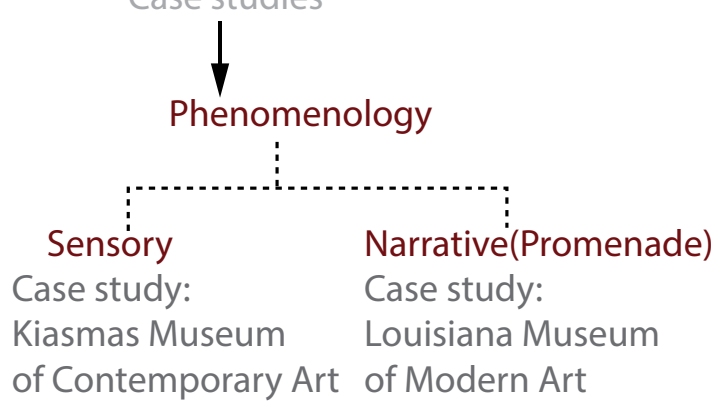

\section{Johnsonville}

3.1 The Suburbia

Situating ageing in context

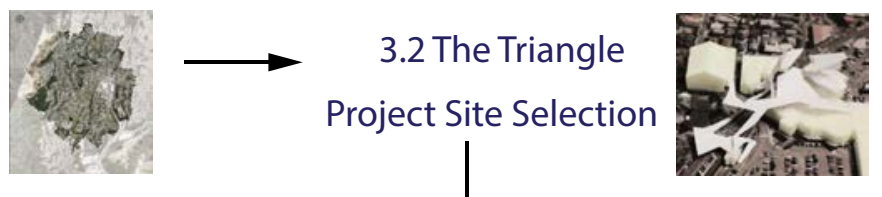

Agora

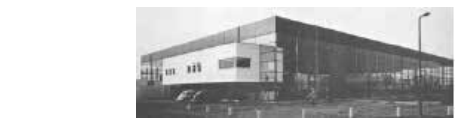

4.1 Agora Case study:

Typology Proposal The Agora of Dronten

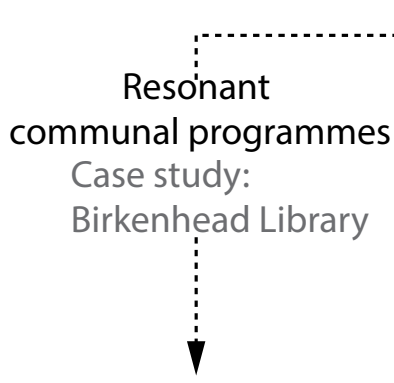

4.2 Community Dynamic

Programmes Proposal
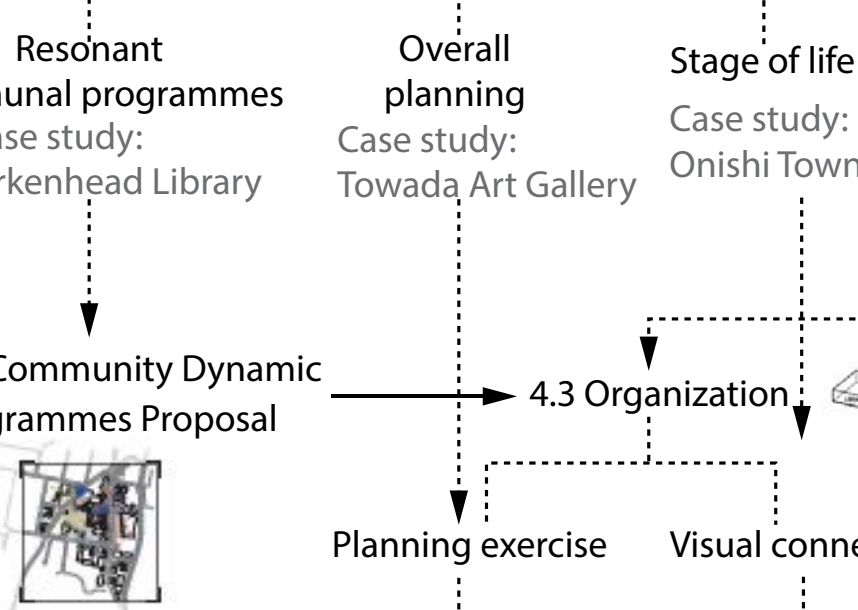

Case study:

Case study:

Onishi Town Hall

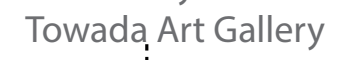

Towada, Art Gallery

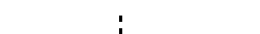

\section{Wander of Life}

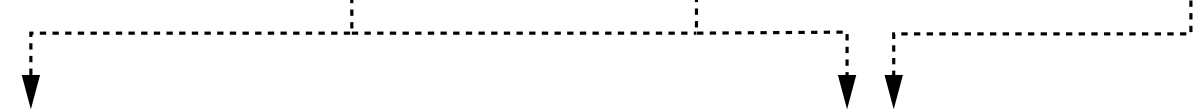

5.1 Formal development

5.2 Phenomenology Turn from circulation to promenade spatial experience to inform design
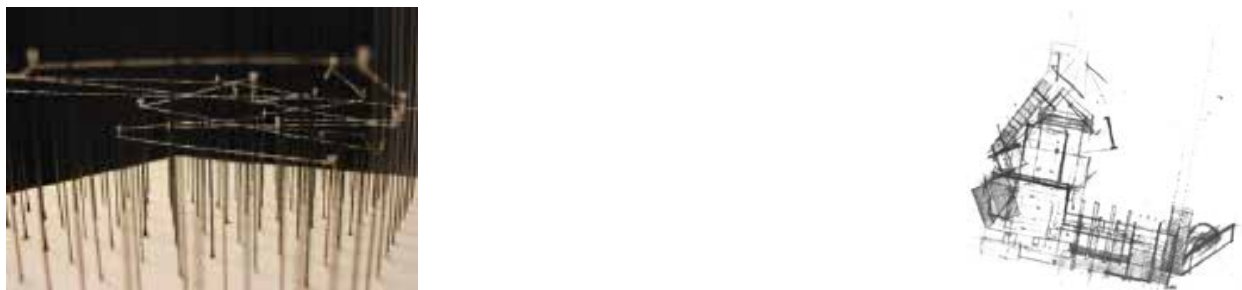
\ulcorner

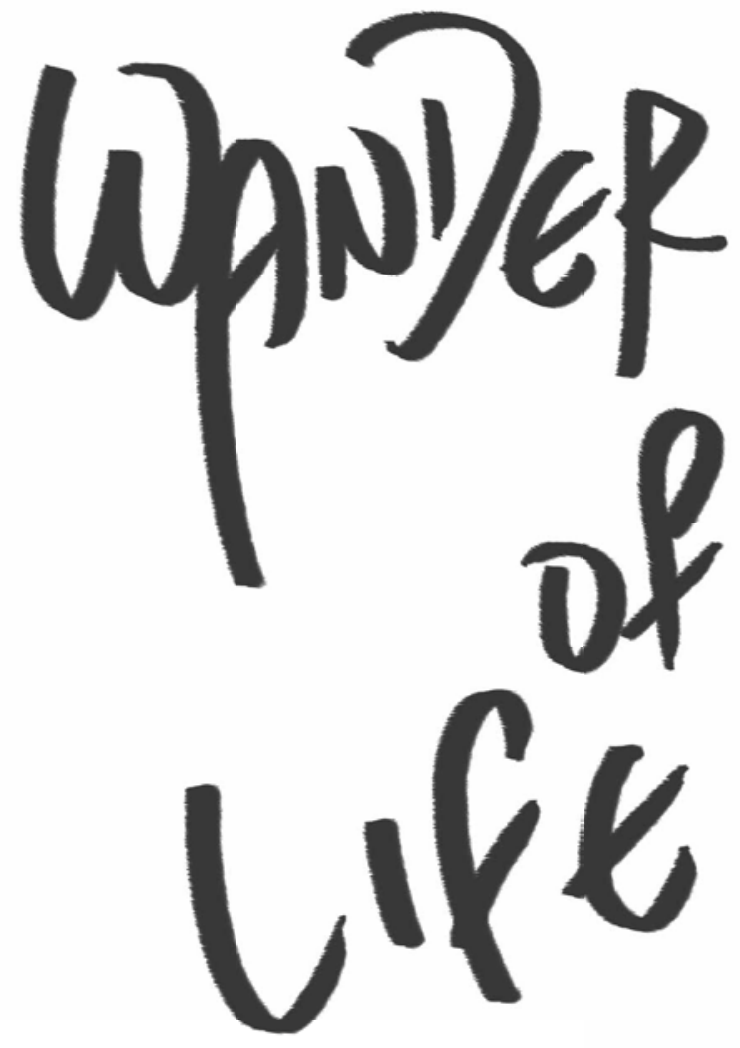

\lrcorner 


\section{FORMAL DEVELOPMNENT}

\section{Starting from Mobility}

Mobility is one of the hinges for seniors to stay active in public space. Mobility is not only the basic requirement for one to physically interact with other people outside home, but also a significant mean to experience spaces around them. According to Professor Cross, "Seamon has eloquently described place attachments developing through the process of body-ballet, moving the body through space and time, and simultaneously using language to make meaning out of our sensory experiences"(494).

Responding to prior reflection, a continuous ramp is prioritized. Such provision of shared circulation route allows interaction among people with different mobility. To connect Broderick Road and Johnsonville Mall with a significant height difference, and keeping the ramp as gradual as possible for the ease to walk on, how to accommodate the length of the ramp within the agora and make it effortless to use become a major design challenge. 


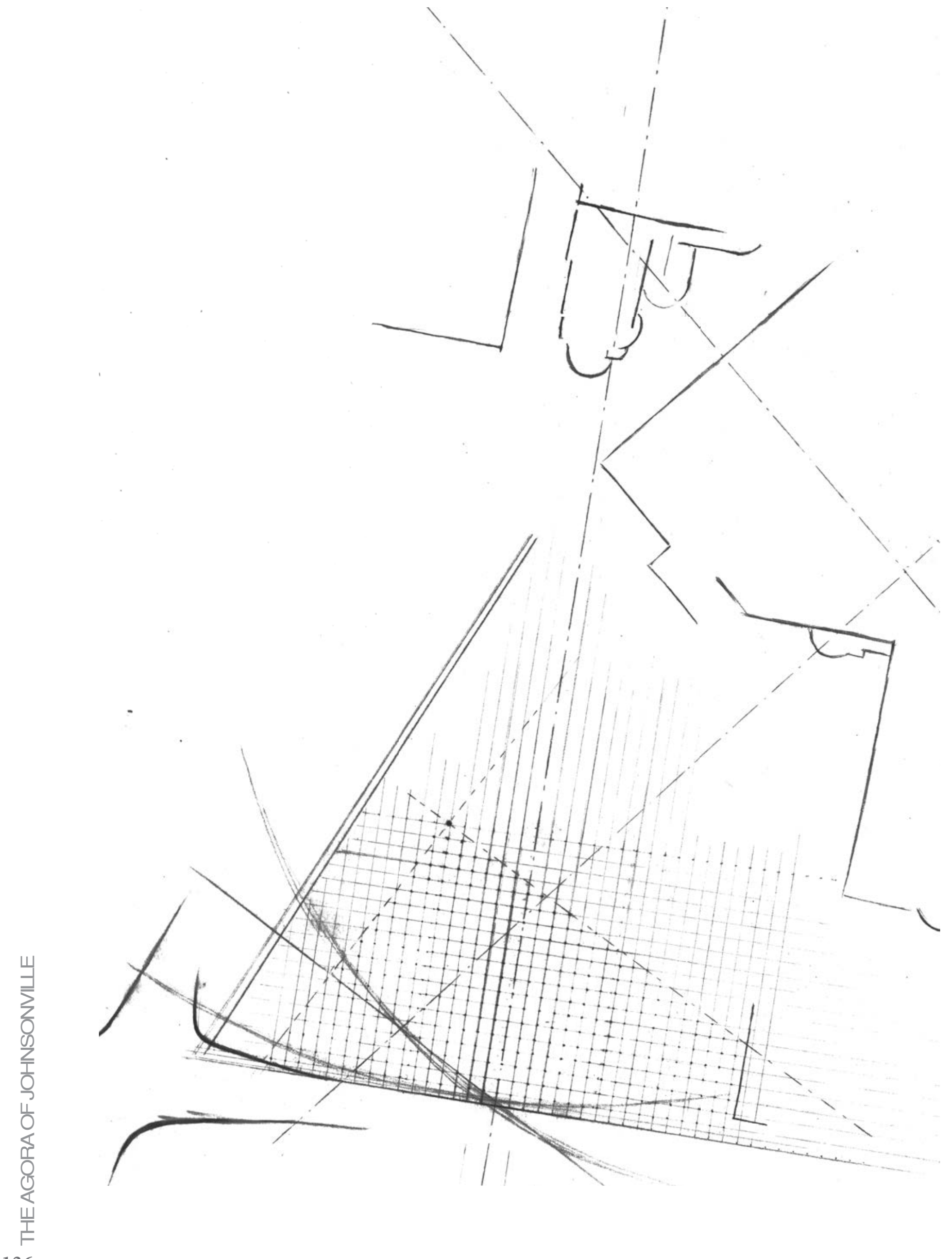


To explore the design opportunities, following the underlying axis revealed in previous sketch models, a set of grids are set up as guides. Strings are used on these guides as a tool to experiment different circulation options to connect different programmes with a minimum length requirement.
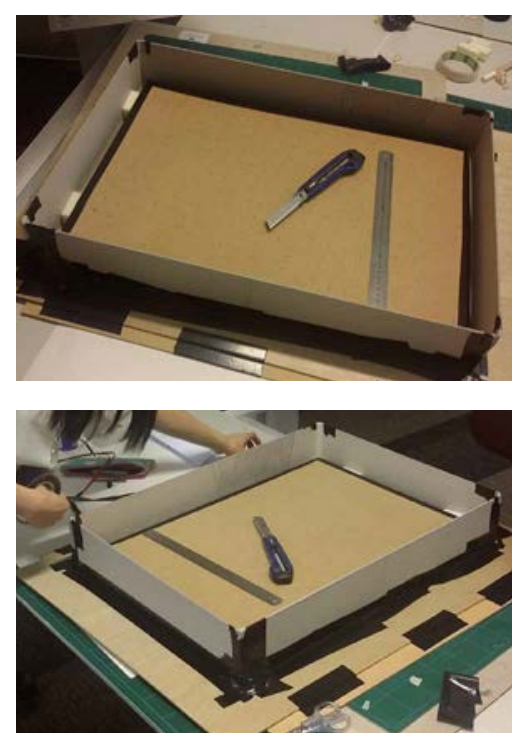

Fig 5.44. [Opposite]Drawing interpreting site condition and establishing a set of grids as location guides.

Fig 5.45. [Right]Photosofthe process of constructing the tool for design experiments.
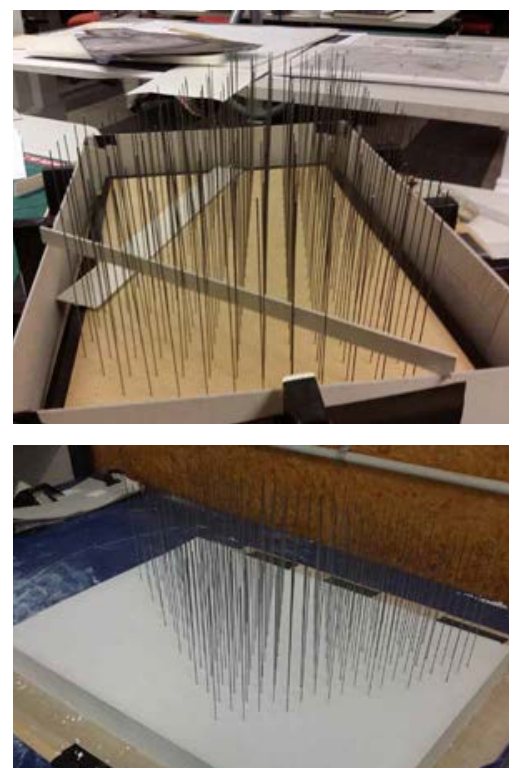


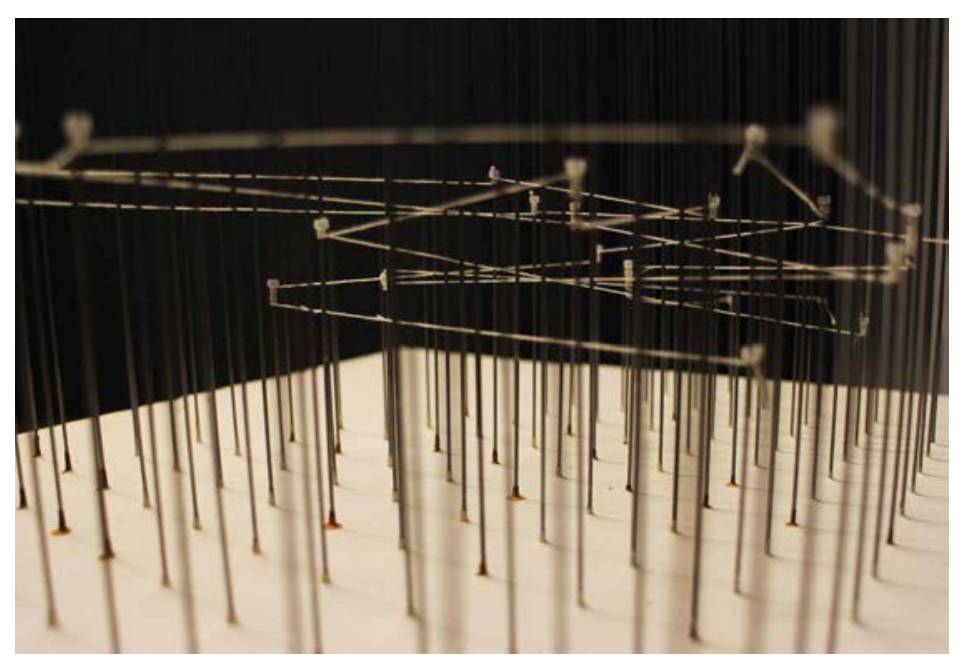

Fig 5.46. Using the model as an interactive design tool to test circulation options with considerations of level difference, context and programmes.
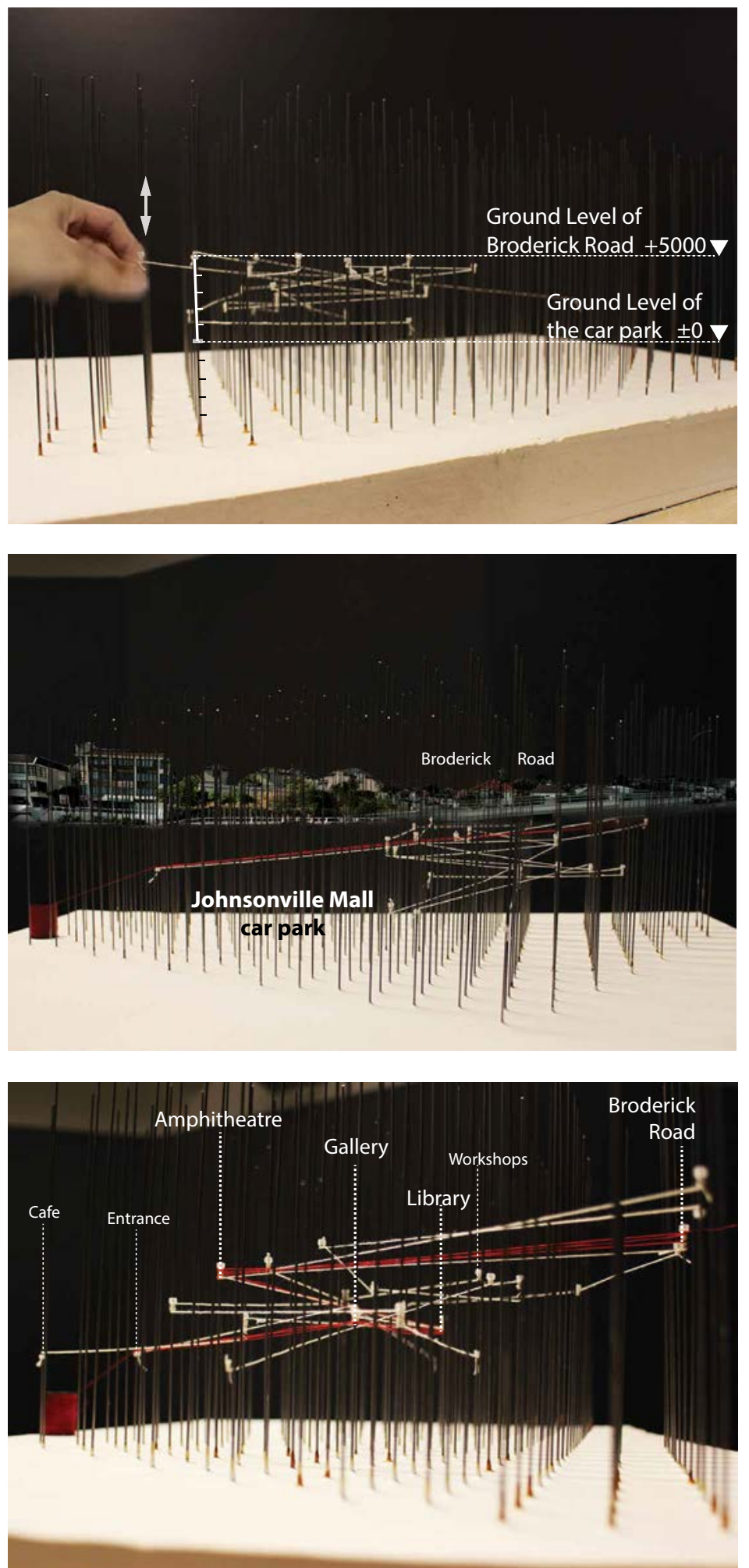

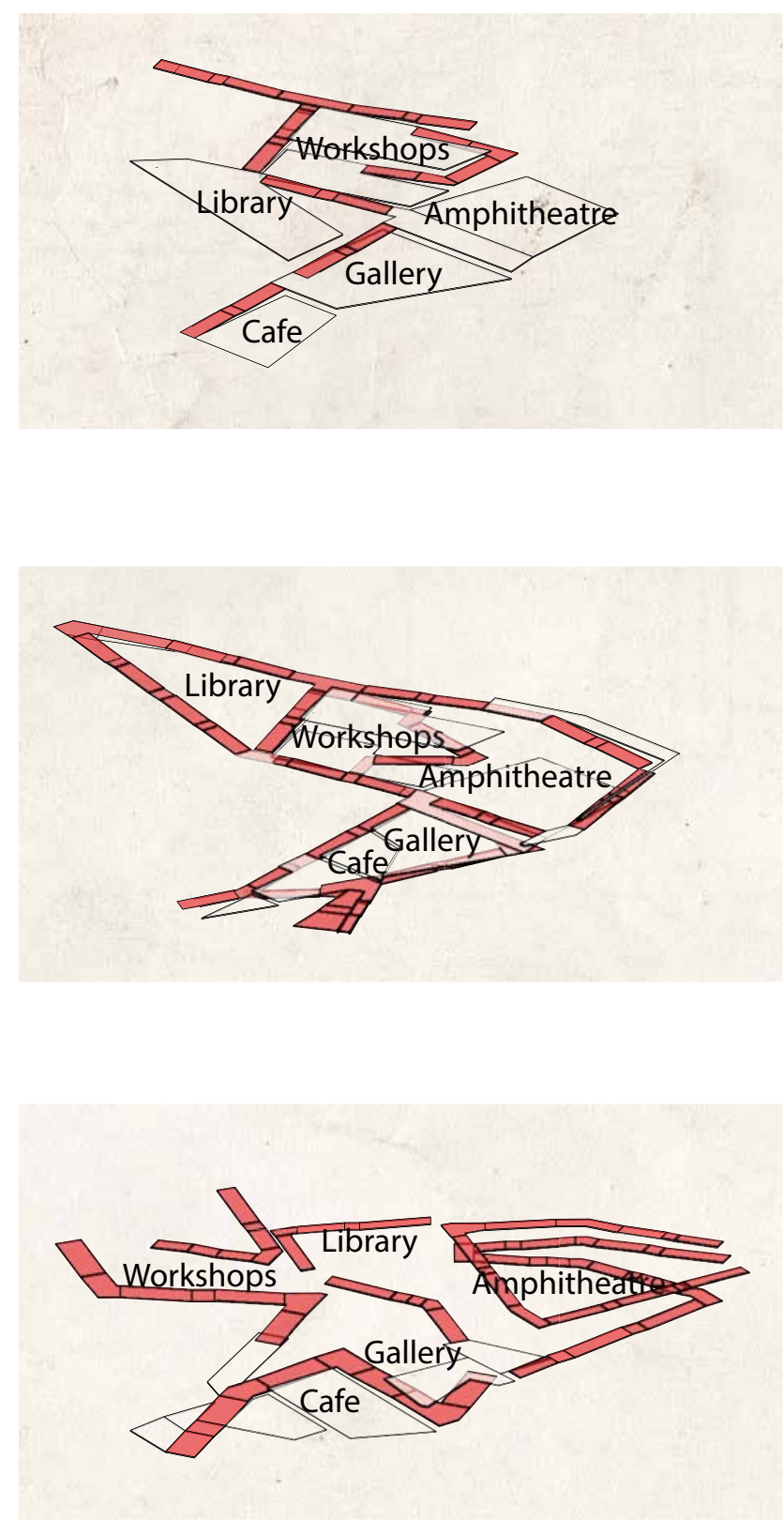

Fig 5.47. Iterations of ramp configuration generated from the model.

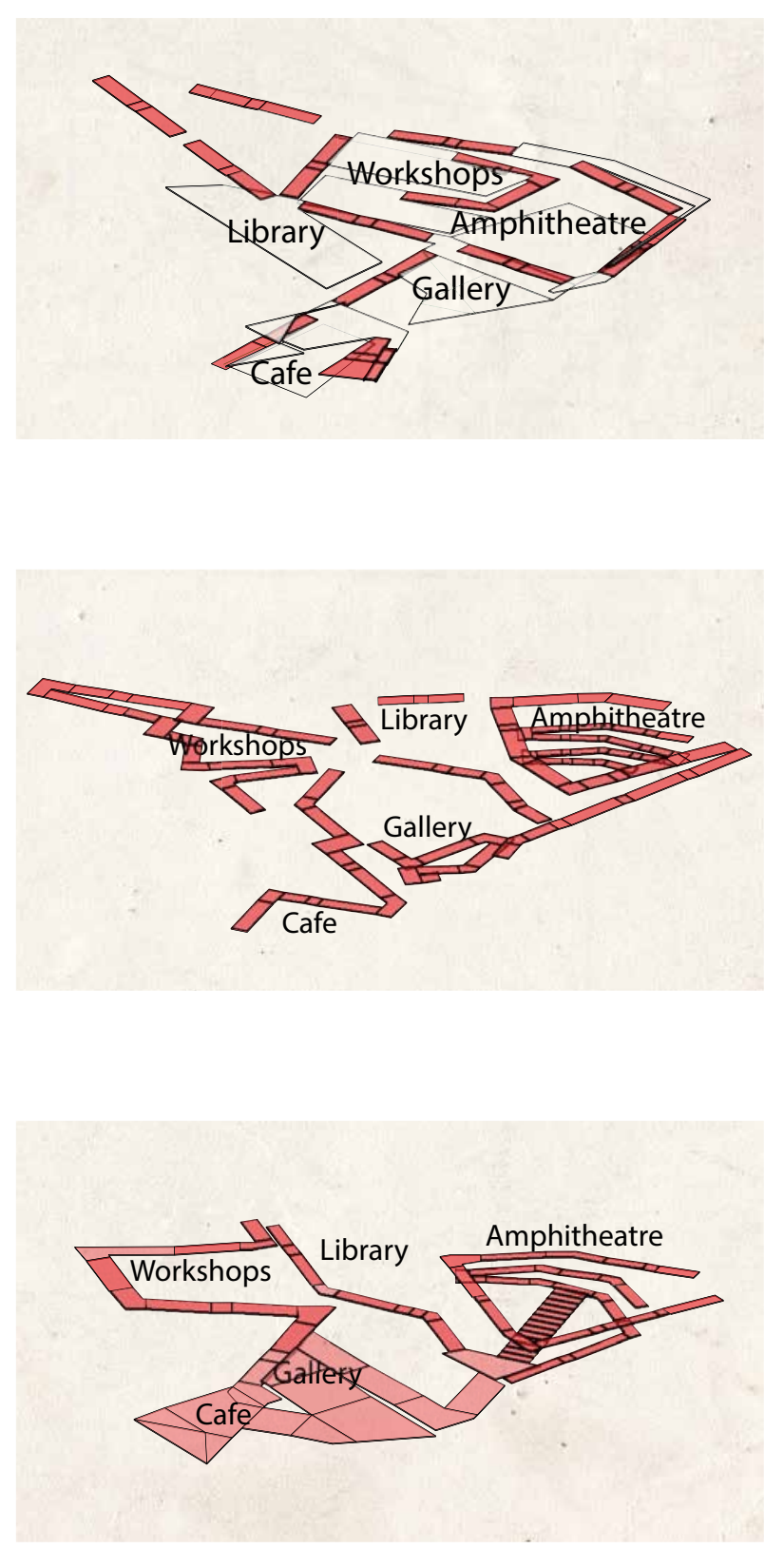




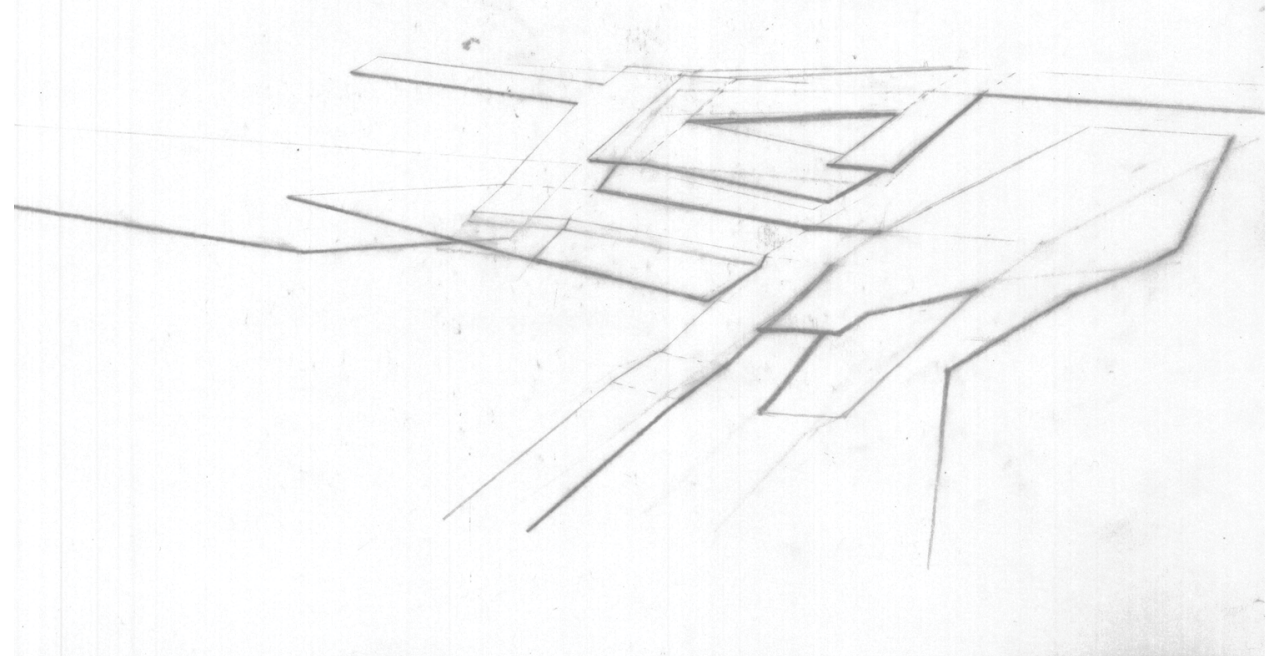

Fig 5.48. One of the sketches of floor plane developed from ramp configuration iterations.

Fig 5.49. Developed floor plane with consideration of programmes. The agora is under one great roof in the sense that all programmes are connected by sheltered path, and yet separated for practicality.

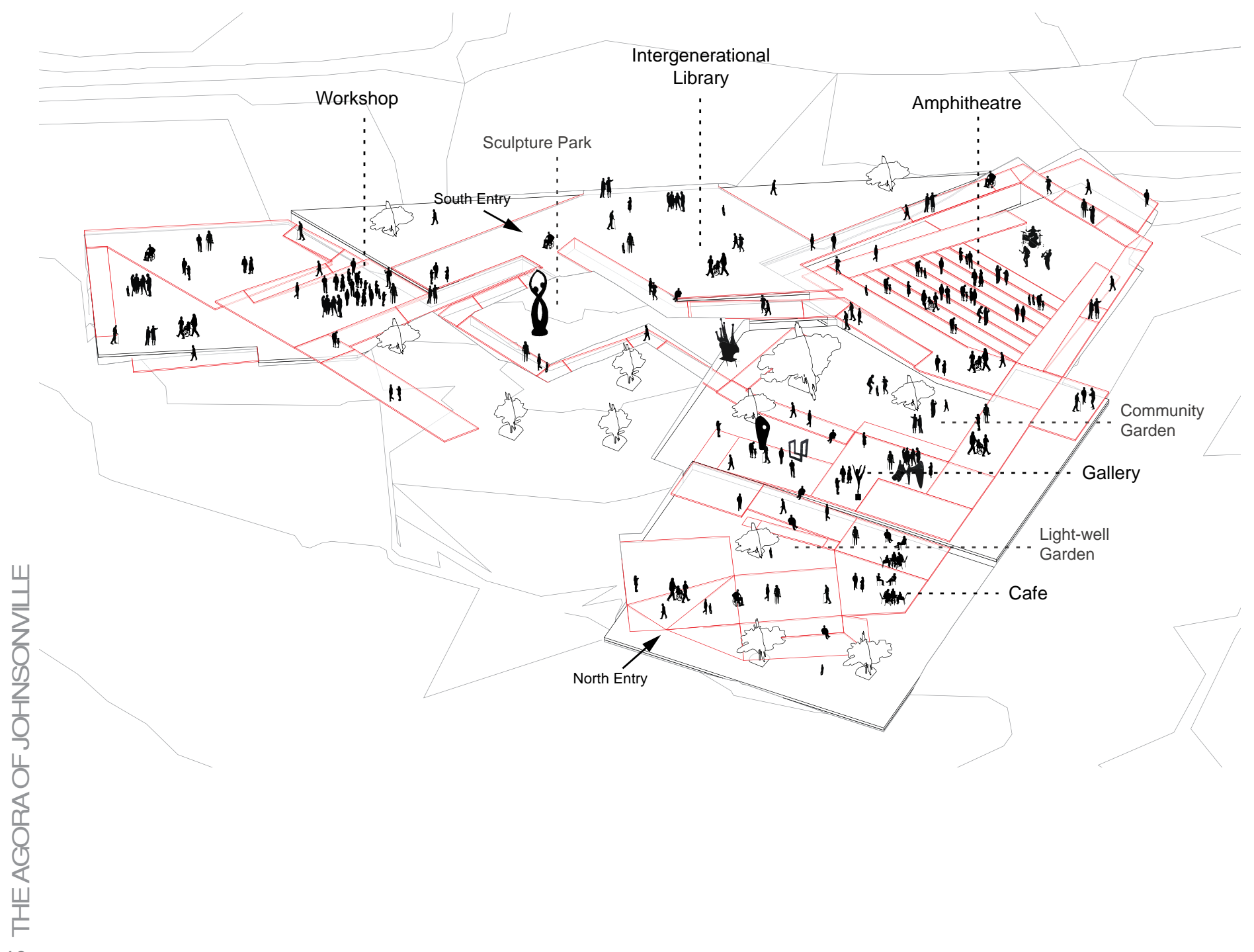


Fig 5.50. [Continued to next page] Sketches of the process of formal explorations. Based on the circulation option tested with the model, geometry is extracted from the model to inform the spaces along the promenade.
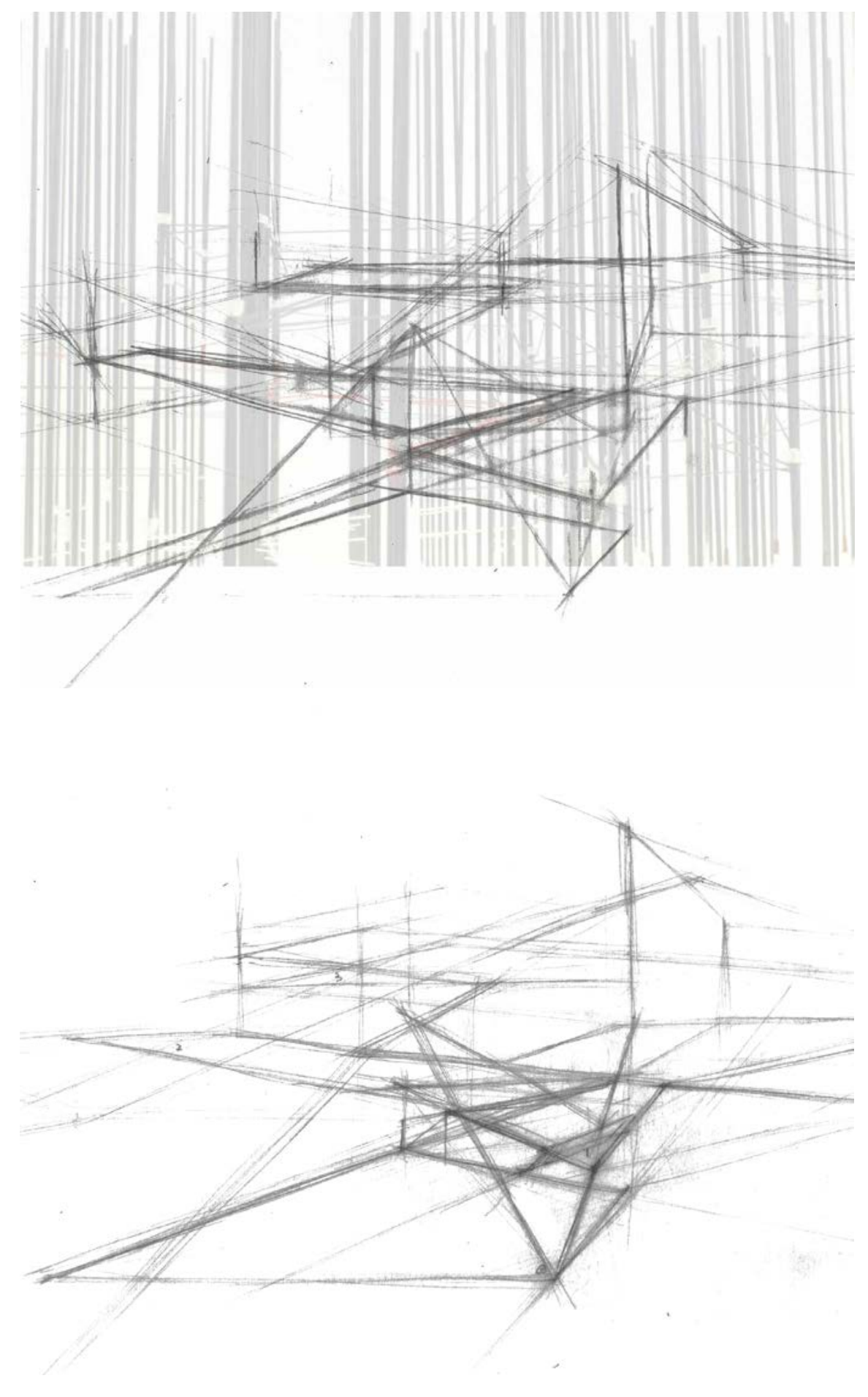

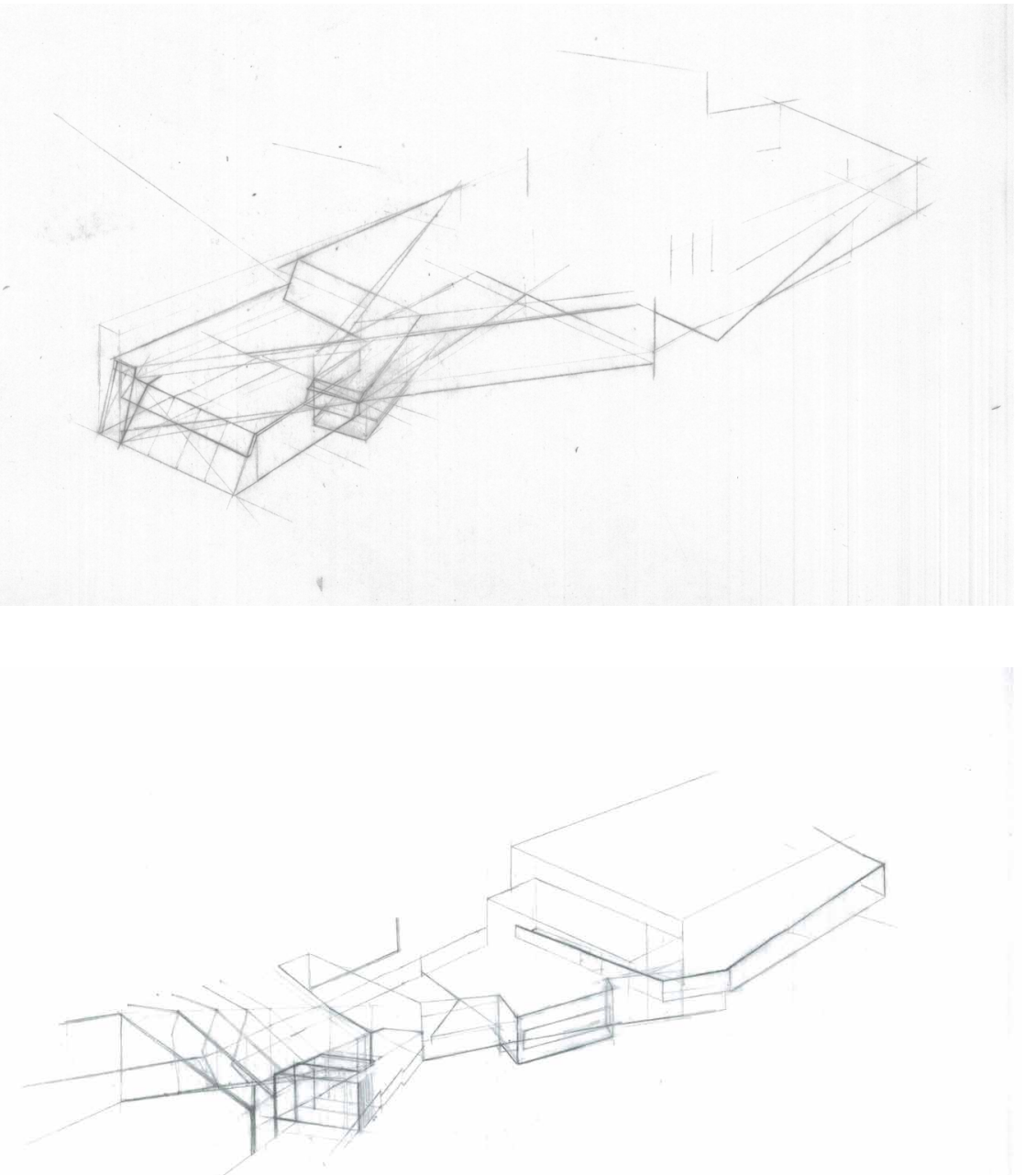

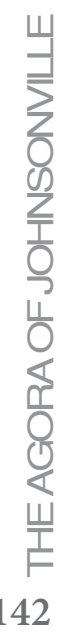

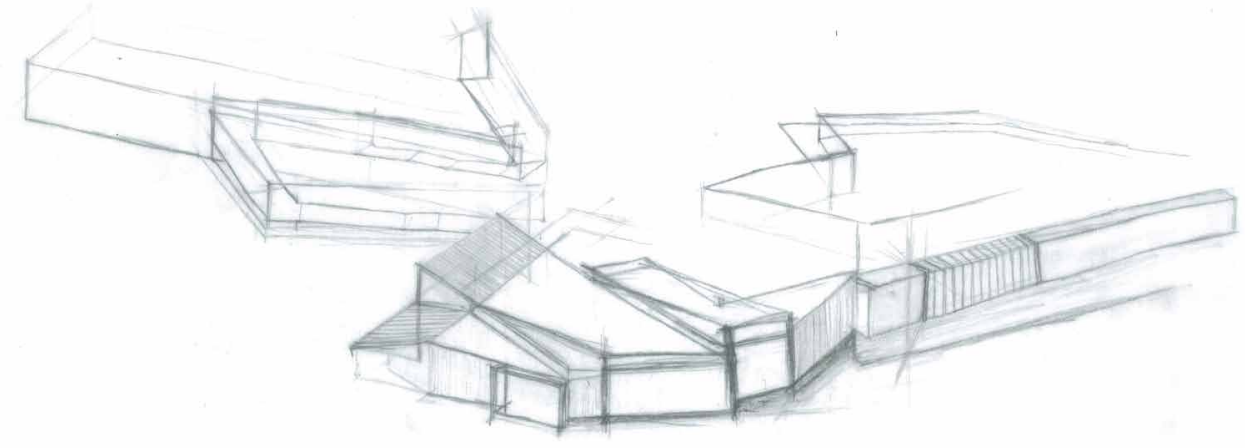




\section{Reflection}

During the attempts of informing the architecture through mobility, it comes to the realization that with the drivers of mobility and physical context, the formal expression is limited to the physical dimension and neglects the complexity of the spatial experience of the elderly. Hence, at this point, it is believed necessary to introduce phenomenology into the design iterations. To re-position focus on the occupants spatial experience, formal strategy is orientated to inside-out, meaning that the architecture will be informed from a series of crafted moments within the agora and developed to the overall form accordingly. 


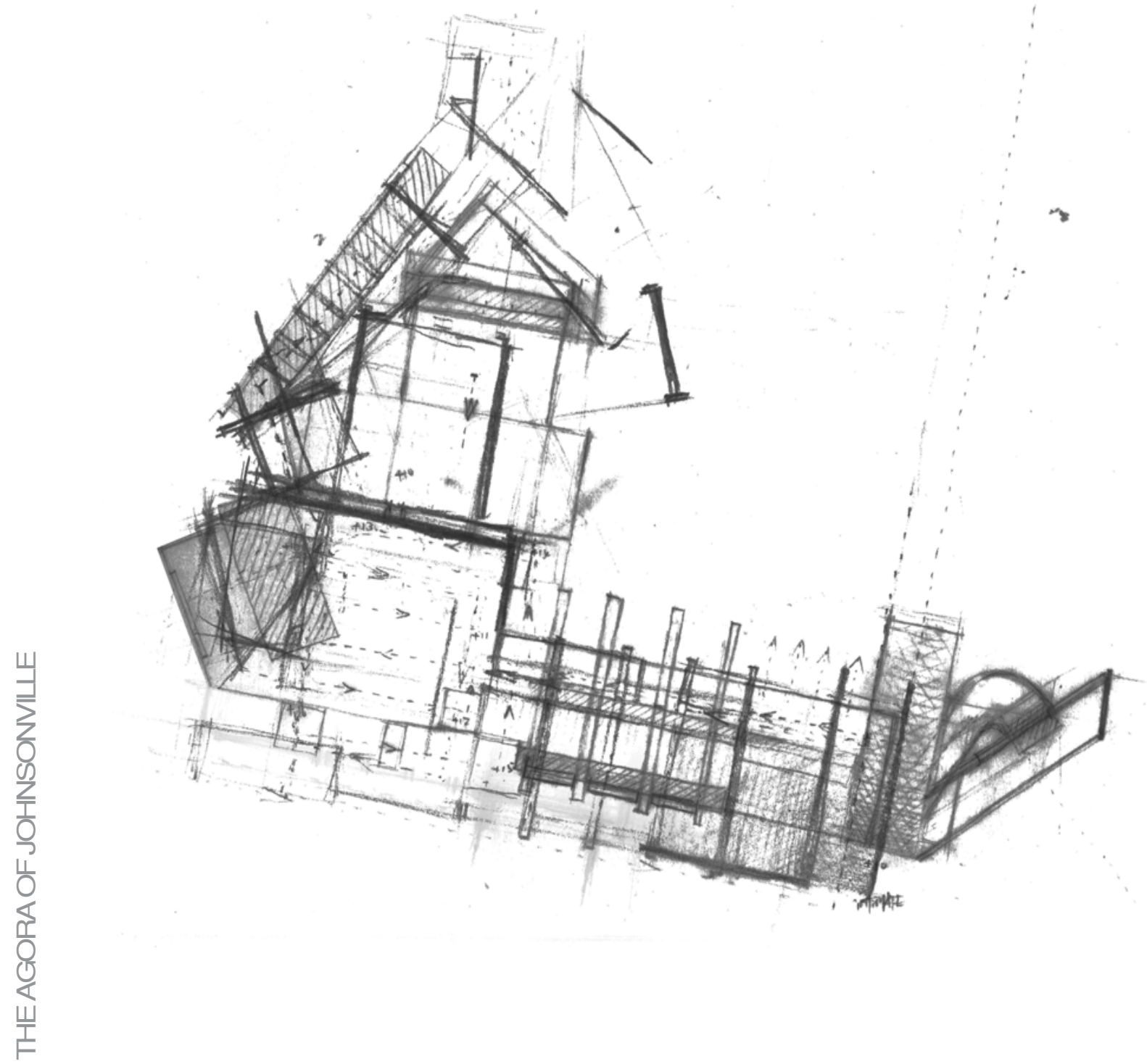




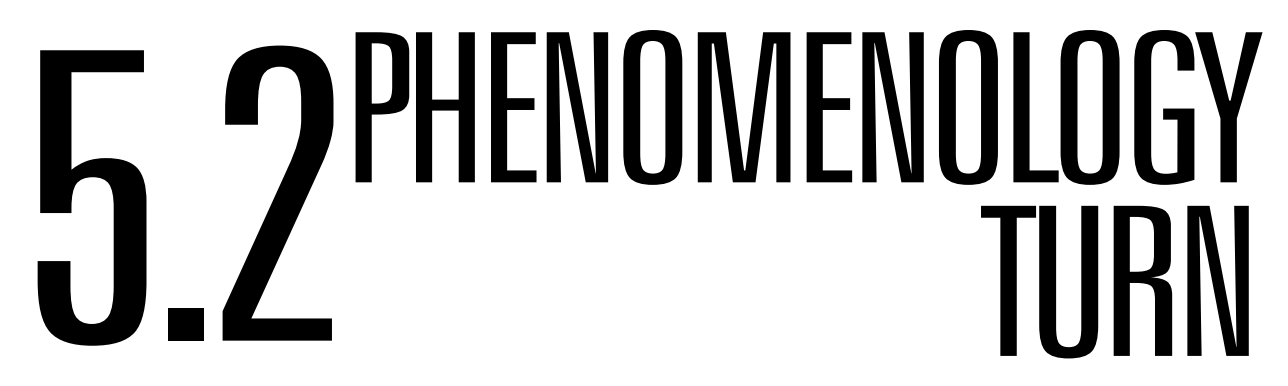

Design for senior's spatial experience

Fig 5.51. [ O p p o s i t e ] Drawing exploring the spatial relationship between movements and pauses within the space,
Adopting the phenomenology approach, spatial experience becomes the main driver in the process of form making. Based on the analysis of case studies in previous chapters, the relation between body and movement, sensory experience and the making of a promenade are explored in creating spaces to facilitate the autonomy and connectedness of the elderly.

This series of phenomenological explorations starts with the depiction of potential dominant movements and pauses in the agora upon the developed floor. To be specific, movements refer to primary circulation flow and pauses mean varied stationary activities take place. The drawing on the left explores different possibilities of creating formal and informal meeting venues along the promenade, and then reflects on the formal response. 


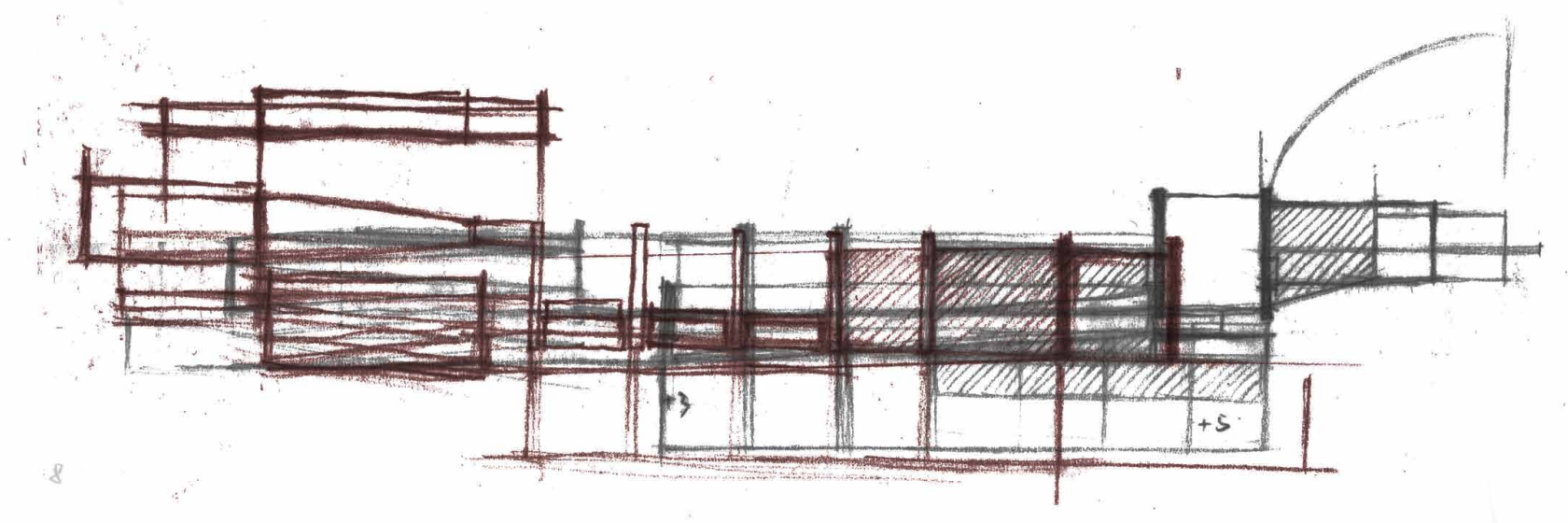

In this drawing, it is demonstrated that the variety of spaces created as rest points along the promenade ramping up and down the site. It also implicates the potential conversation between the agora to its context.

Fig 5.52. Drawing of a eastwest sction of the potential design exploring varied pause spaces on different levels of the agora. 
Fig 5.53. Drawing of a south-north sction of the potential design exploring the volume of ovaried pause spaces against the site context.
From this section, potential built volumes are explored along the promenade where the level changes is experienced. The form aims to respond to the character of chaging levels, at the same time, provide visual charity to navigate occupancy.

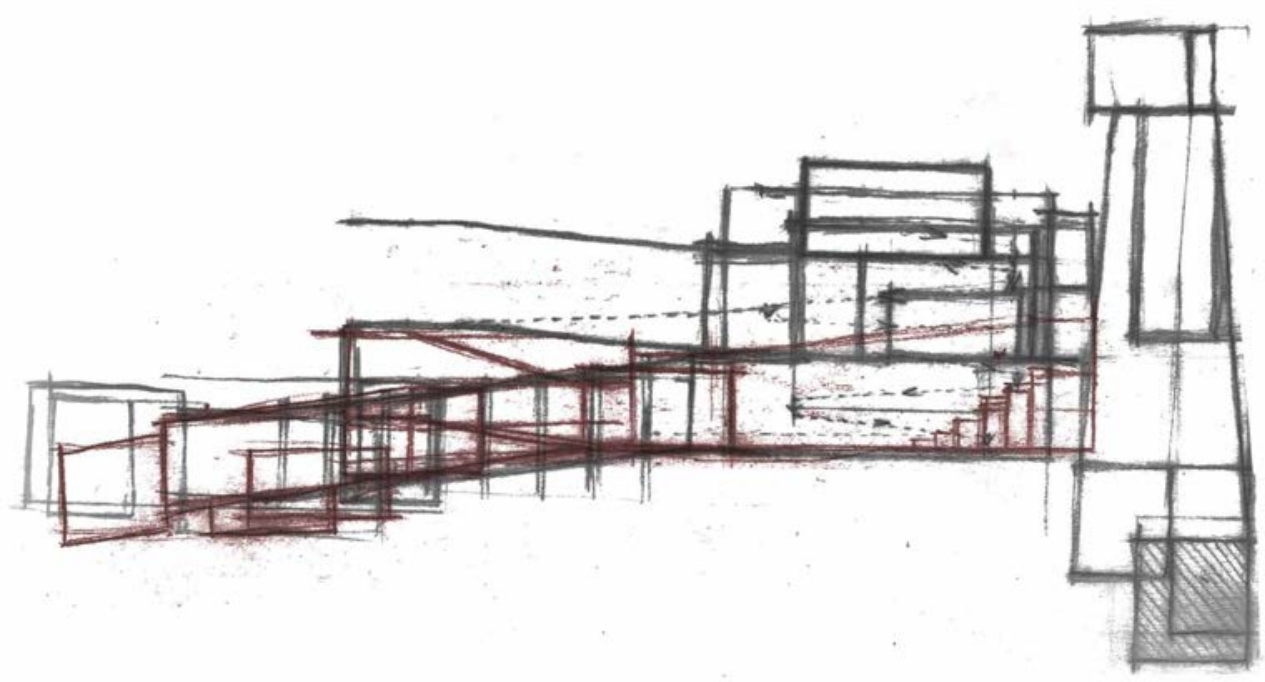




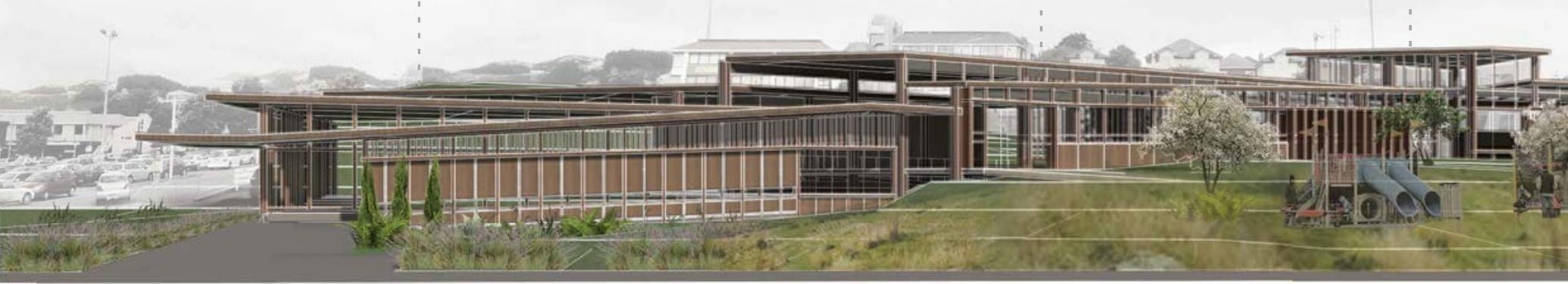

'The Circuit

of Wander

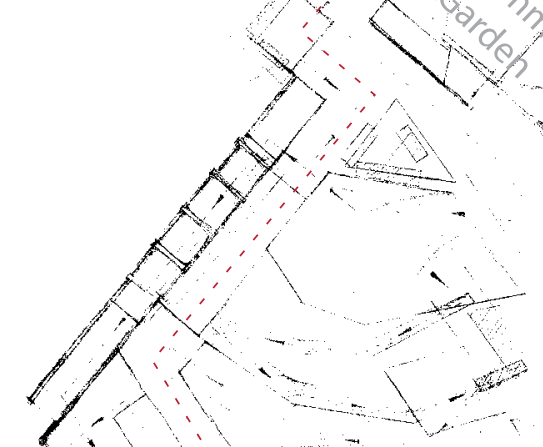

Amphitheatre
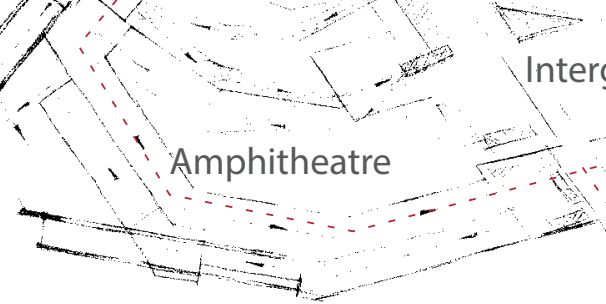

Intergenterational Libräry

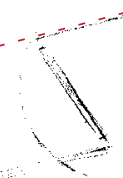

\section{South Entrance}

Playground

Park

Workshop Spaces

Broderick Road 
Windows are lowered to be friendly to young kids and people in wheelchairs or scooters.
Provision of seating by the window sill facilitates potential stationary activities and interactions
Strong visual connection to the outside, including the landscape and human activities.
High level openings luminates the space without intense glare.
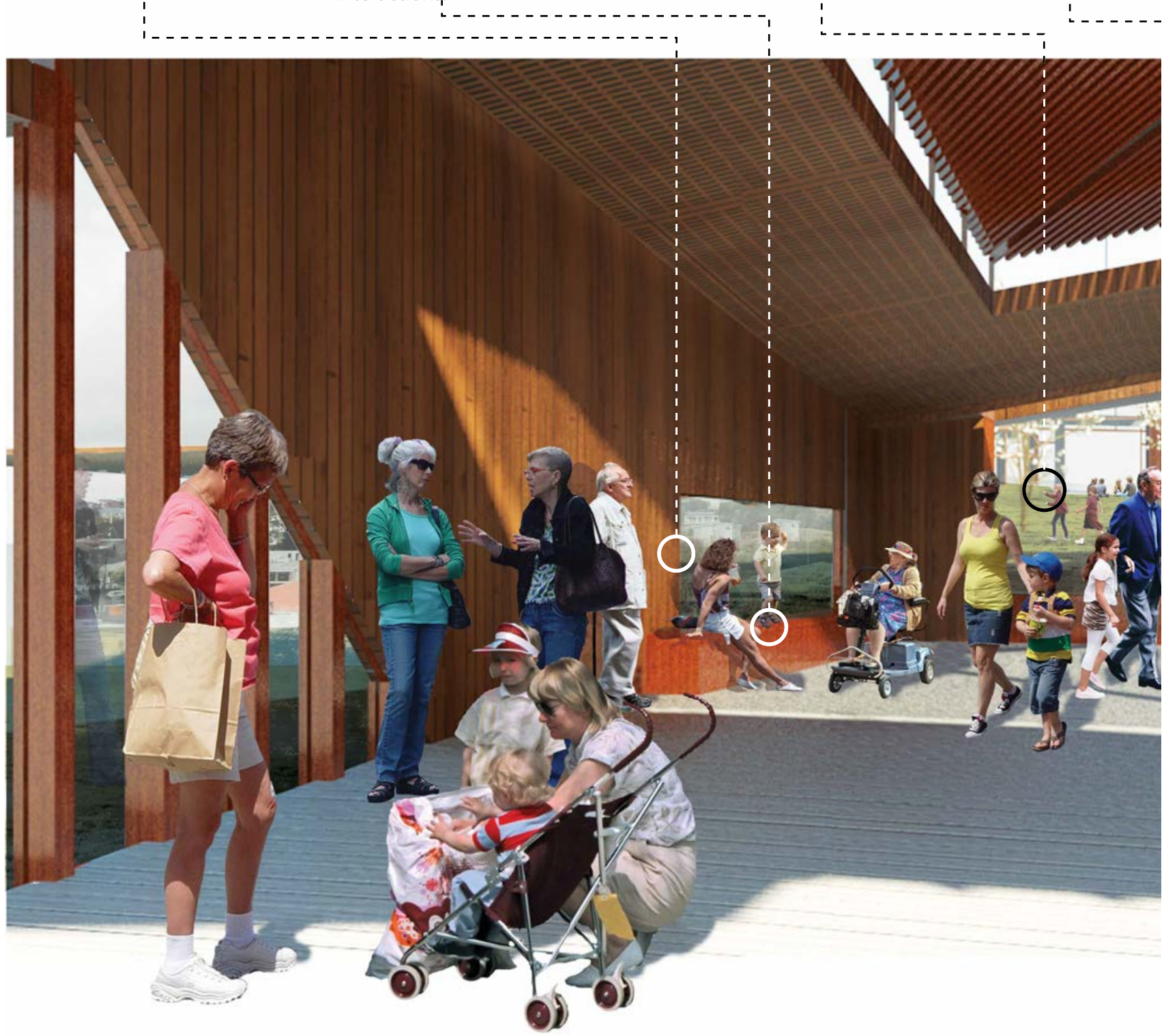


\section{The north lobby}

The north lobby is the first space occupants arrive in coming from the north side. It acts as a reception space of the community gallery in the guesture of reaching out to the bus stop and train station, providing an adjacent casual cultural

Louvred ceiling filters sunlight to a comfortable level for occupancy inside.

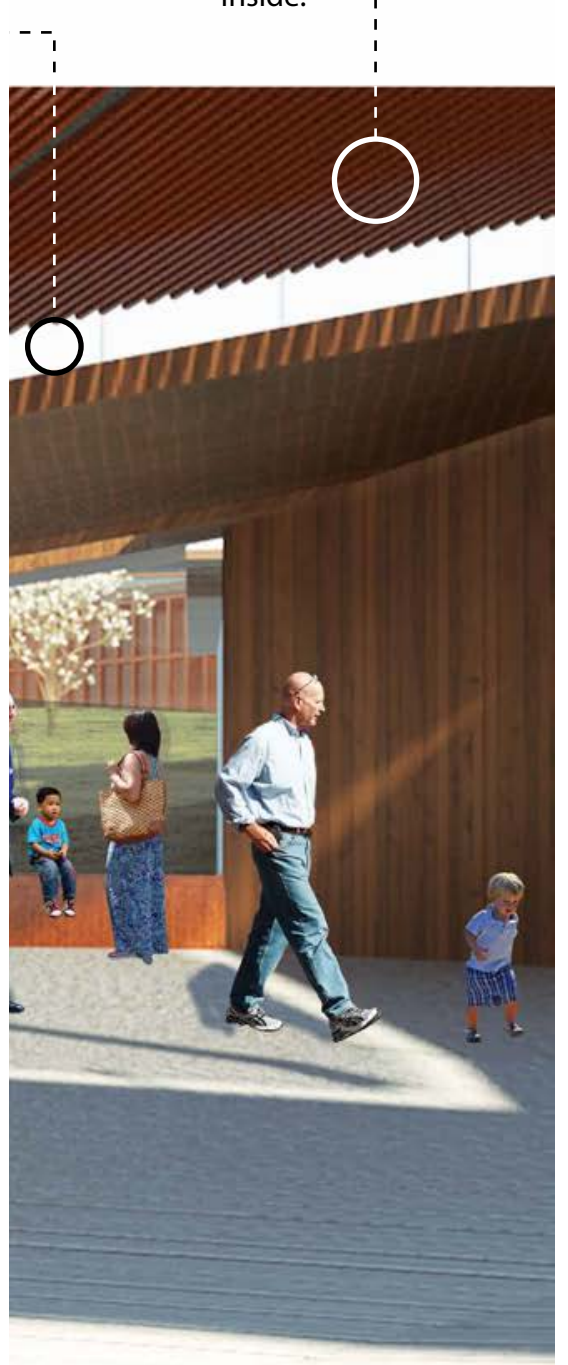

venue for people waiting to commute.

Fig 5.56. View of the north lobby from the entrance.

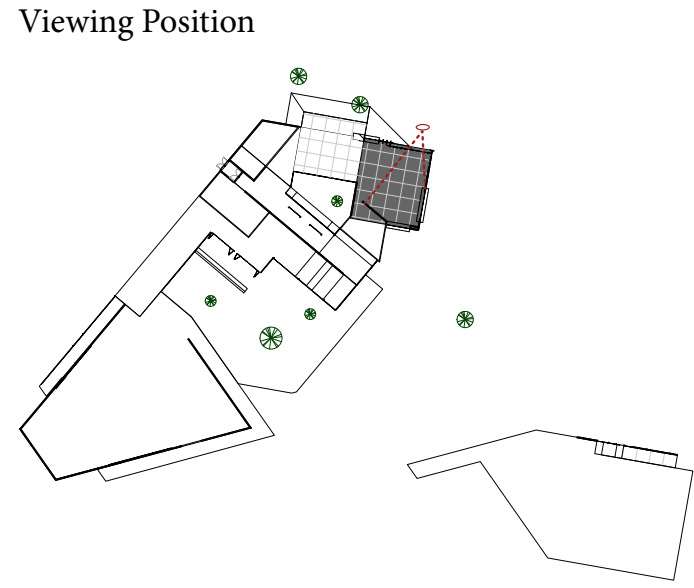




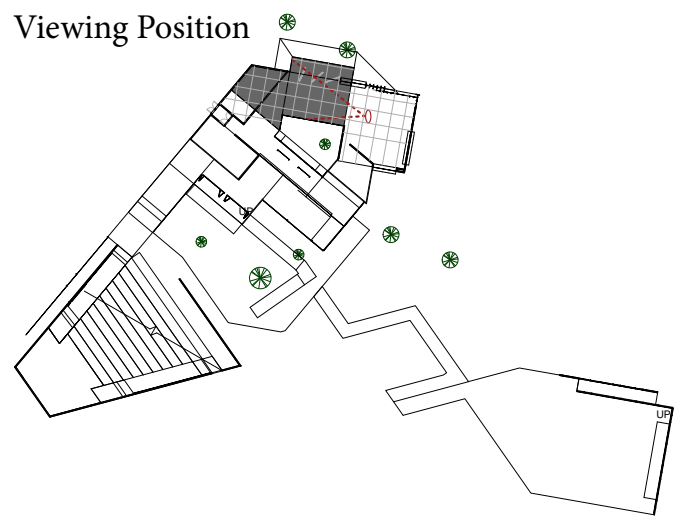

The Agora Cafe

The cafe area is a transitional spacec establishing visibility and connectivity in different dimensions. On the east-west axis, it links between the lobby and the community space. Generious space is provided for stationary activities and movements of varied users, including walking on foot or with walking stick, wheel chairs, mobility scooters and others. one the north-south axit, it opens up to both the pergola on the north and the light-well garden on the south.

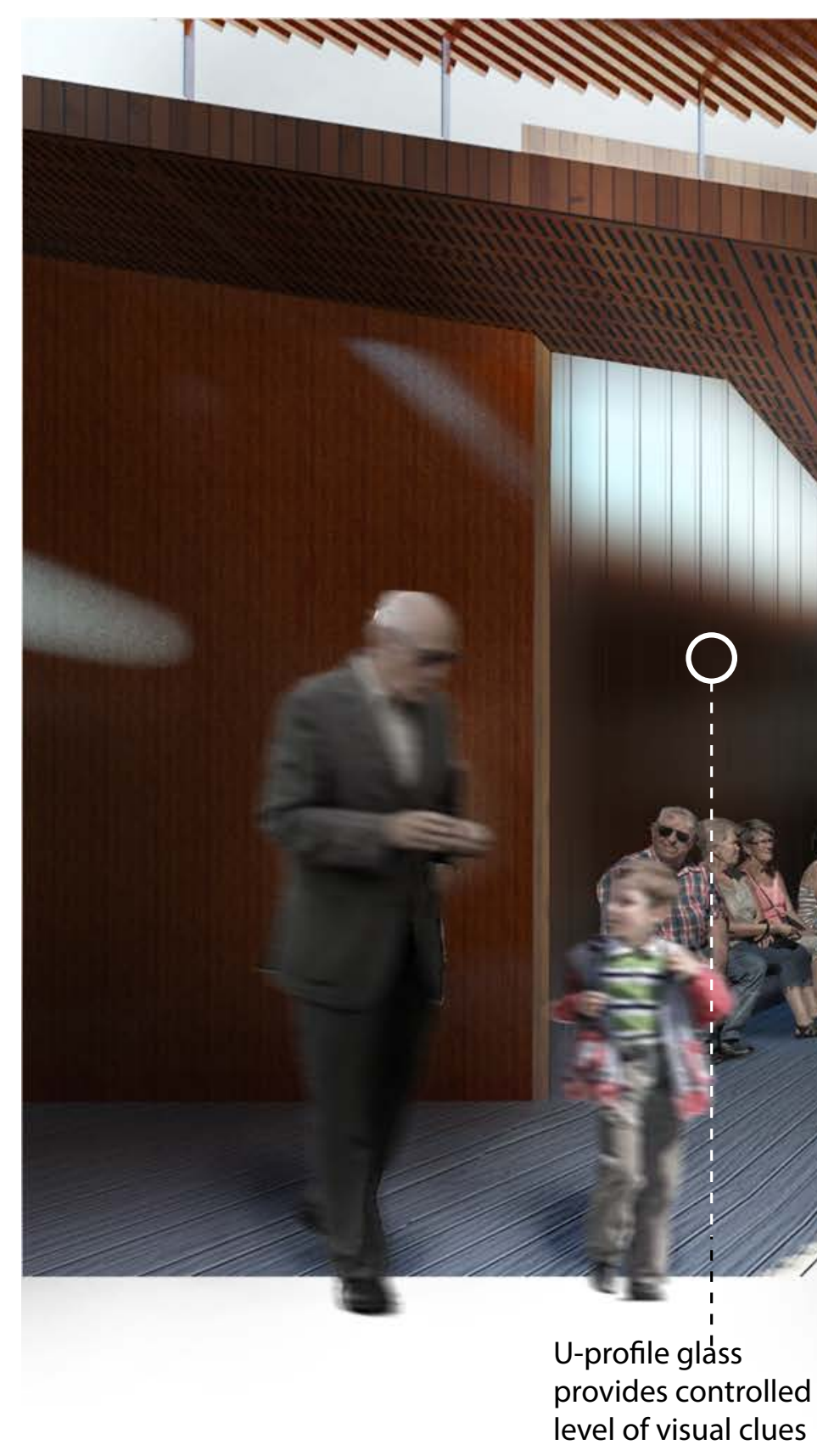


Fig 5.57. View towards the cafe from the north lobby.

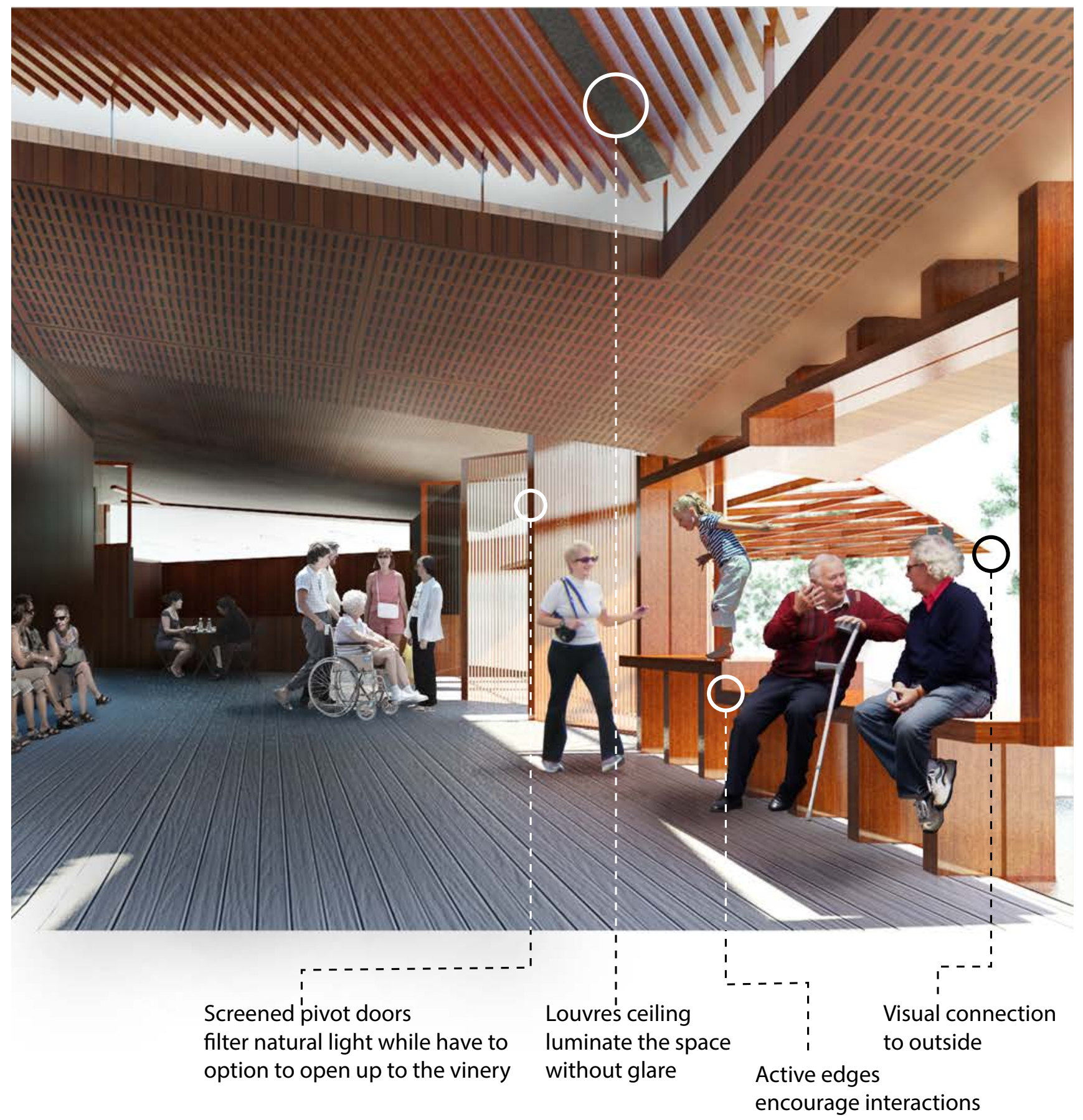




\section{light-well Garden Verandah}

As the verandah skirts around the lightwell garden, it slowily brings the visitors from the cafe into the gallery space. The light-well garden set up a subtle buffer between the active space and the passive gallery space while still remaining the visual continuation.

Viewing Position

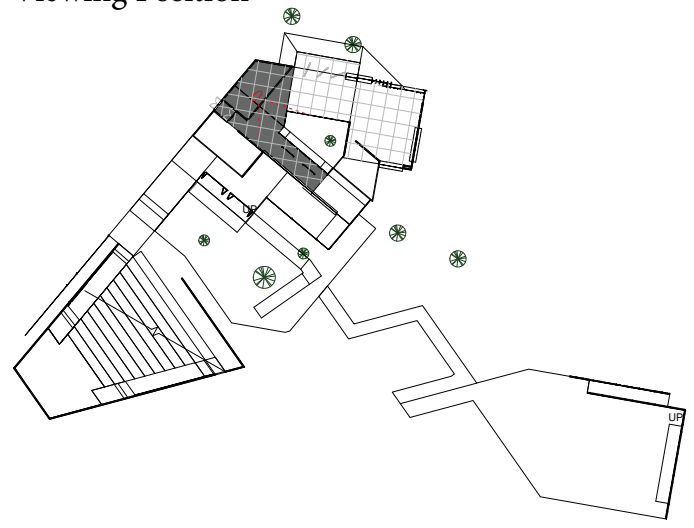

Fig 5.58. View towards the light-well garden verandah from the cafe.
U-profile glass as a sourse of diffused daylight and hint of visual path without distraction of spatial focal points.

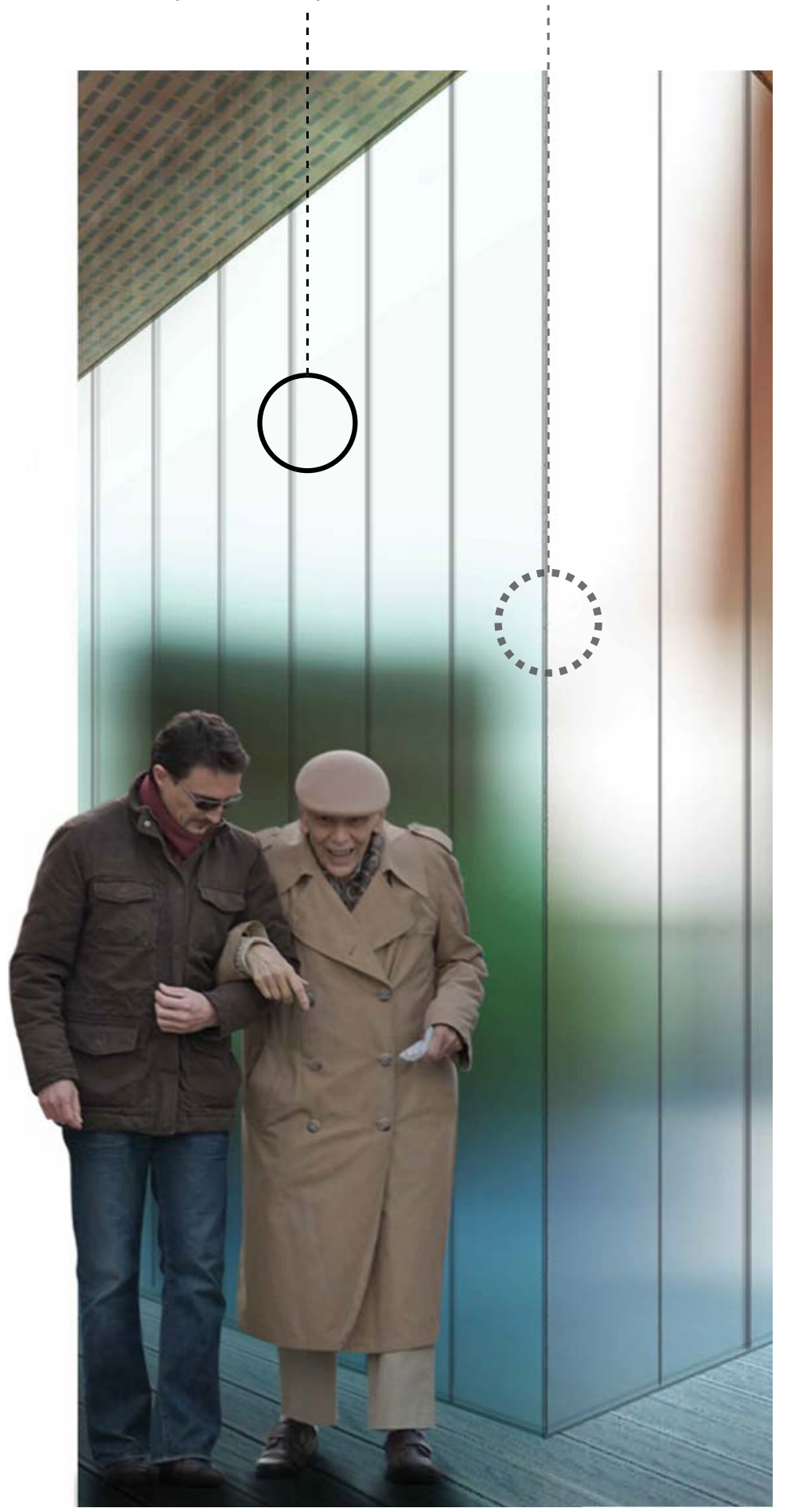

Light-well garden creates opportunities for human activities as visual interest. 
Garden is accessible through ramp and make it possible for people have diverse mobility to interact.
Louvred screens

provide shelter for

people who are

sensitive to glare.
Seating and opening to visual interests encourage stationary activities to take place.

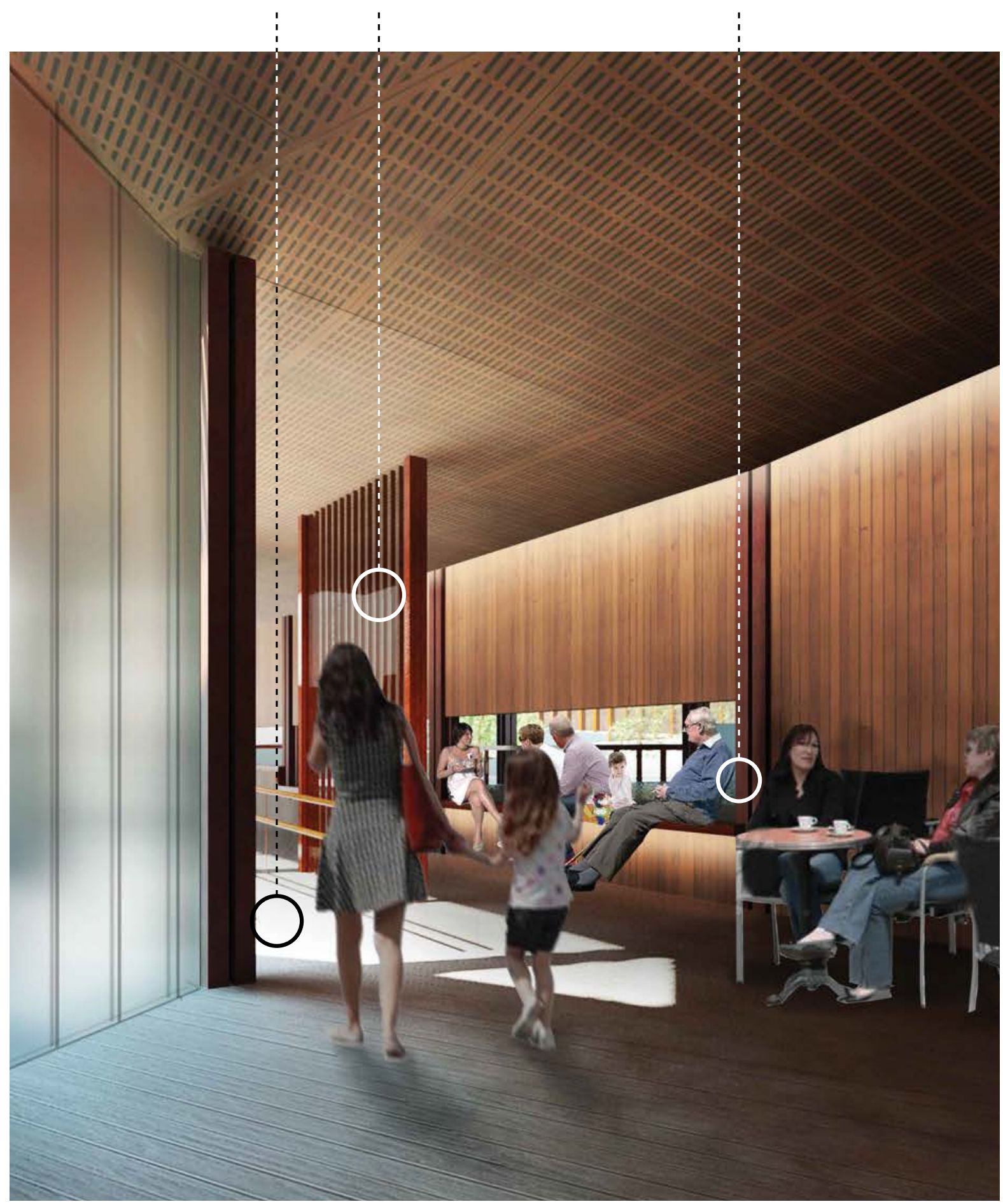




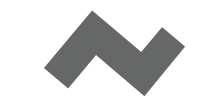

Fig 5.59. View from the gallery space.

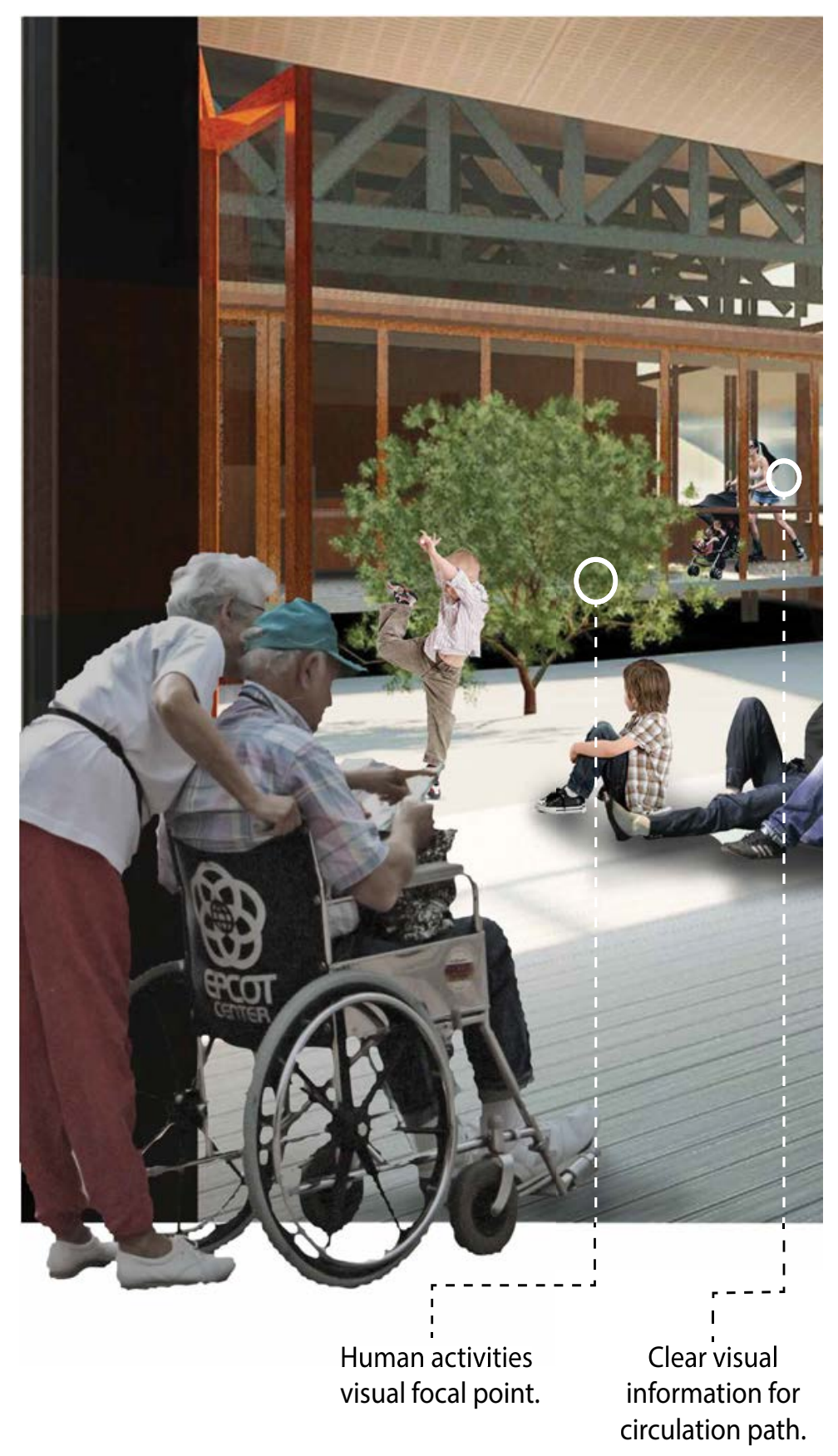

In the gallery space, one side of the wall is designed to be plain for the needs of exhibits. On the other side, glazed folding doors provide adequent daylight and flexibility to open up to the community garden on events or just a nice sunny day. 


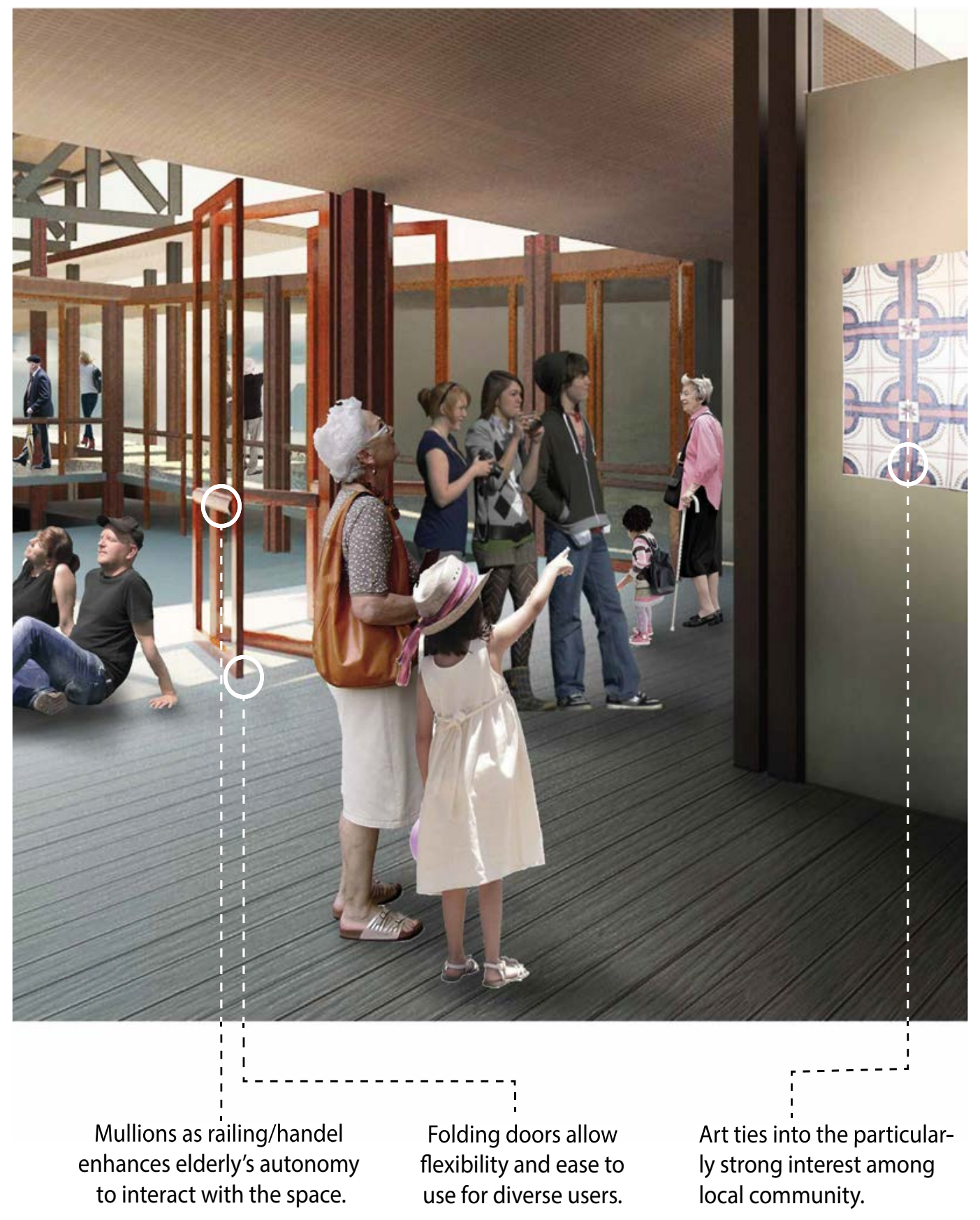


Fig 5.60. View of the multi-functional amphitheatre during an informal performance.

Viewing Position

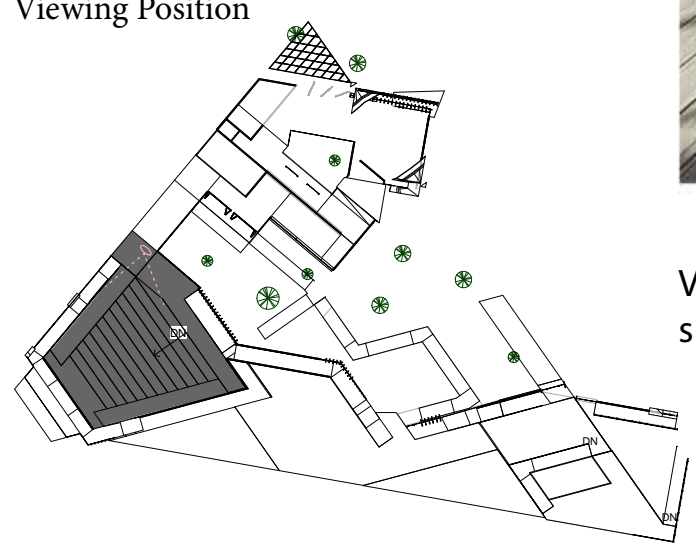

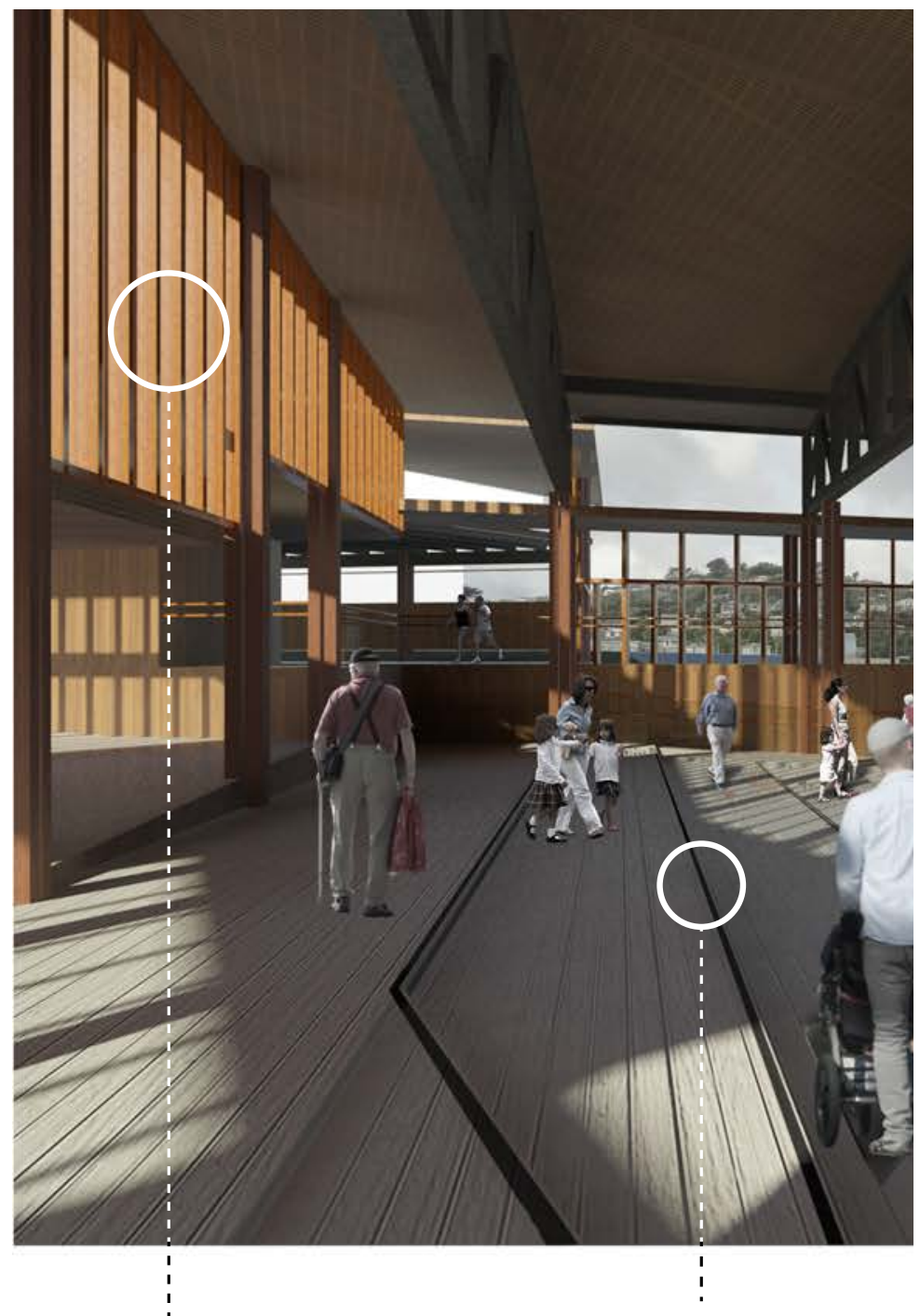

Vertical louvres filters sunlight to limit glare.
Retractable auditorium seating provides flexibility to formal events or informal public gathering.

Gradual level change makes it easier for people with wheelchair to move up and down.

\section{Amphitheatre}

This multi-funtional amphitheatre can be transform into venues for sports actvities or events by storaging portable seating underfloor. The ramp leading to the south entry goes around the amphitheatre, allowing interactions 


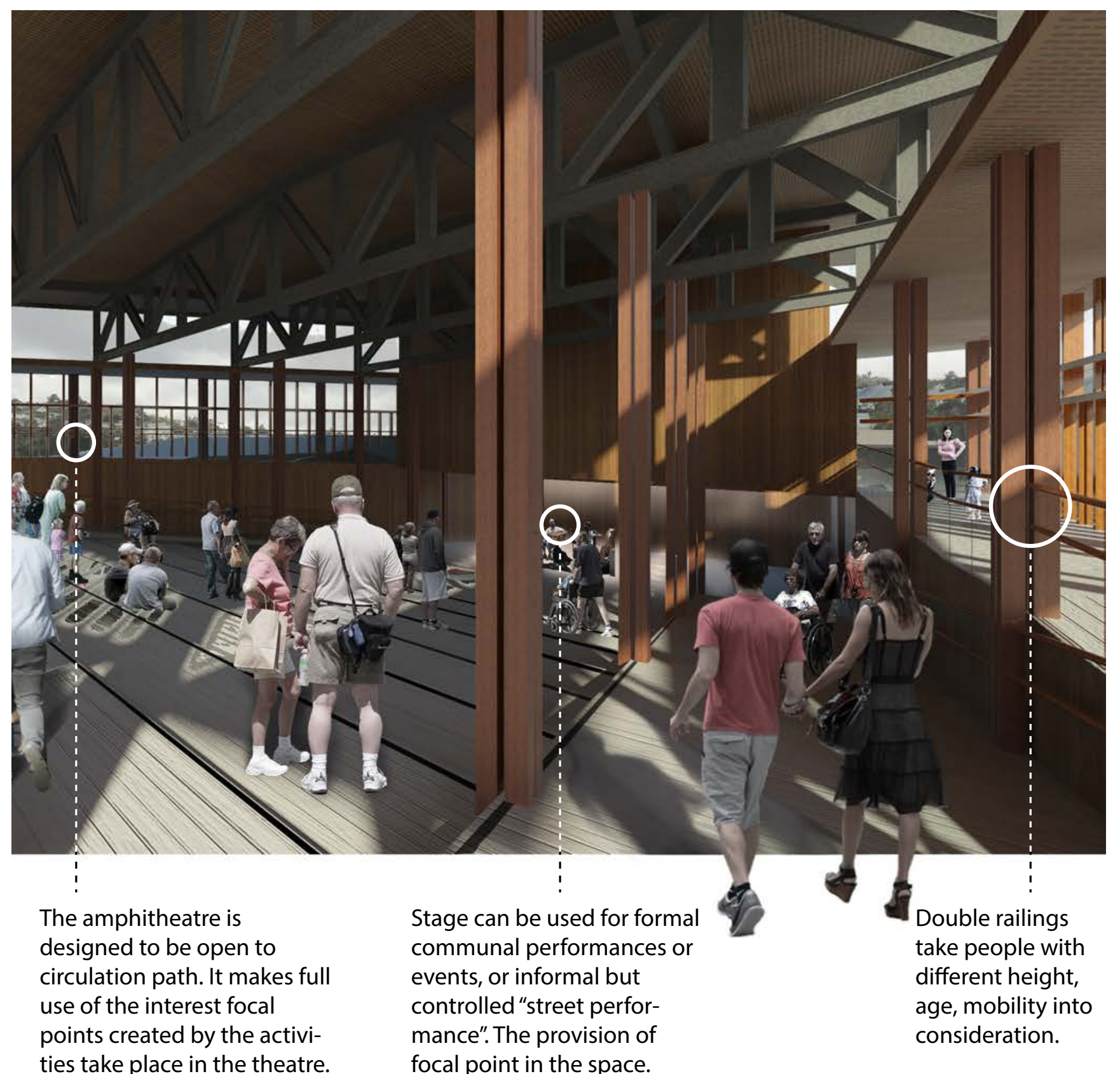

between the corridor and the amphitheatre, and maximising the focal effect of the activities housed. Each level of the seatings are designed to be deep enough for a wheel chair to go through with a person sitting on the seat. 


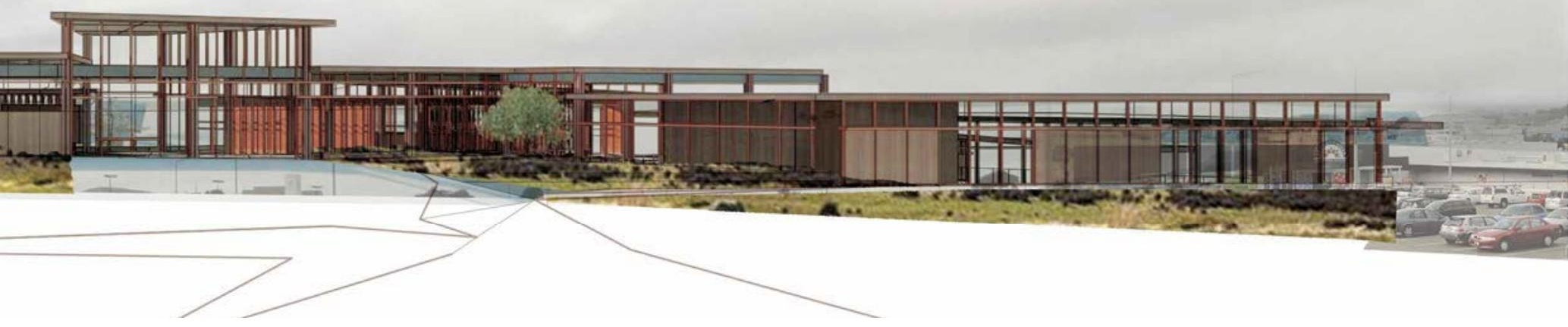

Fig 5.63. Upper floor plan of the agora.

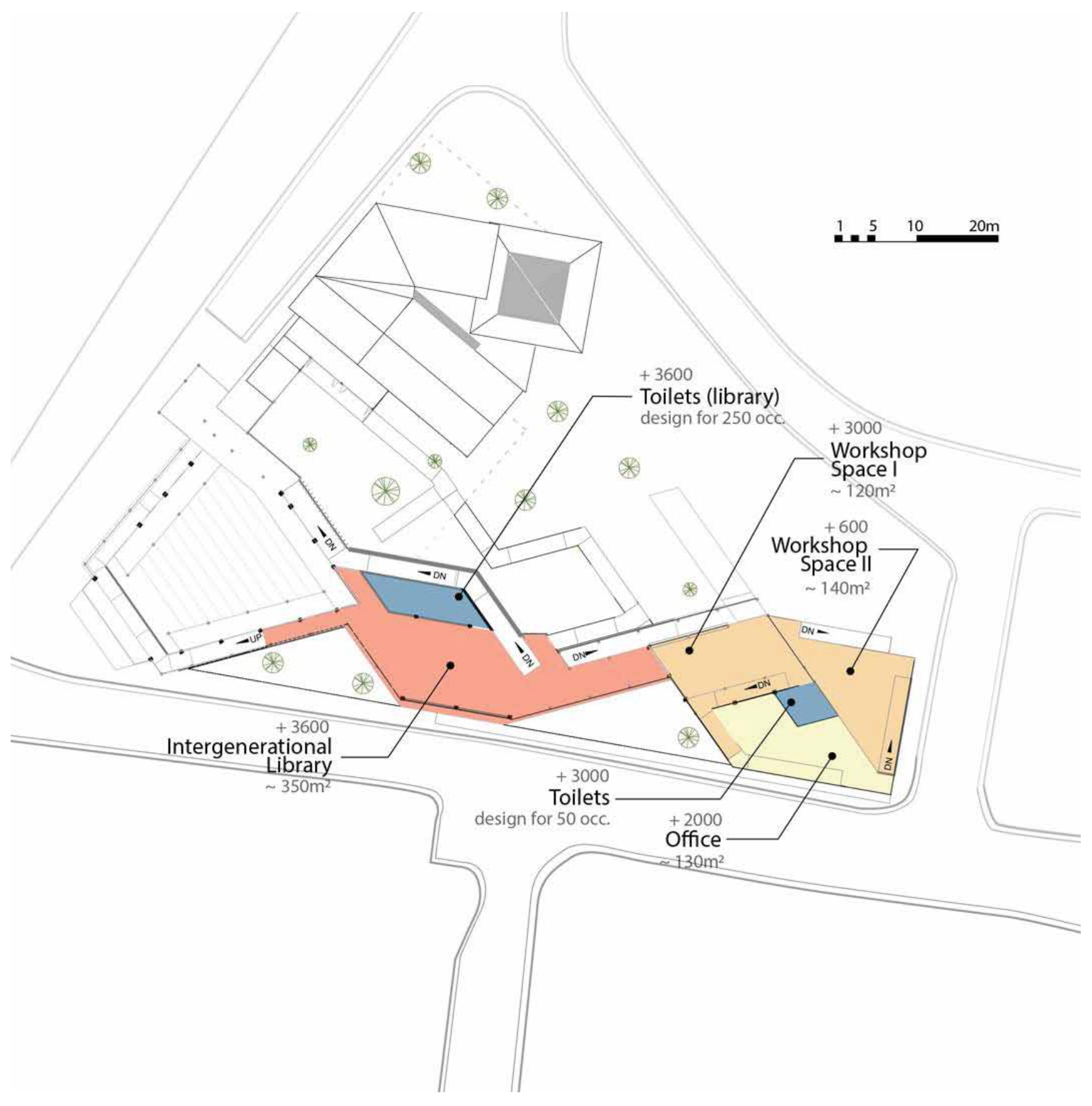




\section{Intergenerational library}

The Intergenerational library is to facilitate active interactions.

It is the venue for pop-up seminars and other culture programmes.

The learning centre is designed to encourage learning from social

Fig 5.64. View of the intergenerational library.

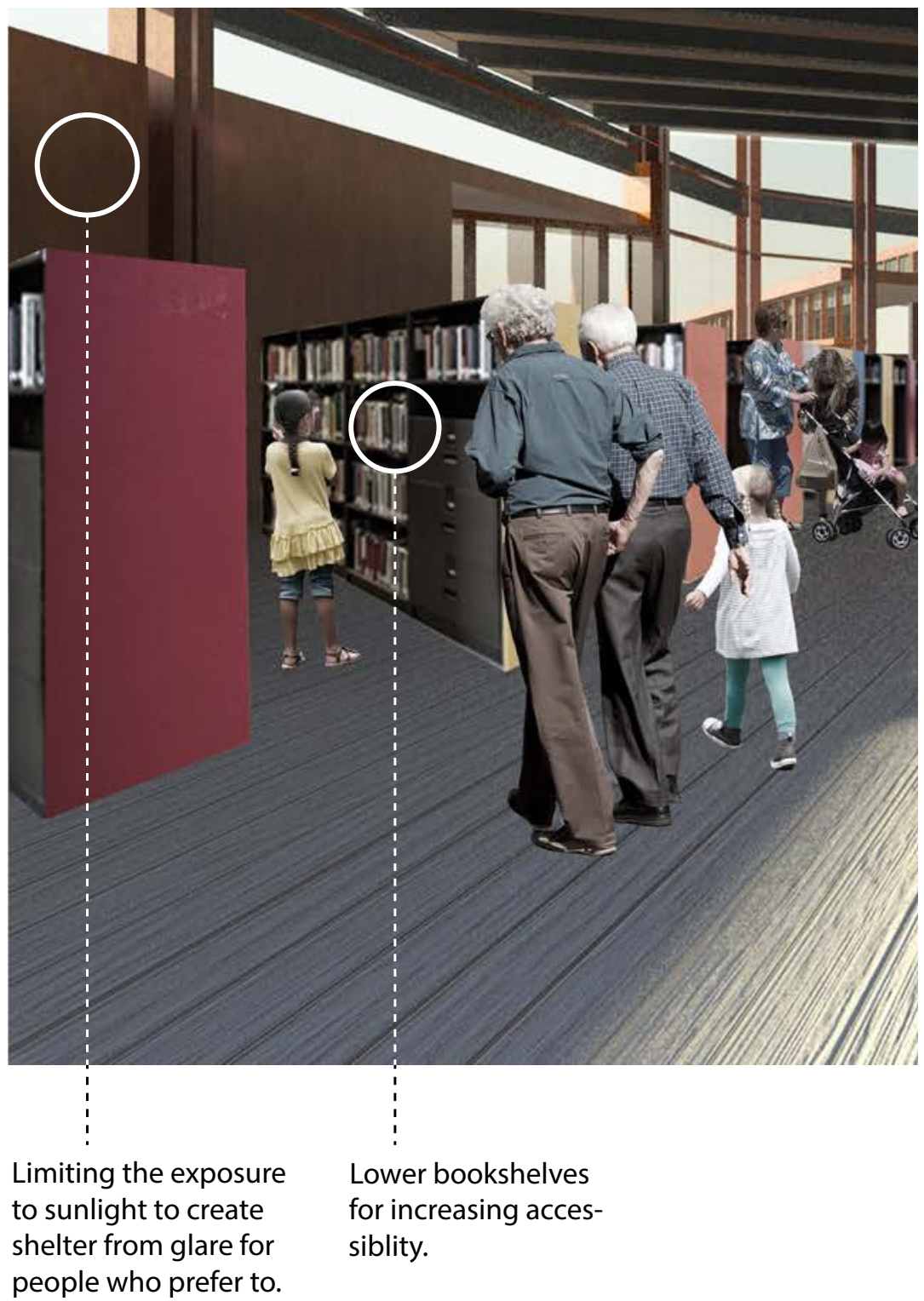


interaction by providing common ground for different

users to actively engage with the community, which is the

old library has been trying to do but constrained by the building itself.
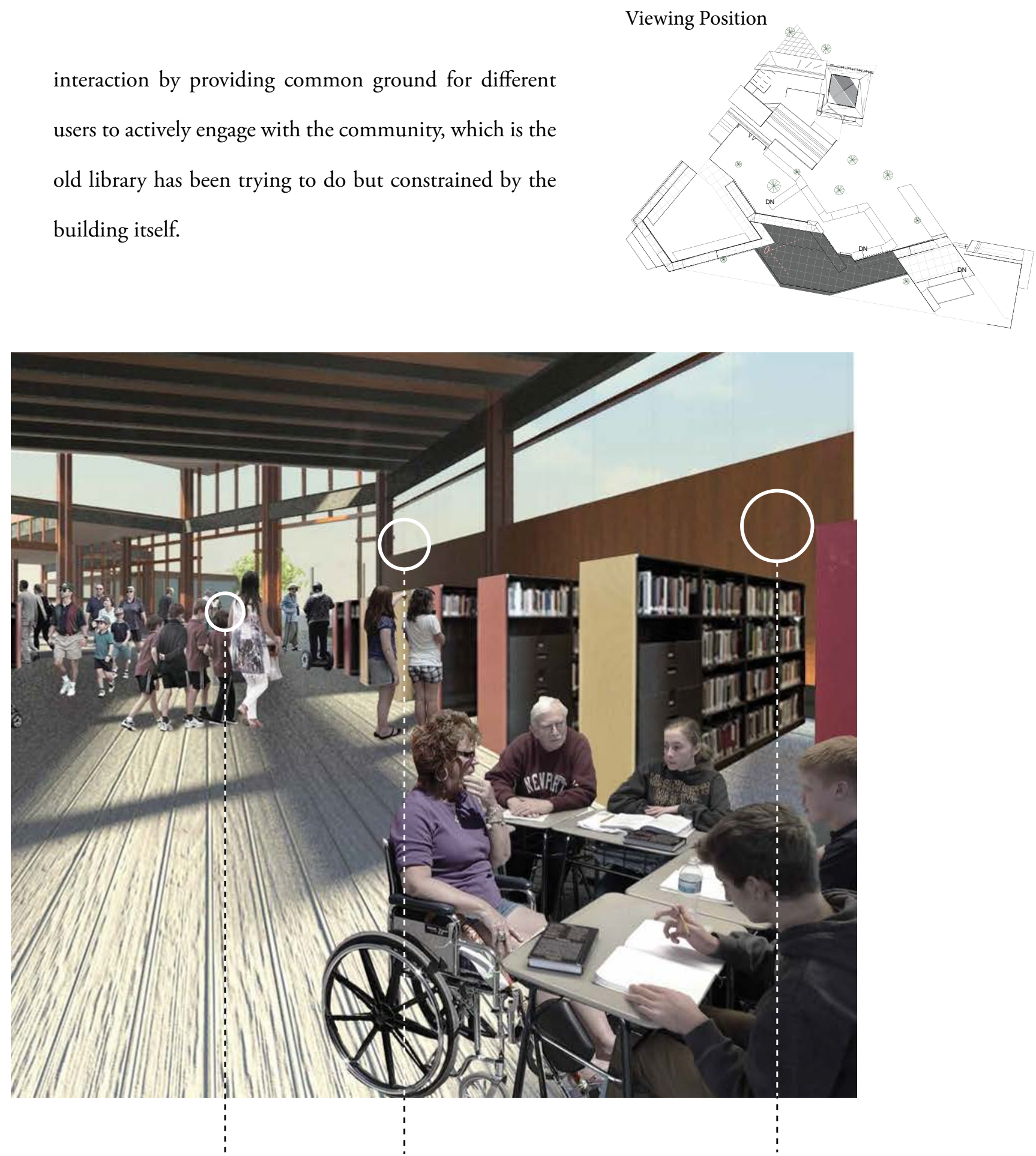

Clear visual path to exit/entrance.
Glazing on the south facade has the advantage of gaining adequate daylight without glare.
Potential to larger the glazing area on the south facade to encourage more interaction with Broderick Road. 


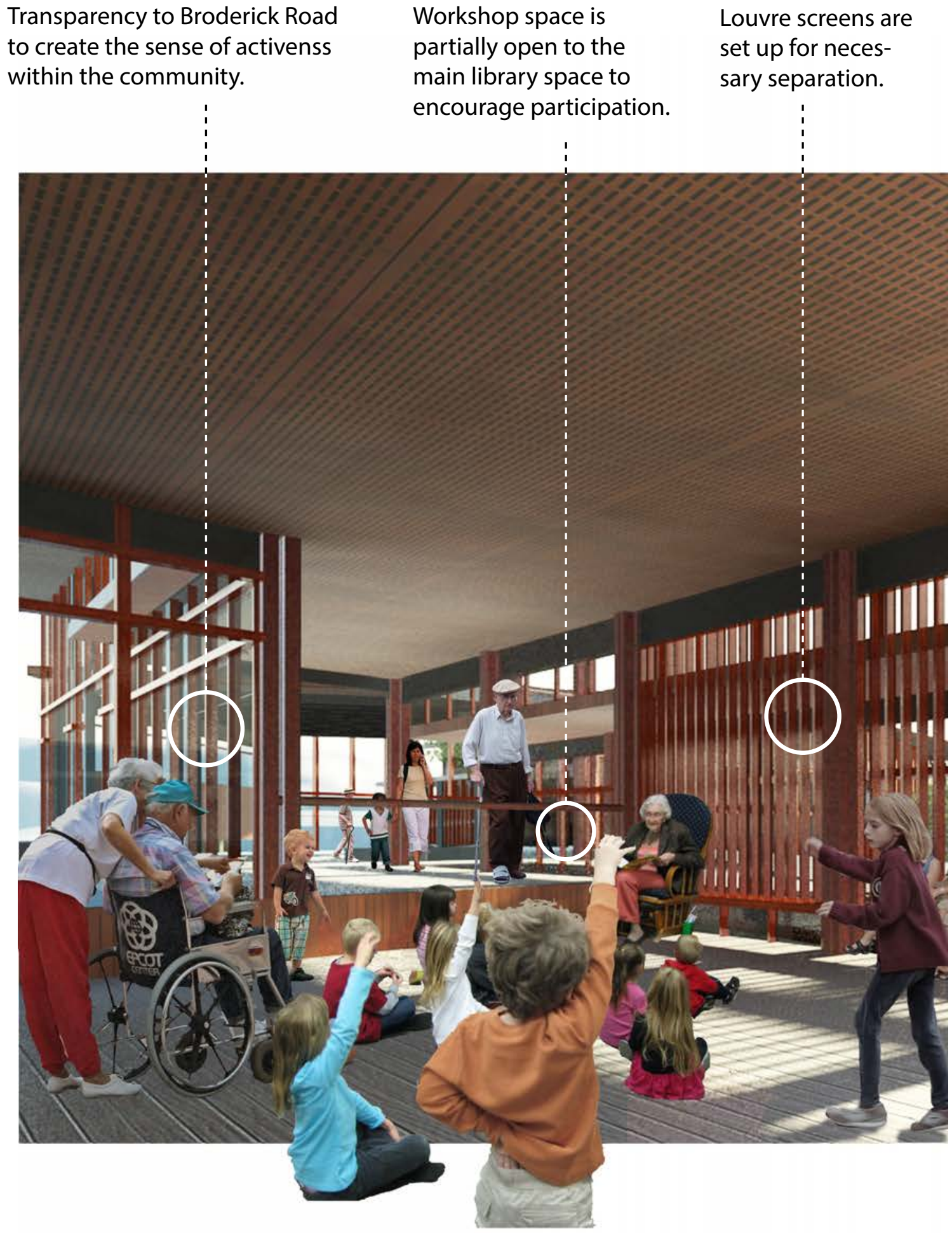

\section{Community Workshop}

Within the learning centre, there are workshop spaces where relatively enclosed environments are created for group meetings, seminars, various classes and other organised programmes. Due to the accessibility of the design, it is easy to transport and reconfigure furnitures and equipment to fit the needs of different activities. 
Seating are provided for passive participation and need for rest for occupants with low physical competence..
Circulation path is designed to maximise its transparency to help navigating within the agora.

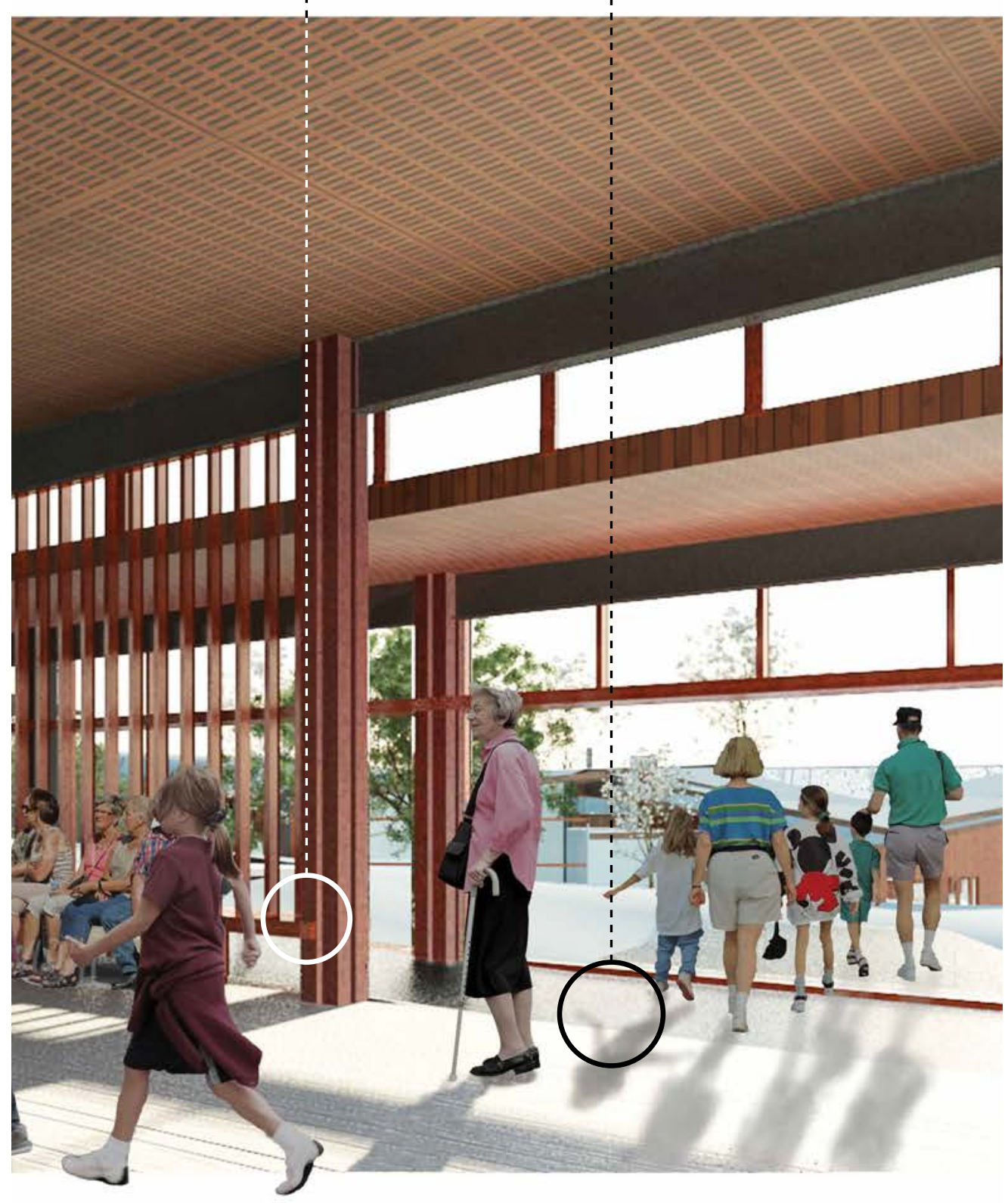

Fig 5.65. View of the workshop space during a intergenerational programme.

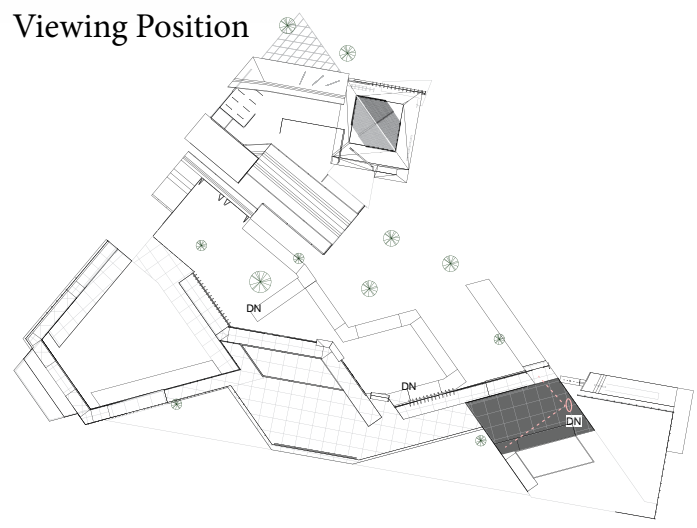




\section{Reflection}

In this thesis, design explorations are grounded on the theoretical background of environmental gerontology and phenomenology architecture, aiming to improve the quality of public space for the increasing number of elder users. Following the template set up by the Agora of Dronten as an exemplar, responding to the contextual situation of Johnsonville, design is driven by the idea of an accessible agora promenade. All the sloped floor surfaces in the agora are less than 3 degree for the maximum comfort and accessibility for the occupants. A series of spaces are designed to create moments of pauses for active or passive interactions along the journey. In these spaces, the form of architecture is quiet, allowing visitors just immerse themselves into the experience constructed by the connections created with other people within the space. Due to the constraints of the thesis, details of the design are yet to be fully resolved. However, all the attempted explorations shows a variety of possibilities that space can be accessible, not just physically, but sensorially, psychologically. 
Г<smiles>CC1CCCCC1=O</smiles> 
As elderly are taking an increasing share of the total population, design for elderly, what used to be a consideration for the minority, will become a significant design requirement for future public buildings. Issues brought by ageing population involve a wide spectrum of fields, a lot of which are deeply embedded in social structures and value. This thesis is set on such background to explore the potential for developing architecture design base on the consideration of the spatial experience of the elderly rather than just meeting specific regulations. 
During the study, it was acknowledged that to avoid generalising elderly as one isolated group in the design process, design consideration needs to be highly specified to the context, geographically, culturally and demographically, to get a comprehensive view of the needs of local elderly in Johnsonville. As a phenomenological approach to the theoretical context of environmental gerontology, the thesis focuses on the spatial experience of elderly. In the investigation of case studies and design iterations, it considers not only physically enabling elderly to maintain their social life, but also the psychological implications from the environment and their impacts on their autonomy and connection between elderly and others. 
However, the design exploration is constrained by the timeframe of a master degree thesis and the limited number of research publications available on New Zealander elderly and their use of public environment. Certain assumptions about the site, based mainly on field research by the author, may affect the design implication. The design exploration is not an attempt to be the one and only solution, considering the complex nature of the discourse, but more raising attention to the issues of current public spaces for elderly and the vision for public space sensitive to the needs of the elderly. Methods adopted in the thesis, from site analysis, demographic study, to typology analysis and instrumental design experiments, can be used for design explorations of various civic projects which have significant priority on their occupancy. 
As a larger population ages, the elderly has become one of the main user groups of public spaces. The design of these spaces needs to be more accessible to them, sensorially, physically and psychologically. Designing for elderly should not be simplified to just meeting their physical needs, but the whole spatial experience should be made accessible for them. In the process of designing an elderly-accessible architecture, it is beneficial for all members within the community. Their specific needs, which may vary to different contexts and individuals, need to be investigated thoroughly. These investigations are carried under the constraints of a thesis structure and timeframe of a degree. Further studies from different perspectives, such as urban planning and gerontology would be highly beneficial to this area of research. There is great potential to apply the findings of this thesis to the subject of architecture for ageing, accessible civic and/or community architecture. 


\section{[Bibliography]}

Altman, I., M.P. Lawton, and J.F. Wohlwill. Elderly People and the Environment. Springer US, 1984. Print.

Baars, Jan, and Chris Phillipson. "Connecting Meaning with Social Structure: Theoretical Foundations.” Ageing, Meaning and Social Structure Connecting Critical and Humanistic Gerontology. Ed. Baars, Jan. Bristol: Bristol: Policy Press, 2013. 11-30. Print.

Ball, M. Scott. Livable Communities for Aging Populations : Urban Design for Longevity. 2012. Web <http://VUW.eblib.com/patron/FullRecord.aspx?p=821715>.

Ball, Mary M., et al. “Independence in Assisted Living.” Journal of Aging Studies 18.4 (2004): 467-83. Print.

Boys, Jos. Doing Disability Differently : An Alternative Handbook on Architecture, Dis/Ability and Designing for Everyday Life. Abingdon, Oxon ; New York: Routledge, 2014. Print.

Chapman, Katie. "Story of a Suburb: Johnsonville.” The Dominion Post (2010). Web. Cross, Jennifer Eileen. "Processes of Place Attachment: An Interactional Framework.” Symbolic Interaction 38.4 (2015): 493-520. Print.

Davey, Judith, et al. "Accommodation Options for Older People in Aotearoa/New Zealand.” Ed. The Centre for Housing Research Aotearoa/New Zealand2014. Print.

Davis, Lisa Selin. "Aging in Place: Suburban Style." Planning 79.6 (2013): 24-8. Print.

Day, Christopher. Places of the Soul: Architecture and Environmental Design as a 
Healing Art. 3rd ed. New York: Routledge, 2007. Print.

Dougherty, Linda. "Age-Related Physical Decrement and Objective Self-Awareness in the Elderly: A Simulation Technique." ProQuest Dissertations Publishing, 1985. Print.

Föbker, Stefanie, and Reinhold Grotz. "Everyday Mobility of Elderly People in Different Urban Setting: The Example of the City of Bonn, Germany." Urban Studies 34.1 (2006): 99-118. Print.

Faletti, Martin V. "Human Factors Research Nd Functional Environments for the Aged." Elderly People and the Environment. Eds. Altman, Irwin, M. Powell Lawton and Joachim F. Wohlwill. New York: New York : Plenum Press, 1984. 191-237. Print.

Gehl, Jan. Cities for People. Washington, DC: Island Press, 2010. Print.

Grabow, Stephen. The Architecture of Use : Aesthetics and Function in Architectural Design Ed. Spreckelmeyer, Kent F. New York Routledge, 2015. Print.

Graham, James E., et al. "Walking Speed Threshold for Classifying Walking Independence in Hospitalized Older Adults." Journal of the American Physical Therapy Association 2010. Web. 19/06/2015.

Harris, Catherine. "Satellite City: Kapiti Coast Is Set to Boom.” The Dominion Post (2012). Web. 15/03/2015.

Havighurst, Robert J., and Ruth E. Albrecht. Older People. New York: Longmans, 1953. Print.

Hernández, Bernardo, et al. "Place Attachment and Place Identity in Natives and Non-Natives.” Journal of Environmental Psychology 27.4 (2007): 310-19. Print. 
Hidalgo, M. Carmen, and Bernardo HernÁNdez. "Place Attachment: Conceptual and Empirical Questions.” Journal of Environmental Psychology 21.3 (2001): 273-81. Print.

Hillcoat-Nalletamby, Sarah. "The Meaning of "Independence" for Older People in Different Residential Settings." Journals of Gerontology, Series B: Psychological Sciences and Social Sciences 69.3 (2014): 419-30. Print.

Hillcoat-Nalletamby, Sarah, and Jim Ogg. "Moving Beyond 'Ageing in Place': Older People's Dislikes About Their Home and Neighbourhood Environments as a Motive for Wishing to Move.” Ageing and Society 34.10 (2014): 1771 - 96. Print.

Holl, Steven. Parallax. New York: Princeton Architectural Press, 2000. Print.

Holland, Caroline. Social Interactions in Urban Public Places. Eds. Holland, Caroline and Foundation Joseph Rowntree. York: Joseph Rowntree Foundation, 2007. Print.

Hughes-Stanton, Corin. “Closed Environment for Living Space.” Design. 241 (1969): 40-49. Web. 28/07/2016.

Imrie, R. "From Universal to Inclusive Design in the Built Enviornment." Disabling Barriers - Enabling Environments. Eds. Swain, J., et al. 2nd ed. London, UK: Sage Publications, 2004. 279 - 84. Print.

Johnson, Kimberly J., and Jan E. Mutchler. “The Emergence of a Positive Gerontology: From Disengagement to Social Involvement.” The Gerontologist 54.1 (2014): 93-100. Print. 
Kendig, Hal, et al. "Developing Age-Friendly Cities and Communities in Australia." Journal of aging and health 26.8 (2014): 1390-414. Print.

Laws, Glenda. "Spatiality and Age Relations." Critical Approaches to Ageing and Later Life. Eds. Jamieson, Anne, et al. Buckingham

Philadelphia: Open University Press, 1997. 90-100. Print.

Lazzaro, Joseph. “The Principles of Universal Design.” E Media Professional 10.2 (1997): 56-57. Print.

Lupien, S. J., and N. Wan. "Successful Ageing: From Cell to Self." Philosophical Transactions: Biological Sciences 359.1449 (2004): 1413-26. Print.

Mace, Ronald L., Graeme J. Hardie, and Jaine P. Place. "Accessible Environments: Toward Universal Design.” Web. 13/05/2015.

Machielse, Anja, and Roelof Hortulanus. "Social Ability or Social Frailty? The Balance between Autonomy and Connectedness in the Lives of Older People.” Ageing, Meaning and Social Structure Connecting Critical and Humanistic Gerontology. Ed. Baars, Jan. Bristol: Bristol: Policy Press, 2013. 119-38. Print.

Madge, James. “The Agora at Dronten.” Architectural Design 75.2 (2005): 28-33. Print.

McDowell, Linda. "Gender, Identity, and Place : Understanding Feminist Geographies." Minneapolis: University of Minnesota Press, 1999. Print.

Mead, David. "Intensification and the District Plan - Wellington City." Ed. Council, 
Wellington City: Hill Young Cooper Ltd., 2007. Print.

Oerlemans, Wido G. M., Arnold B. Bakker, and Ruut Veenhoven. "Finding the Key to Happy Aging: A Day Reconstruction Study of Happiness.” Journals of Gerontology Series B: Psychological Sciences and Social Sciences 66B.6 (2011): 665-74. Print.

Orillard, Clément. "Between Shopping Malls and Agoras: A French History of 'Protected Public Space'.' Heterotopia and the City : Public Space in a Postcivil Society / Edited by Michiel Dehaene \& Lieven De Cauter. Eds. Dehaene, Michiel and Lieven de Cauter. London

New York: Routledge, 2008. Print.

Oswald, Frank, and Hans-Werner Wahl. "Creating and Sustaining Homelike Places in Residential Environments." Environmental Gerontology: Making Meaningful Places in Old Age. Eds. Rowles, G.D. and M.A. Bernard. New York: Springer Publishing Company, 2013. 53-78. Print.

Ozanne, E., S. Biggs, and W. Kurowski. "Competing Frameworks in Planning for the Aged in the Growth Corridors of Melbourne." Journal of aging \& social policy 26.1-2 (2014): 147-65. Print.

Pallasmaa, Juhani. "The Geometry of Feeling: The Phenomenology of Architecture.” The Architecture Reader : Essential Writings from Vitruvius to the Present. Ed. Sykes, Krista. 1st ed.. ed. New York: New York : George Braziller Publishers, 1985. 241-45. Print. Peace, Sheila. "Social Interactions in Public Spaces and Places." Environmental Gerontology: Making Meaningful Places in Old Age. Eds. Rowles, G.D. and M.A. Bernard. 
New York: Springer Publishing Company, 2013. 25-52. Print.

Persson, Hans, et al. "Universal Design, Inclusive Design, Accessible Design, Design for All: Different Concepts-One Goal? On the Concept of Accessibility-Historical, Methodological and Philosophical Aspects." Universal Access In The Information Society 14.4 (2015): 505-26. Print.

Phillips, Judith, Kristine J. Ajrouch, and Sarah Hillcoat-Nalletamby. "Key Concepts in Social Gerontology / Judith E. Phillips, Kristine Ajrouch, and Sarah Hillcoat-Nalletamby." (2010). Print.

Powell, Jason L., and Tony Gilbert. Aging Identity : A Dialogue with Postmodernism. Hauppauge, NY, USA: Nova Science Publishers, Inc., 2009. Print.

Psarra, Sophia. Architecture and Narrative : The Formation of Space and Cultural Meaning / Sophia Psarra. Milton Park, Abingdon, Oxon

New York, NY: Milton Park, Abingdon, Oxon

New York, NY : Routledge, 2009. Print.

Ring, Trudy, Robert M. Salkin, and Sharon La Boda. International Dictionary of Historic Places Historic Places. Chicago: Fitzroy Dearborn, 1994. Print.

Rosenberg, Buck C. “Social Spaces for Seniors: Exploring Seniors' Centres and Clubs in Australia.” Journal of Sociology 51.3 (2015): 464-77. Print.

Rowles, G.D., and M.A. Bernard. "The Meaning and Significance of Place in Old Age.” Environmental Gerontology: Making Meaningful Places in Old Age. Eds. Rowles, G.D. and M.A. Bernard. New York: Springer Publishing Company, 2013. 3-24. Print. 
Scheidt, R.J., and B. Schwarz. Environmental Gerontology: What Now? : Taylor \& Francis, 2013. Print.

Taylor, Mark, and Laurie Buys. "Ageing in Suburbia: Designing for Demographic Change in Australia and New Zealand.” Architectural Design 84.2 (2014): 54-59. Print.

Walker, Jarrett. “Basics: Walking Distance to Transit.” Human Transits. 2011. Web. $10 / 06 / 2015$.

White, Rob, Julie-Anne Toohey, and Nicole Asquith. "Seniors in Shopping Centres." Journal of Sociology 51.3 (2015): 582-95. Print.

Wiles, Janine L., et al. "Older People and Their Social Spaces: A Study of Well-Being and Attachment to Place in Aotearoa New Zealand.(Report)." Social Science \& Medicine 68.4 (2009): 664 - 71. Print. 


\section{[SOURCESOFFIGIRES]}

* Figures not listed below are by author

2.3. Cashmere home. Elderlynet. Retrieved on 20/03/2015. <https://www. eldernet.co.nz/Facilities/Hospital_Care/Cashmere_Home_Cashmere_Heights_Home/ Service/DisplayService/FaStID/178>

$\neg$ Google map. Google. Feb. 2015. Web. Retrieved on 10/05/2015. <https://www. google.co.nz/maps/place/Johnsonville,+Wellington/@-41.2246382,174.7826179,14z/dat $\mathrm{a}=! 3 \mathrm{~m} 1 ! 4 \mathrm{~b} 1 ! 4 \mathrm{~m} 2 ! 3 \mathrm{~m} 1 ! 1 \mathrm{~s} 0 \mathrm{x} 6 \mathrm{~d} 38 \mathrm{ade} 6 \mathrm{ccf0e} 329: 0 \times 500 \mathrm{ef6} 143 \mathrm{a} 2 \mathrm{~d} 010>$

2.8. Heikkinen, Katrina. Meals on Wheels delivery. Retrieved on 13/05/2015. <http://www.malmstrom.af.mil/shared/media/photodb/photos/111124-F-ES731-043. jpg>

2.9. Blacksburg, Va. Intergenerational program is national contender for Eisner Prize. Retrieved on 02/05/2015. <http://www.vtnews.vt.edu/articles/2012/09/091112clahs-intergenerationalaward.html>

2.13. "Seniors Centre". City of Maple Grove. 2016. Web. Retrieved on $22 / 05 / 2015$.

2.15. Altman, I., M.P. Lawton, and J.F. Wohlwill. Elderly People and the Environment. Springer US, 1984. Print.

Phillips, Judith, Kristine J. Ajrouch, and Sarah Hillcoat-Nalletamby. "Key Concepts in Social Gerontology / Judith E. Phillips, Kristine Ajrouch, and Sarah Hillcoat-Nalletamby." (2010). Print. 
2.16. Accessible Architecture Ed. Meuser, Philipp. 2nd revised ed. Berlin: DOM, (2012): 224. Print.

2.18. Holl, Steven. Parallax. New York: Princeton Architectural Press (2000) 39. Print.

2.19. Cross, Jennifer Eileen. "Processes of Place Attachment: An Interactional Framework.” Symbolic Interaction 38.4 (2015): 493-520. Print.

2.20. Holl, Steven. Parallax. New York: Princeton Architectural Press (2000) 23-25. Print.

2.21. Luke Fiederer. "AD Classics: Kiasma Museum of Contemporary Art / Steven Holl Architects" 19 Apr 2016.ArchDaily. Accessed 5 May 2016. <http://www. archdaily.com/784993/ad-classics-kiasma-museum-of-contemporary-art-steven-hollarchitects/>

2.22. David. "Louisiana, from one back yard to another". Web. Retrieved on 05/08/2015. > http://www.fromonebackyardtoanother.com/Louisiana-Museum-JorgenBo-and-Vilhelm-Wohlert>.

2.23. "Louisiana Museum of Modern Art". Louisiana Museum of Modern Art. Web. Retrieved on 05/08/2015. < https://en.louisiana.dk/wessel-bagge-collection>

Grabow, Stephen and Kent Spreckelmeyer. The Architecture of Use : Aesthetics and Function in Architectural Design. Ed. Spreckelmeyer, Kent F.: New York: Routledge, 2015. Print. 
3.2 Google map. Google. Feb. 2015. Web. Retrieved on 10/05/2015. < <https://www.google.co.nz/maps/place/Johnsonville,+Wellington/@41.2246382,174.7826179,14z/data=!3m1!4b1!4m2!3m1!1s0x6d38ade6ccf0e329:0x500ef $6143 \mathrm{a} 2 \mathrm{~d} 010>$

3.3. Statistics New Zealand. "2013 Census Map - Quickstats About a Place." 2013. Web. Retrieved on 05/04/2015.

<http://www.stats.govt.nz/StatsMaps/Home/Maps/2013-census-quickstatsabout-a-place-map.aspx?viewer=viewer_config_2013_Live.txt\&webmap=map_config. txt\&layerId=3\&featureId $=09>$

3.4. Statistics New Zealand. "2013 Census Map - Quickstats About a Place.” 2013. Web. Retrieved on 05/04/2015.

<http://www.stats.govt.nz/StatsMaps/Home/Maps/2013-census-quickstatsabout-a-place-map.aspx?viewer=viewer_config_2013_Live.txt\&webmap=map_config. txt\&layerId=3\&featureId $=09>$

3.5. Chapman, Katie. "Story of a Suburb: Johnsonville." The Dominion Post (2010). Web.

3.14. Walker, Jarrett. "Basics: Walking Distance to Transit." Human Transits. 2011. Web. Retrieved on 10/06/2015.

Graham, James E., et al. "Walking Speed Threshold for Classifying Walking Independence in Hospitalized Older Adults." Journal of the American Physical Therapy Association 2010. Web. Retrieved on 19/06/2015. 
4.2. "De Meerpaal, Dronten”. Nationale Renovatie Prijs. Web. Retrieved on 26/08/2015. < http://www.nationalerenovatieprijs.nl/archief/nrp2007/Inzendingen/ Utiliteitsbouw/Demeerpaaldronten.html>

4.3. Madge, James. “The Agora at Dronten.” Architectural Design 75.2 (2005): 28-33. Print.

4.4. Hughes-Stanton, Corin. "Closed Environment for Living Space.” Design. 241 (1969): 40-49. Web. 28/07/2016.

4.6. "Birkenhead Library and Civic Centre / Archoffice" 14 Jun 2010. ArchDaily. Retrieved on 26/08/2015. <http://www.archdaily.com/63926/birkenheadlibrary-and-civic-centre-archoffice/>

4.7. "Birkenhead Library and Civic Centre / Archoffice" 14 Jun 2010. ArchDaily. Retrieved on 26/08/2015. <http://www.archdaily.com/63926/birkenheadlibrary-and-civic-centre-archoffice/>

4.8. "Birkenhead Library and Civic Centre / Archoffice" 14 Jun 2010. ArchDaily. Retrieved on 26/08/2015. <http://www.archdaily.com/63926/birkenheadlibrary-and-civic-centre-archoffice/>

4.10. "Birkenhead Library and Civic Centre / Archoffice"14 Jun 2010. ArchDaily. Retrieved on 26/08/2015. <http://www.archdaily.com/63926/birkenheadlibrary-and-civic-centre-archoffice/>

4.11. "Plattegrond voor De Meerpaal te Dronten door F. van Klingeren". Doorzoek het Geheugen van Nederland. Web. Retrieved on 26/08/2015. < http://www. 
geheugenvannederland.nl/?/nl/items/TIN02:G00000458.003>.

4.14. "Sightseeing spot in down town area". Yururira Towada. Web. Retrieved on 26/07/2015. < http://www.towada-kankou.jp/english/downtown.html>.

4.16. "Sightseeing spot in down town area". Yururira Towada. Web. Retrieved on 26/07/2015. < http://www.towada-kankou.jp/english/downtown.html>.

4.17. "Towada Art Centre by Ryue Nishizawa“, Daily Icon. Web. Retrieved on 26/07/2015. <http://www.dailyicon.net/magazine/wp-content/uploads/2008/10/ towada01dailyicon.jpg>.

4.23. “Onishi Town Hall”. Machigatta Kenchiku No Mikata, Arukikata. Web. Retrieved on 26/07/2015. < http://zubora.daa.jp/blog/>.

4.24. Baan,Iwan. “Onishi Town Hall”. Web. Retrieved on 26/07/2015. < http:// iwan.com/photo_SANAA_Onishi_Town_Hall.php>.

4.25. Baan,Iwan. “Onishi Town Hall”. Web. Retrieved on 26/07/2015.< http:// iwan.com/photo_SANAA_Onishi_Town_Hall.php>. 
